\title{
MECHANICAL BEHAVIOR OF TRANSPARENT FIBER REINFORCED POLYESTER COMPOSITES AT EXTREME TEMPERATURES
}

A Dissertation Presented to the Faculty of the Graduate School University of Missouri

In Partial Fulfillment of the Requirements for the Degree Doctor of Philosophy of Mechanical Engineering By

SAAD RAMADHAN AHMED

Dr. Sanjeev K. Khanna, Dissertation Supervisor

December 2018 
The undersigned, appointed by the dean of the Graduate School, have examined the dissertation entitled;

\section{MECHANICAL BEHAVIOR OF TRANSPARENT FIBER REINFORCED POLYESTER COMPOSITES AT EXTREME TEMPERATURES}

presented by Saad Ramadhan Ahmed, a candidate for the degree of Doctor of Philosophy, and hereby certify that, in their opinion, it is worthy of acceptance.

Professor Sanjeev K. Khanna

Professor Ahmed Sherif El-Gizawy

Professor Robert A. Winholtz

Professor Qingsong Yu

Professor Hani Salim 


\section{DEDICATION}

To spirit of my gone father, Professor Dr. Ramhadan Ahmed Iltaef, who taught me spiritually how to learn, grow and develop and who has been a source of encouragement and inspiration to me throughout my life. A very special thank you for providing me a role model of a sincere professor, researcher and academic leader. And also, for my mother for the myriad of ways in which, throughout my life, she has actively supported me in my determination to find and realize my potential, and to make this contribution to my precious country, Iraq, and our world. It's also dedicated to all my family in Iraq with a great passion and honesty.

Saad R. Ahmed 


\section{ACKNOWLEDGMENT}

First and foremost, I would like to thank Dr. Sanjeev Khanna his guidance, support and mentorship. His scientific and technical advice was essential in the progression and completion of this project, in addition to the continual support (editorial and visiting) and has taught me many valuable lessons. I am grateful to have had the opportunity to work under his guidance and direction. My thanks also go to Dr. Frank Feng, Director of Graduate Studies in MAE, for his support and unlimited help to facilitate granting my $\mathrm{PhD}$ scholarship and admission process.

My thanks also go to Drs. Ahmed El-Gizawy, Robert Winholtz, and Hani Salim for their roles as graduate committee members.

Many other thanks to Dr. Ammar J. Khaleel, governor of Salah Alden Province in Iraq, and Dr. Haytham Al Jubury, Senator of Iraqi Parliament, for their great support in facilitating traveling to United States of America.

My special thanks to my colleagues Saher, Waleed, Faten, Iqbal, and Mohammed Mutanbk for their continual support during the scholarship. Also extend my appreciation (and apologies!) to Chen for helping in solving the equations and coding required for this work. Lastly, I thank the Gods of heavy music. in helping with process, aid and figures used in thesis and thanks to Ghassan and Mathew of mechanical workshop at Mizzou for their guidance and continual support in shaping of specimens.

Last but certainly not least, I must thank Iraqi Ministry of Higher Education and Scientific Research and Dr. Tahani Al Sandooq, former Iraqi Cultural Attaché in Washington DC, whom have made this all possible by granting me the $\mathrm{PhD}$ scholarship and their continual and outstanding support. 


\section{TABLE OF CONTENTS}

\section{MECHANICAL BEHAVIOR OF TRANSPARENT FIBER REINFORCED}

POLYESTER COMPOSITES AT EXTREME TEMPERATURES

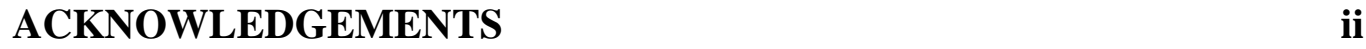

TABLE OF CONTENTS iii

LIST OF FIGURES vii

LIST OF TABLES - xii

$\begin{array}{lll}\text { ABSTRACT } & \text { xiv }\end{array}$

$\begin{array}{ll}\text { CHAPTER } 1 \text { INTRODUCTION } & 1\end{array}$

$\begin{array}{ll}\text { 1.1 Problem statement } & 1\end{array}$

1.2. Effect of Temperature on physical and Mechanical Characteristics 5

of Composites

$\begin{array}{lr}\text { 1.2.1 Environmental degradation } & 5\end{array}$

1.2.2 Chemistry of Polymer Composite 6

1.3 Environmental Effects on Components of Composites 12

$\begin{array}{ll}\text { 1.3.1 Environmental Effects on Glass Fibers } & 13\end{array}$

$\begin{array}{ll}\text { 1.3.2 Environmental Effects on Polymer Matrices } & 13\end{array}$

1.3.3 Environmental Effects on the Fiber / Matrix Interface 16

1.4 Coefficient of Thermal Expansion (CTE) 21

1.4.1 Factors Affecting the Coefficient of Thermal Expansion 22

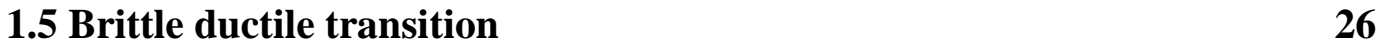

$\begin{array}{lr}\text { 1.6 Specific heat } & 27\end{array}$ 
1.7 Thermal conductivity

1.8 Mechanical deformation behavior 31

1.9 Refractive Index of Polymer Matrix 33

$\begin{array}{ll}\text { References } & 42\end{array}$

CHAPTER TWO: FABRICATION OF TRANSPARENT

POLYESTER COMPOSITE AND LAMINATE

2.1 Preparation of interlayer unsaturated polyester composite

2.2. Fabrication of Damage Resistant Composite Interlayer and Glass $\quad 54$

Panel Fabrication

$\begin{array}{ll}2.3 \text { Haze test } & 59\end{array}$

2.3.1. Introduction $\quad 59$

$\begin{array}{ll}\text { 2.3.2 Haze test } & 63\end{array}$

$\begin{array}{ll}2.4 \text { Results and discussion } & 68\end{array}$

$\begin{array}{ll}2.5 \text { Conclusions } & 72\end{array}$

$\begin{array}{lr}\text { References } & \mathbf{7 3}\end{array}$

CHAPTER THREE: TENSILE BEHAVIOR OF GLASS FIBER REINFORCED COMPOSITE

$\begin{array}{ll}3.1 \text { Introduction } & \mathbf{7 6}\end{array}$

$\begin{array}{ll}3.2 \text { Experimental work } & \mathbf{7 8}\end{array}$

$\begin{array}{ll}\text { 3.2.1 Specimen Preparation } & \mathbf{7 8}\end{array}$

$\begin{array}{lr}\text { 3.2.2 Machine Software Setup } & \mathbf{8 0}\end{array}$ 
$\begin{array}{lr}\text { 3.2.4 Conducting tensile test } & 83\end{array}$

$\begin{array}{lr}\text { 3.3 Results and Discussion } & 84\end{array}$

$\begin{array}{lr}\text { 3.3.1 Thermal analysis } & 84\end{array}$

$\begin{array}{ll}\text { 3.3.2 Tensile properties at different temperatures } & 85\end{array}$

$\begin{array}{lr}\text { 3.3.3 Thermal expansion coefficient } & 93\end{array}$

3.3.4 Microstructural analysis of failure in polyester composite $\quad 96$

$\begin{array}{ll}3.5 \text { Conclusions } & 100\end{array}$

$\begin{array}{ll}\text { References } & 101\end{array}$

CHAPTER 4: FATIGUE BEHAVIOR

$\begin{array}{ll}\text { 4.1. Introduction } & 104\end{array}$

$\begin{array}{ll}4.2 \text { Experimental work } & 108\end{array}$

$\begin{array}{ll}\text { 4.2.3 Fatigue test method } & 111\end{array}$

$\begin{array}{ll}4.3 \text { Result and discussion } & 114\end{array}$

$\begin{array}{ll}\text { 4.4 Conclusions } & 123\end{array}$

$\begin{array}{ll}\text { References } & 124\end{array}$

CHAPTER 5: PUNCTURE RESISTANCE 127

$\begin{array}{ll}5.1 \text { Introduction } & 127\end{array}$

5.2 Experimental work $\quad 129$

$\begin{array}{lr}\text { 5.2.1 Background } & 129\end{array}$

5.2.2 Experimental setup 132

5.3 Results and Discussion 136

$\begin{array}{ll}\text { 5.3.1 Impact Loading Characteristic } & 136\end{array}$ 
5.3.2 Energy absorption 142

5.3.3 Fragmentation characteristics under dynamic loading 146

$\begin{array}{ll}\text { 5.4. Conclusions } & 150\end{array}$

$\begin{array}{ll}\text { References } & 151\end{array}$

CHAPTER 6: CONCLUSIONS AND FUTURE WORK 156

6.1 Conclusions

$\begin{array}{lc}\text { 6.2 Future Work } & 158\end{array}$

6.2.1 introduction to fracture toughness of polyester composite 159

$\begin{array}{ll}\text { 6.2.2 Experimental method } & 161\end{array}$

$\begin{array}{ll}\text { 6.2.3. Results and discussion } & 165\end{array}$

6.2.4 Visual analysis of fracture-tested composites 168

$\begin{array}{ll}\text { References } & 172\end{array}$

$\begin{array}{ll}\text { Vita } & 174\end{array}$ 


\section{LIST OF FIGURES}

Figure

$\underline{\text { Page }}$

Figure 1.1 Networking of unsaturated polyester with styrene monomer.

Figure 1.2 Effect of moisture on glass transition temperature

Figure 1.3 Schematic diagram of the CNT/polymer composites under thermal environment

Figure 1.4 Variation of CTE of an epoxy-glass fiber lamina with fiber content of $60 \%$

Figure 1.5 Variation of CTE of an epoxy-glass fiber lamina with fiber content of $60 \%$.

Figure 1.6 The temperature dependence of the linear thermal expansions for the glass fiber reinforced composites

Figure 1.7 Chemical reactions occurring during the curing process of polyester

Figure 1.8 Reflection and refraction of light in two materials interfaces

Figure 1.9 Experimental and calculated results comparison (Cobalt effect)

Figure 1.10 Experimental and calculated results comparison (MEKP effect)

Figure 1.11 Structure of phenanthrene

Figure 1.12 Experimental and calculated results comparison (Phenanthrene effect)

Figure 2.1 Mold for the composite

Figure 2.2 Vacuum chamber

Figure 2.3 Mold clamped with C-clamps

Figure 2.4 Transparency of the composite interlayer 
Figure 2.5 Damage resistant glass structure

Figure 2.6 Reaction happening in the silane process 56

Figure 2.7 Transparency comparison between the laminated glass and the composite interlayer

Figure 2.8 Transparency comparison between the laminated glass and the composite interlayer

Figure 2.9. Transparency of the composite interlayer

(paper with words was placed underneath the composite)

Figure 2.10 Transparency of the composite interlayer (paper with words was placed 8 inches from the composite)

Figure 2.11 Total transmittance of unreinforced specimens of unsaturated polyester matrix at different temperatures

Figure 2.12. Total transmittance of reinforced specimens of unsaturated polyester matrix at different temperatures

Figure 2.13: Total diffuse luminous transmittance of unreinforced specimens of unsaturated polyester matrix at different temperatures

Figure 2.14. Total diffuse luminous transmittance of fiber glass reinforced specimens of unsaturated polyester at different temperatures

Figure 3.1 Tensile test setup: specimen and gages installation

$\begin{array}{lr}\text { Figure 3.2 Cooling system } & 82\end{array}$

$\begin{array}{lr}\text { Figure 3.3 Heating system } & 83\end{array}$

Figure 3.4 Stress-strain behavior of UPM at difference temperature 
Figure 3.5 Stress-strain behavior of reinforced unsaturated polyester composite at room temperature

Figure 3.6. Stress at fracture of RPC and UPM under transverse loads at different temperature.

Figure 3.7 Chord modulus of RPC and UPM under transverse loads at different temperature.

Figure 3.8. Strain at fracture of RPC and UPM under transverse loads at different temperature.

Figure 3.9 Thermal expansion $\left(\right.$ in $/$ in $\left.* 1 /{ }^{\circ} \mathrm{C}\right)$ vs. temperature difference of UPM 94 Figure 3.10. Thermal expansion vs. temperature difference of the RPC 95

Figure 3.11. microstructure of failed UPR specimen at different temperatures 96

Figure 3.12. microstructure of failed RPM specimen at different temperatures $\quad 98$

Figure 4.1. Typical da/dN versus $\Delta \mathrm{K}$ curve $\quad 107$

Figure 4.2. CT specimen dimensions and actual test specimen 110

Figure 4.3. View of the MTS servo-hydraulic multipurpose testing system used 112 for fatigue at low temperature. Right hand picture is a close-up view of the environment chamber.

Figure 4.4. Ongoing fatigue crack growth test specimen

Figure 4.5. Fatigue crack growth test of unreinforced specimen at $\mathrm{a} / \mathrm{w}=0.2$ and room temperature

Figure 4.6. The relationship between $\log (\mathrm{da} / \mathrm{dN})$ and $\log (\Delta \mathrm{K})$ of unreinforced 116 specimen at $\mathrm{a} / \mathrm{w}=0.2$ and room temperature 
Figure 4.7. Fatigue crack growth test of unreinforced specimen at $\mathrm{a} / \mathrm{w}=0.35$

and room temperature

Figure 4.8. The relationship between $\log (\mathrm{da} / \mathrm{dN})$ and $\log (\Delta \mathrm{K})$ of unreinforced

specimen

at $\mathrm{a} / \mathrm{w}=0.35$ and room temperature

Figure 4.9. Fatigue crack growth test of un-reinforced specimen at $\mathrm{a} / \mathrm{w}=0.2$

119

and $-60^{\circ} \mathrm{C}$

Figure 4.10 The relationship between $\log (\mathrm{da} / \mathrm{dN})$ and $\log (\Delta \mathrm{K})$ of unreinforced

specimen

at $\mathrm{a} / \mathrm{w}=0.2$ and $-60^{\circ} \mathrm{C}$

Figure 4.11. Fatigue crack growth test of unreinforced specimen at $a / w=0.35$ and $-60^{\circ} \mathrm{C}$.

Figure 4.12. Fatigue Crack Growth Curves of un-reinforced $\mathrm{a} / \mathrm{W}=0.35$ and $60^{\circ} \mathrm{C}$

Figure 5.1 Example of the operation of a drop weight impact test machine

130

Figure 5.2 Puncture test assembly

Figure 5.3 Experimental setup of puncture resistance test

Figure 5.4 Post impact drop weight test specimen

Figure 5.5. load - time traces of puncture event in the reinforced polyester

138 composite material

Figure 5.6 Load - time traces of puncture event in the unreinforced polyester composite material 
Figure 5.7 Damage stages in the punctured specimens

Figure 5.8. load - deflection traces of puncture event in the reinforced polyester composite material

Figure 5.9. Load - deflection traces of puncture event in the unreinforced polyester composite material

Figure 5.10. Absorbed energy as a function of time during a drop - weight puncture test of the reinforced polyester composite.

Figure 5.11. Absorbed energy as a function of time during a drop - weight 144 puncture test of the unreinforced polyester composite

Figure 5.12. Velocity as a function of time during a drop - weight puncture test 145 of the reinforced polyester composite.

Figure 5.13. Velocity as a function of time during a drop - weight puncture test 146 of the unreinforced polyester composite

Figure 5.14. Fragmentation characteristics under dynamic loading for 146 unreinforced specimens.

Figure 5.15. Fragmentation characteristics under dynamic loading for 149 reinforced specimens. 


\section{LIST OF TABLES}

Table

Page

Table 1.1. Types and specifications of Fiber glass 9

$\begin{array}{ll}\text { Table 1.2 Properties of glass fibers } & 10\end{array}$

Table 1.3 E-glass compositions (wt. \%) 11

Table 1.4. Brittle-ductile transition temperatures (decrease with cold working) 27

Table 1.5 Temperature dependence of the specific heat of polymers at low $\quad 28$ temperatures

Table 1.6 Thermal expansion of 60\% CF filled PEEK composites 29

Table 1.7 Thermal expansion according to [무, 58] and [55] 29

Table 1.8 Temperature dependence on the thermal conductivity 31

Table 1.9 E-modulus at low temperatures $\quad 32$

Table 1.10 $10 \mathrm{~s}$ Brinell hardness values for materials tested at $\mathrm{T}=293 \mathrm{~K}$ and $\quad 32$ $\mathrm{T}=77 \mathrm{~K}$

Table 1.11 Refractive index of polyester with different cobalt contents 38

Table 1.12 Refractive index of polyester with different MEKP contents 39

Table 1.13 Refractive index of polyester with different phenanthrene contents $\quad 40$

Table 2.1. Candidate polyester formulations 54

Table 2.2 Haze, total luminous transmittance and diffuse of glass fiber 65 unreinforced polymer and polymer matrix at room temperature

Table 2.3 Haze, total luminous transmittance and diffuse of glass fiber reinforced polymer and polymer matrix at different temperatures

Table 3.1. ASTM D638 Tensile test results for UPM at different temperatures 
Table 3.2. ASTM D638 Tensile test results for glass fiber RPC at different temperatures

Table 4.1. Fatigue crack growth parameters per ASTM E647 at room temperature

Table 4.2. Fatigue crack growth parameters per ASTM E647 at $-60^{\circ} \mathrm{C}$ and $\mathrm{a} / \mathrm{w}=0.2$

Table 4.3. Fatigue Crack Growth Parameters per ASTM E647 at $-60^{\circ} \mathrm{C}$ and $\mathrm{a} / \mathrm{w}=0.35$

Table 5.1 Specifications of puncture test machine 


\begin{abstract}
Selecting materials for harsh or extreme environmental conditions can be a challenge. The combination of a harsh environment, large forces over extended periods and the need for lowest possible cost restricts the choice of materials. One potential material is glass fiber reinforced polymers that are widely used in structural systems as load bearing elements, they are relatively low cost and can be tailored to achieve a range of mechanical properties. This investigation presents the preparation of transparent glass fiber reinforced unsaturated polyester composite and the evaluation of its optical and mechanical properties under extreme conditions of temperature. The polyester resin was reinforced with E-glass fibers to manufacture a composite using the hand layup method. Transparency was achieved by modifying the refractive index of the polyester resin to match that of the glass fibers. This investigation also presents the evaluation of glass fiber reinforced unsaturated polyester under quasi-static tension loading and puncture testing using a drop weight at extreme conditions. The results showed that the reinforced composite had a higher fracture stress and chord modulus at all temperatures ranging from $+60{ }^{\circ} \mathrm{C}$ to $-80{ }^{\circ} \mathrm{C}$ as compared to the unreinforced polyester matrix. The unreinforced polyester has a higher stiffness at lower temperatures due to reduced polymer chain mobility and higher clamping pressure of the matrix on the glass fiber reinforcement. The damage created by the impact reduces with decreasing temperatures, while the energy absorb remains constant with temperature.
\end{abstract}




\section{CHAPTER ONE: INTRODUCTION}

\subsection{Problem Statement}

Fiber reinforced polymer (FRP) composites have many merits, such as high stiffness/weight and strength/weight ratios, advanced fatigue and corrosion resistances, etc., providing significant functional and economic benefits, ranging from strength enhancement and weight reduction to durability features[1]. Many studies worldwide have shown that FRP composite provide an excellent lightweight and strong substitute for steel and glass. A variety of structural products and shapes are currently being produced by utilizing the beneficial structural properties of these composite materials. Structural elements reinforced with FRP, however, might be subjected to static or dynamic loadings, such as wind loads, earthquake loads, explosions, etc. and varying temperature conditions during their service life. Also, debris produced in explosion, especially the sharp glass fragments produced in blast, can lead to large casualties. So the need of mitigating the hazard caused by glass fragments is essential [2]. Under such conditions, the mechanical properties of FRP involving Elastic's Modulus, tensile strength, toughness, puncture and fatigue resistances etc. may undergo great changes [3-7]. Therefore, the investigation of the mechanical properties of FRP composites under static and dynamic loadings and different temperatures is essential to design structures with these kinds of materials. However, the mechanical properties of these FRP composites vary from one product to another as a result of varied manufacturing processes. Therefore, detailed material characteristics need to be established for specific loading and atmospheric conditions. Research projects have often focused on the polymer composite's high glass transition 
temperature $(\mathrm{Tg})$, and the effects of moisture, while variable environment temperature FRP performance data for cold and hot environments is limited and often unavailable. Preliminary reports bring to our attention the potential benefits of the use of FRP products at low temperatures. Tests outlined by Karbhari et al. [8] show how off-axis and transverse strength can increase at low temperatures due to matrix hardening. Other low temperature tests mentioned by Karbhari revealed increased strength properties of wound fiberglass composites, and an improvement in the static load response of unfilled polymeric materials. On the other hand, complexities may arise due to water absorption and freeze-thaw cycling. At low temperatures, large residual stresses in composite components may develop because of the thermal expansion mismatch between the fibers and the resin, which produce microcracks in the composites. Also the strength has to be maintained at cryogenic temperatures. Thus interest in studying the rate of generation of these microcracks at cryogenic temperatures and its effect on strength of composites. The microcracks in composites may cause leakage of fluids if the FRP is part of a storage vessel. And if a transparent FRP is being used the transparency could be last in addition. Permeability is a measure of how easily a given material can be penetrated by a fluid or gas. Hence the study of permeability of composites to space fuels/gases in the cryogenic temperatures is of much importance. Dutta [9] realized the importance of considering composite constituents and the negative effects of matrix cracking due to extreme low temperatures. Discrepancies in coefficients of thermal expansion of the constituent elements cause high residual stresses to occur in composites at low temperatures. Comparative low temperature experiments are a limited few and information regarding design of composites in cold temperatures or climates is developing at a slow rate. The benefits of FRP reinforcement use in cold 
weather environments may best be seen in rehabilitation of our glass windows structures, bridge decks, and roadway systems. Construction benefits include lower residential, transportation, labor, and maintenance costs. The deteriorating effects of reinforced structures in other corrosive environments such as marine sites, waste water plants, and near cooling towers, provide additional opportunities to consider FRP reinforcement. The performance of FRP composite when exposed to elevated temperatures and harsh environment. Hawileh et al. [10] experimentally investigated the variation of mechanical properties in terms of the elastic modulus and tensile strength of composite glass (C), composite glass $(\mathrm{G})$ sheets and their hybrid combinations (CG) when exposed to different temperatures, ranging from 25 to $300^{\circ} \mathrm{C}$. Results showed that the elastic modulus of the $\mathrm{C}$, $\mathrm{G}$ and $\mathrm{CG}$ at $250^{\circ} \mathrm{C}$ was reduced by nearly $28 \%, 26 \%$ and $9 \%$, respectively, and their tensile strength at the same temperature was reduced by about $42 \%, 31 \%$ and $35 \%$, respectively, all as compared to room temperature values. Robert et al. [11] evaluated the variation of mechanical properties of sand-coated FRP reinforcing bars subjected to extreme temperatures (ranging from 0 to $315^{\circ} \mathrm{C}$ ) and discovered that low temperature has a positive influence on the strength of composites, while at very high temperatures, near the glasstransition temperatures of the polymer matrix, the mechanical properties, especially the stiffness and the strength of the composites are decreased significantly. Reis et al. [7] conducted tensile tests on FRP at different strain rates and temperatures and found that strain rate greatly affects the ultimate tensile strength while the Elastic's modulus is almost insensitive to it, however the temperature only influences the modulus. It is therefore essential to develop a firm understanding of the durability of fiber-reinforced polymers exposed to severe and frequently changing environments. 
A good way to mitigate the damage caused by glass fragments at extreme conditions is from windows to use damage resistant window glass, which is conventionally composed of one polymer interlayer, one glass outerlayer and glass innerlayer. The polymer interlayer of damage resistant glass can retain fragmented glass pieces and continue offering resistant to the harsh environment. Currently available damage resistant glass is usually made of one Polyvinyl Butyral (PVB) interlayer and two glass plies for low temperatures [12-15]. PVB interlayer is the industry standard interlayer because of its excellent adhesion and optical qualities. But this kind of damage resistant glass is very thick and expensive for very low temperatures [16], so it's very difficult and costly to use them as windows in the buildings which are located in extremely hot or cold areas. Therefore, a new damage resistant glass, which is thinner and cheaper than traditional ones, should be developed. A cost-effective technique for this purpose is to develop a kind of glass panel that replaces the PVB interlayer with a transparent glass fibers reinforced polymer composite. Glass fibers reinforced interlayer that is transparent is able to provide more strength to the glass panel, which means the damage resistant glass with glass fibers reinforced composite interlayer can be thinner than the damage resistant glass panel with PVB interlayer. Because the composite glass panel is thinner, it uses less material and will therefore, be cheaper while possessing higher damage resistance than what is currently in use.

The goals of the research are:

1. Fabricate glass fibers reinforced polymer composite interlayer. Study the transparency characteristics of the composite and propose new method(s) to improve the transparency of the composite. 
2. Study the mechanical properties and fracture properties of the composite interlayer at high (up to $+80^{\circ} \mathrm{C}$ ) and very low temperatures (up to $-80^{\circ} \mathrm{C}$ ).

3. Fabricate a laminated transparent composite interlayer glass panels and study the quasi-static and dynamic response of these laminated glass panels under different loading and environmental conditions numerically.

\subsection{Effect of Temperature on physical and Mechanical Characteristics of Composites}

\subsubsection{Environmental degradation}

Composite materials consist of two or more physically distinct and mechanically separable components called reinforcement and matrix. These two components can be mixed in a controlled way to achieve optimum properties, which are superior to the properties of each individual component. Composite materials have been widely used in the glass laminate manufacture because of the following advantages: high strength and modulus to weight ratio, high transparency, low cost and flexibility in material and structure design. Glass laminate should have a service life of 10 years in a variety of climates, which makes environmental resistance one of the most important factors in the glass laminate design. Actually, it has been reported that composite materials can be degraded by environmental attack such as moisture diffusion, thermal spikes, ultraviolet radiation, and thermal oxidation, etc [[17],[18]]. Moisture diffusion, for example, can decrease the strength of composites, degrade the fiber / matrix interface, swell and plasticize the resin to lower its glass transition temperature (the temperature where the resin transforms from the glassy solid state to a visco-elastic state) [[17-27]16-26]. The relative degree of the degradation process is related to the chemistry of the reinforcement and matrix, as well as the exposure time [[21, 25, 27-29]. Different kinds of composites, however, are also sensitive to different 
environmental attacks. The combination of two or more individual environmental factors can aggravate the degradation of composite performance.

Composites for glass laminate may be exposed to low temperature conditions (up to $-80^{\circ} \mathrm{C}$ ) or high temperature conditions (up to $+80^{\circ} \mathrm{C}$ ) in their service life. Exposure to low temperature of some tough polymers may make them more brittle and the elastic modulus may increase [30]. In recent years, a lot of tests have been carried out to evaluate the response of composite materials to elevated temperature [31]. It has been reported that the temperature effect on the fiber-matrix interface is as strong as those of the fiber treatment and resin properties [32]. Other mechanical properties such as compression strength, ultimate tensile strength, and tensile strength (which is matrix dominated) have also been reported to decrease at elevated temperature $[23,25,26,33]$. Temperature effects on the fracture properties of composites were widely investigated by Marom [34]. The study showed that interlaminar fracture energy decreased $25-30 \%$ as the temperature increased from $-50^{\circ}$ to $100^{\circ} \mathrm{C}$. The interlaminar fracture surface characteristics of graphite/epoxy were also investigated and pronounced differences were observed in the amounts of fiber/matrix separation and resin-matrix fracture with increasing temperature.

The temperature effect on the mechanical properties of composites derives partly from the internal stresses introduced by the differential thermal coefficients of composite components. Such internal stresses change magnitude with temperature change, in some cases producing matrix cracking at very low temperatures. In practical applications each polymer has its own operating temperature range. Usually a polymer has a maximum use temperature slightly below its glass transition temperature ( $\mathrm{Tg}$ ), at which the polymer transfers from rigid state to rubbery state and suffers substantial mechanical property loss. 
Elevated temperatures combined with humid environments have been found to exacerbate the problem by further reducing $\mathrm{Tg}$, among other factors.

\subsubsection{Chemistry of Polymer Composite}

A polymer matrix is obtained by converting liquid resins into hard and brittle solids by chemical cross-linking. Polymers can be classified as thermoplastic (capable of being softened and hardened repeatedly by increasing and decreasing temperatures) or thermoset (changing into a substantially infusible and insoluble materials when cured by the application of heat or by chemical means). In glass laminate manufacture, thermoset resins, including polyester, and a crosslinking agent are of interest. The variety of thermoset resins provides flexibility for designers. Actually, the properties of the polymer resin depend on the molecule units making up the three-dimensional network and, on the length, and density of cross links. The former is determined by the initial chemical reactions and the latter is determined by the control of processing and curing.

\subsubsection{Polyester Resins.}

Generally polyester resins can be made by a dibasic organic acid and a dihydric alcohol. They can be classified as saturated polyester, such as polyethylene terephthalate, and unsaturated polyester. To form the network of the composite matrix, the unsaturated group or double bond needs to exist in a portion of the dibasic acid. By varying the acid and alcohol, a range of polyester resins can be made. Orthophthalic polyesters are made by phthalic anhydride with either maleic anhydride or fumaric acid. Isophthalic polyesters, however, are made from isophthalic acid or terephthalic acid. The polyester resin is usually dissolved in monomer (styrene is the most widely used), which will copolymerize with it 
and contribute to the final properties of the cured resin. The addition of catalyst will cause the resin to cure. The most frequently used catalyst is methyl ethyl ketone peroxide (MEKP) or benzoyl peroxide (BPO) and the amount varies from 1-2\%. The catalyst will decompose in the presence of the polyester resin to form free radicals, which will attack the unsaturated groups (like $\mathrm{C}=\mathrm{C}$ ) to initiate the polymerization.

The processing temperature and the amount of the catalyst can control the rate of polymerization, the higher temperature or the more the catalyst, the faster the reaction. After the resin turned from liquid to brittle solid, post cure at higher temperature may need to be done. The purpose of the post cure is to increase $\mathrm{Tg}$ of the resin by complete crosslinking. The properties of the polyester resin are affected by the type and amount of reactant, catalyst and monomers as well as the curing temperature. The higher the molecular weight of polyester and the more points of unsaturation in molecules, the higher is the strength of the cured resins. Orthophthalic polyesters are environmentally sensitive and have limited mechanical properties. They have been replaced in some applications by unsaturated polyesters due to the excellent environment resistance and improved mechanical properties of the latter. The crosslinking reaction of unsaturated polyester resin is shown in Figure 1.1. 


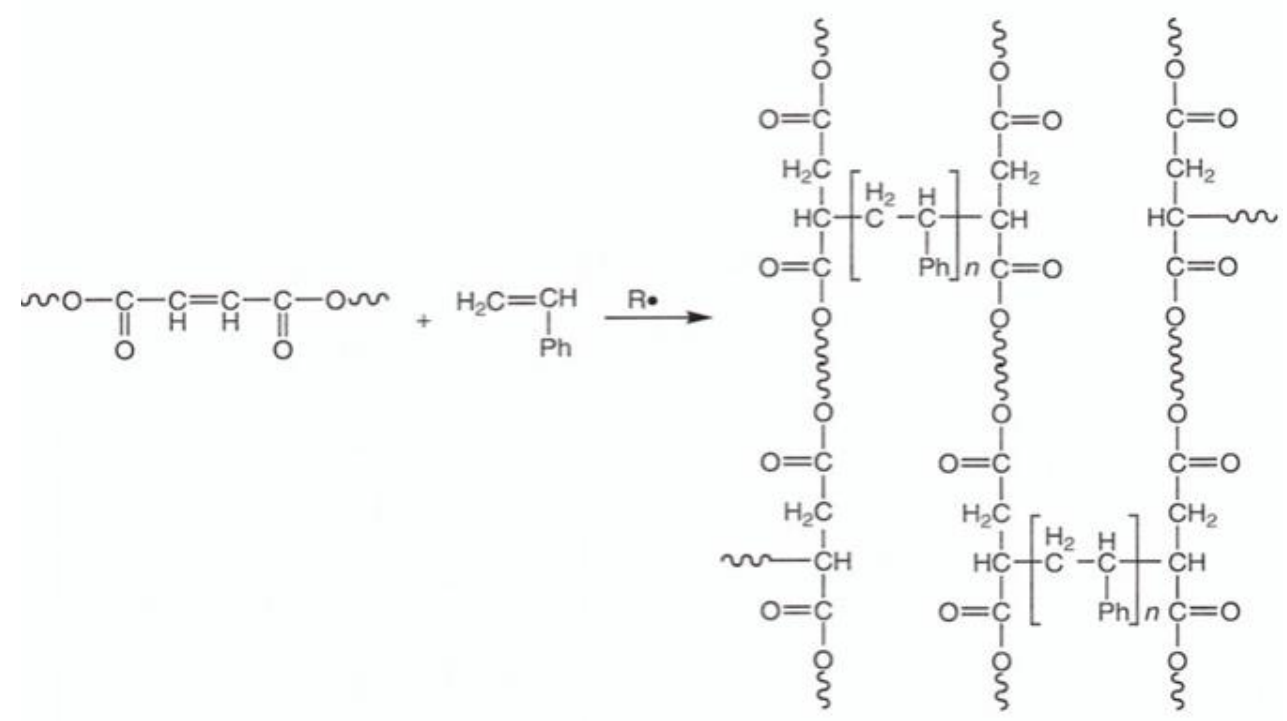

Figure 1.1 Networking of unsaturated polyester with styrene monomer.

\subsubsection{Chemistry of Glass Fibers}

Glass fibers fall into two categories, low-cost general-purpose fibers and premium specialpurpose fibers. Over $90 \%$ of all glass fibers are general-purpose products. These fibers are known by the designation E-glass and are subject to ASTM specifications[35]. The remaining glass fibers are premium special-purpose products. Many, like E-glass, have letter designations implying special properties [36]. Some have tradenames, but not all are subject to ASTM specifications. Specifically:

Table 1.1. Types and specifications of Fiber glass

\begin{tabular}{l|l} 
Letter designation & Property \\
\hline C, chemical & High chemical durability \\
\hline E, electrical & This kind of glass combines the characteristics \\
& of C-glass with very good insulation to electricity. \\
\hline S, strength & High strength
\end{tabular}




\begin{tabular}{l|l} 
M, modulus & High stiffness \\
\hline A, alkali & High alkali or soda lime glass \\
\hline $\mathrm{D}$, dielectric & Low dielectric constant
\end{tabular}

The properties of glass fibers reinforced polymer composite depend on many factors such as matrix and fiber strength, fiber length, fiber volume fraction, fiber bonding with the matrix, etc. It can be seen that fiber's properties are very important to the composite properties. According to the component, glass fibers can be classified as E-glass, S-glass, Carbon and Boron fibers. Carbon and Boron fibers are very expensive. Therefore, in most situations, only E-glass and S-glass fibers are used as the reinforcement in composite materials. Although S-glass fibers' mechanical properties are better than those of E-glass fibers, the price of S-glass fibers is much higher than that of E-glass fibers (Table 1.2). So considering the cost-performance ratio, E-glass fibers are used as the reinforcement in our research[37].

Table 1.2 Properties of glass fibers [37]

\begin{tabular}{|c|c|c|c|c|c|c|c|c|}
\hline $\begin{array}{l}\text { Fiber } \\
\text { Data }\end{array}$ & $\begin{array}{l}\text { Density } \\
\left(\mathrm{lb} / \mathrm{in}^{3}\right)\end{array}$ & $\begin{array}{l}\text { Tensile } \\
\text { strength } \\
\text { (Kpsi) }\end{array}$ & $\begin{array}{l}\text { Tensile } \\
\text { modulus } \\
\text { (Mpsi) }\end{array}$ & $\begin{array}{l}\text { Strain } \\
(\%)\end{array}$ & $\begin{array}{l}\text { Tensile } \\
\text { ratio }\end{array}$ & $\begin{array}{l}\text { Diameter } \\
\text { Range } \\
(\mu \mathrm{m})\end{array}$ & $\begin{array}{l}\text { Refracti } \\
\text { ve index }\end{array}$ & $\begin{array}{l}\text { Price per } \\
\text { pound }(\$)\end{array}$ \\
\hline E-glass & 0.094 & 500 & 11 & 4.76 & 1.1 & $3-20$ & 1.55 & $\begin{array}{l}0.75- \\
1.00\end{array}$ \\
\hline S-glass & 0.09 & 700 & 14 & 5.15 & 1.5 & $8-13$ & 1.54 & $\begin{array}{l}6.00- \\
8.00\end{array}$ \\
\hline
\end{tabular}


E-glass fibers can be obtained from E-glass which is a family of glasses with a calcium aluminoborosilicate composition and a maximum alkali content of $2 \%$. The composition of E-glass is shown in Table 1.3.

Table 1.3 E-glass compositions (wt. \%) [36]

\begin{tabular}{l|l} 
Components & E-glass range \\
\hline Silicon dioxide & $52-56$ \\
\hline Aluminium oxide & $12-16$ \\
\hline Boric oxide & $5-10$ \\
\hline Sodium oxide and potassium oxide & $0-2$ \\
\hline Magnesium oxide & $0-5$ \\
\hline Calcium oxide & $16-25$ \\
\hline Titanium dioxide & $0-1.5$ \\
\hline Iron oxide & $0-0.8$ \\
\hline Iron & $0-1.0$
\end{tabular}

At present, E-glass fibers have been widely used in fiber reinforced plastics not only because they have the advantage of low price, availability, ease of processing and high strength, but also because they have good resistance to moisture. E-glass fibers were reported to show a weight loss of $1.7 \%$ when exposed to boiling water for 1 hour. Moisture does produce the well-known static fatigue effect in E-glass, with a loss in strength of about $4 \%$ for each factor of ten in time under tensile stress. 


\subsubsection{Chemistry of Fiber / Matrix Interface}

The interface plays an important role in composite materials. Composite materials with weak interfaces have relatively low strength and stiffness but can have high resistance to fracture. On the contrary, composite materials with strong interfaces have relatively high strength and stiffness but may be brittle. The nature of the interface depends on the atomic arrangement and chemical properties of the fiber and on the molecular conformation and chemical constitution of the polymer matrix [38].

Besides chemical adhesion at the interface, adsorption and mechanical adhesion also contribute to the interfacial bonding. Coupling agents have been proposed to promote better wetting between polymer matrix and reinforcement surface for reduced voids at the interface by displacing the air (especially between closely packed fibers). In composites there are a lot of internal stresses induced in the processing operations. For example, resin shrinkage and the differential thermal coefficient of fibers and matrix can bring tensile, compressive or shear stresses, which will affect the fiber / matrix interfacial strength.

\subsection{Environmental Effects on Components of Composites}

Environmental effects on composite materials depend on the environmental effects on the individual components - fiber, matrix, and the interface between the fiber and the matrix. Actually, overall effects depend on the environmental effects on the dominant component materials. For example, transverse tension is a matrix dominant property, so the environmental degradation of this property depends on the matrix sensitivity to environment. The evaluation of environmental effects on composites can be well understood if the effects on individual components are studied. 


\subsubsection{Environmental Effects on Glass Fibers}

Today, E-glass fibers have been widely used in glass laminate manufacture because of their cost / performance characteristics. E-glass is a kind of low-alkali content borosilicate glass, which provides good mechanical properties as well as chemical resistance. Since the glass fibers are dispersed uniformly into the matrix, the resin protects them from many environments, except where small molecules such as water can diffuse through the matrix. The degradation of glass fibers with polymer matrices is not usually as great as that of the matrix and interface between them. Shen and Springer [39] reported that for 0 degree laminates (glass fiber dominant), changes in temperature from $200 \mathrm{~K}$ to $380 \mathrm{~K}$ have negligible effects on the ultimate tensile strength, regardless of the moisture content. There may be a slight decrease in strength $(<20 \%)$ as the temperature increases from $380 \mathrm{~K}$ to $450 \mathrm{~K}$. When the moisture content is below $1 \%$, the effects of moisture seem to be negligible. Above $1 \%$, the tensile strength decreases with increasing moisture content. The maximum decrease reported was about $20 \%$.

\subsubsection{Environmental Effects on Polymer Matrices}

The purpose of matrix is to bind the glass fibers together, keep them the right orientation, provide for load transfer, provide the interlaminar shear strength and protect the glass fibers from environmental attack. Generally, it is the matrix that determines the acceptable working environments and controls the environment resistance. Typical polymer literature lists environmental agents which attack particular matrix materials. The environment has strong effects on the properties of the polymers. These effects can be classified as reversible effects and irreversible effects. For example, when water diffuses into the matrix it can plasticize and swell the polymer network, decrease the surface free energy and increase the 
free volume of the polymer [32], thus inducing a reduction in the glass transition temperature (Tg). The change in $\mathrm{Tg}$ as a function of moisture is shown in Figure 1.2. This process is a reversible process, so the property will recover after drying the material.

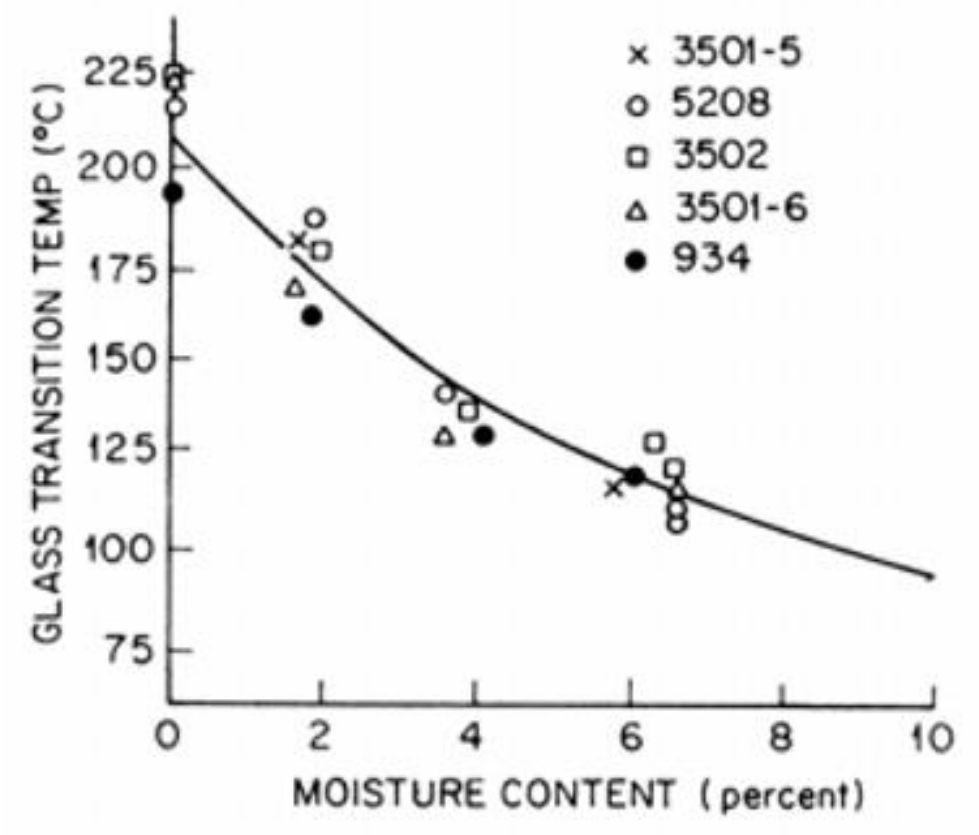

Figure 1.2 Effect of moisture on glass transition temperature

Long term exposure to moisture can also result in irreversible damage (hydrolysis and microcracking). Hydrolysis may be a primary reason for the weight loss of polymers after long term immersion[19]. Microcracking in the matrix, on the other hand, may contribute to further mechanical property degradation and more water absorption beyond the usual equilibrium level of the undamaged matrix. When composites are exposed to moisture, water molecules will diffuse into the matrix, passing through the open structure of the polymer even in the absence of porosity. The uptake of the moisture is a function of the 
chemistry of the matrix. Different kinds of resins have different diffusivity and maximum moisture content.

The mechanical properties of composites, especially those matrix dominated properties such as transverse tension strength and [ \pm 45$]$ tension strength, have been widely reported to decrease in wet conditions[25, 27]. However, Hale and Gibson [28] reported no property change due to oil exposure. Oil was not absorbed into the particular polymers like moisture was, so the degradation of properties generally occurs when the agent is taken up by the matrix. This tendency depends both on the size of the molecules of the environmental agent and the interactions with matrix chemistry. Besides accelerating the water absorption process, temperature also has strong effects on resins. Shen and Springer [40] concluded that for 90 degree laminates (resin dominated), an increase in temperature can cause a decrease in elastic moduli and strength. The reduction may be as high as 60 to 90 percent. Parvatareddy et al [41] aged a Ti-6Al-4V/FM5 adhesive bonded system at three different temperatures, 150, 177 and $204{ }^{\circ} \mathrm{C}$. Results showed that the greatest loss occurs at the highest aging temperature, $204^{\circ} \mathrm{C}$. The strain energy release rate dropped by $10-20 \%$ after aging for six months. Bowles [42] and the coworkers studied the physical and chemical aging effects in PMR-15 neat polyimide resin. The polymer showed weight loss and length decreased as a function of aging time at $316^{\circ} \mathrm{C}$ in nitrogen and air environment. The glass transition temperature $(\mathrm{Tg})$ varied as a function of aging time as well. Thus, temperature alone can cause significant permanent degradation in some polymers, depending on polymer chemistry. 


\subsubsection{Environmental Effects on the Fiber / Matrix Interface}

Composite materials consist of reinforcement and matrix, which have different elastic and physical properties. It is the interface that provides the adhesion between them in order to give the macroscopic mechanical properties of composite. The chemistry, morphology and properties of the fiber-matrix interface play a major role in the properties of composites. To produce high quality composite materials, the bond between the matrix to the fibers must be strong. To retain the properties of composites under environment attack, the fibermatrix interface must have excellent environmental resistance. To understand environmental effects on the fiber/matrix interface, the composition and structure of fiber/matrix interface must be known. As noted earlier, coupling agents are applied on the surface of glass fibers to improve the interfacial bonding to transfer the load through the matrix to the fibers, and to resist heat/cold attack.

Generally speaking, the strength of the fiber/matrix interface decreases as the time of exposure to water increases. Schultheisz and his coworkers [21] showed the degradation of the interfacial strength after immersion in water at $25^{\circ} \mathrm{C}$ and $75^{\circ} \mathrm{C}$ by using single fiber fragmentation test. Grant and Bradley [29] studied the degradation of graphite / epoxy composites due to sea water immersion. Through observation by scanning electron microscopy (SEM), they found that the measured 17\% decrease in transverse tension strength was associated with the degradation of the interface, which changed the mechanism of fracture from matrix cracking to interfacial failure. According to Choqueuse et al. [43], degradation in the interfacial strength may be related to the reduction of radial residual compressive stress. The coefficient of thermal expansion of polymer matrices is much greater than that for glass fibers. This results in a residual compressive stress across 
interface after the composite cools down from curing temperature. The residual compressive stress provides mechanical frictional bonding. However, elevated temperature and the swelling stress brought on by the water absorption in the matrix both can decrease this kind of compressive residual stress, and thus degrade the interfacial strength. Besides the type of coupling agent, the degree of network formation within the coupling agent and the degree of interdiffusion of coupling agent with resin influence the mechanical properties and durability of the interface $[44,45]$. All these factors provide for an on-going research field on the area of environmental resistance of the interface region, which is not completely understood at this time.

Zhang and Wang [44] proposed a mechanical model of the construction for the pull-out test of an fiber/polymer composite under temperature change, $\Delta \mathrm{T}$, as shown in Figure 1.3. They presented an analytical method to investigate thermal effects on interfacial stress transfer characteristics of single/multi-walled carbon nanotubes/polymer composites system under thermal loading by means of thermoelastic theory and conventional fiber pullout models. In example calculations, the mechanical properties and the thermal expansion coefficients of carbon nanotubes and polymer matrix are, respectively, treated as the functions of temperature change. Numerical examples showed that the interfacial shear stress transfer behavior can be described and affected by several parameters such as the temperature field, volume fraction of $\mathrm{CNT}$, and numbers of wall layer and the outermost radius of carbon nanotubes. From the results carried out it is found that mismatch of thermal expansion coefficients between the carbon nanotubes and polymer matrix may be more important in governing interfacial stress transfer characteristics of CNT/polymer composite system. [43] 
Here, the tubes with radius $\mathrm{R}_{\mathrm{N}}$ and length $\mathrm{L}$ is located with multi tube glass; spacing between each glass layer $\left(3.4 \mathrm{~A}^{\circ}\right)$,

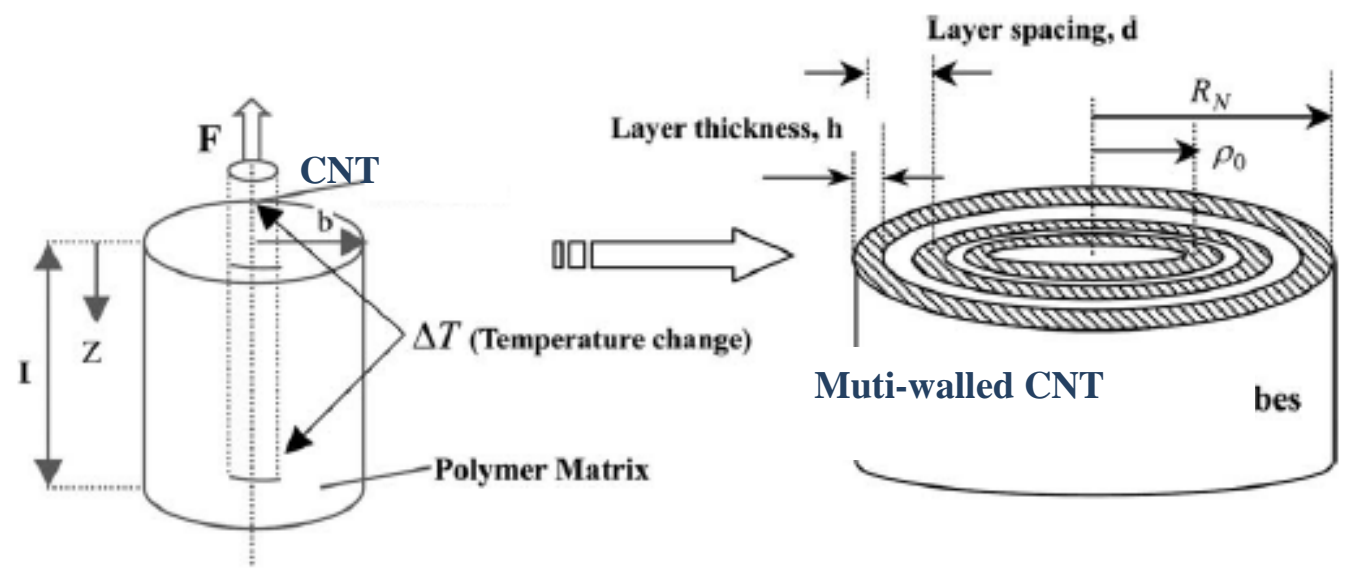

Figure 1.3 Schematic diagram of the CNT/polymer composites under thermal environment [43].

the effective wall thickness $h$ of the single walled glass tube SWGF is about $3.4 \mathrm{~A}^{\circ}$. According to the effective stiffness, $\mathrm{Eh}=360 \mathrm{~J} / \mathrm{m}^{2}$ [46], the corresponding effective elastic modulus is $\mathrm{E}=1.1 \mathrm{TPa}$. The outermost radius of the MWGF as shown in Figure 2.3 could be expressed as;

$\mathrm{R}_{\mathrm{N}}=\rho_{0}+\mathrm{d}(\mathrm{N}-1)$

Because the role of the glass fibers in advanced composite structures is to take up all stresses that are transferred from the matrix through the interfacial shear stress $[47,48]$, a well-known classical fiber pullout model was used to study the interfacial stress transfer problem of $\mathrm{CNT} /$ polymer composites system and three dimensional, axial-symmetric cylindrical thermoelastic model was proposed to analyze the stress transfer characteristics. 
Based on thermoelastic theory, the physical relationships between the stresses and strains in reinforcing material or in polymer matrix, under thermal environment, are expressed as [49];

$\varepsilon_{j}^{r}=\frac{\partial u_{j}^{r}}{\partial r}=\frac{1}{E_{j}}\left[\sigma_{j}^{r}-v_{j}\left(\sigma_{j}^{Z}+\sigma_{j}^{\theta}\right)\right]+\alpha_{j} \Delta T_{j}$

$\varepsilon_{j}^{\theta}=\frac{\partial u_{j}^{r}}{\partial r}=\frac{1}{E_{j}}\left[\sigma_{j}^{\theta}-v_{j}\left(\sigma_{j}^{r}+\sigma_{j}^{\theta}\right)\right]+\alpha_{j} \Delta T_{j}$

$\varepsilon_{j}^{Z}=\frac{\partial u_{j}^{Z}}{\partial r}=\frac{1}{E_{j}}\left[\sigma_{j}^{Z}-v_{j}\left(\sigma_{j}^{r}+\sigma_{j}^{\theta}\right)\right]+\alpha_{j} \Delta T_{j}$

where superscripts, $\mathrm{r}, \mathrm{h}$ and $\mathrm{z}$, are used to denote the components of stresses and strains in the cylindrical coordinate axes and the subscript, $\mathrm{j}$, may be $\mathrm{N}$ which represents the physical relationship of CNT or may be $\mathrm{m}$ which represents the physical relationship of polymer matrix.

In the above formula, $\mathrm{E}_{\mathrm{N}}, \alpha_{\mathrm{N}} \mathrm{E}_{\mathrm{m}}$ and $\alpha_{\mathrm{m}}$ are, respectively, Elastic's modulus and thermal expansion coefficients of CNT and polymer matrix, under temperature change environments, which may be a function of temperature change as follows for carbon nanotube reinforced polymer [50, 51].

$\mathrm{E}_{\mathrm{N}}=E_{N}^{o}(1-0.0005 \Delta \mathrm{T}), \quad \mathrm{E}_{\mathrm{m}}=E_{m}^{o}(1-0.0003 \Delta T)$

$\alpha_{N}=\alpha_{N}^{o}(1-0.0005 \Delta T), \quad \alpha_{\mathrm{m}}=\alpha_{m}^{o}(1-0.0003 \Delta T)$

$E_{N}^{o}, \alpha_{N}^{o}, E_{m}^{o}$ and $\alpha_{m}^{o}$ are, respectively, elastic modulus and thermal expansion coefficients of CNT and polymer matrix, under a room temperature environment. The Elastic's 
modulus $E_{N}^{o}$ of CNT estimated by using the local density approximation model and elastic shell theory is written as [52];

$E_{N}^{o}=\frac{N}{N-1+R} E_{S W G F}^{o} R$

where $\mathrm{R}$ expresses the thickness to spacing ratio of the GFs (h/d) and $E_{S W G F}^{o}$ expresses Elastic's modulus of $S W G F$ under room temperature environment. It is noted that for $\mathrm{N}=$ 1, the $E_{N}^{o}=E_{S W G F}^{o}$.

From the mechanics model of the construction as shown in Figure 2.3, the equilibrium equations between the matrix axial stress, GFs axial stress and interfacial shear stress are expressed as;

$$
\begin{aligned}
& \frac{d \sigma_{m}^{2}(z)}{d z}=\frac{2 \gamma}{R_{N}} \tau(z) \\
& \frac{d \sigma_{N}^{2}(z)}{d z}=-\frac{2}{R_{N}} \tau(z)
\end{aligned}
$$

where $\gamma=\frac{R_{N}^{2}}{b^{2}-R_{N}^{2}}$

Solving equation (2.9) and utilizing the boundary conditions at the two ends of the GFs/polymer composite

model, and $\sigma_{N}^{2}(0)=\sigma_{\text {pullout }}, \sigma_{N}^{2}(L)=0$;

$$
\begin{gathered}
\sigma_{N}^{2}(z)=\omega_{1}\left(\sigma_{\text {pullout }}\right) \sinh (\lambda z)+\omega_{2}\left(\sigma_{\text {pullout }}\right) \cosh (\lambda z) \\
-\left(\frac{A_{2}}{A_{1}} \sigma_{\text {pullout }}+\frac{A_{3}}{A_{1}} \sigma^{T}\right)
\end{gathered}
$$


Substituting equation 1.10 into equation 1.9, the GFs interfacial shear stress in the completely bonded region is given by

$\tau\left(R_{N, z}\right)=\frac{-R_{N} \lambda}{2}\left[\omega_{1}\left(\sigma_{\text {pullout }}\right) \cosh (\lambda z)+\omega_{2}\left(\sigma_{\text {pullout }}\right) \sinh (\lambda z)\right]$

where the parameters of $A_{1}, A_{2}, \lambda, \omega_{1}$ (pullout) and $\omega_{2}$ (pullout) are the functions of the mechanical properties and geometrical factors of the GFs and matrix under thermal environments,

$A_{1}=\frac{\alpha\left(1-2 k v_{N}\right)+\gamma\left(1-2 k v_{m}\right)}{U_{2}-2 k U_{1}}$

$A_{1}=\frac{-\gamma\left(1-2 k v_{m}\right)}{U_{2}-2 k U_{1}}$

\subsection{Coefficient of Thermal Expansion (CTE)}

An increase in temperature causes the vibrational amplitude of the atoms in the crystal lattice of the solid to increase. Therefore, the average spacing between the atoms increases, causing the material to expand. If the temperature change, $\Delta \mathrm{T}$, is such that the material does not go through a phase change, then the coefficient of volumetric thermal expansion $\left(\alpha_{\mathrm{v}}\right)[53,54]$ of a material is defined as;

$\alpha_{v}=\frac{1}{V}\left(\frac{\partial V}{\partial T}\right)$

where $V$ is the total volume of the material. If we consider one dimension only, we obtain the coefficient of linear thermal expansion $\left(\alpha_{1}\right)$ as

$\alpha_{v}=\frac{1}{l}\left(\frac{\partial l}{\partial T}\right)$

where $l$ is the total length of the body. If the length increases approximately linearly with the temperature in the temperature range observed and 
$\Delta l=l_{o}-l$

is small when compared with the initial length $l_{0}$, then coefficient of linear thermal expansion can be written as

$\alpha_{l}=\frac{\Delta l}{l_{o}} \cdot\left(\frac{1}{\Delta T}\right)$

For most materials $\alpha_{l}$ is positive and $\Delta l / l_{0}$ becomes negative on cooling. Thermal expansion of polymers originates from different modes of vibrations and is strongly influenced by the degree of crystallization and by glass transitions.

\subsubsection{Factors Affecting the Coefficient of Thermal Expansion}

Factors affecting the thermal expansion coefficient of composite materials are : fiber and void volumes, lay-up angle, thermal cycling, temperature dependence, moisture effects and material viscoelasticity.

\subsubsection{Fiber Volume Fraction}

The dependence of fiber volume is illustrated in Figure 1.4 for a unidirectional lamina consisting of glass fibers dispersed in an epoxy matrix. These curves were calculated based on formulas given by Schapery [53]. As seen in Figure 1.4, at approximately 60 percent fiber content, the longitudinal coefficient of expansion (CTE) is unaffected by any changes in the laminate fiber content. In the case of transverse CTE, the sensitivity is more pronounced. For the angle ply laminates comprised of several layers, the effect of fiber volume on the thermal expansion behavior of the laminate may not be negligible. 


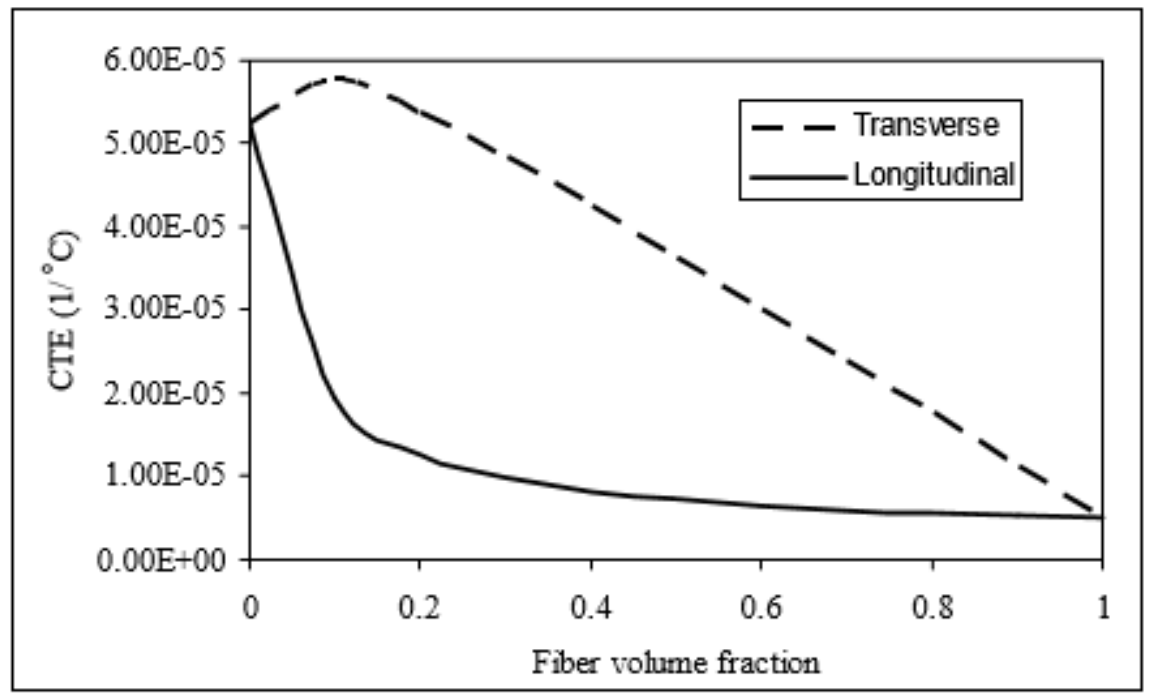

Figure 1.4 Variation of CTE of an epoxy-glass fiber lamina with fiber content of $60 \%$

\subsubsection{Void Volume}

The direct effect of voids on the CTE of composites is small within the bounds of practical manufacturing requirements (1.5 percent max. void volume) [55]. However the presence of voids can indirectly affect the CTE of a composite by initiating microcracks in the matrix. Voids in the matrix also tend to increase the potential moisture content of the matrix.

\subsubsection{Lay-up Angle}

One of the main advantages of laminated fiber reinforced composites is that mechanical and thermal response of composites can be tailored directionally to satisfy design requirements. This is accomplished by varying the orientation of each layer in a systematic manner to reach the desired effect. Figure 1.5 shows the variation of CTE of unidirectional composites with fiber orientation [56]. 


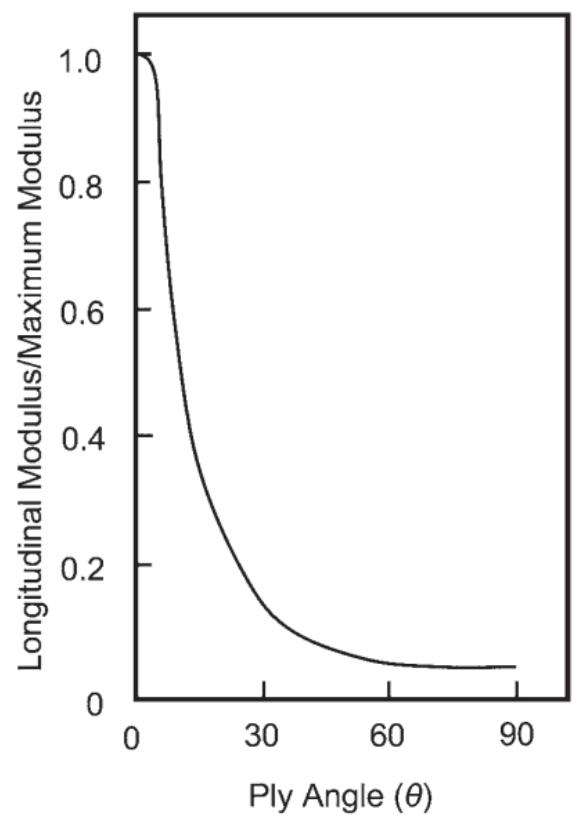

Figure 1.5 Variation of CTE of an epoxy-glass fiber lamina with fiber content of 60\%.

The sensitivity of the composite CTE to variations of fiber orientations can be severe. Although manufacturing tolerances for the lay-up angles are typically $\pm 3^{\circ}$, this practice can lead to serious CTE deviations for dimensionally critical structures [55].

\subsubsection{Thermal Cycling}

The primary influence of thermal cycling on CTE of composites is to induce matrix microcracking. When microcracking occurs, composite becomes partially decoupled. Matrix degradation proceeds gradually at first, and then somewhat more rapidly, and can be detected by changes in the composite thermal response. Therefore, CTE of the composite changes. This drift depends on many factors including materials, rate and number of thermal cycles, temperature extremes, and mechanical load level and lay-up angle[55]. 


\subsubsection{Moisture Effects}

The dimensional stability of composites is highly affected by exposure to complex hygrothermal histories. Moisture causes swelling and plasticization of the resin system. The swelling phenomenon alters internal stresses, thus causing a dimensional change in the laminate. Coupled with plasticization of the resin system, permanent dimensional changes up to 30 percent have been observed in laboratory experiments after exposure to complex hygrothermal histories. Dimensional changes caused by a temperature change are much less than the dimensional change due to moisture exposure. It is therefore important to account for moisture effects in assessing dimensional changes due to thermal effects [55].

\subsubsection{Viscoelasticty}

Changes in the internal stresses due to moisture and thermal environment can result in significant dimensional changes in composites. Internal stress levels also change due to the viscoelastic phenomenon called the relaxation of the matrix. Actually, relaxation of the internal stresses is a continuous process even without any mechanical, thermal or moisture excursions. This process is usually minimized by placing fibers in the direction where dimensional stability is required.

\subsubsection{Temperature Dependence}

It is a common way to report the CTE of materials as a single quantity and these values are often used by designers and analysts in the same manner. This practice may precipitate significant errors in composite design because of the temperature dependence of the thermal expansion behavior of composite materials. This temperature dependence is mainly caused by the mechanical and physical changes in the resin system. The CTE is a 
calculated value, which is the slope of the thermal strain-temperature curve between two temperatures, and the CTE values should be obtained from thermal expansion test data for the specific design temperature. Figure 1.6 shows temperature dependence of linear CTE data of the carbon reinforced composite. It is observed that all samples show a linear expansion as function of temperature at room temperature and the slope decreases gradually with decreasing temperature, which is similar to that observed in most materials $[55]$.

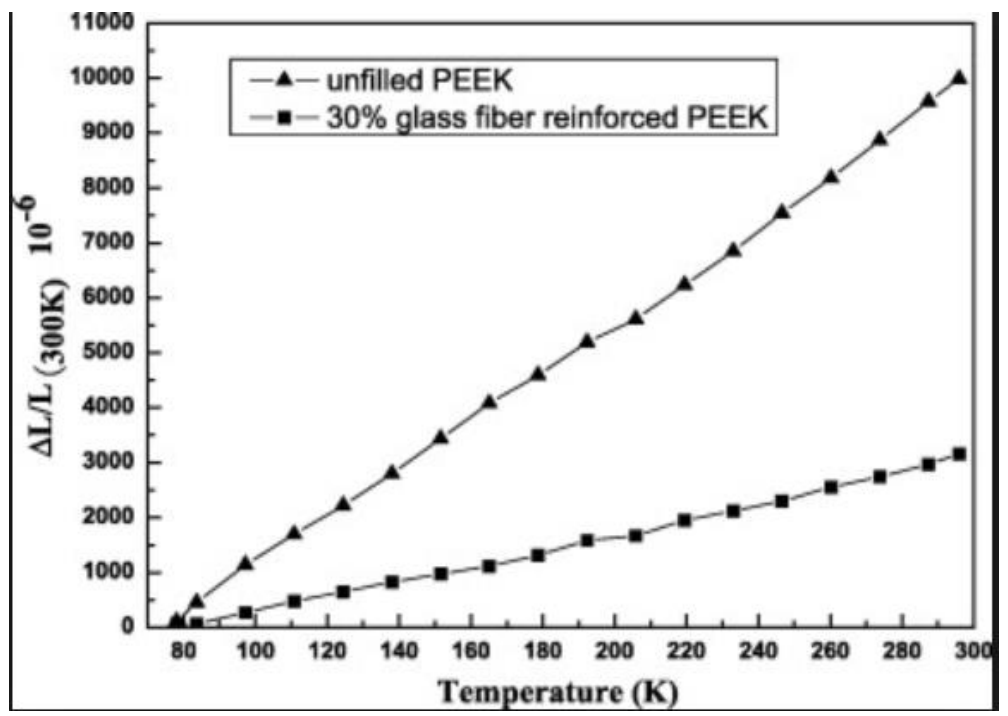

Figure 1.6 The temperature dependence of the linear thermal expansions for the glass fiber reinforced composites [55].

\subsection{Brittle ductile transition}

Some metals and polymers show a fracture behavior strongly dependent on temperature (and somehow on the stress); at low temperature the material undergoes a transition, known as the ductile-to-brittle transition temperature (DBTT). They show a brittle fracture, and at high temperature a ductile one. This represents passage through a lower-order transition. During this transition, the polymer loses a substantial level of kinetic energy, which results in restricted motion of the chains. This transition results in a sudden, sharp loss in ductility. 
Table 1.4. Brittle-ductile transition temperatures (decrease with cold working)[49]

\begin{tabular}{lc} 
Material & $\begin{array}{c}\text { Brittle-ductile } \\
\text { Temperature } \\
{\left[{ }^{\circ} \mathrm{C}\left({ }^{\circ} \mathrm{F}\right)\right]}\end{array}$ \\
\hline Polyethylene (low density) & $-110(-165)$ \\
Polytetrafluoroethylene & $-97(-140)$ \\
Polyethylene (high density) & $-90(-130)$ \\
Polypropylene & $-18(0)$ \\
\hline Nylon 6,6 & $57(135)$ \\
Polyester (PET) & $69(155)$ \\
\hline Polyvinyl chloride & $87(190)$ \\
Polystyrene & $100(212)$ \\
Polycarbonate & $150(300)$
\end{tabular}

Body-centred-cubic (bcc) crystals, and amorphous materials, show a thermal brittleductile transition (e.g. carbon steels, polymers), whereas stainless steels have face-centercubic (fcc) crystals and do not show a thermal brittle-ductile transition. Brittle-ductile transition temperature in amorphous solids corresponds to the glass transition temperature. Inclusions, dissolved gases, neutron irradiation, etc may also enhance brittleness.

The general behaviour for polymers is that they have brittle fracture if their glass-transition temperature is above room temperature (as for PMMA and many epoxies), and ductile fracture if they are near room temperature (as for PE); elastomers have their glass-transition temperature below room temperature[57].

\subsection{Specific heat}

Specific heat $(\mathrm{Cp})$ of polymers as a function of temperature has been investigated by Hartwig [57] who observed that $\mathrm{Cp}$ decreases drastically at low temperatures. This is explained by a quantum-mechanical theory [53]. The thermal vibrations which are the carriers of heat, can be described by phonons. The quantization of the phonon energy causes a temperature dependence of the internal energy quite different from the classical theory. This change is especially strong at low temperatures at which phonon energy is 
small, and only few phonons are activated. At elevated temperature $\mathrm{Cp}$ is proportional to the temperature $\mathrm{T}$, which is specific for linear polymers. At low temperatures and especially for composites with small coefficients of expansion, there is nearly no difference of the specific heat at constant pressure or volume. Furthermore, the temperature dependence of the specific heat is different for amorphous polymers and crystalline polymers below $\mathrm{T}=60 \mathrm{~K}$ (Table 1.5 ). For composite materials, the specific heat $\mathrm{c}_{\mathrm{com}} \mathrm{can}$ be calculated from the specific heat $c_{m}$ of the matrix and $c_{f}$ of the fillers by a linear mixing rule;

$c_{\text {com }}=V_{f} c_{f}+\left(1-V_{f}\right) c_{m}$

where $V_{f}$ is the volume content of the fillers.

Table 1.5 Temperature dependence of the specific heat of polymers at low temperatures[55]

\begin{tabular}{|l|l|l|}
\hline Temperature range & Crystalline polymers & Amorphous polymers \\
\hline$>100 \mathrm{~K}$ & $\mathrm{Cp} \alpha \mathrm{T}$ & $\mathrm{Cp} \alpha \mathrm{T}$ \\
\hline$\sim 10 \mathrm{~K}-60 \mathrm{~K}$ & $\mathrm{Cp} \alpha \mathrm{T}^{3}$ & $\mathrm{Cp} \alpha \mathrm{T}^{2}$ \\
\hline$\sim 1 \mathrm{~K}-10 \mathrm{~K}$ & $\mathrm{Cp} \alpha \mathrm{T}^{3}$ & $\mathrm{Cp} \alpha \mathrm{T}^{3.5}$ \\
\hline$>10 \mathrm{~K}$ & $\mathrm{Cp} \alpha \mathrm{T}^{3}$ & $\mathrm{Cp} \alpha \mathrm{T}$ \\
\hline
\end{tabular}

The Grueneisen relation relates the coefficient of thermal expansion $\alpha_{\mathrm{e}}$ to the specific heat $\mathrm{Cp}$

$\alpha_{e}=\frac{1}{3} \frac{\rho}{K} \gamma_{g} \mathrm{C}_{p}$ 
where $\rho$ is the density, $\mathrm{K}$ the compression modulus and $\gamma_{\mathrm{g}}$ the Grueneisen parameter. In composite materials, thermal expansion depends on the direction of the reinforcement and on the volume fraction. The thermal expansion along the reinforcing fiber tends to be dominated by the fiber, while transverse to the reinforcement the thermal expansion is dominated by the matrix [55]. One particularity of carbon fibers (and Kevlar) is that they are anisotropic. They show a small negative thermal expansion coefficient $\alpha_{e}$ in the fiber direction, but a very large positive one in the transverse direction. Experiments indicated that in carbon fiber filled PEEK composites the transverse expansion of unidirectional composites is $\Delta l / l_{0}=-0.6 \%$ to $-0.8 \%$ between $\mathrm{RT}$ and $\mathrm{T}=4.2 \mathrm{~K}$, whereas the thermal expansion in parallel direction is slightly positive (Table 1.6).

Table 1.6 Thermal expansion of 60\% CF filled PEEK composite [55]

\begin{tabular}{|c|c|}
\hline Fiber direction & Thermal expansion $\Delta l / l o(293 \mathrm{~K} \rightarrow 4.2 \mathrm{~K})$ \\
\hline$I I$ & +0.004 \\
\hline$\perp$ & -0.6 \\
\hline
\end{tabular}

Table 1.7 Thermal expansion according to [50,58] and [55]

\begin{tabular}{|c|c|c|}
\hline \multirow{2}{*}{ Material } & \multicolumn{2}{|c|}{ Thermal expansion $\Delta l / l o(\%)$} \\
\cline { 2 - 3 } & $293 \mathrm{~K} \rightarrow 4.2 \mathrm{~K}$ & $293 \mathrm{~K} \rightarrow 77 \mathrm{~K})$ \\
\hline PTFE & -1.8 & -1.7 \\
\hline PEEK & -1.0 & -0.9 \\
\hline Copper & -0.32 & -0.30 \\
\hline Carbon fiber in epoxy matrix (II) & & +0.01 \\
\hline
\end{tabular}


Problems arise for most designs of cryogenic support structures from the thermal expansion, especially if different materials are involved. In composite materials, different thermal coefficients of expansion between matrix and fibers can lead to mechanical stresses at the interface of components. Table 1.7 summarizes some data on thermal expansion of different materials from the literature.

\subsection{Thermal conductivity}

Thermal conductivity occurs when a thermal excitation gives rise to transport of energy with permanent local thermalization. The resulting temperature gradient drives the flux of energy carriers which are phonons in the case of insulators [55]. The relationship between the heat power $\dot{Q}$ per area A and the temperature gradient is given by the thermal conductivity $\mathrm{k}$

$$
\frac{\dot{Q}}{A}=-k \operatorname{grad} T
$$

Thermal conductivity $\mathrm{k}$ is proportional to the specific heat

$$
k=\kappa \rho C_{p}
$$

where

$\kappa$ is the thermal diffusivity. The temperature dependence of thermal conductivity is summarized in Table 1.8. 
Table 1.8 Temperature dependence on the thermal conductivity [49]

\begin{tabular}{|l|l|}
\hline Temperature range & Temperature dependence \\
\hline Amorphous polymers $<1 \mathrm{~K}$ & $k_{a} \propto T^{2}$ \\
\hline $\mathrm{T} \sim 4 \mathrm{~K}-10 \mathrm{~K}$ & $k_{a} \propto$ constant \\
\hline $\mathrm{T}>30 \mathrm{~K}$ & $k_{a} \propto T^{0.3}$ to $T^{0.5}$ \\
\hline Semicrystalline & \\
$\mathrm{T}<20 \mathrm{~K}$ & $k_{\text {semi }} \propto T^{2}$ \\
\hline $\mathrm{T}>30 \mathrm{~K}$ & $k_{\text {semi }}$ is determined mainly by $k_{a}$ \\
\hline
\end{tabular}

The thermal conductivity of polymers at cryogenic temperatures depends little on the composition. For semi-crystalline polymers, it depends mainly on the crystalline content and on the crystallite size [49]. Carbon fiber composites have a strong temperature dependence. They exhibit a very low thermal conductivity at very low temperatures.

\subsection{Mechanical deformation behavior}

The correlation between applied mechanical load and resulting deformation is described by viscoelastic moduli. The basic component of viscoelastic moduli is controlled by binding forces, originating from deformations of the electron configurations. The load acts against the binding forces. This component reacts nearly immediately and is responsible for the elastic behaviour. External forces cause deformations of molecular segments and of electron orbital in polymers. The deformation can be elastic, viscoelastic or viscous. At very low temperatures and not too high stress levels the deformation behaviour is 
determined by Vander waals binding potential. Time-dependent viscoelastic effects are negligible and most polymers behave elastically [49]. Experiments reveal that the chemical compositions of polymers have a rather small influence on the low-temperature deformation behaviour. Also, below $\mathrm{T}=100 \mathrm{~K}$, no large differences exist between the modulus of amorphous and crystalline polymers (Table 1.9). In the vicinity of secondary and tertiary glass transitions, however, viscoelastic processes decrease the modulus of the amorphous domains. Table 1.10 indicates Brinell hardness values for materials tested at $\mathrm{RT}$ and at $\mathrm{T}=77 \mathrm{~K}$.

Table 1.9 E-modulus at low temperatures [55]

\begin{tabular}{|c|c|}
\hline Polymer & \multicolumn{1}{|c|}{ E-modulus } \\
\hline Semicrystalline and cross-linked & $E=7-9$ Gpa (below $100 \mathrm{~K}$ \\
\hline Amorphous & $E=5-8$ Gpa \\
\hline
\end{tabular}

Table 1.10 $10 \mathrm{~s}$ Brinell hardness values for materials tested at $\mathrm{T}=293 \mathrm{~K}$ and $\mathrm{T}=77 \mathrm{~K}$ [53]

\begin{tabular}{|c|c|c|}
\hline \multirow{2}{*}{ Polymer } & \multicolumn{2}{|c|}{ Hardness (MPa) } \\
\cline { 2 - 3 } & $293 \mathrm{~K}$ & $77 \mathrm{~K}$ \\
\hline PTFE & 33 & 450 \\
\hline Copper & 550 & 800 \\
\hline Stainless steel & 1760 & 3120 \\
\hline
\end{tabular}




\subsection{Refractive Index of Polymer Matrix}

In the 1860's, Maxwell published his famous unified equation [59, 60]:

$\varepsilon=n^{2}$

Where $\varepsilon$ the dielectric constant of a material and $\mathrm{n}$ is the refractive index of the material. According to Maxwell-Garnett effective medium theory [61-63], the bulk dielectric constant of the Composite can be described from the dielectric constants of the host and inclusion as:

$$
\frac{\varepsilon_{c}-\varepsilon_{h}}{\varepsilon_{c}+2 \varepsilon_{h}}=\phi\left(\frac{\varepsilon_{i}-\varepsilon_{h}}{\varepsilon_{i}+2 \varepsilon_{h}}\right)
$$

Where $\varepsilon_{c}, \varepsilon_{h}$ and $\varepsilon_{i}$ are the dielectric constants of the composite, host and inclusion, respectively, and $\phi$ is the volume fraction of the inclusion. The refractive index $n$ of the composite can be calculated by using eqn.1.22 and eqn.1.23. The dielectric constants of the composite, host and inclusion can be measured by using a dielectric meter. It can be seen that by adding inclusion(s) into the host, the refractive index of the composite can be changed. If appropriate amount of inclusion(s) are added into the host, the composite with right refractive index (same or very close to that of glass fibers) can be obtained.

Due to lack of a dielectric meter, this theory is not used now. Another theory- LorentzLorenz effective medium theory- is now used to help us minimize the refractive index difference between the polyester and glass fibers.

The Lorentz-Lorenz effective medium expression for two components is [64-66]:

$$
\frac{n_{12}^{2}-1}{n_{12}^{2}+2}=\phi_{1}\left(\frac{n_{1}^{2}-1}{n_{1}^{2}+2}\right)+\phi_{2}\left(\frac{n_{2}^{2}-1}{n_{2}^{2}+2}\right)
$$


where $n_{12}$ is the refractive index of the mixture or composite, $n_{1}$ and $n_{2}$ are the refractive indices of the pure components respectively, $\phi_{1}$ and $\phi_{2}$ are volume fractions of component 1 and component 2 .

For three components $[65,67]$ :

$$
\frac{n_{c}^{2}-1}{n_{c}^{2}+2}=\phi_{1} \cdot \frac{n_{1}^{2}-1}{n_{1}^{2}+2}+\phi_{2} \cdot \frac{n_{2}^{2}-1}{n_{2}^{2}+2}+\phi_{3} \cdot \frac{n_{3}^{2}-1}{n_{3}^{2}+2}
$$

where $n_{c}, n_{1}, n_{2}$ and $n_{3}$ are the refractive indices of the composite, component 1 , component 2 and component 3 , respectively. $\phi_{1}, \phi_{2}$ and $\phi_{3}$ are the volume fractions of component 1 , component 2 and component 3 , respectively.

This theory can be extended to mixtures with more than 3 components.

According to the Lorentz-Lorenz equation, changing the component(s) or changing the content(s) of component(s) in mixture can change the refractive index of the mixture. The refractive index of modified mixture can be estimated by using the Lorentz-Lorenz equation. In our research, polyester is in liquid state, for turning it to the solid state, an initiator Methyl Ethyl Ketone Peroxide (MEKP) is added into it (Figure 1.7). Polyester's curing time is very long, so polymerization rate accelerator Cobalt Naphthenate (Cobalt) is added into the polyester resin to accelerate the curing speed. In other words, MEKP and Cobalt are two essential components of the polyester mixture. For the convenience of studying, a small program-Refractive index calculator-was developed and used here to calculate the refractive index of polyester mixture and plot the effect of additive on the refractive index of the mixture. 

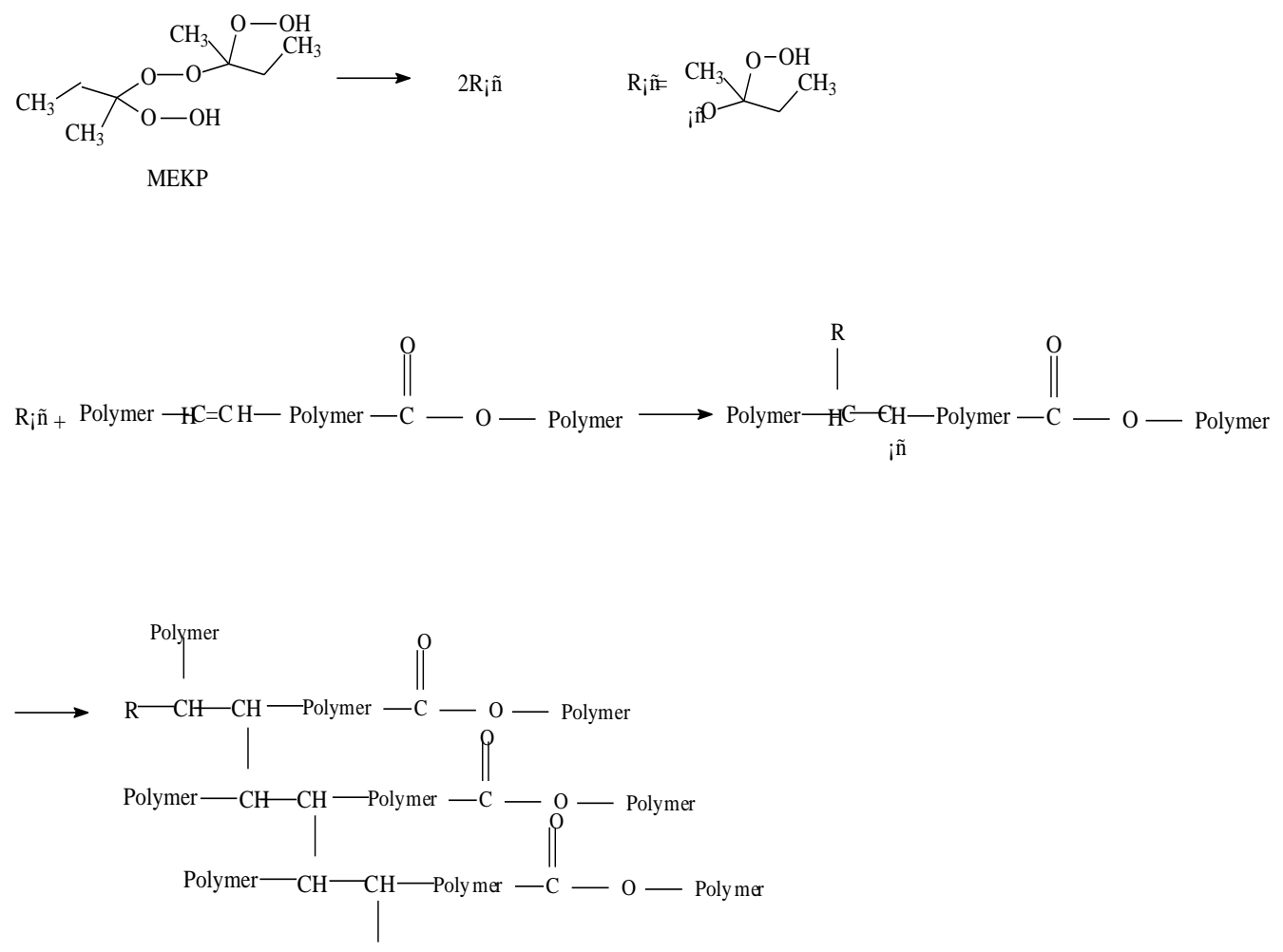

Figure 1.7 Chemical reactions occurring during the curing process of polyester

\subsubsection{Light refraction}

When a light moves from a medium with a refractive index $n_{1}$ into another medium with a refractive index $\mathrm{n}_{2}$, light refraction will occur (Figure 1.8). The angles that incident and refracted rays make to the normal of the interface are given as $\theta_{i}, \theta_{r}$, respectively.

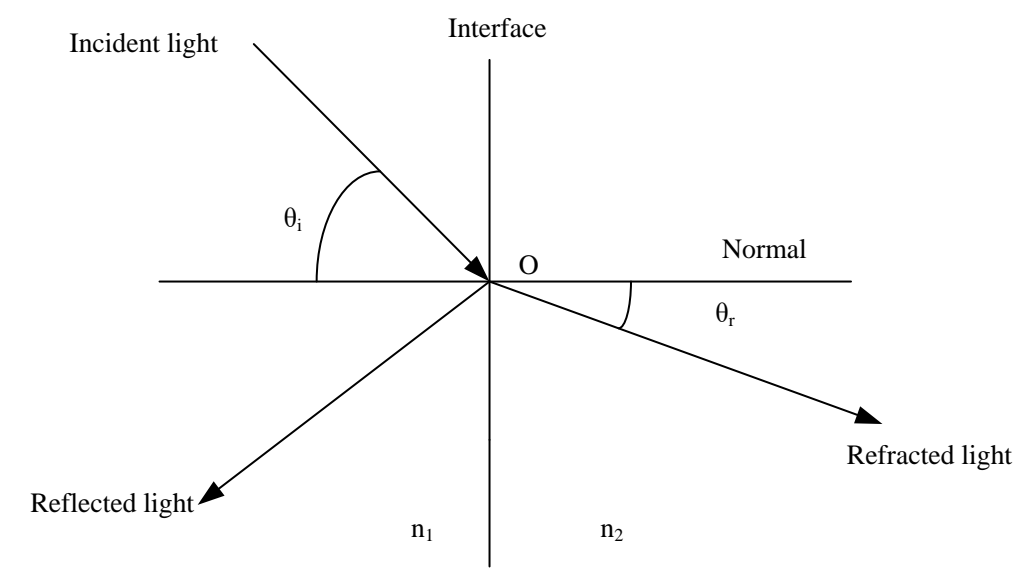

Figure 1.8 Reflection and refraction of light in two materials interface 
The relationship between these angles is given by Snell's law (equation 2.26)[60],

$$
\frac{\sin \left(\theta_{i}\right)}{\sin \left(\theta_{r}\right)}=\frac{n_{2}}{n_{1}}
$$

Where $n_{1}$ and $n_{2}$ denote the refractive indices of two media, $\theta_{i}$ is the angle of incident

light to the normal line and $\theta_{r}$ is the angle of refracted light to the normal line.

The fraction of light that is refracted is given by the transmission coefficient $\mathrm{T}$ ( $\mathrm{T}=$ refracted light/total incident light). As a consequence of the conservation of energy, the transmission coefficient is given by $T=1-R, R$ is the reflection coefficient. The calculation of $R$ depends on the polarization of the incident light, because light can be divided into S-polarized light and P-polarized light. S-polarized light is perpendicular to the plane of Figure 1.8, the reflection coefficient $\left(R_{S}\right)$ of S-polarized light is given by equation 2.27:

$$
R_{s}=\left(\frac{n_{1} \cos \theta_{i}-n_{2} \cos \theta_{r}}{n_{1} \cos \theta_{i}-n_{2} \cos \theta_{r}}\right)^{2}=\left[\frac{n_{1} \cos \theta_{i}-n_{2} \sqrt{1-\left(\left(\frac{n_{1}}{n_{2}}\right) \sin \theta_{i}\right)^{2}}}{n_{1} \cos \theta_{i}+n_{2} \sqrt{1-\left(\left(\frac{n_{1}}{n_{2}}\right) \sin \theta_{i}\right)^{2}}}\right]
$$

P-polarized light is in the plane of Figure 1.8, and the reflection coefficient $\left(R_{p}\right)$ of $\mathrm{P}$ polarized light is given by equation 1.28 [59]:

$$
R_{p}=\left(\frac{n_{1} \cos \theta_{r}-n_{2} \cos \theta_{i}}{n_{1} \cos \theta_{r}+n_{2} \cos \theta_{i}}\right)^{2}=\left[\frac{n_{1} \sqrt{1-\left(\left(\frac{n_{1}}{n_{2}}\right) \sin \theta_{i}\right)^{2}}-n_{2} \cos \theta_{i}}{n_{1} \sqrt{1-\left(\left(\frac{n_{1}}{n_{2}}\right) \sin \theta_{i}\right)^{2}}+n_{2} \cos \theta_{i}}\right]
$$

If $n_{1}$ is not equal to $n_{2}, R_{s}$ and $R_{p}$ will be larger than zero, in other words, $T_{s}$ and $T_{p}$ will be smaller than 1 and this means light transmission decreases. So the best method that can be 
used to improve the transparency of the composite is matching the refractive index of glass fibers with that of the polymer matrix. The refractive index of glass fibers is about 1.559. The refractive indices of polyester, polyurethane and epoxy are 1.552, 1.550 and 1.545, respectively. The refractive index of polyester is closest to that of glass fibers.

So the unsaturated polyester is used as the composite matrix in our research. The refractive index difference between glass fibers and polyester is around 0.007 , method(s) should be developed to minimize this difference to \pm 0.0005 .

\section{a) Effect of Cobalt Content on the Refractive Index of Polyester}

From Table 1.11 and Figure 1.9, it can be known that when the content of MEKP is fixed, an increase of Cobalt content results in a refractive index increase of polyester mixture. But, calculated results show that adding less than $0.1 \%$ Cobalt into polyester can't change its refractive index a lot (Figure 1.9). Cobalt is used as the polymerization accelerator in the study and its color is reddish violet. More Cobalt content in polyester means less gel time, less operation time and deeper color of the product. According to the experimental results, when Cobalt content is more than $0.05 \%$, polyester cures very fast and cured product has a darker color. When the content of

Table 1.11 Refractive index of polyester with different cobalt contents [68]

\begin{tabular}{ccc}
\hline MEKP content & Cobalt content & Refractive index ${ }^{*}$ \\
\hline $1.2 \%$ & $0.02 \%$ & 1.5526 \\
$1.2 \%$ & $0.03 \%$ & 1.5560 \\
$1.2 \%$ & $0.04 \%$ & 1.5564 \\
$1.2 \%$ & $0.06 \%$ & 1.5626 \\
\hline
\end{tabular}

*:Refracive index was measured by using ATAGO NAR3T refractometer 
cobalt is less than $0.01 \%$, polyester cures very slowly. Therefore, appropriate content of Cobalt is between $0.01 \%$ and $0.05 \%$.

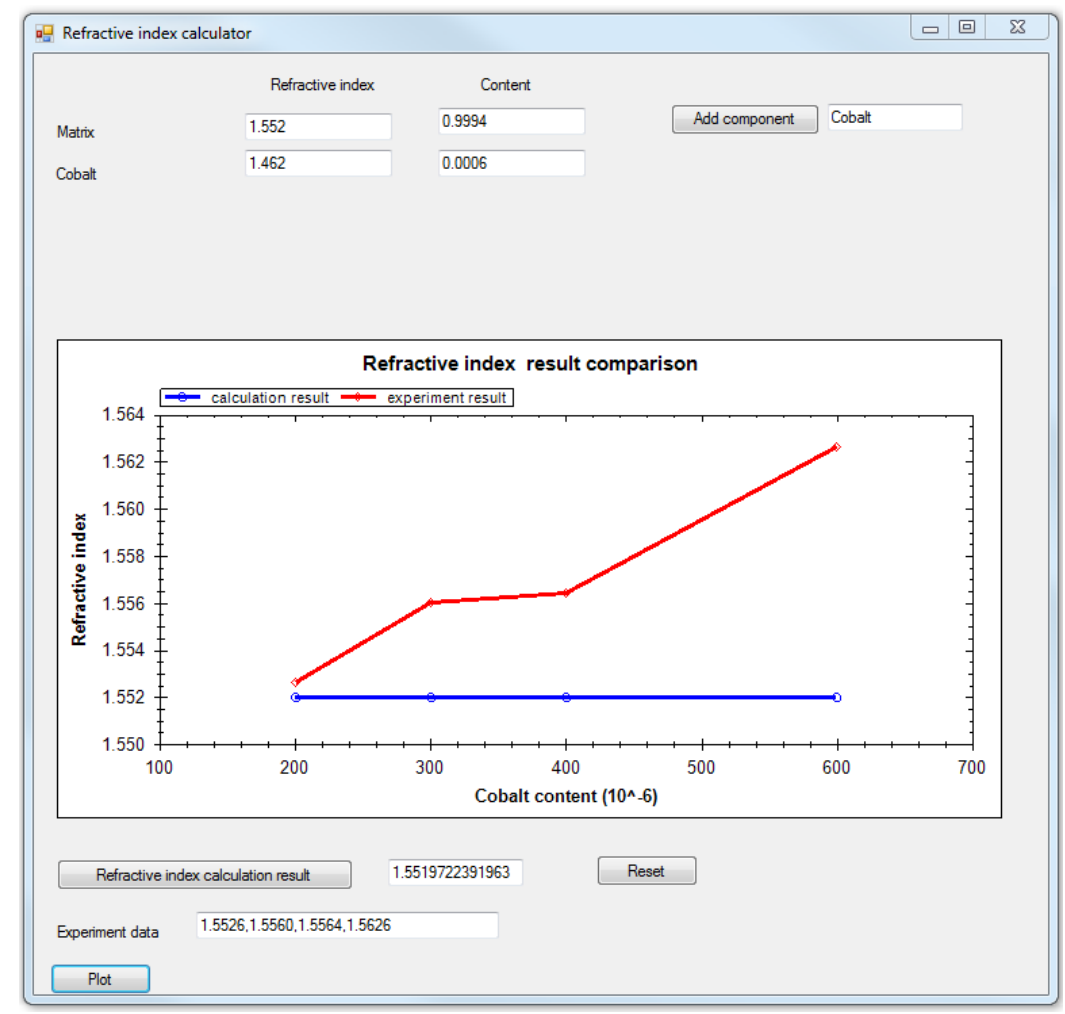

Figure 1.9 Experimental and calculated results comparison (Cobalt effect) [68]

\section{b) Effect of MEKP Content on the Refractive Index of Polyester}

From Table 1.12 and Figure 1.10, it can be known that with the increase of MEKP content, the refractive index of polyester varies around 1.556. Calculated results show that adding MEKP into polyester will decrease its refractive index. The gap between the calculated results and experimental results is about 0.0025 . 
Table 1.12 Refractive index of polyester with different MEKP contents[68]

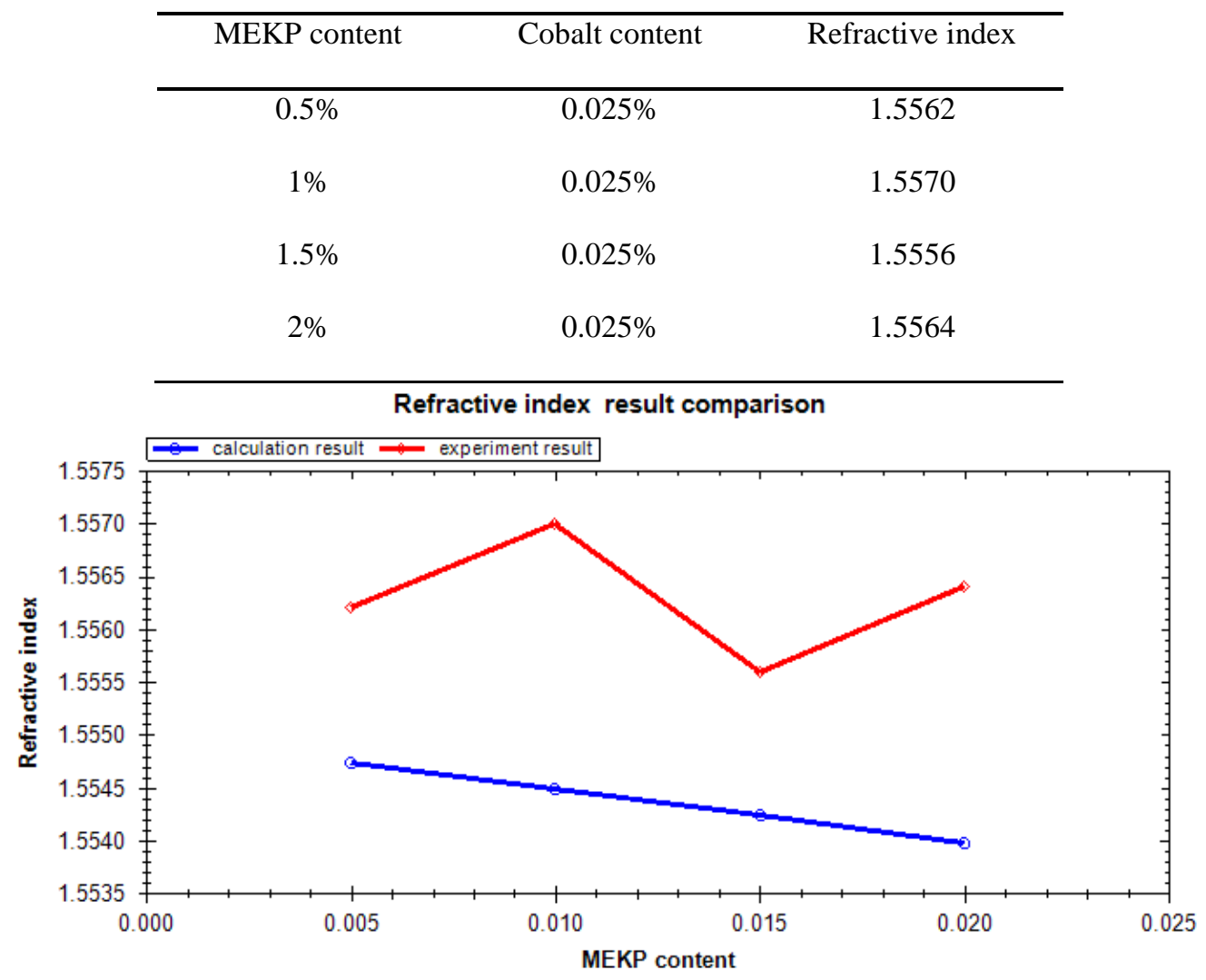

Figure 1.10 Experimental and calculated results comparison (MEKP effect) [68]

According to the experimental results, it is known that increasing MEKP content has almost no effect on the refractive index of polyester. Within the range of appropriate content of Cobalt (0.01- 0.05\%), the refractive index of polyester can't be increased to that of glass fibers (1.5595).

\section{c) Effect of Phenanthrene Content on the Refractive Index of Polyester}

Figure 1.11 shows the structure of phenanthrene. With the increase of Phenanthrene content, experimental results and calculated results both show an increase of 
polyester's refractive index (Table 1.13 and Figure 1.11). But experimental results show a faster increase.

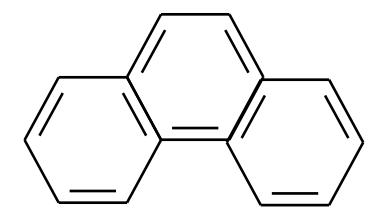

Figure 1.11 Structure of Phenanthrene

Table 1.13 Refractive index of polyester with different Phenanthrene contents[68]

\begin{tabular}{cccc}
\hline MEKP content & Phenanthrene content & Cobalt content & Refractive index \\
\hline $1.2 \%$ & $0 \%$ & $0.03 \%$ & 1.5560 \\
$1.2 \%$ & $0.5 \%$ & $0.03 \%$ & 1.5582 \\
$1.2 \%$ & $0.9 \%$ & $0.03 \%$ & 1.5587 \\
$1.2 \%$ & $1 \%$ & $0.03 \%$ & 1.5599 \\
$1.2 \%$ & $1.2 \%$ & $0.03 \%$ & 1.5608 \\
$1.2 \%$ & $2.5 \%$ & $0.03 \%$ & 1.5611
\end{tabular}

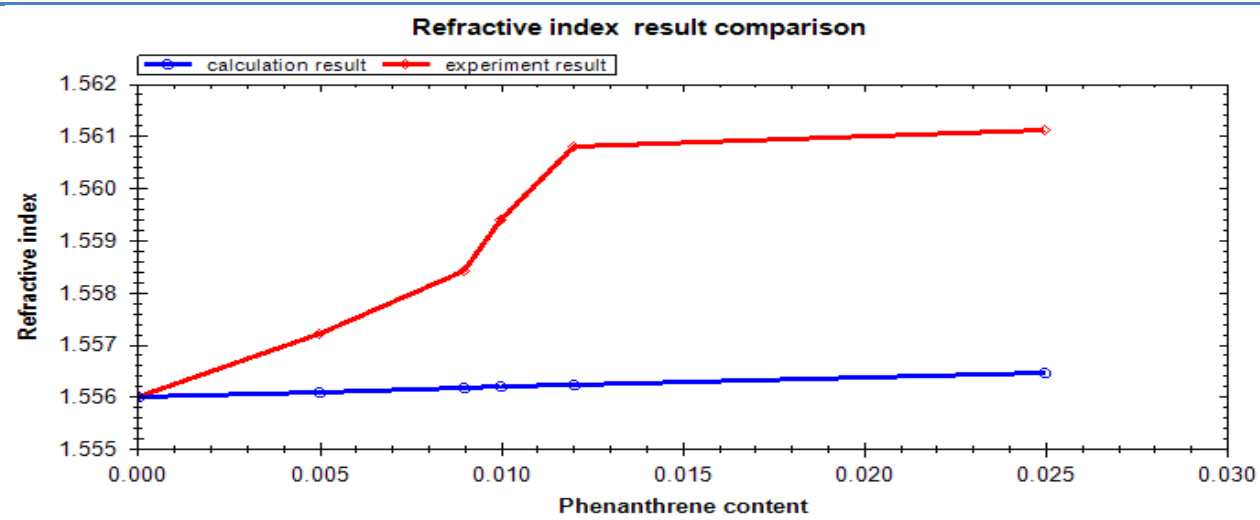

Figure 1.12 Experimental and calculated results comparison (Phenanthrene effect)[68]

According to the data shown above, the effect on harsh environment on mechanical and thermal properties is diverse depending on environment conditions, material composition, material properties and enforcement properties. The resistance polymer matrix or polymer 
composite to different mechanical loads may vary upon exposure to moisture and extreme temperatures. Different applications require different materials and demands. Therefore, a focus on the performance of transparent unsaturated polyester composite at different load scenarios is an essential task for structural design; however, the available literatures didn't discuss these possibilities. Also, refractive indices calculated by the Lorentz-Lorenz equation are always lower than those obtained from experiment. One reason is that the Lorentz-Lorenz equation always gives a lower estimation [67]. According to the literature[23], the Maxwell-Garnett theory can give a better estimation than the LorentzLorenz theory. Another possible reason is that the Lorentz-Lorenz theory doesn't consider the effect of crosslinking density on the refractive index. When experiments based on the Maxwell-Garnett theory are finished, comparison among the Lorentz-Lorenz equation results, the Maxwell-Garnett equation results and experimental results will be done. At that time, the theory that can fit the experimental results better will be used to do a prediction that how a polyester product with needed refractive index can be obtained. 


\section{References}

[1] Bakis, C. E., Bank, L. C., Brown, V., Cosenza, E., Davalos, J., Lesko, J., Machida, A., Rizkalla, S., and Triantafillou, T., 2002, "Fiber-reinforced polymer composites for construction-State-of-the-art review," Journal of composites for construction, 6(2), pp. 73-87.

[2] Wei, J., 2004, "Dynamics and failure analysis of architectural glazing subjected to blast loading."

[3] Bai, Y., Keller, T., and Vallée, T., 2008, "Modeling of stiffness of FRP composites under elevated and high temperatures," Composites Science and Technology, 68(15), pp. 3099-3106.

[4] Yu, B., Till, V., and Thomas, K., 2007, "Modeling of thermo-physical properties for FRP composites under elevated and high temperature," Composites Science and Technology, 67(15), pp. 3098-3109.

[5] Cantwell, W., and Morton, J., 1991, "The impact resistance of composite materials-a review," composites, 22(5), pp. 347-362.

[6] Kim, M.-G., Kang, S.-G., Kim, C.-G., and Kong, C.-W., 2007, "Tensile response of graphite/epoxy composites at low temperatures," Composite structures, 79(1), pp. 84-89.

[7] Reis, J., Coelho, J., Monteiro, A., and da Costa Mattos, H., 2012, "Tensile behavior of glass/epoxy laminates at varying strain rates and temperatures," Composites Part B: Engineering, 43(4), pp. 2041-2046.

[8] Karbhari, V. M., and Pope, G., 1994, "Impact and flexure properties of glass/vinyl ester composites in cold regions," Journal of cold regions engineering, 8(1), pp. 1-20. 
[9] Dutta, P. K., 1988, "Structural fiber composite materials for cold regions," Journal of Cold Regions Engineering, 2(3), pp. 124-134.

[10] Hawileh, R. A., Abu-Obeidah, A., Abdalla, J. A., and Al-Tamimi, A., 2015, "Temperature effect on the mechanical properties of carbon, glass and carbon-glass FRP laminates," Construction and Building Materials, 75, pp. 342-348.

[11] Robert, M., and Benmokrane, B., 2009, "Behavior of GFRP reinforcing bars subjected to extreme temperatures," Journal of Composites for Construction, 14(4), pp. 353-360.

[12] Norville, H. S., and Conrath, E. J., 2006, "Blast-Resistant Glazing Design," Journal of Architectural Engineering, 12(3), pp. 129-136.

[13] Weggel, D. C., and Zapata, B. J., 2008, "Laminated Glass Curtain Walls and Laminated Glass Lites Subjected to Low-Level Blast Loading," Journal of Structural Engineering, 134(3), pp. 466-477.

[14] El-Shami, M., and Mahmoud, S., 2015, "Structural behavior of window laminated glass plies using new interlayer materials," Journal of King Saud University-Engineering Sciences.

[15] Galuppi, L., and Royer-Carfagni, G., 2013, "The design of laminated glass under timedependent loading," International Journal of Mechanical Sciences, 68, pp. 67-75.

[16] Vogelesang, L. B., and Vlot, A., 2000, "Development of fibre metal laminates for advanced aerospace structures," Journal of Materials Processing Technology, 103(1), pp. $1-5$.

[17] Tsotsis, T. K., 1998, "Long-term thermo-oxidative aging in composite materials: experimental methods," Journal of Composite Materials, 32(11), pp. 1115-1135. 
[18] Springer, G. S., and Loos, A. C., 1979, "Effects of Thermal Spiking on GraphiteEpoxy Composites," MICHIGAN UNIV ANN ARBOR DEPT OF MECHANICAL ENGINEERING.

[19] Schutte, C. L., 1994, "Environmental durability of glass-fiber composites," Materials Science and Engineering: R: Reports, 13(7), pp. 265-323.

[20] Carter, H. G., and Kibler, K. G., 1977, "Entropy model for glass transition in wet resins and composites," Journal of Composite Materials, 11(3), pp. 265-275.

[21] Schultheisz, C. R., McDonough, W. G., Kondagunta, S., Schutte, C. L., Macturk, K. S., McAuliffe, M., and Hunston, D. L., 1997, "Effect of moisture on E-glass/epoxy interfacial and fiber strengths," Composite Materials: Testing and Design, Thirteenth Volume, ASTM International.

[22] Davies, P., Pomies, F., and Carlsson, L. A., 1996, "Influence of water absorption on transverse tensile properties and shear fracture toughness of glass/polypropylene," Journal of Composite Materials, 30(9), pp. 1004-1019.

[23] Pomies, F., Carlsson, L., and Gillespie, J., 1995, "Marine environmental effects on polymer matrix composites," Composite Materials: Fatigue and Fracture: Fifth Volume, ASTM International.

[24] Ellyin, F., and Maser, R., 2004, "Environmental effects on the mechanical properties of glass-fiber epoxy composite tubular specimens," Composites Science and Technology, 64(12), pp. 1863-1874.

[25] Soutis, C., and Turkmen, D., 1997, "Moisture and temperature effects of the compressive failure of CFRP unidirectional laminates," Journal of Composite Materials, 31(8), pp. 832-849. 
[26] Cappelletti, C., Rivolta, A., and Zaffaroni, G., 1995, "Environmental effects on mechanical properties of thick composite structural elements," Journal of Composites, Technology and Research, 17(2), pp. 107-114.

[27] Hale, J., and Gibson, G., "Strength reduction of GRP composites exposed to high temperature marine environments," Proc. Proceedings of ICCM11 International Conference on Composite Materials, Australian Composites Structures Society, Australia. [28] Hale, J., and Gibson, A., 1998, "Coupon tests of fibre reinforced plastics at elevated temperatures in offshore processing environments," Journal of composite materials, 32(4), pp. 387-404.

[29] Grant, T., and Bradley, W., 1995, "In-situ observations in SEM of degradation of graphite/epoxy composite materials due to seawater immersion," Journal of Composite Materials, 29(7), pp. 852-867.

[30] Springer, G. S., Sanders, B. A., and Tung, R. W., 1980, "Environmental effects on glass fiber reinforced polyester and vinylester composites," Journal of composite Materials, 14(3), pp. 213-232.

[31] Porter, T., 1981, "Environmental effects on defect growth in composite materials," BOEING MILITARY AIRPLANE CO SEATTLE WA.

[32] Schwartz, M. M., 1997, "Composite Materials-Properties, Nondestructive Testing, and Repair, vol. 1," Prentice Hall Inc, New Jersey, USA.

[33] Brinson, H., 1988, "Accelerated Life Prediction," Engineered Materials Handbook, 2, pp. 788-795.

[34] MAROM, G., 1989, "Environmental effects on fracture mechanical properties of polymer composites," Composite Materials Series, Elsevier, pp. 397-424. 
[35] Standard, A., 2004, "Annual book of ASTM standards," American Society for Testing and Materials Annual, Philadelphia, PA, USA, 4(04.08).

[36] Gupta, P. K., 1988, "Glass fibers for composite materials," Elsevier Science Publishers B. V., Fiber Reinforcements for Composite Materials., 2, pp. 19-71.

[37] Kalluri, R. S., 2007, "Failure of transparent polymer composite laminated glass panels under impact loading," University of Missouri--Columbia.

[38] Laramee, R. C., 1993, "High-strength medium-temperature thermoset matrix composites," Engineered materials handbook., 1, pp. 399-415.

[39] Hull, D., and Clyne, T., 1996, An introduction to composite materials, Cambridge university press.

[40] Shen, C.-H., and Springer, G. S., 1977, "Effects of moisture and temperature on the tensile strength of composite materials," Journal of Composite Materials, 11(1), pp. 2-16. [41] Parvatareddy, H., Pasricha, A., Dillard, D., Holmes, B., and Dillard, J., 1997, "High Temperature and Environmental Effects on the Durability of Ti-6AI-4V/FM5 Adhesive Bonded System," High Temperature and Environmental Effects on Polymeric Composites: 2nd Volume, ASTM International.

[42] Bowles, K. J., Roberts, G. D., and Kamvouris, J. E., 1997, "Long-term isothermal aging effects on carbon fabric-reinforced PMR-15 composites: compression strength," High Temperature and Environmental Effects on Polymeric Composites: 2nd Volume, ASTM International.

[43] Choqueuse, D., Davies, P., Mazeas, F., and Baizeau, R., 1997, "Aging of composites in water: Comparison of five materials in terms of absorption kinetics and evolution of 
mechanical properties," High Temperature and Environmental Effects on Polymeric Composites: 2nd Volume, ASTM International.

[44] Zhang, Y., and Wang, X., 2005, "Thermal effects on interfacial stress transfer characteristics of carbon nanotubes/polymer composites," International journal of solids and structures, 42(20), pp. 5399-5412.

[45] Li, M., 2000, "Temperature and moisture effects on composite materials for wind turbine blades," Montana State University, Bozeman.

[46] Lau, K.-t., and Shi, S.-q., 2002, "Failure mechanisms of carbon nanotube/epoxy composites pretreated in different temperature environments," Carbon, 40(15), pp. 29652968.

[47] Lau, K.-T., Gu, C., Gao, G.-H., Ling, H.-y., and Reid, S. R., 2004, "Stretching process of single-and multi-walled carbon nanotubes for nanocomposite applications," Carbon, 42(2), pp. 426-428.

[48] Timoshenko, S., and Goodier, J., "Theory of Elasticity,(1970), 433," McGraw-Hill. [49] Mallick, P., 1997, "Random fiber composites," Composites Engineering Handbook. Marcel! Dekker, Inc, P. O. Box 5005, Monticello, NY 12701-5185, USA, 1997., pp. 891939.

[50] Shen, H.-S., 2001, "Hygrothermal effects on the postbuckling of shear deformable laminated plates," International Journal of Mechanical Sciences, 43(5), pp. 1259-1281. [51] Tu, Z.-c., and Ou-Yang, Z.-c., 2002, "Single-walled and multiwalled carbon nanotubes viewed as elastic tubes with the effective Elastic's moduli dependent on layer number," Physical Review B, 65(23), p. 233407. 
[52] Callister, W. D., and Rethwisch, D. G., 2000, Fundamentals of materials science and engineering, Wiley London.

[53] Schapery, R. A., 1968, "Thermal expansion coefficients of composite materials based on energy principles," Journal of Composite Materials, 2(3), pp. 380-404.

[54] Johnson, R. R., Kural, M. H., and Mackey, G. B., 1981, "Thermal Expansion Properties of Composite Materials," LOCKHEED MISSILES AND SPACE CO INC SUNNYVALE CA.

[55] Wei, W., Rongjin, H., Chuanjun, H., Zhao, Y., Li, S., and Laifeng, L., "Cryogenic performances of T700 and T800 carbon fibre-epoxy laminates," Proc. IOP Conference Series: Materials Science and Engineering, IOP Publishing, p. 12-16.

[56] Campbell, F. C., 2010, Structural composite materials, ASM international.

[57] Hartwig, G., 2013, Polymer properties at room and cryogenic temperatures, Springer Science \& Business Media.

[58] Callister, W. D., and Rethwisch, D. G., 2011, Materials science and engineering, John Wiley \& Sons NY.

[59] KREVELEN, D. W. V., 1990, Properties of polymers, Elsevier.

[60] Van Krevelen, D. W., and Te Nijenhuis, K., 2009, Properties of polymers: their correlation with chemical structure; their numerical estimation and prediction from additive group contributions, Elsevier.

[61] Haefer, R., 1981, "Tieftemperaturtechnologie (Low temperature technology)," Düsseldorf: VDI-Verlag.

[62] Mehra, R., "Application of refractive index mixing rules in binary systems of hexadecane and heptadecane with n-alkanols at different temperatures," Proc. 
PROCEEDINGS-INDIAN ACADEMY OF SCIENCES CHEMICAL SCIENCES, Indian Academy of Sciences; 1999, pp. 147-154.

[63] Imai, Y., Terahara, A., Hakuta, Y., Matsui, K., Hayashi, H., and Ueno, N., 2009, "Transparent poly (bisphenol A carbonate)-based nanocomposites with high refractive index nanoparticles," European Polymer Journal, 45(3), pp. 630-638.

[64] Aspnes, D. E., 1982, "Local-field effects and effective-medium theory: A microscopic perspective," American Journal of Physics, 50(8), pp. 704-709.

[65] Imai, Y., Terahara, A., Hakuta, Y., Matsui, K., Hayashi, H., and Ueno, N., 2009, "Transparent poly(bisphenol A carbonate)-based nanocomposites with high refractive index nanoparticles," European Polymer Journal, 45(3), pp. 630-638.

[66] Mehra, R., 2003, "Application of refractive index mixing rules in binary systems of hexadecane and heptadecane-alkanols at different temperatures," Journal of Chemical Sciences, 115(2), pp. 147-154.

[67] Khanna, S. K., 2010, "Transparent composites and laminates and methods for making," Google Patents.

[68] Zhu, H., 2014, "Fabrication and characterization of novel transparent laminated glasscomposite panels for dynamic load mitigation," University of Missouri-Columbia. 


\section{CHAPTER TWO: FABRICATION OF TRANSPARENT POLYESTER COMPOSITE AND LAMINATE}

\subsection{Preparation of interlayer unsaturated polyester composite}

Though there are several techniques that have been developed for the preparation of glass fibers reinforced polymer composite, Hand Lay-up technique remains the simplest technique till today. The first step of Hand Lay-up technique is the mold preparation (Figure 2.1).

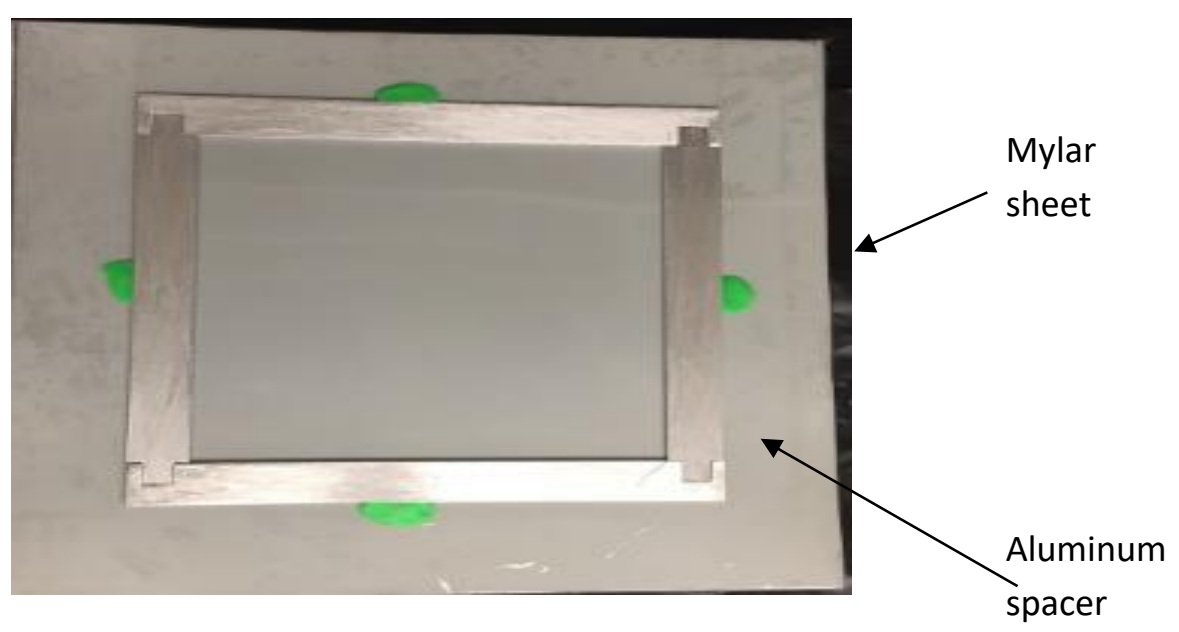

Figure 2.1 Mold for the composite

The second step involves preparing the resin for making the composite. First, the quantity of polyester required to make a composite was dropped in a beaker. Then, initiator MEKP, crosslinking agent Phenanthrene and polymerization rate accelerator Cobalt were added and mixed together. The mixture was placed in a vacuum degassing chamber expel any dissolve air chamber. This step is very important because air bubbles entrapped in the polyester will greatly affect the transparency of the final product and also will affect the damage resistance of the product. An unsaturated polyester-styrene resin (Commercial grade, $65 \mathrm{wt} \%$ polymer, $35 \mathrm{wt} \%$ styrene, untreated, Aropol) was used as a precursor of 
the polymer matrix. The chemical composition of this resin was not supplied by the vendor; a pre-molecular weight experiments by Gel Permeation Chromatography yielded a molecular weight of around $1700 \mathrm{~g} / \mathrm{mol}$ of the as received precursor. Polyester ($\left(\mathrm{R}^{\prime} \mathrm{CH}=\mathrm{CHCOOR}\right)_{\mathrm{n}^{-}}$, Ashland Specialty Co., USA) was mixed with $1.2 \mathrm{wt} \%$ methyl ethyl ketone peroxide (MEKP) $\left(\mathrm{C}_{8} \mathrm{H}_{18} \mathrm{O}_{6}\right.$, Sigma-Aldrich Co., USA) as an initiator, 0.03 wt.\% cobalt (II) 2-ethylhexanoate (CE) $\left(\mathrm{C}_{16} \mathrm{H}_{30} \mathrm{CoO}_{4}\right.$, Sigma-Aldrich Co., USA) as an accelerator and 1.5 wt.\% phenanthrene (PT) $\left(\mathrm{C}_{14} \mathrm{H}_{10}\right.$, Sigma-Aldrich Co., USA), which is a refractive index modifier. All above mentioned components were thoroughly mixed for 3-4 min by a glass rod in a glass bucket. The mixture was set in a vacuum degassing chamber so as to allow air bubbles inside it to escape by creating vacuum inside the chamber. After degassing, the mixture was poured into a $3 \mathrm{~mm}$ deep mold which was made by placing a square aluminum frames on top of polyvinyl chloride (PVC) plate lined with Mylar sheet cover. After filling the mold, another PVC plate with Mylar sheet lining was placed on top of the mold, the top and bottom plates were clamped with C-clamps. The clamped plates were placed vertical to let entrapped air escape from the mold. The setup was left at room temperature for at least three days to ensure complete curing of the polyester. Glass fiber-reinforced composite was prepared using a similar procedure as described above. The polyester was mixed with $1.2 \mathrm{wt} \%$ MEKP, $0.03 \mathrm{wt} \% \mathrm{CE}$ and 1.5 wt\% PT. All components were thoroughly mixed for 2-3 min by hand in a glass bucket. Then, the mixture was degassed in a vacuum chamber. Figure 2.2 shows the vacuum chamber. But this time, after degassing, instead of pouring all mixture into the 3-mm deep mold, a small amount of the mixture was first poured into the mold so as to wet the base surface of the mold. Then a layer of glass fiber cloth (Aerospace Composite Products Co., 
USA) was put in the mold and some more polymer mixture was poured in the mold. This procedure was repeated five times, producing a composite of $3 \mathrm{~mm}$ thick with six layers of glass fiber cloth. The setup was left at room temperature for three days to ensure complete curing of the composite. The cured composite prepared had a fiber volume fraction of $15 \%$. After solidification, the solid polymer was tested in a simultaneous DSC TGA (SDT 600, ) for the thermal transition and the glass transition temperature ( $\mathrm{Tg})$ was obtained.

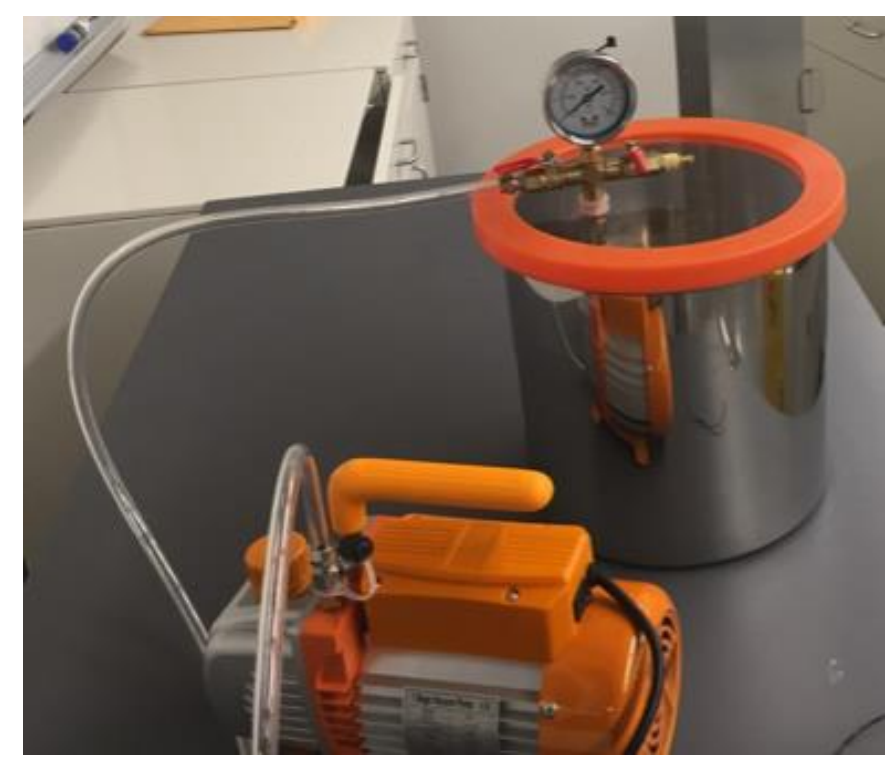

Figure 2.2 Vacuum chamber

The third step is the composite fabrication. First, a small amount of unsaturated polyester mixture was poured into the mold so as to wet the base surface. Then, a layer of fiber cloth which had been cut to the desired shape was placed in the mold and gently some more unsaturated polyester was poured on top of the cloth. Any entrapped air bubbles were removed by using a spatula through gently compacting the glass cloth against the mold. This process was repeated six times to build up the desired thickness and fiber volume fraction in the composite. Finally, the mold was closed and pressure was applied by 
clamping the old with the help of C- clamps (Figure 2.3). After 36-48h, open the mold and get the desired composite.

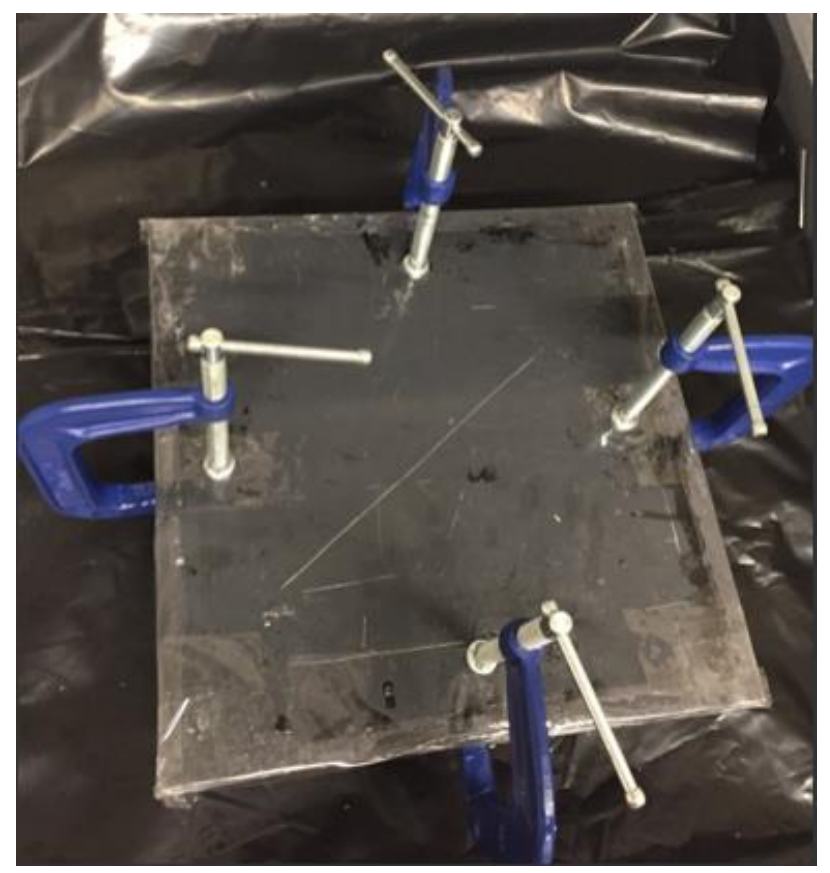

Figure 2.3 Mold clamped with C-clamps

Although a precise prediction can't be made at present, according to the experimental results, three candidate polyester formulations that can be used to make the composite interlayer are shown in Table 2.1. The products made by using these formulations have good, not the best, transparency (Figure 2.4). 
Table 2.1. Candidate polyester formulations

\begin{tabular}{cccc}
\hline MEKP content & Phenanthrene content & Cobalt content & Refractive index \\
\hline $1.2 \%$ & $0.9 \%$ & $0.03 \%$ & 1.558 \\
$1.2 \%$ & $0.95 \%$ & $0.03 \%$ & 1.5582 \\
$1.2 \%$ & $1.0 \%$ & $0.03 \%$ & 1.559 \\
$1.2 \%$ & $5.0 \%$ & $0.03 \%$ & 1.4758 \\
$1.2 \%$ & $5.5 \%$ & $0.03 \%$ & 1.50593 \\
$1.2 \%$ & $6.0 \%$ & $0.03 \%$ & 1.5232 \\
\hline
\end{tabular}

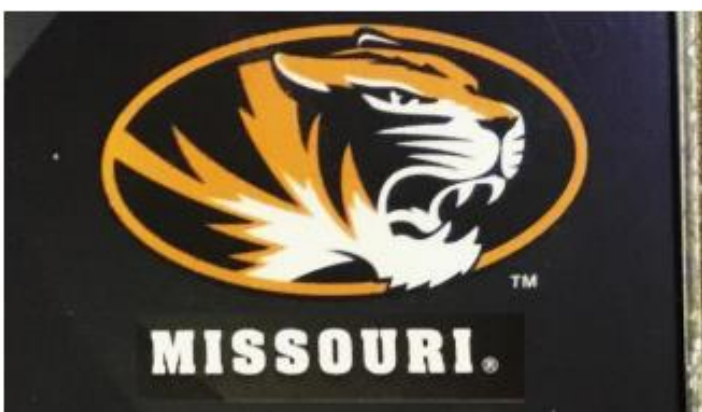

Unreinforced

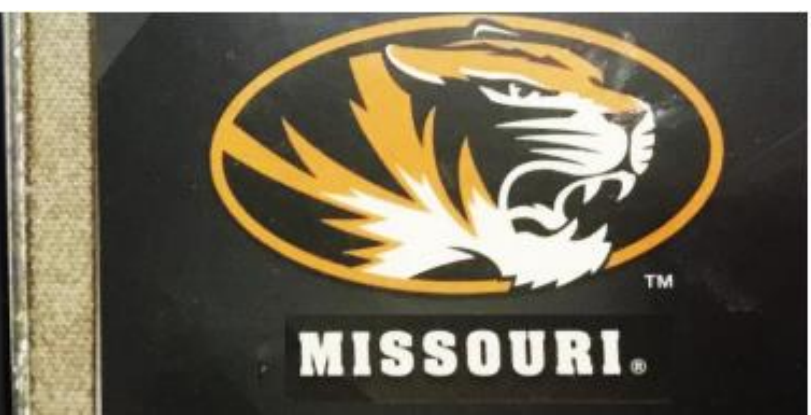

Reinforced

Figure 2.4 Transparency of the composite interlayer

(paper with words was placed underneath the composite)

\subsection{Fabrication of Damage Resistant Composite Interlayer and Glass Panel}

\section{Fabrication}

In our research, damage resistant glass consists of two parts, glass plies and reinforced transparent composite interlayer. The structure of damage resistant glass is shown in Figure 2.5 . 


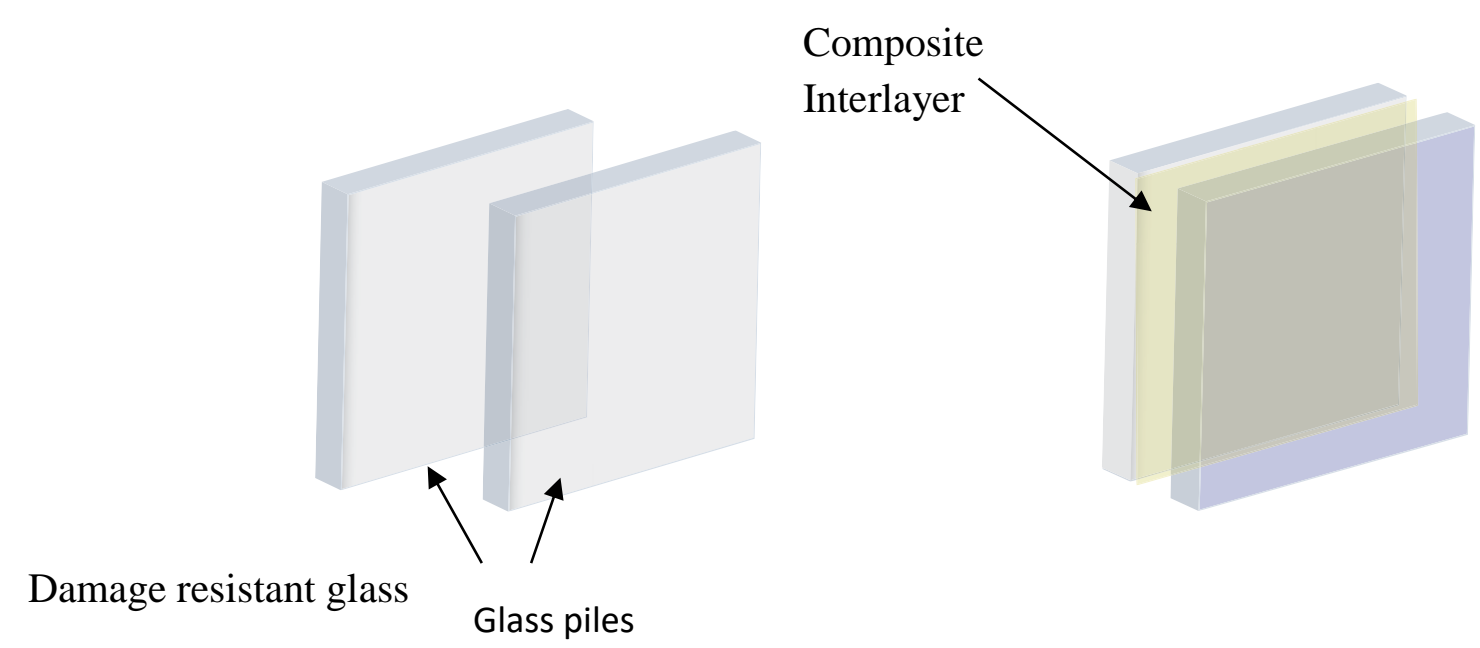

Figure 2.5 Damage resistant glass structure

Laminated environment resistant glass panel is fabricated by sandwiching composite interlayer between two glass plies. A two-part polyurethane resin is used as an adhesive between the composite and glass plies. Because increasing the adhesive force among the composite, glass and adhesive can increase the impact strength of environment resistant glass [1]. Thus the composite and glass plies should be pretreated with silane before laminating [2]. Because the $\mathrm{NH}_{2}$ group on the silane agent can react with the $\mathrm{NCO}$ group on the adhesive (polyurethane) and this reaction generates a new $\mathrm{NH}-\mathrm{C}-\mathrm{N}-$ bond (Figure 2.6). Since the new bond is very strong, so the adhesive force among the composite, glass and adhesive is promoted. 


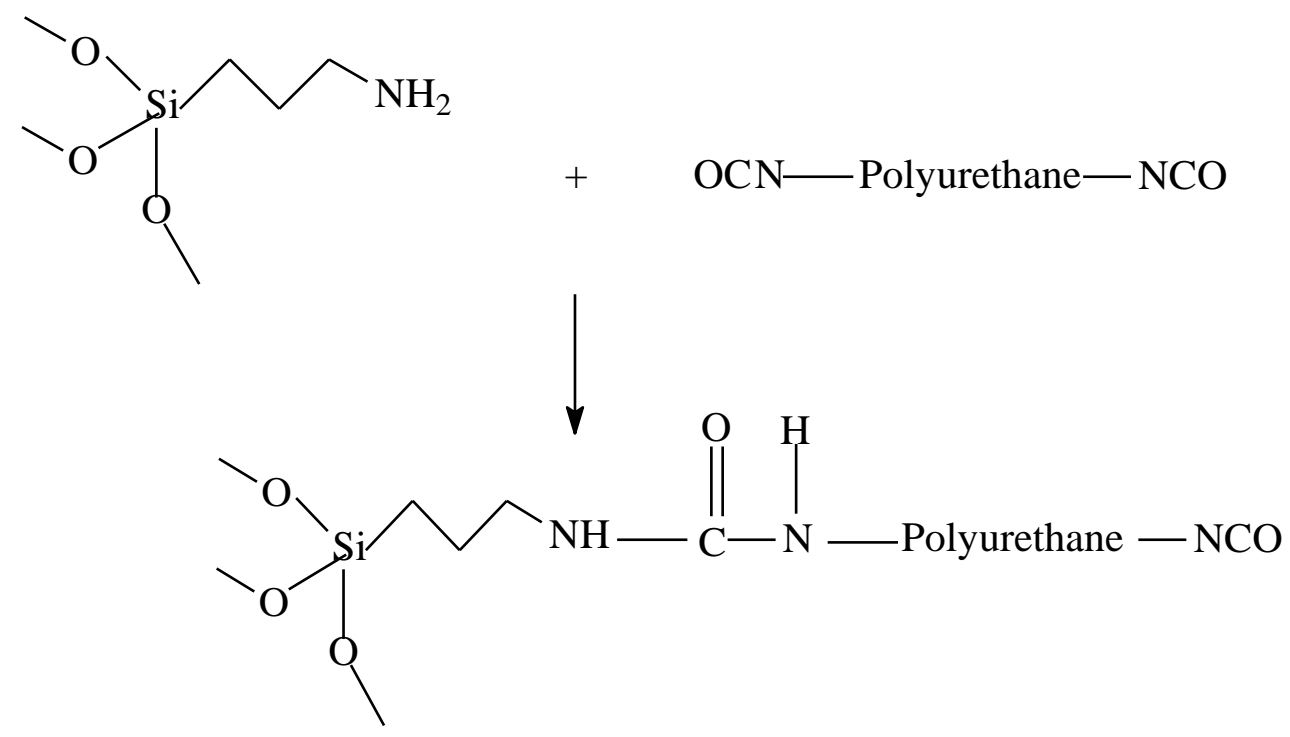

Figure 2.6 Reaction happening in the silane process

The procedure for laminated blast resistant glass panel fabrication is as follows:

1) A glass sheet was placed on a table and a thin layer of the polyurethane resin was evenly spread on the upper side of the sheet.

2) The composite interlayer was placed on the glass sheet. Suitable pressure was applied to evenly spread the urethane and help in removing any entrapped air bubbles.

3) A thin layer of polyurethane was evenly spread on the composite interlayer and the second glass sheet was placed on it.

4) Guides were placed on all sides in order to prevent the glass sheets from moving relative to the composite.

5) The setup was left to cure for 48 hours at room temperature $\left(23{ }^{\circ} \mathrm{C}\right)$ 
The environment resistant glass fabricated by using this method can have a better transparency than the composite interlayer itself. For S-polarized incident light, transparency comparison between the laminated glass and the composite interlayer is shown in Figure 2.7. For P-polarized incident light, transparency comparison between the laminated glass and the composite interlayer is shown in Figure 2.8. Both figures demonstrate that the laminated glass has a better transparency than the composite interlayer.

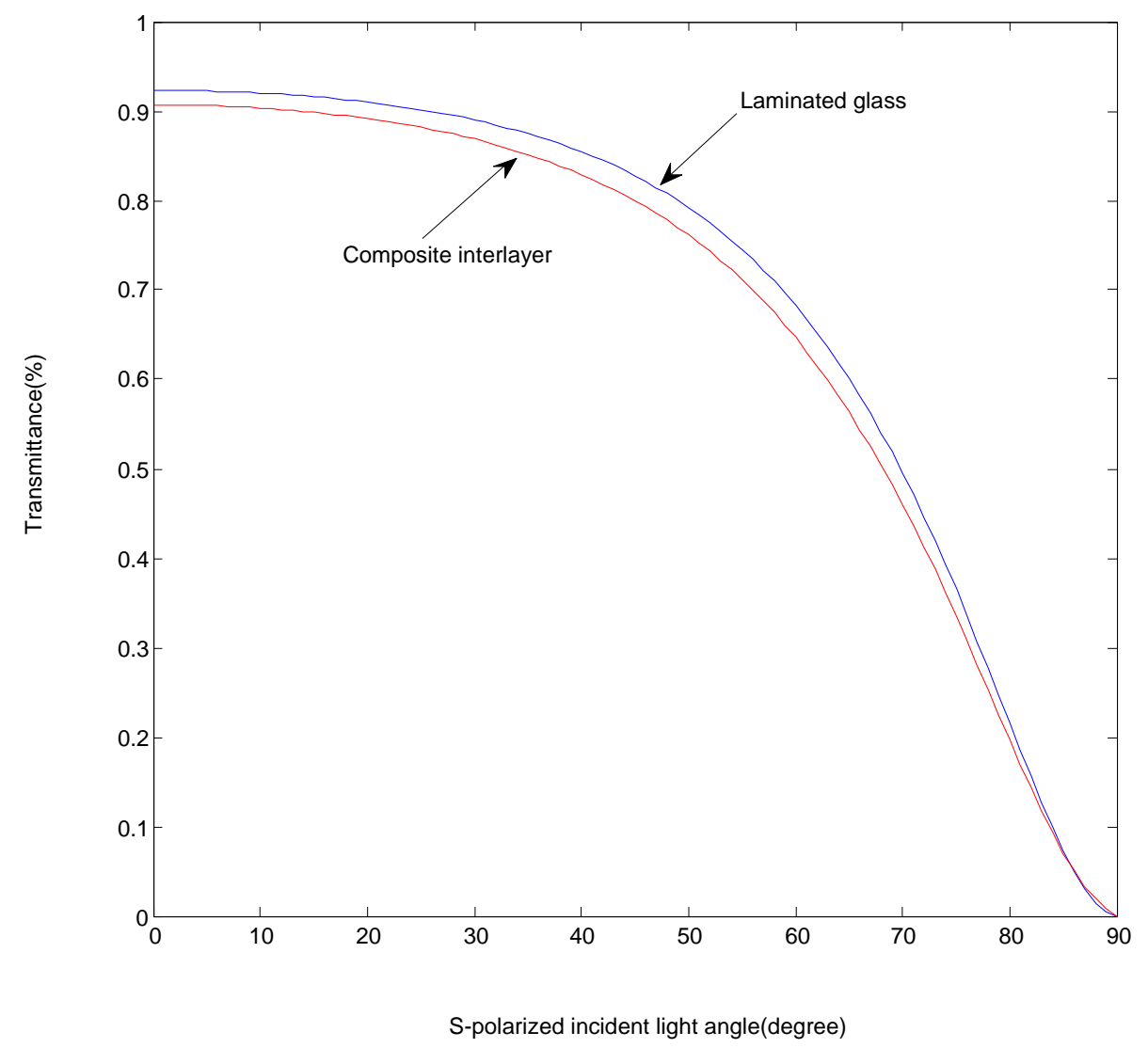

Figure 2.7 Transparency comparison between the laminated glass and the composite interlayer

(calculated by eqn.1.27)[3] 


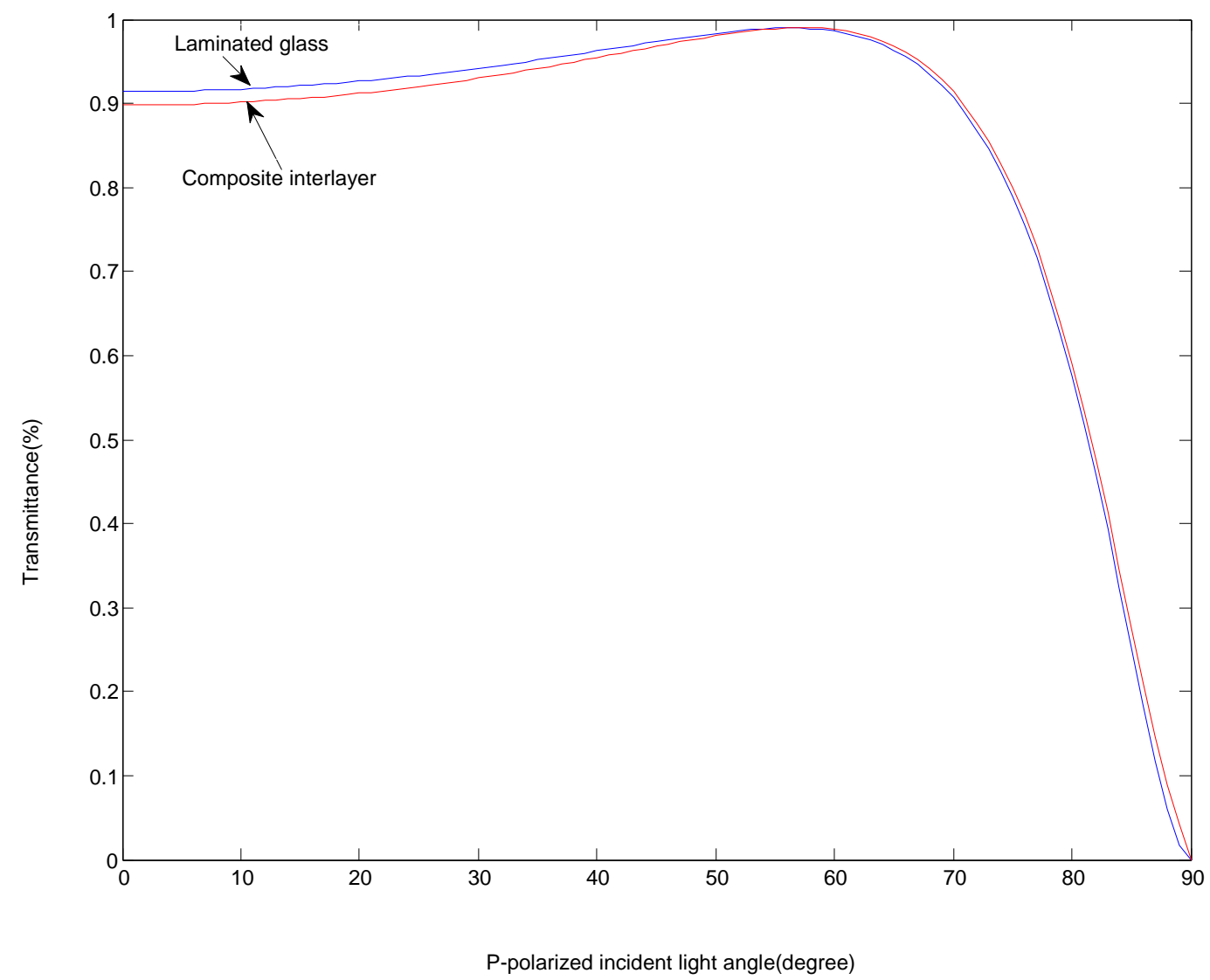

Figure 2.8 Transparency comparison between the laminated glass and the composite interlayer (calculated by eqn.1.28)[3]

The refractive index is one of the most important fundamental properties of optical components such as lenses and solar cells. Refractive index control is an essential technique for processing light by manipulating its speed and passage, and material studies for pursuit of high/low refractive index, Abbe's number (wavelength dependence of the refractive index) control and birefringence control have actively been studied. 


\subsection{Haze test}

\subsubsection{Introduction}

The industrial applications of polymer composites have significantly increased due to their outstanding performance and properties compared to those of conventional materials. Composite materials exhibit high strength weight and stiffness-weight ratios, corrosion resistance and thermal stability, and are well suited for use in structures in which the weight is a fundamental variable in the design process [4]. Polymer composites are increasingly being utilized for automotive, aerospace, energy, packaging, and flame-retardant applications [5-8]. Recently, polymer composite is also used to make window sheets and utilized in buildings architects. Visual perception of the building facade is made to change with the illumination conditions, increasing therefore the architectural expression of the building. To this purpose, high light transmittance glass fiber-reinforced polymer (GFRP) laminates are increasingly used due to their low cost, lightweight and impact resistance compared to traditional glass components. Moreover, amorphous silicon (a-Si) flexible photovoltaic (PV) solar cells can be encapsulated in the GFRP skins of freeform building envelopes [9-11], integrating electric energy production in lightweight and low-cost structures. Reducing the cost of the encapsulation process of PV cells has been a main issue since the early age of photovoltaic energy and for this purpose systems using GFRP composites can constitute a valuable option [11]. The integration of PV cells in multifunctional composite elements has begun to be explored recently for high-tech applications in aerospace $[4,6]$. However, in such cases, FRP composites are subjected to harsh environmental conditions such as high temperature, low temperature and humidity. These conditions make an obvious impact om mechanical and transmission properties. In 
practical applications each polymer has its own operating temperature range. Usually a polymer has a maximum use temperature slightly below its glass transition temperature $\left(\mathrm{T}_{\mathrm{g}}\right)$, at which the polymer transfers from rigid state to rubbery state and suffers substantial mechanical property loss. Elevated and low temperatures combined with humid environments have been found to exacerbate the problem by further reducing $\mathrm{T}_{\mathrm{g}}$, among other factors. With this in mind, a general and scalable strategy to achieve transparent and hazy glass fiber reinforced polymer with excellent mechanical properties remains an obstacle. Herein, we incorporate transparent glass fiber reinforced polyester of a uniformly distributed fiber network into a laminated window glass sheets to fabricate transparent and hazy composite with strong mechanical properties. The polymer prepared serves as a matrix to enhance the transparency and smoothness, whereas the unidirectional network of long and slender E-glass fibers simultaneously acts as a reinforcing phase to improve the mechanical properties and a light scatting source to enhance the optical haze. Consequently, the proposed composite sheet would combine a high transparency and optical haze with superior mechanical. For this purpose, the present research investigates light transmittance of GFRP laminates used as translucent window sheets, load-bearing structures and encapsulants of solar cells. In the first part, the high transmittance polyester matrix and composites are prepared and tested for its transparency at room temperature, and the influence of environment on optical properties of GFRP laminates surrounded by air at different temperatures. The refractive index is one of the most important fundamental properties of optical components such as lenses and solar cells. Refractive index control is an essential technique for processing light by manipulating its speed and passage, and material studies for pursuit of high/low refractive index. Abbe's number (wavelength 
dependence of the refractive index) control and birefringence control have actively been studied. Light transmittance mainly determined by the surface reflection. The surface reflection $(r)$ is given by the following equation [12],

$r=\frac{1-n^{2}}{1+n^{2}}$

where $\mathrm{n}$ denotes the refractive index.

According to the Lorentz-Lorenz equation;

$$
\frac{n_{12}^{2}-1}{n_{12}^{2}+2}=\phi_{1}\left(\frac{n_{1}^{2}-1}{n_{1}^{2}+2}\right)+\phi_{2}\left(\frac{n_{2}^{2}-1}{n_{2}^{2}+2}\right)
$$

Where $\mathrm{n}_{12}$ is the refractive index of the mixture or composite, $\mathrm{n}_{1}$ and $\mathrm{n}_{2}$ are the refractive indices of the pure components respectively, $\varnothing_{1 \text { and }} \emptyset_{2}$ are volume fractions of component 1 and component 2 .

Changing the component(s) or hanging the content(s) of component(s) in mixture can change the refractive index of the mixture. The refractive index of modified mixture can be estimated by using the Lorentz-Lorenz equation. In our research, polyester is in liquid state, for turning it to the solid state, an initiator Methyl Ethyl Ketone Peroxide (MEKP) is added into it. Polyester's curing time is very long, so polymerization rate accelerator Cobalt Naphthenate (Cobalt) is added into the polyester resin to reduce the curing time. In other words, MEKP and Cobalt are two essential components for curing of the polyester mixture. The refractive index of glass fibers ( $589 \mathrm{~nm}$ ) was measured using the Central Illumination Method (Becke Line Method) Abbe refractometer (NAR-3T, Atago, Co., Japan, with a refractive index precision of 0.0001 in the range of 1.3 to 1.7 ) at room temperature. Table 2.1 shows the results of testing. Figure 2.9 shows the level of transparency obtained in 
making the polymer matrix and composite. Also, a fair transparency is obtained when picturing was implemented by placing the sheets eight inches away from the paper. Figure 2.9 and 2.10 give a fundamental information on how to utilize these sheets in engineering design of automotive, construction, architect and aerospace applications.

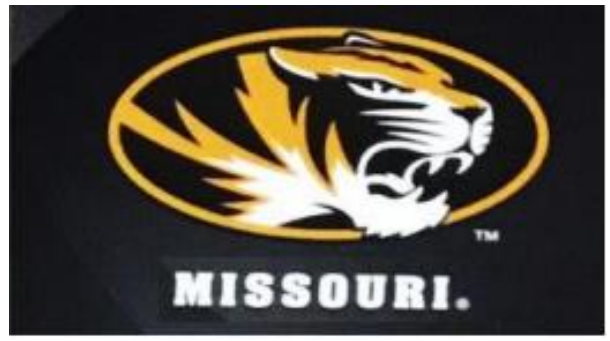

Bare picture

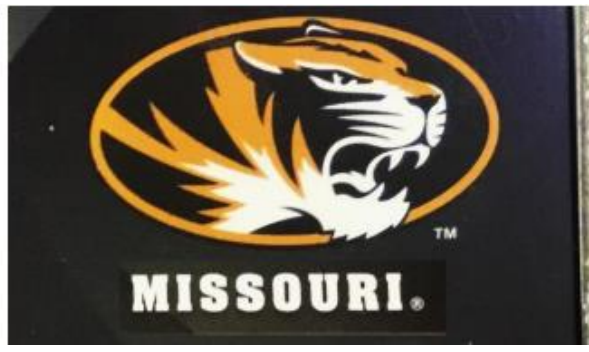

Unreinforced

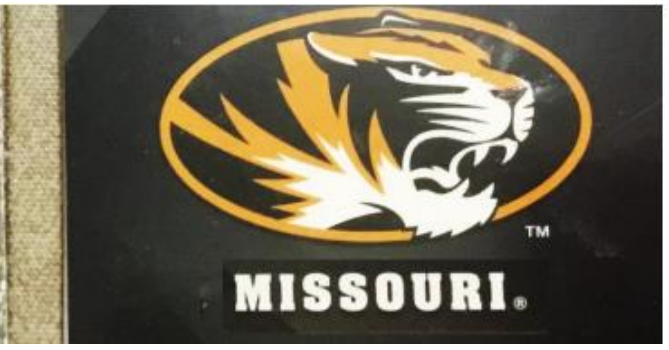

Figure 2.9. Transparency of the composite interlayer

(paper with words was placed underneath the composite) 


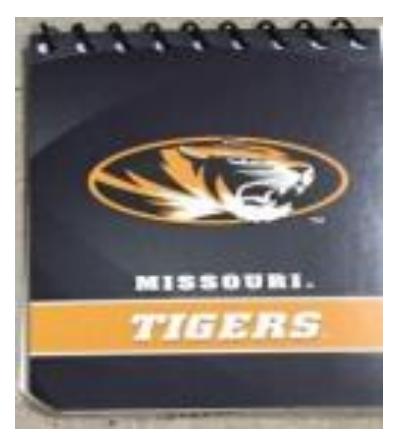

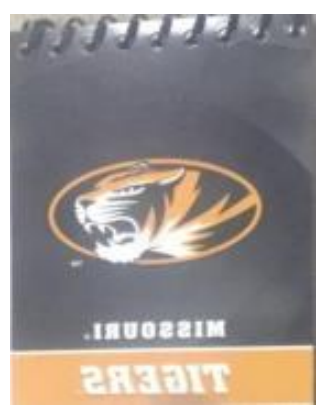

Unreinforced

Bare picture

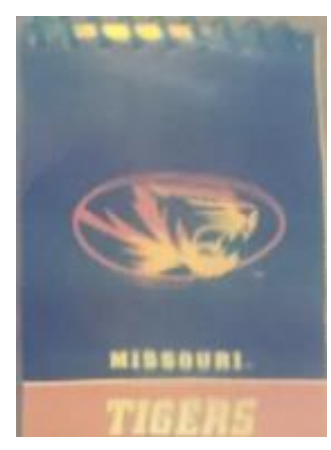

Reinforced

Figure 2.10 Transparency of the composite interlayer (paper with words was placed 8 inches from the composite)

\subsubsection{Haze test}

Haze is the scattering of light as it passes through a film or sheet of a material, resulting in poor visibility and/or glare. Light that is scattered upon passing through can produce a hazy or smoky field when objects are viewed through the material. Another effect can be veiling glare, as occurs in an automobile windshield when driving into the sun [13]. Haze can be inherent in the material, a result of the molding process, or a result of surface texture. Haze can also be a result of environmental factors such as weathering or surface abrasion. Luminous Transmittance measures the amount of light that passes through a sample. The transparency of materials is characterized by both haze and luminous transmittance. Luminous transmittance of a specimen is defined as the ratio of transmitted to incident 
light. In general, the higher is the luminous transmittance of a material, the lower is its haze. But the experience is not applicable for all materials; many special materials could not only have a high light transmittance but also have a high haze. Usually, transparent plastic could loss its transparence for reasons of its crystallization, inorganic particles filled or blended and so on. The loss transparence results from reflection and refraction of light [14], which occur on the phase interface of non-homogeneous materials such as composites. Thus, haze and transmittance measurements can be useful in product development, process development, and end use performance testing.

2.3.2.1 Haze at room temperature: The Haze and Luminous Transmittance test of GFRP and polymer matrix was conducted according to Haze and Luminous Transmittance of Transparent Plastics Test Method: ASTM D1003-13 Procedure A (Hazemeter Method) which is defined as [15];

Haze $\%=\left(\frac{T_{4}}{T_{2}}-\frac{T_{3}}{T_{1}}\right) \times 100$

Where;

$\mathrm{T}_{1}$ : incident light

$\mathrm{T}_{2}$ : total light transmitted by specimen

$\mathrm{T}_{3}$ : light scattered by instrument

$\mathrm{T}_{4}$ : light scattered by instrument and specimen

If $T_{3}$ is zero, the diffuse luminous transmittance, $T_{d}$, is calculated as follows:

$T_{d}=\frac{\mathrm{T} 4}{\mathrm{~T} 1}$

Total luminous transmittance, $\mathrm{Tt}$, is calculated as follows: 
$T_{t}=\frac{\mathrm{T} 2}{\mathrm{~T} 1}$

Model, specifications and test conditions were as follow;

Hazemeter : BYK haze-gard i

Illumination: CIE C

Observer: $0^{\circ}$

Testing Conditions: $23^{\circ} \mathrm{C} \pm 2^{\circ} \mathrm{C} / 50 \% \pm 10 \% \mathrm{RH}$

Sample Preparation: Tested as received.

Sample Conditioning: $40+$ Hours At $23^{\circ} \mathrm{C} \pm 2{ }^{\circ} \mathrm{C} / 50 \% \pm 10 \% \mathrm{RH}$

Significance: ASTM D1003 specifies that haze, total luminous transmittance and diffuse transmittance be reported to the nearest $0.1 \%$.

Each test was repeated three times.

Table 2.2 shows the results of Haze and Luminous Transmittance test of GFRP and polymer matrix at room temperature. 
Table 2.2 Haze, total luminous transmittance and diffuse of glass fiber reinforced polymer and polymer matrix at room temperature

\begin{tabular}{|c|c|c|c|c|}
\hline Sample name & $\begin{array}{c}\text { Thickness } \\
\text { (in) }\end{array}$ & $\begin{array}{c}\text { Haze } \\
\%\end{array}$ & $\begin{array}{c}\text { Total Luminous } \\
\text { Transmittance \% }\end{array}$ & $\begin{array}{c}\text { Diffuse } \\
\text { Transmittance \% }\end{array}$ \\
$\begin{array}{c}\text { polymer } \\
\text { matrix }\end{array}$ & & 5.6 & 92.2 & 5.2 \\
& & 6.1 & 92.0 & 5.6 \\
\hline Average & & 5.8 & 92.2 & 5.3 \\
\hline Glass fiber & 0.11 & 22.1 & 92.1 & 5.4 \\
reinforced & & 22.5 & 80.1 & 17.6 \\
composite & & 22.4 & 79.3 & 18.4 \\
\hline Average & & 22.3 & 80.7 & 16.8 \\
\hline
\end{tabular}

2.3.2.2 At different temperatures: The Haze and Luminous Transmittance test of GFRP and polymer matrix was conducted according to Haze and Luminous Transmittance of Transparent Plastics Test Method: ASTM D1003-13 Procedure A (Hazemeter Method). Model, specifications and test conditions were the same as listed in the previous section for room temperature testing, though samples at other temperatures were soaked for one hour to obtain uniform temp-erratum through the thickness.

For post exposure:

Exposure No. 1: 1 hour at $60^{\circ} \mathrm{C} / 50 \% \mathrm{RH}$

Exposure No. 2: 1 hour at $0^{\circ} \mathrm{C}$

Exposure No. 3: 1 hour at $-30^{\circ} \mathrm{C}$

Exposure No. 4: 1 hour at $-60^{\circ} \mathrm{C}$ 
Each test was triplicated for high percent of precision.

Table 2.3 shows the results of testing the GFRP and polymer matrix at different temperatures. At the time of experimentation, the post exposed specimens were left to return back to room temperature. Then, retested for their Haze, total luminous transmittance and diffuse transmittance. All results obtained were identical to Tables 2.2 and 2.3 .

Table 2.3 Haze, total luminous transmittance and diffuse of glass fiber reinforced polymer and polymer matrix at different temperatures

\begin{tabular}{|c|c|c|c|c|c|}
\hline \multirow{2}{*}{$\begin{array}{c}\text { Exposure } \\
\text { NO. }\end{array}$} & \multirow[t]{2}{*}{ Sample ID } & \multicolumn{2}{|c|}{$\operatorname{Haze}(\%)$} & \multirow{2}{*}{$\begin{array}{c}\text { Total } \\
\text { Luminous } \\
\text { Transmission }\end{array}$} & \multirow{2}{*}{$\begin{array}{c}\text { Diffuse } \\
\text { Luminous } \\
\text { Transmission }\end{array}$} \\
\hline & & Pre & Post & & \\
\hline \multirow[t]{2}{*}{1} & $\begin{array}{c}\text { Non- } \\
\text { Reinforced }\end{array}$ & 4.4 & 4.6 & 88.1 & 3.6 \\
\hline & Reinforced & 22.5 & 18.9 & 79.7 & 16.1 \\
\hline \multirow[t]{2}{*}{2} & $\begin{array}{c}\text { Non- } \\
\text { Reinforced }\end{array}$ & 4.4 & 4.5 & 87.3 & 3.8 \\
\hline & Reinforced & 21.3 & 15.1 & 81.1 & 19.2 \\
\hline \multirow[t]{2}{*}{3} & $\begin{array}{c}\text { Non- } \\
\text { Reinforced }\end{array}$ & 3.9 & 4.4 & 87.4 & 3.6 \\
\hline & Reinforced & 21.4 & 21.0 & 80.4 & 20.5 \\
\hline \multirow[t]{2}{*}{4} & $\begin{array}{c}\text { Non- } \\
\text { Reinforced }\end{array}$ & 3.4 & 4.2 & 87.8 & 3.4 \\
\hline & Reinforced & 23.9 & 22.8 & 77.6 & 20.5 \\
\hline
\end{tabular}




\subsection{Results and discussion}

Optical properties like total and diffuse transmittance are of great importance for some applications such as architectural glasses and natural light reflection buildings [16, 17]. In these applications, polymers are extensively used. The prepared composite must meet the requirements of total and diffuse transmittance. In the present study, the measured spectral light transmittance curves of the unreinforced specimens at different temperatures are shown in Figure 2.11. The test was conducted at room temperature of $23^{\circ} \mathrm{C}, 60^{\circ} \mathrm{C}, 0{ }^{\circ} \mathrm{C}$, $30^{\circ} \mathrm{C}$ and $-60^{\circ} \mathrm{C}$. Light transmittance decreased when the specimens were exposed to high or low temperatures. Light transmittance of unreinforced polyester resin at $60{ }^{\circ} \mathrm{C}$ was approximately $4.3 \%$ lower than for unreinforced specimens at room temperature but, the test at low temperatures showed that the percent of total transmittance reduction compared to room temperature was $4.6 \%$. The total transmittance decreases between room temperature and $0{ }^{\circ} \mathrm{C}$, but begins to increase marginally with temperature below $0{ }^{\circ} \mathrm{C}$. The measured spectral light transmittance curves of the GFRP at different temperatures are shown in Figure 2.12. The transmittance results of the polyester composite specimen show an observed drop of total transmittance owing to adding glass fiber enforcement. Also, exposing of specimens to different temperatures have reduced the total transmission. Light transmittance of reinforced polyester resin at $60{ }^{\circ} \mathrm{C}$ was approximately $12 \%$ lower than the reinforced specimens at room temperature but, the test at low temperatures, $-60{ }^{\circ} \mathrm{C}$ for example, showed that the percent of total transmittance reduction compared to room temperature was $14 \%$. For both materials, the reinforced and the unreinforced, total transmittance increased linearly as temperature decreases until $-60{ }^{\circ} \mathrm{C}$. 


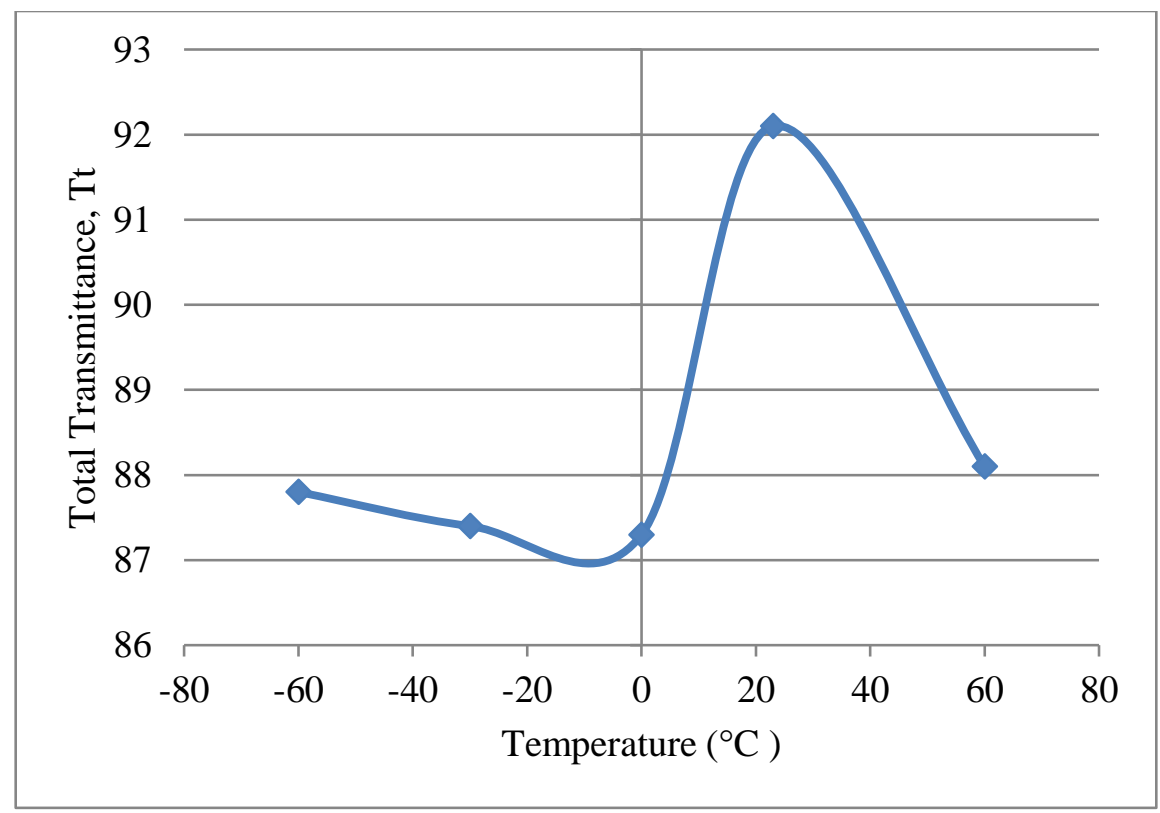

Figure 2.11 Total transmittance of unreinforced specimens of unsaturated polyester matrix at different temperatures

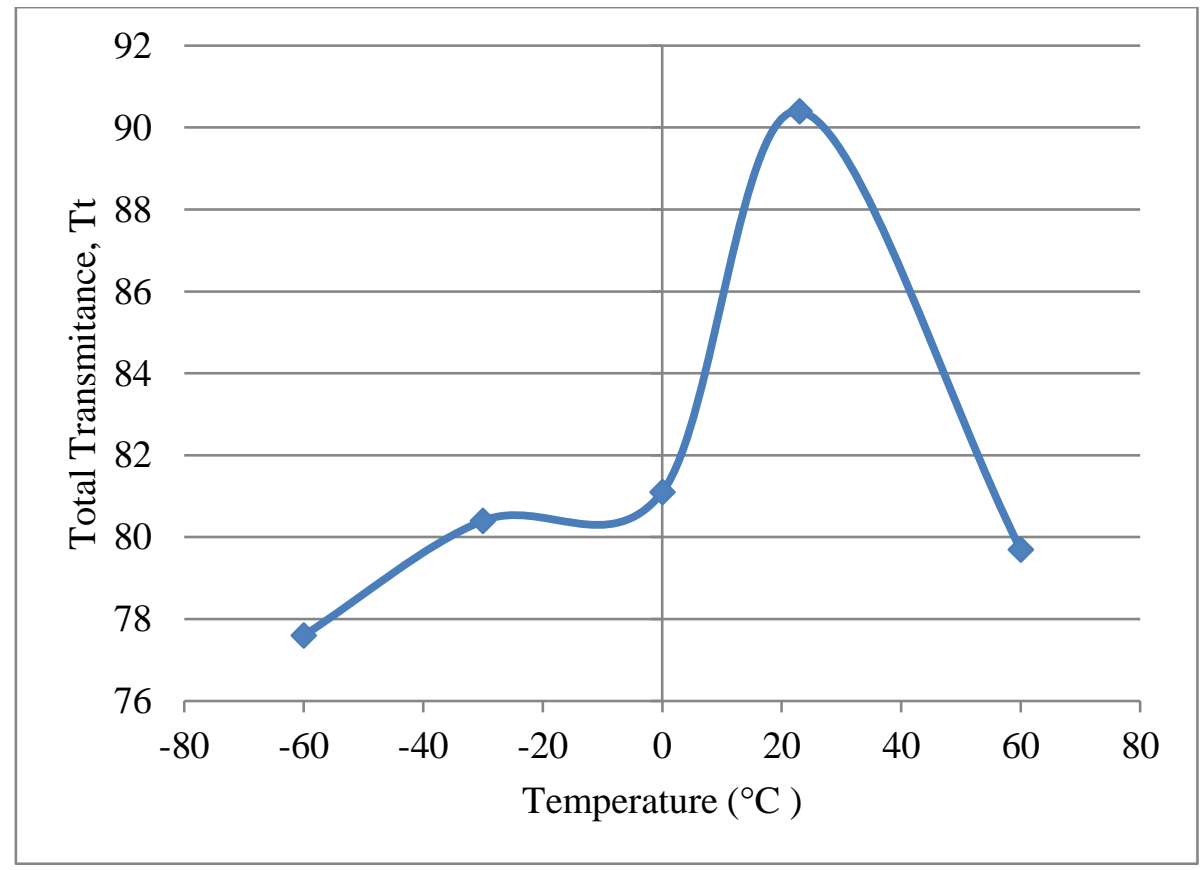

Figure 2.12. Total transmittance of reinforced specimens of unsaturated polyester matrix at different temperatures 


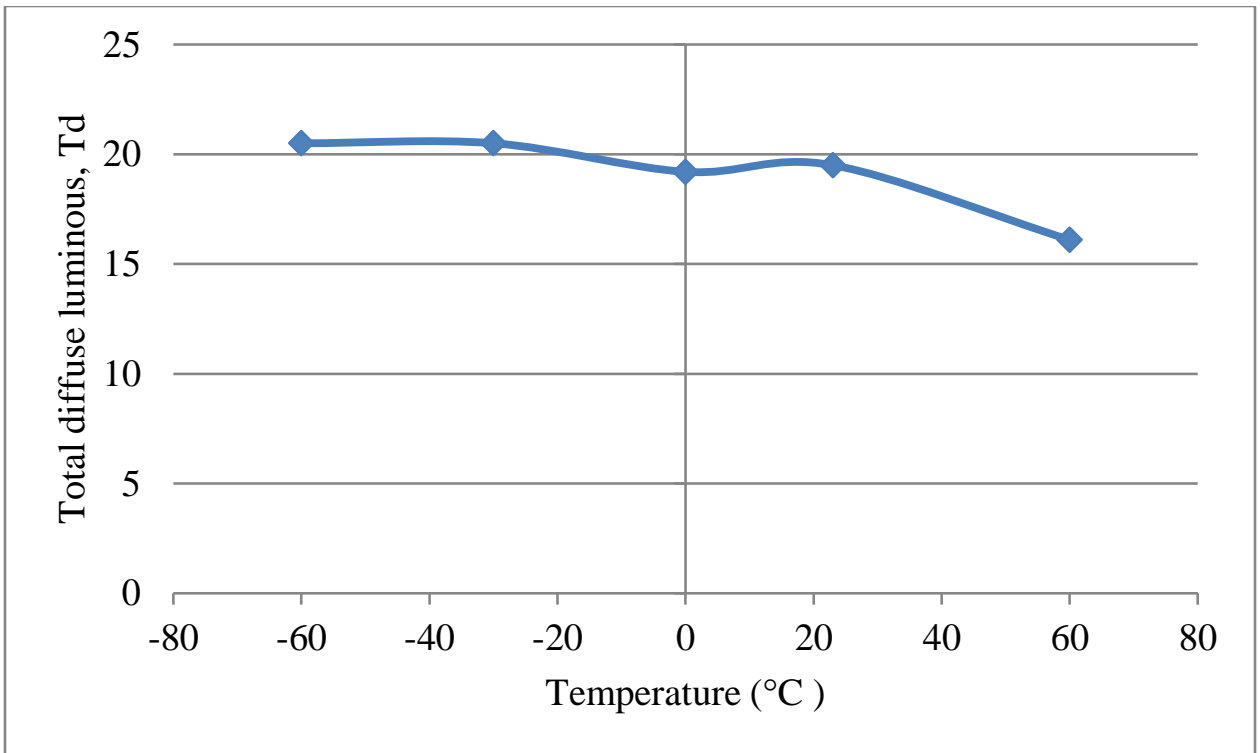

Figure 2.13. Total diffuse luminous transmittance of fiber glass reinforced specimens of unsaturated polyester at different temperatures.

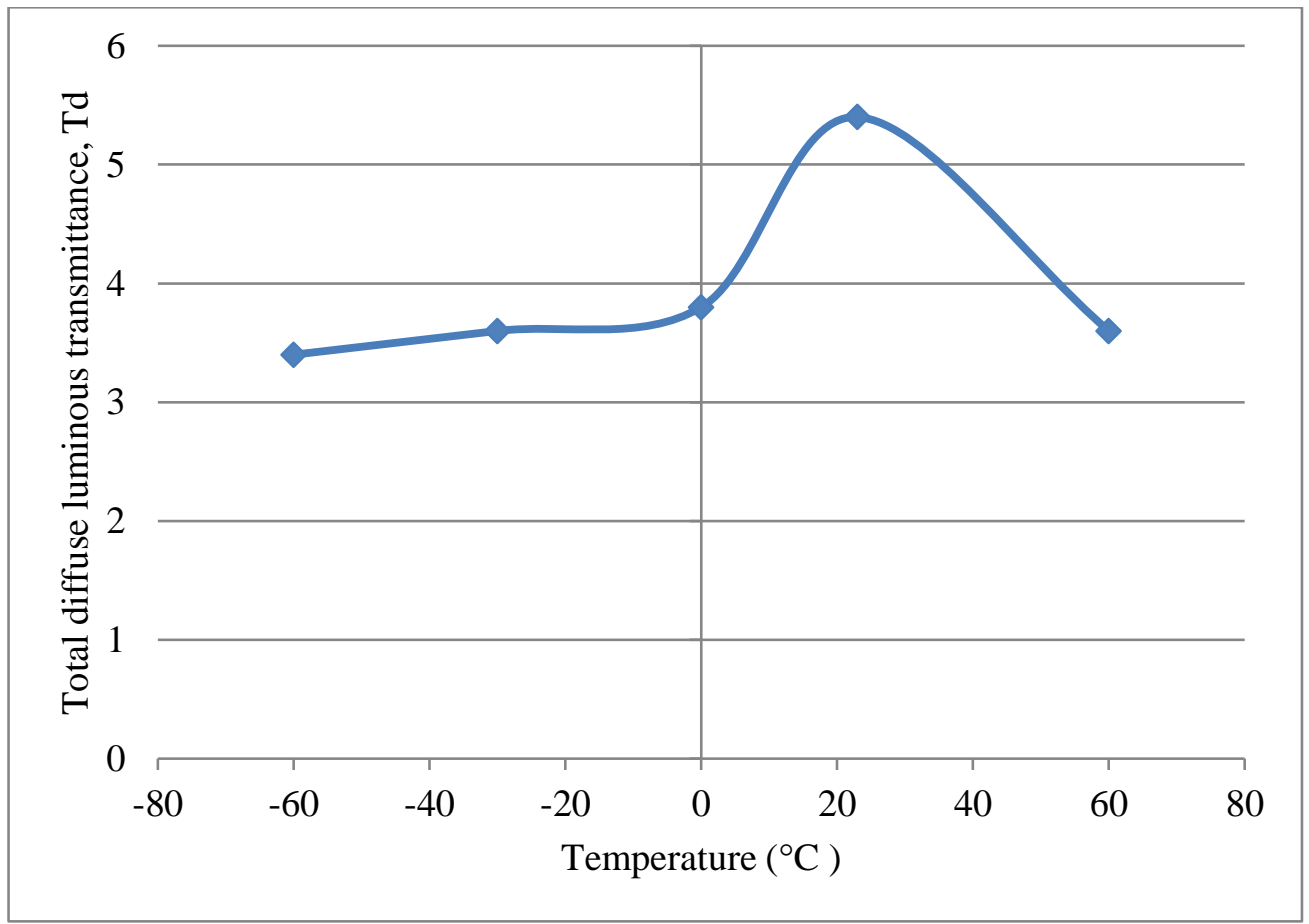

Figure 2.14: Total diffuse luminous transmittance of unreinforced specimens of unsaturated polyester matrix at different temperatures 
Total diffuse luminous transmittance of unreinforced specimens of unsaturated polyester matrix was determined at different temperatures. Figure 2.13 shows that changing temperature from very low to high does not influence the total diffuse luminous transmittance significantly. The only noticeable change in the slope of the curve is observed at room temperature where the diffuse luminous increases to 5.4. The diffuse light transmittance of glass fiber-reinforced polymer (GFRP) laminates was also determined. Figure 2.14 shows the effect of chaining temperature on total diffuse luminous transmittance and the big difference in values of the diffuse light compared to the unreinforced specimens. It shows that going from very low to high temperature makes a clear slope of the curve going from 20.5 to 16.1 . The values of diffuse transmittance at room temperature is higher than the values determined at high and low temperatures too. Also, going through the low range of operation, changing temperature does not affect the diffuse transmittance, i.e they are almost the constant. Refractive index mismatches between glass fibers and resin and the presence of air flaws in the laminates were the major parameters increasing light diffusion. 


\subsection{Conclusions}

Total light transmittance of GFRP laminates for building construction applications was measured. The following conclusions were drawn:

- The most important parameter affecting the light transmittance of GFRP is the fiber Reinforcement of the laminate: transmittance increases with decreasing weight.

- Big change was observed in the values of total transmittance as temperature changes from low to high.

-Small change was observed as temperature going from room to low and high temperature.

- Overall, adding enforcement and working at fairly low temperatures does not make the optical properties changes significantly. However, operating at high temperatures modified the optical properties significantly. Thus, these window sheets, solar cell panels or fronts of building are reliable for low scattering laminates only.

The properties described above and the low refractive index of the GFRP composite make it an attractive choice for fronts building and aerospace applications. However, the indices were different at low and high temperatures. This drawback, however, can be compensated by the possible modification of glass transition temperature into high transition temperature polymer matrix, opening up new possibilities in well environment resisted architectural design. 


\section{References}

1. Khanna, S.K., 2011. "Transparent composites and laminates and methods for making", The Curators of the University of Missouri USA.

2. Yeung, P. and L.J. Broutman, 1978, "The effect of glass-resin interface strength on the impact strength of fiber reinforced plastics". Polymer Engineering \& Science, 18(2): p. $62-72$.

3. Zhu, Hua., 2014, "Fabrication and characterization of novel transparent laminated glass-composite panels for dynamic load mitigation," University of MissouriColumbia.

4. Sawai H, Toshikawa H, Shibata A, Takemoto T, Tsuji T. 1982, “The development of a low cost photovoltaic module using FRP molded encapsulation". Proceedings of the 16th IEEE Photovoltaic Specialists Conference; 1982 September 28; San Diego, USA. IEEE; p. 932-937.

5. Rion J. 2008, “Ultra-light photovoltaic composite sandwich structures '. Ph.D.thesis, Lausanne: Ecole Polytechnique Fédérale de Lausanne.

6. Maung KJ, Hahn HT, Ju YS. 2010, "Multifunctional integration of thin-film silicon solar cells on carbon-fiber-reinforced epoxy composites”. Solar Energy; 84(3):450458.

7. Keller T, Vassilopoulos AP, Manshadi BD. 2010, “Thermomechanical behavior of multifunctional GFRP sandwich structures with encapsulated photovoltaic cells". Journal of Composites for Construction, 14(4):470-478.

8. Samuels SL, Glassmaker NJ, Andrews GA, Brown MJ, Lewittes ME. 2010, “Teflon® FEP frontsheets for photovoltaic modules: improved optics leading to higher module 
efficiency”. Proceedings of the 35th IEEE Photovoltaic Specialists Conference; June 20-25; Honolulu, USA. IEEE; 2010. p. 2788-2790.

9. ASTM G173-03. Standard Tables for Reference Solar Spectral Irradiances: Direct Normal and Hemispherical on $37^{\circ}$ tilted Surface. ASTM International; October 2008.

10. Markvart T, editor. 2000. "Solar electricity". 2nd ed. Chichester: John Wiley \& Sons.

11. Pélisset S, Joly M, Chapuis V, Schüler A, Mertin S, Hody-Le Caër V, 2011. "Efficiency of silicon thin-film photovoltaic modules with a front coloured glass". Proceedings of CISBAT International Conference; 2011 September 14-16; Lausanne, Switzerland. Lausanne: LESOPB; p. 37-42.

12. Zhu, H. L.; Parvinian, S.; Preston, C.; Vaaland, O.; Ruan, Z. C.; Hu, L. B. 2013, “High Yield Preparation Method of Thermally Stable Cellulose Nanofibers". Nanoscale 5, $3787-3792$.

13. M. Born, E. Wolf, 1999, "Principle of optics: electromagnetic theory of propagation, Interference and Diffraction of Light", Seventh ed., Cambridge University Press, Cambridge.

14. ASTM Standard Test Method for Haze and Luminous Transmittance of Transparent Plastics ASTM D1003 - 13; ASTM 2000.

15. Lidong Feng, Xinchao Bian, Zhiming Chen, GaoLi Xuesi Chen.2013, "Mechanical, aging, optical and rheological properties of toughening polylactide by melt blending with poly(ethylene glycol) based copolymers". Polymer Degradation and Stability, 98( 9), pp.1591-1600. 
16. Yuanyuan Li, Qiliang Fu, Shun Yu, Min Yan, Lars Berglund. 2016, “Optically Transparent Wood from a Nanoporous Cellulosic Template: Combining Functional and Structural Performance”. Biomacromolecules 17(4), pp. 1358-1364.

17. Alicia Larena and Marcelo A.Villar. 2001. Optical properties of $\mathrm{CaCO}_{3}$-filled poly(ethylene-co-vinyl acetate) films. Optical Materials. 17(3), pp. 437-442 


\section{CHAPTER THREE: TENSILE BEHAVIOR OF GLASS FIBER REINFORCED COMPOSITE}

\subsection{Introduction}

Polymer composite materials are commonly utilized in civilian military and aerospace applications. Thus, they are often exposed to a hostile environment, in which conditions may change considerably and composite properties could change. In order to use these in extreme environments, it is essential to determine how environmental conditions impact their performance and life time. Many uses of these composites involve exposure to high or low temperature such as in aircrafts or automotive applications. Although a variety of polymers are used we have focused on investigating unsaturated polyester matrix composites. This polymer is relatively low cost and when reinforced with glass fibers provides high mechanical strength [1]. However, any changes in temperature and humidity can affect the properties of the polymer matrix, which could in turn influence the durability of the composite. Tensile and other quasi-static mechanical properties at temperatures beyond the ambient condition are examined to obtain principle information about failure and damage mechanism, and to provide essential data for utilization in simulation studies at extreme temperatures. The tension test is the most widely used for understanding mechanical behavior. This test supports designers with the necessary information on elastic modulus and the ultimate tensile strength, among other properties. Tensile test is specified as an applied load, transverse or longitudinal, for multidirectional and unidirectional composites with respect to reinforcement orientation. In the longitudinal test, which is a fiber control test, if a perfect interfacial linkage between the fibers and matrix is assumed, the fiber and polymer matrix strains are equal. At the ultimate stress in 
the longitudinal direction the fibers reach their fracture strain. The transverse tensile test is a polymer matrix-controlled test where the load is perpendicular to the fiber orientation and the strain is concentrated in the matrix. Findings obtained by investigators [2-9] described the mechanical behavior of reinforced composite under quasi static loading at room temperature while references [10-14] describe the mechanical behavior of a fiber reinforced composite under quasi static loading as a function of temperature from high to low temperature. Ou et al [12] reported that there is an obvious dependence of the temperature on the mechanical properties of glass fiber reinforced polyester (GFRP). They reported that for GFRP, the tensile strength linearly decreases by about (31\%) when temperature increases from room temperature to $75^{\circ} \mathrm{C}$. However tensile strength showed almost no change (within $3 \%$ ) when temperature increased from -25 to $50^{\circ} \mathrm{C}$. Elanchezhia et al [15] determined the mechanical properties of glass fiber reinforced polyeater at different strain rates and temperatures. For a temperature range $35-70{ }^{\circ} \mathrm{C}$ they found a negligible change at a constant strain rate. Lamb et al [9] reported a variation of 22\% in the tensile properties of a laminate made of unsaturated polyester reinforced with glass fiber from $-70^{\circ} \mathrm{F}$ to $200{ }^{\circ} \mathrm{F}$. The increase in modulus of elasticity was about 40 to $80 \%$ at $-70^{\circ} \mathrm{F}$ and moderate decreases up to about $25 \%$ at $200^{\circ} \mathrm{F}$. They also observed an increase in flexural strength and flexural modulus of elasticity of about $17 \%$ at $-38^{\circ} \mathrm{F}$ compared to values at $78^{\circ} \mathrm{F}$ and $40 \%$ relative humidity. All these studies focused on damage modes and strain rate sensitive nature of these opaque polymer matrix composites that are used for automotive bodies and structures at room and extreme temperatures. The focus of this investigation is to determine the behavior of a glass like fiber reinforced polyester composite sheets under quasi-static loading as the temperature changes from $+60^{\circ} \mathrm{C}$ to very 
cold temperature of $-80^{\circ} \mathrm{C}$, which are encountered by structural composites in outer space applications, in arctic regions on earth and low temperature storage. The mechanical behavior at various temperatures has been determined primarily using the tension test.

\subsection{Experimental method}

\subsubsection{Specimen Preparation}

The polymer specimens were cut into dog-bone shapes as shown in Figure 3.1. Their dimensions were determined according to the ASTM D 638 standard mentioned earlier in the introduction. The following procedure were followed to conduct this test;

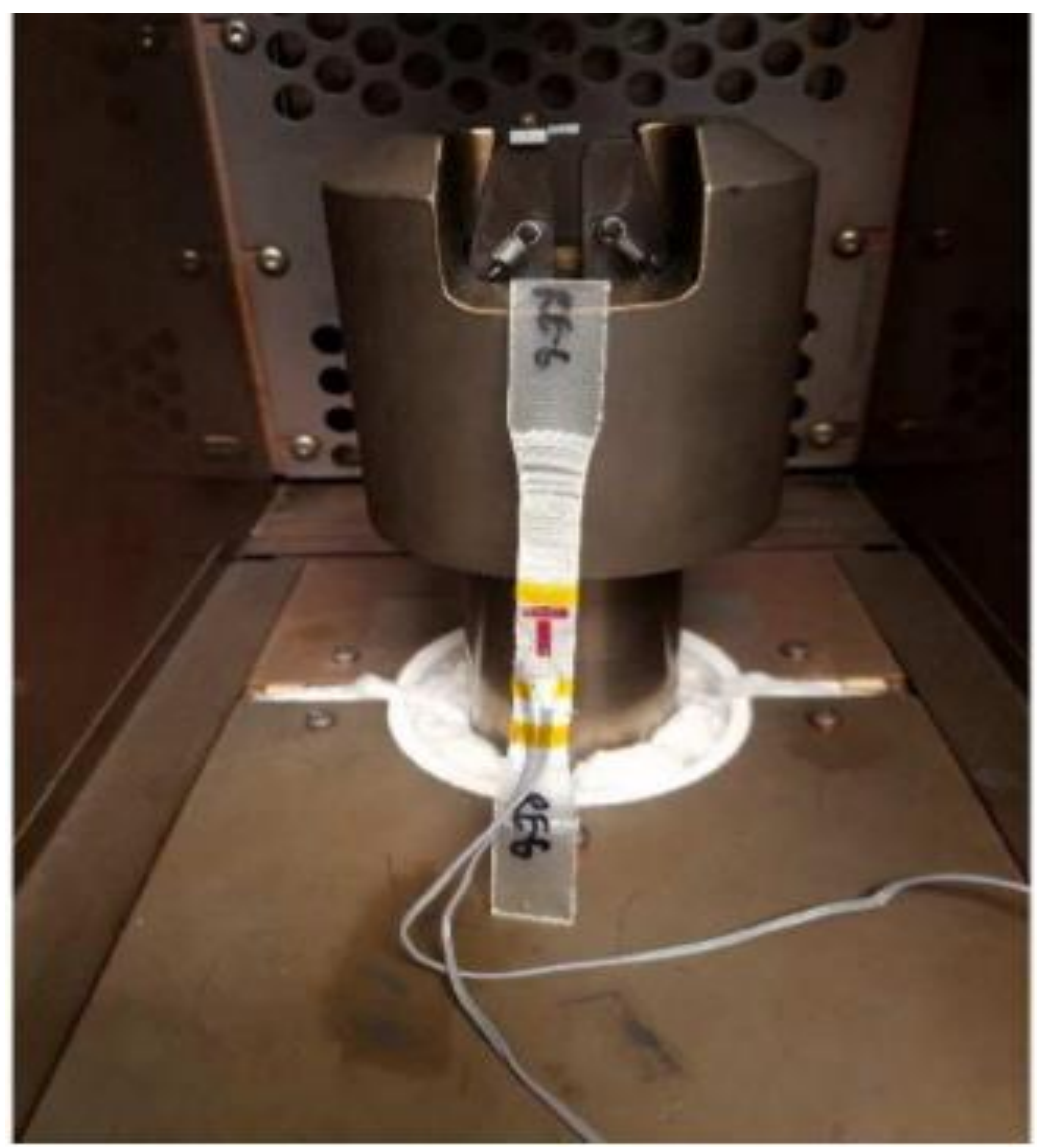

Figure 3.1 Tensile test setup: specimen and gages installation 
(1) Measuring the thickness, width and gage length of polymer samples in mm. These dimensions should be approximately the same for each sample.

(2) Making note of any sample defects (e.g. impurities, air bubbles, etc.).

The following samples were tested:

1) Unsaturated polyester polymer for analysis of tensile properties at room temperature.

2) Unsaturated polyester composite for analysis of tensile properties at room temperature.

3) Unsaturated polyester polymer for analysis of tensile properties at very low temperatures $\left(0^{\circ} \mathrm{C}-+80^{\circ} \mathrm{C}\right)$.

4) Unsaturated polyester composite for analysis of tensile properties at very low temperatures $\left(0^{\circ} \mathrm{C}--80^{\circ} \mathrm{C}\right)$.

5) Unsaturated polyester polymer for analysis of tensile properties at high temperatures $\quad\left(30^{\circ} \mathrm{C}-+60^{\circ} \mathrm{C}\right)$.

6) Unsaturated polyester composite for analysis of tensile properties at high temperatures $\left(30^{\circ} \mathrm{C}--60^{\circ} \mathrm{C}\right)$.

Over the temperature range we planned, FLA-5-11-3LJC single axis gages (-196 $+150^{\circ} \mathrm{C}$, Manufacturer: Tokyo Sokki Kenkyujo Co. Ltd.) were used. The -3LJC in the part number indicates $3 \mathrm{~m}$ long pre-attached lead wires that can connect directly to the tensile frame and avoid having to place connecting terminals and soldering leads. 
Cyanoacrylate adhesive $\left(\mathrm{CN},-196 \sim+120^{\circ} \mathrm{C}\right.$, Tokyo Sokki Kenkyujo Co. Ltd.) was used for these gages and a primer chemical was used first to roughen the surface so the adhesive can bond with the specimen.

\subsubsection{Machine Software Setup}

1. Turning on the tensile test machine. The switch is located on the right side of the machine. Also turning on the video extensometer.

2. On the main page, select Test to start a new sample. Name your test and click Browse to select the folder you would like to save it in. Click next.

3. Choosing which method, we would like to use.

4. Method set up: Saving after any changes are made.

- General: used for display purposes

- Specimen: specifies sample dimensions and parameters. A dogbone sample is used for tensile testing. Select rectangular, and specify the width, thickness and gauge length of the sample. The gauge length is the distance between the clamps before starting the test.

- Control: describes the actual test. Select extension for mode of displacement, then specify the rate of extension. Most use $5 \mathrm{~mm} / \mathrm{min}$ or $50 \mathrm{~min} / \mathrm{mm}$, depending on if we want a slow or fast test.

- End of Test: identification the criteria for the end of the test. A large load drop is experienced when sample failure occurs. For this test, when the sample load drops by a certain percentage of the peak load, the machine will stop. 
- Data: specifying if the data is acquired manually or automatically, while the strain tab recognizes whether the strain is measured from the video extensimeter or the extension.

- Results and Graphs: select what data is shown and how it is displayed.

\subsubsection{Instrument Setup}

1. Making sure the proper load cell is installed, $10 \mathrm{kN}$ was used for this test.

2. Calibration of the load cell by clicking on the button in the upper right-hand corner. Make sure all loads are removed from the load cell and click calibrate.

3. Installation of the correct type of clamps for the testing. For tensile testing, $5 \mathrm{kN}$ or $50 \mathrm{kN}$ samples can be used. Install the clamps using the pins. Also, installation of height brackets if needed. Setting the load to zero once the clamps are installed.

4. Pressing the up and down arrows on the controller until the clamps are just touching. Press of the reset gauge length button at the top of the screen to zero the position of the clamps.

5. Using the up and down arrows until the clamps are about $100 \mathrm{~mm}$ apart. This is a typical gauge length for the dog bone samples.

6. The polymer sample was placed between the grips of both the tensile test machine. While holding the sample vertically with one hand, another hand was used to turn the handle of the top grip in the closing direction as tightly as possible. (The specimen should be gripped such that the two ends of the specimen are covered by the grip, approximately $3 \mathrm{~mm}$ away from its gage-length. It is important that the specimens are tightly gripped onto the specimen grips to prevent slipping, which will otherwise result in experimental errors. 
a. Making sure that the specimen is vertically aligned, if not a torsional force, rather than axial force, will result.

b. Turning the bottom handle in the "close" direction as tightly as possible. Visually verifying that the sample is gripped symmetrically at its two ends.

7. Zeroing the extension by pushing zero extension button at the top of the screen. Also zeroing the load if needed. Waiting for a few seconds to let the computer return its value to zero.

The cooling system involves the supply of liquid nitrogen from the commercially available liquid nitrogen tank through a control valve, which releases the evaporated liquid nitrogen in to the environment chamber. The chamber has tin fins surrounded on a copper rod, which circulates the gas inside the chamber. A feedback loop of temperature sensed by a thermocouple controls the release of liquid nitrogen so that the temperature inside the chamber is maintained steady within $+/-1^{\circ} \mathrm{C}$. Figure 3.2 shows the cooling system. Also, the thermocouple is connected to the data logger.

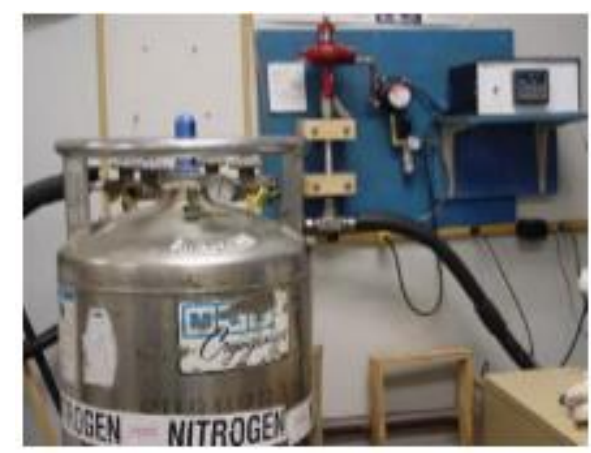

Liquid nitrogen tank

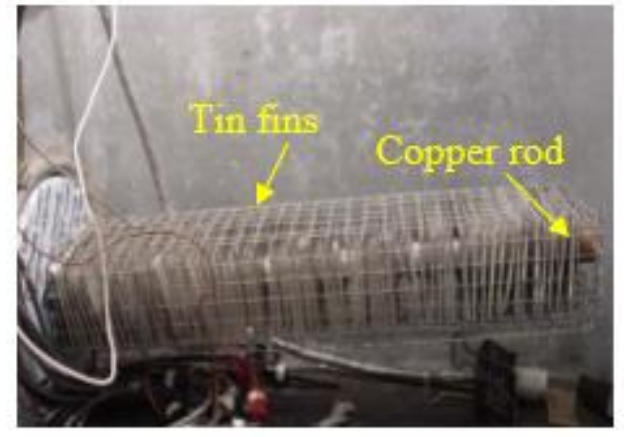

cooling coil in the chamber

Figure 3.2 Cooling system 
The chamber could also be heated to a higher temperature by the heating coil mounted inside the test chamber. Figure 3.3 shows the test chamber with the heating coil. Again, a feedback loop control using thermocouple controls the temperature of the chamber. The USP samples are tested at $-80^{\circ} \mathrm{C},-60^{\circ} \mathrm{C},-30^{\circ} \mathrm{C} 0{ }^{\circ} \mathrm{C}, 30^{\circ} \mathrm{C}$, and $60^{\circ} \mathrm{C}$ temperatures.

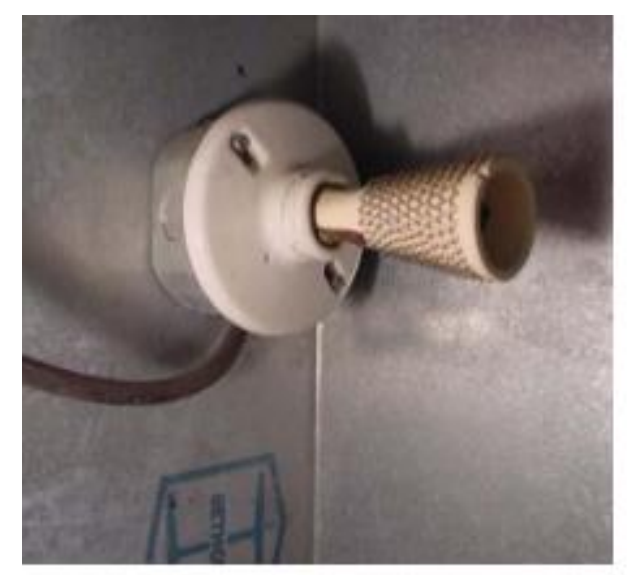

Heating coil in the chamber

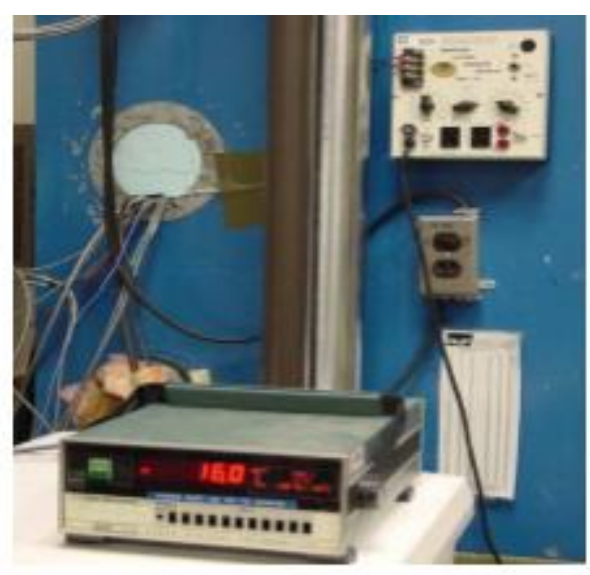

Temperature recorder

Figure 3.3 Heating system

\subsubsection{Conducting tensile test}

1. Entering geometry of the sample before starting.

2. Clicking on the Start button. Both the upper and bottom grips will start moving in opposite directions according to the specified pulling rate. Observing the experiment at a safe distance (about 1.5 meters away) at an angle and take note of the failure mode when the specimen fails.

3. A plot of tensile stress $(\mathrm{MPa})$ versus tensile strain $(\mathrm{mm} / \mathrm{mm})$ was generated in realtime during the experiment. 


\subsection{Results and Discussion}

The composite specimens were prepared, shaped and examined for tension resistance under extreme temperature conditions. Different behavior was observed at each temperature and there were significant observations. In the next sections these observations are expressed and discussed.

\subsection{Thermal analysis}

Highly crystalline polymeric materials with a $\mathrm{T}_{\mathrm{g}}$ above the room temperature are usually brittle which is proven by differential scanning calorimetry (DSC) test. The polymer matrix prepared in this study was found to have a glass transition temperature, $\mathrm{Tg}$, of $73.2^{\circ} \mathrm{C}$, at this temperature the polymer matrix softens and turns into a more ductile polymer. This polymer matrix is a semi-crystalline polymer and when subject to tensile stress the amorphous chains will become aligned. This is usually evident for transparent and translucent materials, which become opaque upon turning crystalline. The results of DSC study show that the curing reaction starts at room temperature and gets completed almost around $50^{\circ} \mathrm{C}$. This clearly indicates that the unsaturated polyester resins have good induction period under this condition and therefore it can be expected that at room temperature the unsaturated polyester resins would have a very long induction period which is needed for better damage resistance. The sample was heated at $20 \mathrm{~K} / \mathrm{min}$ while the sample was cooled slowly $(0.1 \mathrm{~K} / \mathrm{min})$ it goes through its glass transition temperature, $\mathrm{Tg}$, at $73.2^{\circ} \mathrm{C}$. 


\subsection{Tensile properties at different temperatures}

The objective of this test is to determine the effect of high and very low temperatures on chord modulus (calculated over 0.1 to $0.2 \%$ strain range), ultimate strain and Poisson's ratio of unreinforced polyester matrix (UPM) and reinforced polyester composite (RPC). Tables 3.1 and 3.2 summarize the various mechanical properties of the prepared UPC and RPC specimens, respectively, for better comparison. Each value in these tables is the average of five replicates' experimental results. Tests were done at room temperature first as a basis for the other temperatures. 
Table 3.1. ASTM D638 Tensile test results for UPM at different temperatures

\begin{tabular}{|c|c|c|c|c|}
\hline $\begin{array}{c}\text { Temperature } \\
{\left[{ }^{\circ} \mathrm{C}\right]}\end{array}$ & $\begin{array}{c}\text { Chord Modulus } \\
\qquad \begin{array}{c}\text { kpsi }] \\
{[\mathrm{GPa}]}\end{array}\end{array}$ & $\begin{array}{c}\text { Stress at Fracture } \\
\text { [kpsi }] \\
{[\mathrm{MPa}]}\end{array}$ & $\begin{array}{c}\text { Strain at fracture } \\
{[\%]}\end{array}$ & Poisson's Ratio \\
\hline 60 & $\begin{array}{l}28.52 \\
{[1.96]}\end{array}$ & $\begin{array}{l}0.544 \\
{[3.75]}\end{array}$ & 6.99 & 0.419 \\
\hline 30 & $\begin{array}{c}311 \\
{[2.14]}\end{array}$ & $\begin{array}{c}6.07 \\
{[41.85]}\end{array}$ & 3.83 & 0.403 \\
\hline 0 & $\begin{array}{l}537 \\
{[3.7]}\end{array}$ & $\begin{array}{c}6.66 \\
{[45.92]}\end{array}$ & 1.45 & 0.397 \\
\hline-30 & $\begin{array}{c}641 \\
{[4.41]}\end{array}$ & $\begin{array}{c}5.24 \\
{[36.13]}\end{array}$ & 1.19 & 0.382 \\
\hline-60 & $\begin{array}{c}662 \\
{[4.56]}\end{array}$ & $\begin{array}{c}4.14 \\
{[28.54]}\end{array}$ & 0.64 & 0.380 \\
\hline-80 & $\begin{array}{c}697 \\
{[4.80]}\end{array}$ & $\begin{array}{c}5.08 \\
{[35.03]}\end{array}$ & 0.73 & 0.358 \\
\hline
\end{tabular}


Table 3.2. ASTM D638 Tensile test results for glass fiber RPC at different temperatures

\begin{tabular}{|c|c|c|c|c|}
\hline $\begin{array}{c}\text { Temperature } \\
{\left[{ }^{\circ} \mathrm{C}\right]}\end{array}$ & $\begin{array}{c}\text { Chord Modulus } \\
\qquad \begin{array}{c}\text { [kpsi }] \\
{[\mathrm{GPa}]}\end{array}\end{array}$ & $\begin{array}{c}\text { Stress at Fracture } \\
\qquad \begin{array}{c}\text { [kpsi }] \\
{[\mathrm{MPa}]}\end{array}\end{array}$ & $\begin{array}{c}\text { Strain at fracture } \\
{[\%]}\end{array}$ & $\begin{array}{c}\text { Poisson's } \\
\text { Ratio }\end{array}$ \\
\hline 60 & $\begin{array}{c}925 \\
{[6.38]}\end{array}$ & $\begin{array}{c}8.7 \\
{[59.58]}\end{array}$ & 1.03 & 0.22 \\
\hline 30 & $\begin{array}{l}1090 \\
{[7.52]}\end{array}$ & $\begin{array}{c}13.7 \\
{[94.46]}\end{array}$ & 1.41 & 0.18 \\
\hline 0 & $\begin{array}{c}1510 \\
{[10.41]}\end{array}$ & $\begin{array}{c}12 \\
{[82.74]}\end{array}$ & 0.93 & 0.24 \\
\hline-30 & $\begin{array}{c}1640 \\
{[11.31]}\end{array}$ & $\begin{array}{c}14.4 \\
{[99.28]}\end{array}$ & 1.14 & 0.21 \\
\hline-60 & $\begin{array}{c}1700 \\
{[11.72]}\end{array}$ & $\begin{array}{c}15.7 \\
{[108.25]}\end{array}$ & 1.38 & 0.24 \\
\hline-80 & $\begin{array}{c}1830 \\
{[12.62]}\end{array}$ & $\begin{array}{c}17.1 \\
{[117.90]}\end{array}$ & 1.48 & 0.21 \\
\hline
\end{tabular}

The results displayed in Tables 3.1 and 3.2 clearly demonstrate the favorable impact of glass fiber reinforcement on mechanical properties of the composite material. Figures 3.4 and 3.5 depict stress-strain curves of UPM and RPC specimens, respectively, under tensile loading at different temperatures. The chord modulus of the unreinforced polyester increases with a decrease in temperature, implying that the polyester matrix is becoming stiffer. The stress at fracture increase up to a low temperature of $-30{ }^{\circ} \mathrm{C}$ but decreases for lower temperatures up to $-80{ }^{\circ} \mathrm{C}$. 
The increase in stress at fracture with decreasing temperature up to $-30^{\circ} \mathrm{C}$ is due to lower mobility of polymer chains and hence higher stress could be sustained before failure. However, for further decrease in temperature, the polymer matrix becomes too brittle and could start developing microcracks that reduce the fracture stress from the peak value. The Poisson's ratio monotonically decreases with temperature, potentially due to reduced chain mobility in the polymer matrix. The glass fiber reinforced polyester composite has a chord modulus that is significantly higher than the unreinforced matrix nearly 2-3 times higher. The chord modulus continuously increases with decreasing temperature and this trend is similar to the response of the matrix. The stress at fracture also increases with decreasing temperature and is the highest at $-80^{\circ} \mathrm{C}$. The addition of glass fiber reinforcement reduces the Poisson's ratio compared to the unreinforced polyester matrix. However, no particular trend in the variation of Poisson's ratio with temperature for the composite was obtained. Both the unreinforced polyester matrix and the reinforced polyester composite display a nearly linear deformation behavior with load at all temperatures below room temperature, as can be seen in Figures 3.4 and 3.5. 


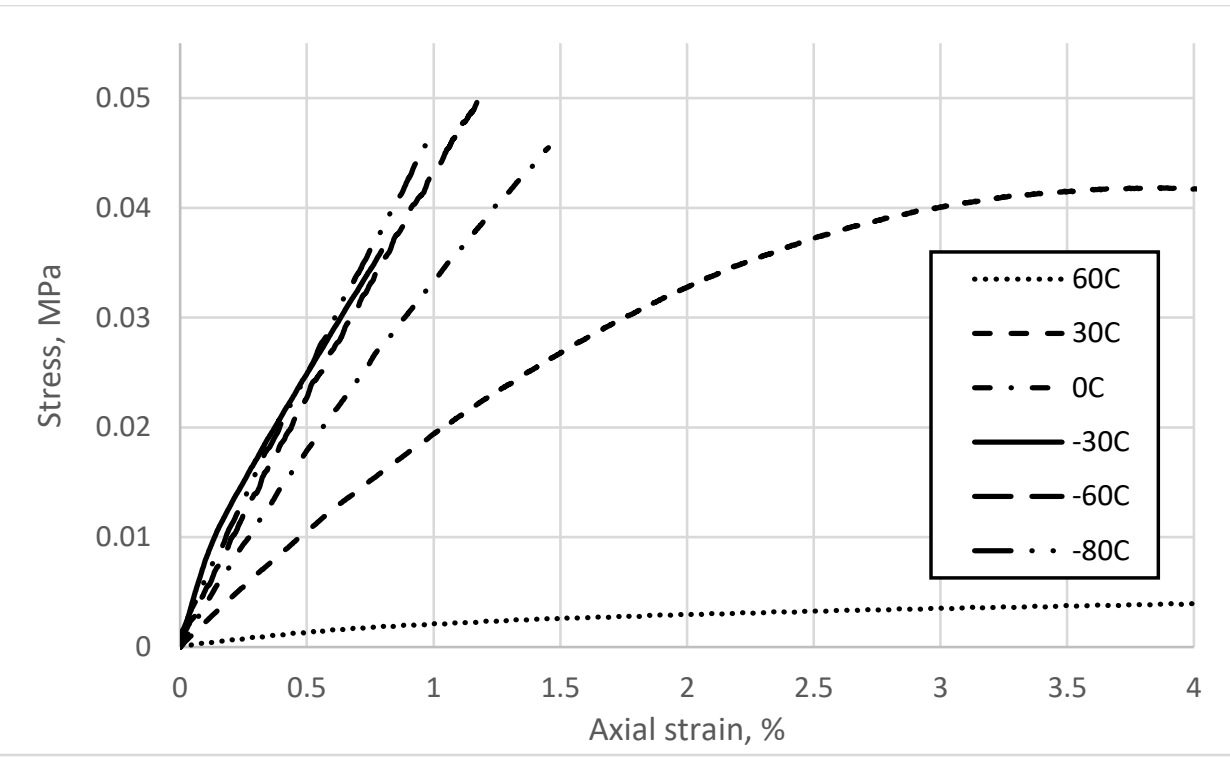

Figure 3.4. Stress-strain curves of UPM under transverse tensile loads at different

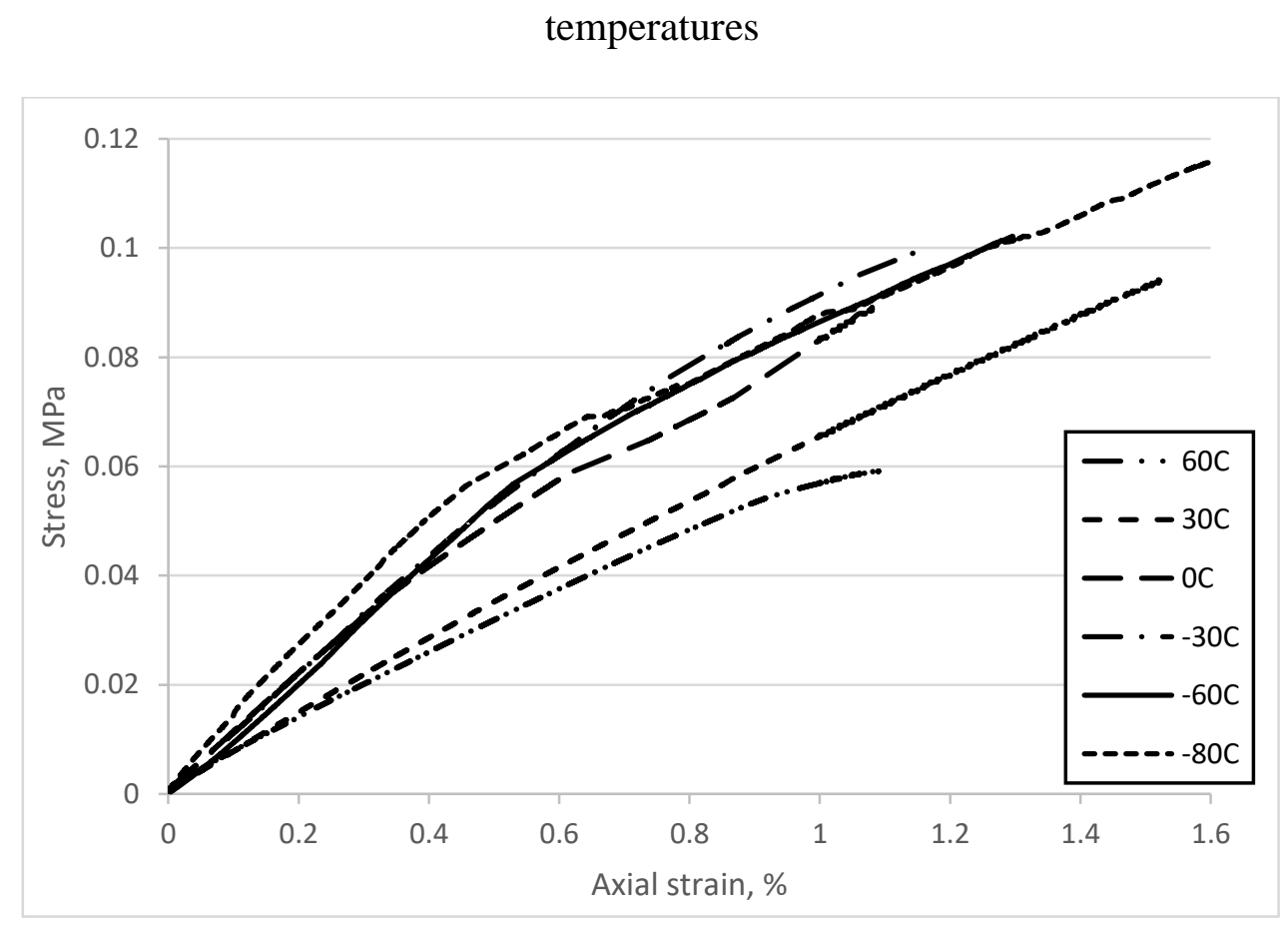

Figure 3.5 Stress-strain curves of a RPC under transverse tensile loads at different temperatures 


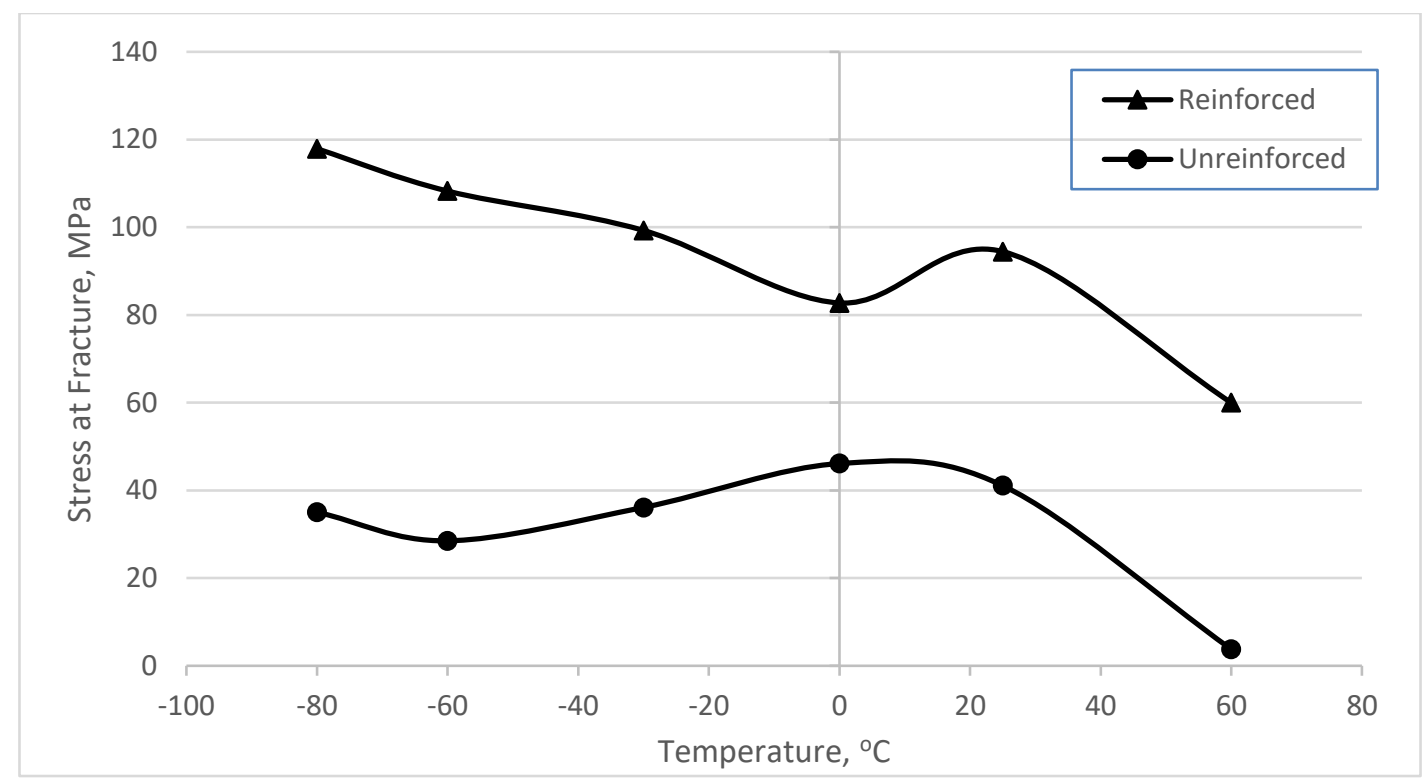

Figure 3.6. Stress at fracture of RPC and UPM under transverse loads at different temperature.

Generally, it is observed that the fracture stress of the RPC composite is higher than unreinforced polyester by about three times, as shown in Figure 3.6. The RPC shows a maximum in stress at fracture of $17.1 \mathrm{kpsi}(117.9 \mathrm{MPa})$ at $-80^{\circ} \mathrm{C}$ and the corresponding elongation is $1.48 \%$, which is also the highest. For the effect of temperature, peak stress shows an increase as temperature reduced from -60 to $-80^{\circ} \mathrm{C}$. This may attribute to the progressive growth of micro cracks at fiber matrix interfaces as temperature goes down. Heating up reveals more reduction in peak stress over a temperature range of -80 to $60{ }^{\circ} \mathrm{C}$, which is caused by a transition from semi crystalline to amorphous phase (weakening of bonding between polymer chains), which was already determined by thermal transition test and continues to increase toward room temperature. A sharp decrease is observed at $60{ }^{\circ} \mathrm{C}$ due to softening of the resin matrix when glass transition temperature of UPM $(\mathrm{Tg}=73.2$ ${ }^{\circ} \mathrm{C}$ ) is approached. This softening effect would weaken the bonding between the polymer 
matrix and fibers. The unreinforced UPM specimen has the maximum value of ultimate stress as $6.66 \mathrm{kpsi}(45.9 \mathrm{MPa})$ and the corresponding elongation as $1.45 \%$ at $0{ }^{\circ} \mathrm{C}$. The maximum displacement observed during the testing was $3 \mathrm{~mm}$ at $60^{\circ} \mathrm{C}$. The ultimate load at which the sample breaks is $6.69 \mathrm{kpsi}(46.125 \mathrm{kN})$. For composites, the shear strength increases at cryogenic temperatures but, due to the difference in thermal expansion coefficient between the matrix and the reinforcement, thermal stresses are induced at decreasing temperatures. These stresses may seriously weaken the interface bonding and thus adversely affect the structural integrity of the composite material.

Figure 3.7 shows the effect of temperature change on the chord modulus of RPC with $15 \%$ fiber volume fraction. The chord modulus was calculated over a strain range of $0.1 \%$ to $0.2 \%$. The chord modulus increases with decreasing temperature for both unreinforced polyester and glass fiber reinforced composite. The behavior of both materials is shown in Figure 3.7, the trend is similar; however, the RPC exhibits a larger change in modulus for temperatures below $0^{\circ} \mathrm{C}$. The highest values of chord modulus were $1830 \mathrm{kpsi}(12.65 \mathrm{GPa})$ and $697.4 \mathrm{kpsi}(4.78 \mathrm{GPa})$ at $-80^{\circ} \mathrm{C}$ for RPC and UPM, respectively. The lowest values for chord modulus were recorded for both RPC and UPM at $60^{\circ} \mathrm{C}$ because this temperature is close to the glass transition temperature of polyester matrix. 


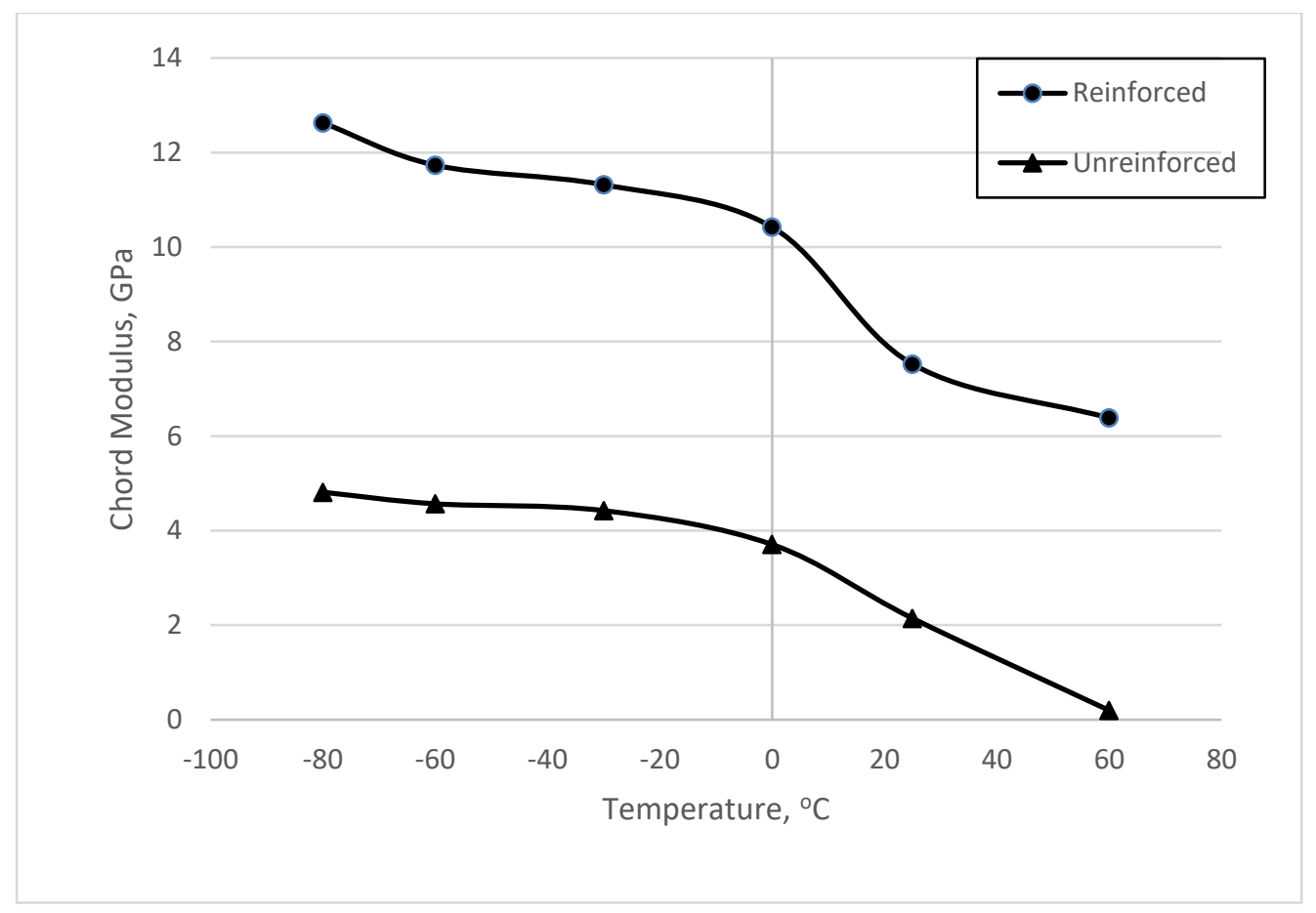

Figure 3.7 Chord modulus of RPC and UPM under transverse loads at different temperature.

Figure 3.8 shows the effect of temperature on strain at fracture for RPC and UPM. For $\mathrm{RPC}$, the strain at fracture is in the range of $0.93-1.48 \%$ as the temperature changes from $+60^{\circ}$ to $-80^{\circ} \mathrm{C}$. There is a gradual increase in strain at fracture as temperature decrease from $0^{\circ} \mathrm{C}$ to $-80^{\circ} \mathrm{C}$. For UPM the strain at fracture gradually decreases with temperature below $0^{\circ} \mathrm{C}$. Thus, the stress at fracture and strain at fracture are correlated as can be seen from Figures 3.6 and 3.8. In contrast, an obvious increase occurred in UPM at high temperatures where strain at fracture jumped to $6.99 \%$ at $60^{\circ} \mathrm{C}$. The lowest strain at fracture obtained was $0.73 \%$ at $-80^{\circ} \mathrm{C}$ in the UPM and $0.93 \%$ at $0^{\circ} \mathrm{C}$ in the RPC. Figure 3.8 reveals an obvious improvement in strength of the polyester material and a low strain at fracture for the composite manufactured. 


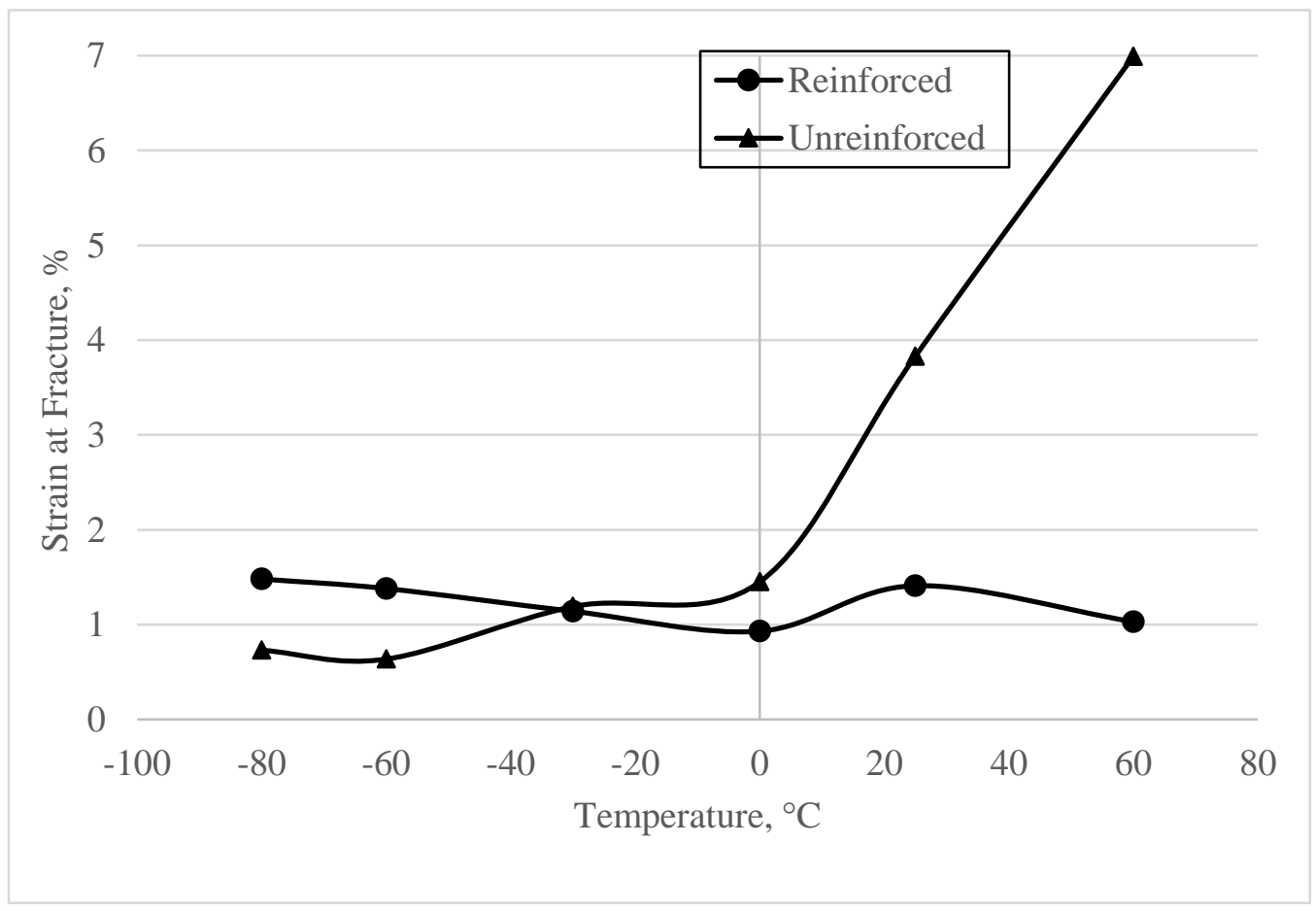

Figure 3.8. Strain at fracture of RPC and UPM under transverse loads at different temperature.

\subsection{Thermal expansion coefficient}

Thermal expansion, $\alpha_{l}$, was determined by employing equation (1) to the axial strain measured experimentally in this study and taking the temperature difference with respect to room temperature;

$\alpha_{l}=\frac{\Delta l}{l_{o}} \cdot\left(\frac{1}{\Delta T}\right)$

For most materials $\alpha_{l}$ is positive during heating and becomes negative on cooling and $\Delta l / l_{0}$ is the strain. Figure 3.9 shows the change in thermal expansion coefficient for temperature 
difference for unreinforced polymer (UPM). Equation 2 represent the polynomial relationship of thermal expansion coefficient with temperature difference in the range of 80 to $60^{\circ} \mathrm{C}$;

$\alpha_{l}=3 \times 10^{-6} \Delta \mathrm{T}^{2}+0.0004 \Delta \mathrm{T}+0.0154$

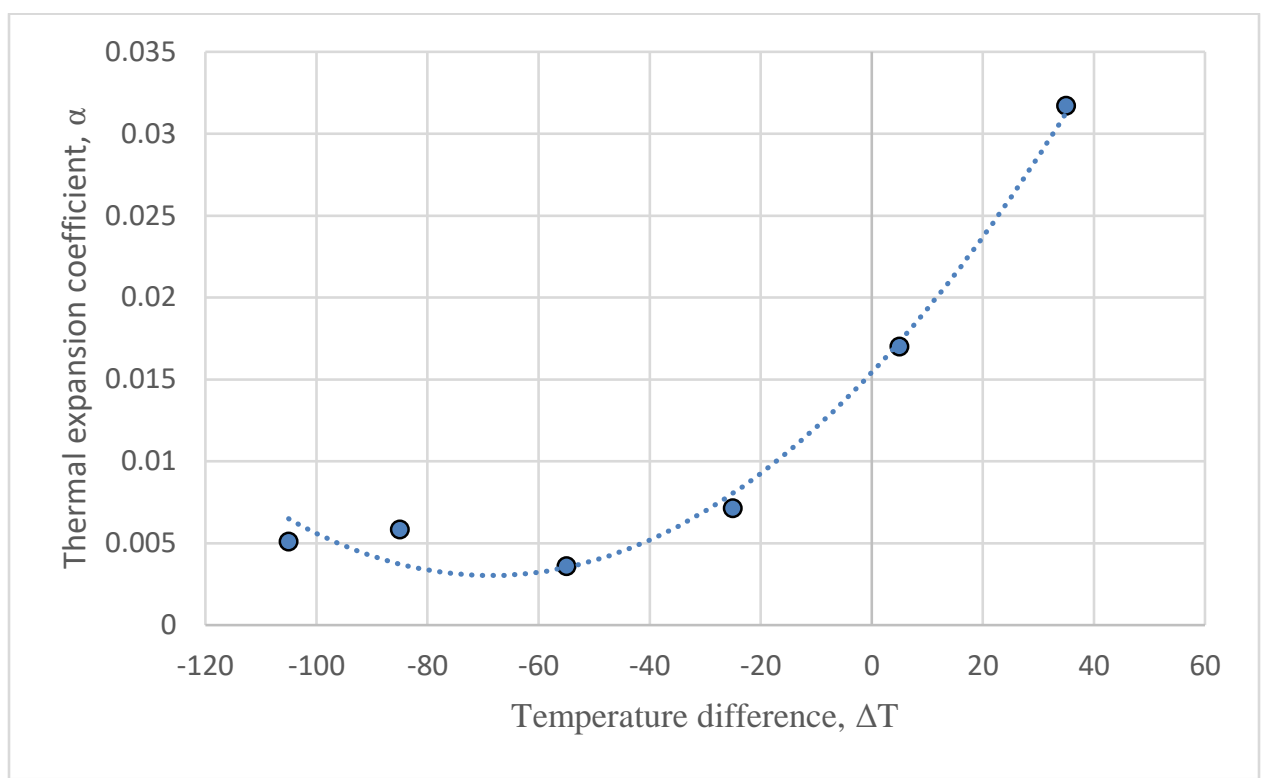

Figure 3.9. Thermal expansion $\left(\mathrm{in} / \mathrm{in} * 1 /{ }^{\circ} \mathrm{C}\right)$ vs. temperature difference of UPM

Figure 3.10 shows the change in thermal expansion coefficient with temperature difference for reinforced polymer composite (RPC). Equation 3 represent the polynomial relationship of thermal expansion coefficient with temperature difference in the range of -80 to $60^{\circ} \mathrm{C}$;

$\alpha_{l}=7.0 \times 10^{-8} \Delta \mathrm{T}^{3}+1.0 \times 10^{-5} \Delta \mathrm{T}^{2}+0.0006 \Delta \mathrm{T}+0.0081$

It can be seen that the behavior of thermal coefficient of RPC was positive at high temperatures and negative at low temperatures. 


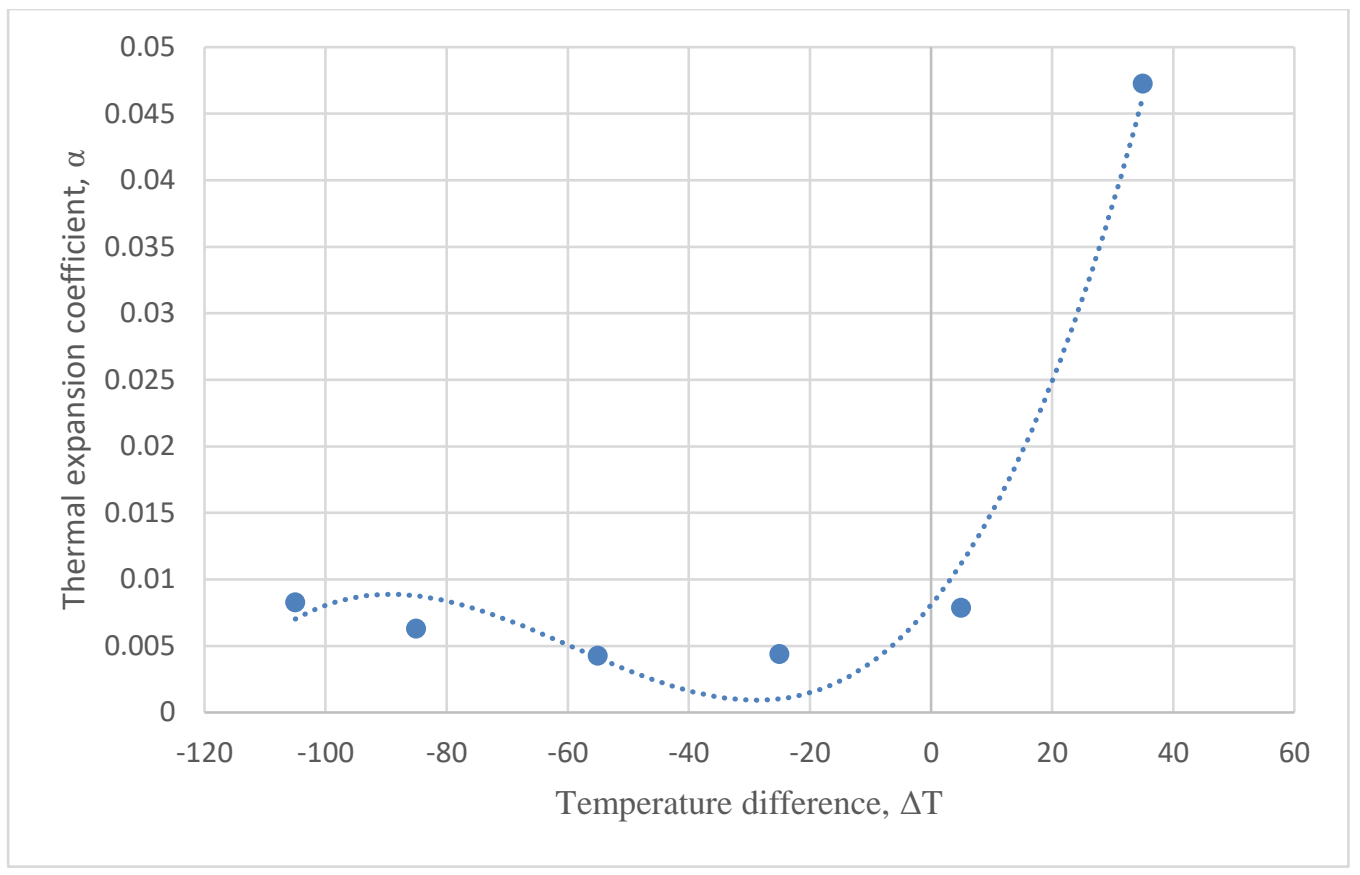

Figure 3.10. Thermal expansion vs. temperature difference of the RPC

Moreover, the intrinsic thermal expansion coefficient values of the RPC are much lower compared to that of UPM due to the physical constraint created by fiber reinforcement. On heating, the polymer matrix expands more as compared to the fillers; however, if the interphases are capable of transmitting stress, the expansion of the matrix will decrease giving rise to a reduced value of thermal expansion coefficient for the composite as a whole [16]. When the composite is cooled below room temperature $(\Delta T=0)$ the thermal expansion coefficient decreases due to the increased clamping pressure on the fibers created by the matrix, which contracts more than the glass fibers. 


\subsection{Microstructural analysis of failure in polyester composite}

Scanning electron microscopy (SEM) was used to study the fractured surfaces of the samples at different temperatures. Figure 3.11 shows fracture surfaces in the UPM at different temperatures. Figure 3.11a shows areas of smooth fracture surface with in depth cracking and pickling of layer of polymer material at $60^{\circ} \mathrm{C}$. The surface has a layered appearance and potentially excessive stretching of the polymer due to the temperature being close to glass transition temperature $(\mathrm{Tg})$. Figure $3.11 \mathrm{~b}$ shows the surface at $30^{\circ}$ and has the appearance of a delaminating material with visible cracks and areas of a rough surface. Figure $3.11 \mathrm{c}$ at $-60^{\circ} \mathrm{C}$ has the appearance of flaky surface with small size and smooth regions. The room temperature fracture surface points to a relatively higher energy absorption compared to the smoother surface appearances for the high and low temperature.

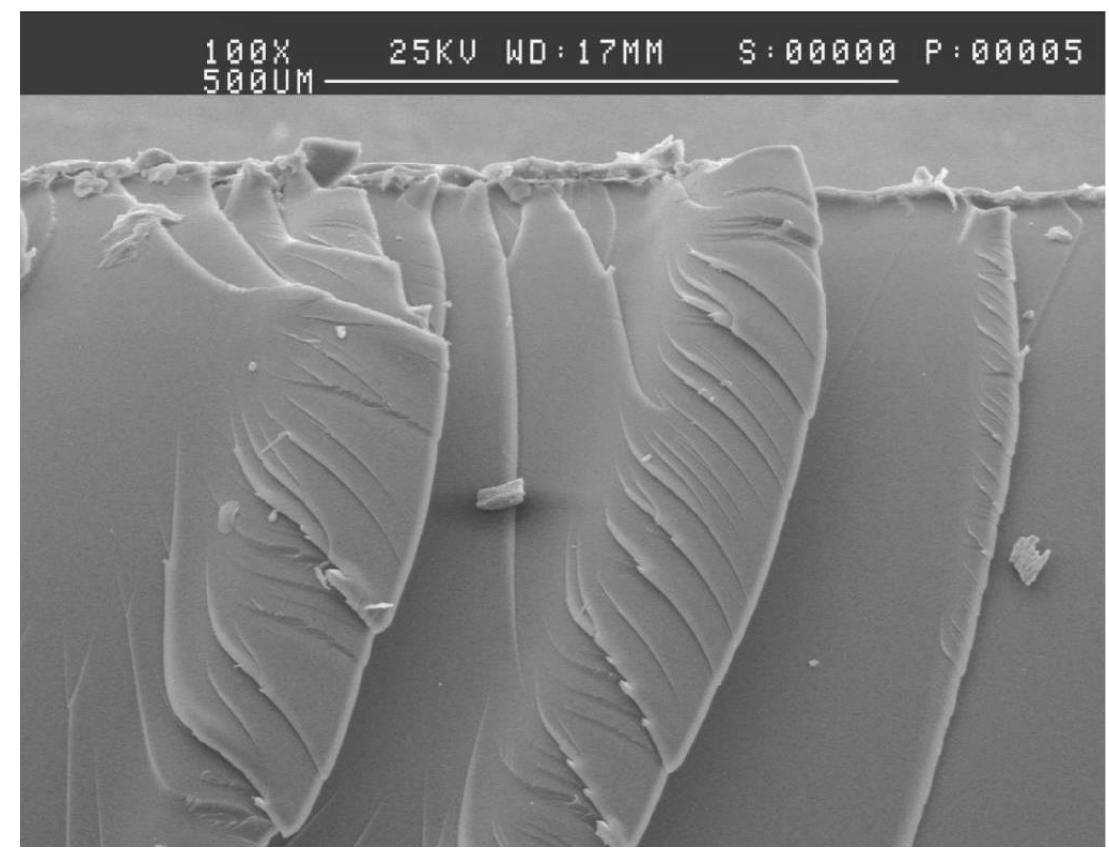

Figure 3.11.a. Microstructure of failed UPR specimen at $60{ }^{\circ} \mathrm{C}$ 


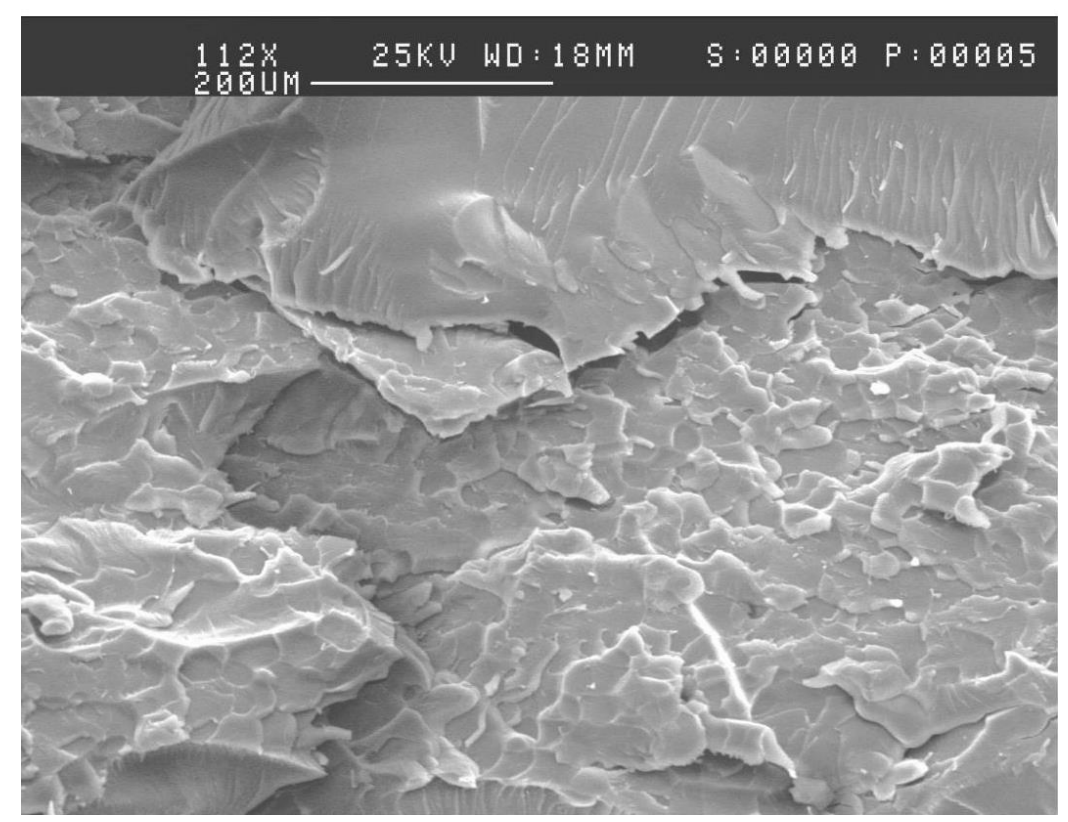

Figure 3.11b. Microstructure of failed UPM specimen at $30^{\circ} \mathrm{C}$.

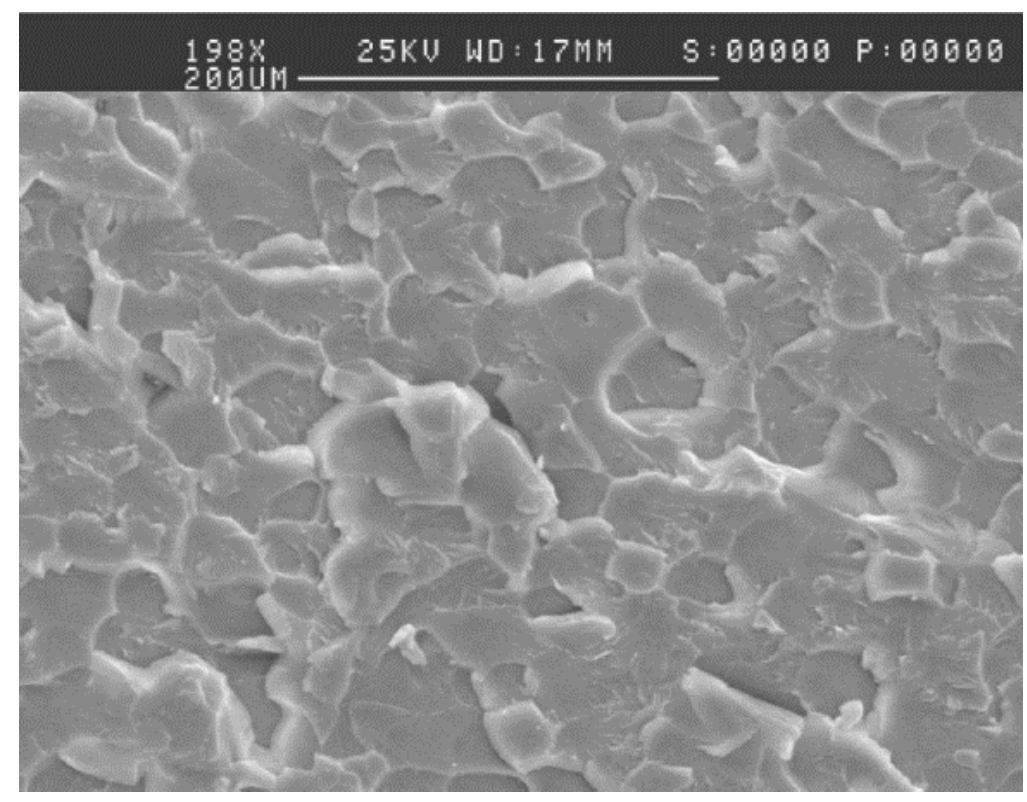

Figure 3.11c. Microstructure of failed UPM specimen at $-60{ }^{\circ} \mathrm{C}$

Figures 3.12 a, b and c show SEM images of the fractured surface in RPC at different temperatures. Fiber pull-out is evident in all cases and the fracture surface in the matrix is nearly flat and smooth except for $-60^{\circ} \mathrm{C}$ where the surface is stepped and slightly rougher. More extensive adhesion of the matrix to the fibers is noticed for the low temperatures 
range around $-60^{\circ} \mathrm{C}$. This implies that there is stronger interface bonding stress transfer for lower temperatures and that is reflected in higher tensile strength of low temperature tests. However, between the low temperature specimens, that is $0^{\circ} \mathrm{C}$ and below, the energy absorption is only marginally different and the increases in strength with decreasing temperature is relatively moderate. Even though tensile strength increases due to increased bonding and clamping pressure of polymer on the fiber, the microcracks formed and the extensive fiber fracture due to reduced fiber delamination limits the increase in energy absorption. Herrera-Franco et al. [17] also observed a similar behavior for a high-density polyethylene-continuous henequen-fiber composites.

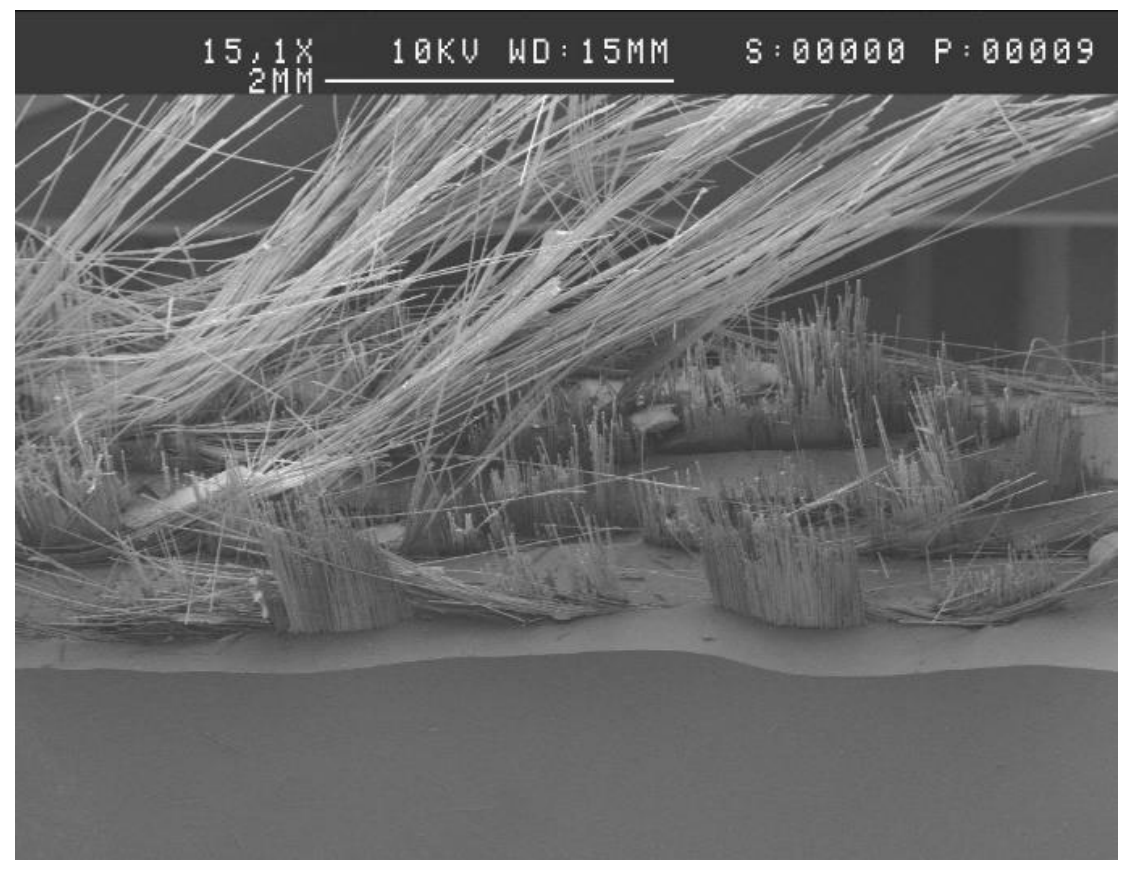

Figure 3.12a. Fracture surface of reinforced composite specimen at $60{ }^{\circ} \mathrm{C}$ 


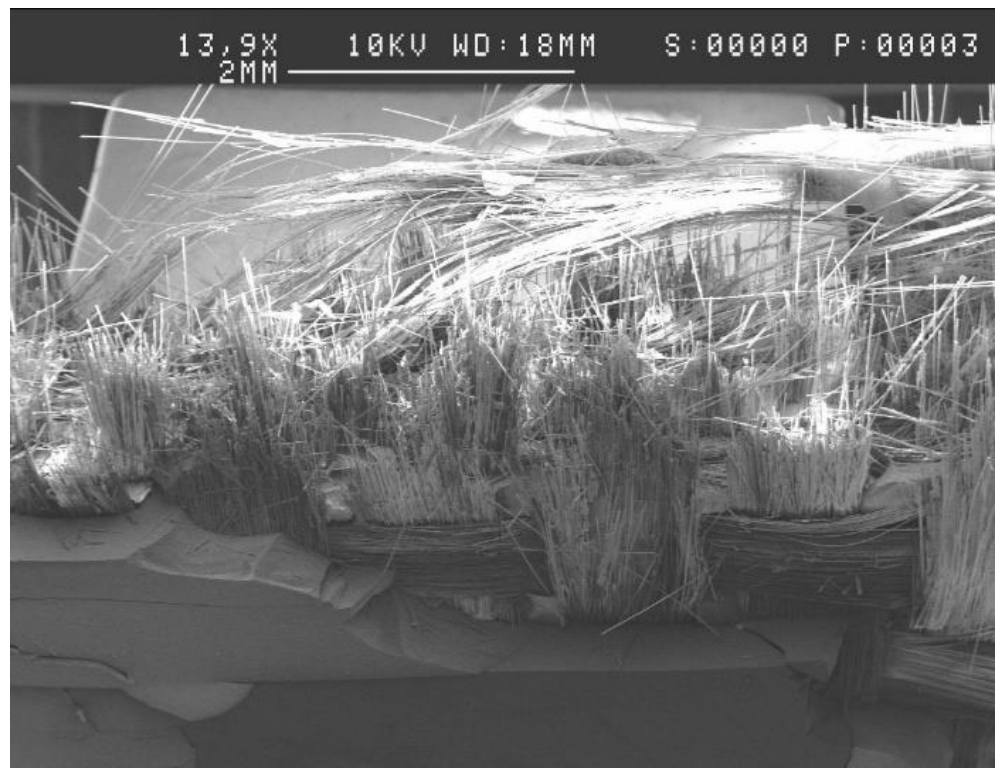

Figure 3.12b. Fracture surface of reinforced composite specimen at $-60{ }^{\circ} \mathrm{C}$

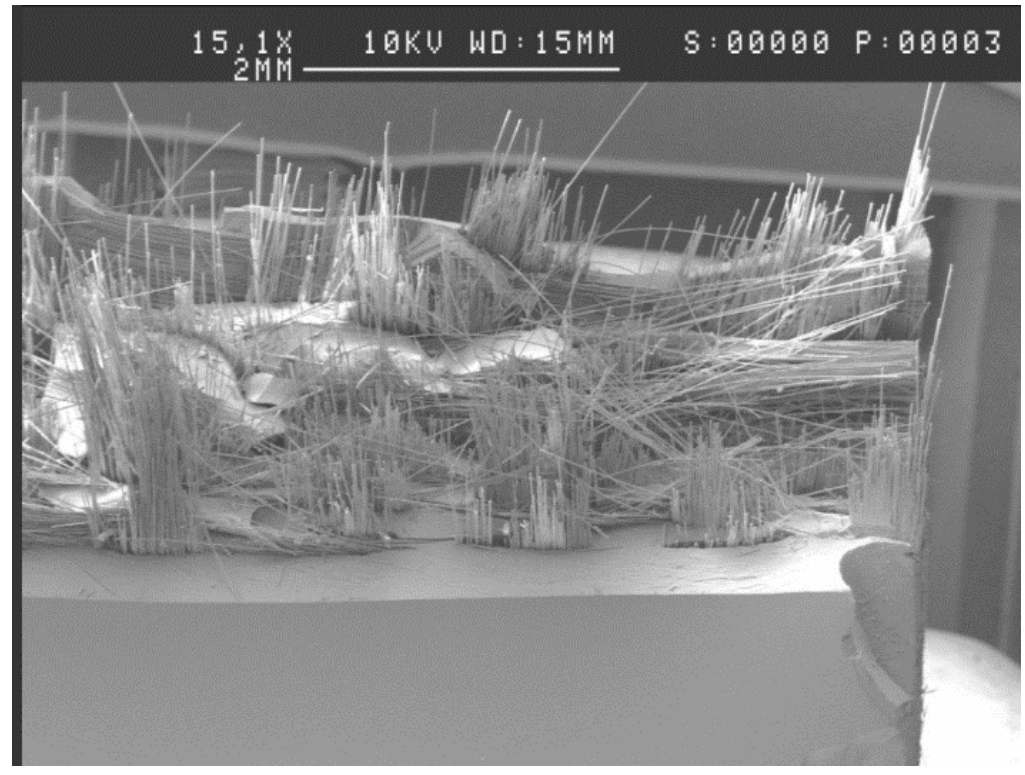

Figure 3.12c. Fracture surface of reinforced composite specimen at $30{ }^{\circ} \mathrm{C}$ 


\subsection{Conclusions}

A glass-like fiber reinforced polyester composite has been manufactured using E-glass fiber as reinforcement and unsaturated polyester as a matrix. The quasi-static tensile behavior was determined under different temperature conditions. A different tensile behavior was noted between reinforced and unreinforced specimens at all temperatures tested; the reinforced specimens exhibit a more uniform brittle trend at temperatures below room temperature and a reasonable portion of ductility at and above room temperature. Tensile properties of the unreinforced material were found to degrade above room temperature. The reinforced composite showed less degradation and better performance under all temperatures and specifically possessed better performance at cryogenic conditions. Different mechanisms of fracture and fracture surface were observed as temperature varies. For temperatures below room temperature both materials show a brittle behavior, though reinforced composites display small ductility potentially due to microcracking. 


\section{References}

1. O. C. Zaske and S. H. Goodman; 1998, "Unsaturated Polyester and Vinyl Ester Resins”, S. H. Goodman; (Ed.); Handbook of Thermoset Plastics; 2nd Ed.; Noyes Publication, Westwood, pp. 97.

2. Naik NK, Venkateswara Rao K, Veerraju C, Ravikumar G. 2010, "Stress-strain behavior of composites under high strain rate compression along thickness direction: Effect of loading condition”. Materials \& Design, 31, pp. 396-401.

3. Ochola RO, Marcus K, Nurick GN, Franz T. 2004, "Mechanical behavior of glass and carbon fiber reinforced composites at varying strain rates”. Composite Structures; 63:455-467.

4. Oguni K, 2001, "Ravichandran G. Dynamic compressive behavior of unidirectional Eglass/vinylester composites”. Journal of Materials Science. 36(4), pp. 831-838.

5. Shokrieh MM, Omidi MJ. 2009, "Compressive response of glass-fiber reinforced polymeric composites to increasing compressive strain rates”. Composite Structures, 89, pp. 517-523.

6. Tarfaoui M, Neme, A., Choukri, S. 2009, "Damage Kinetics of Glass/Epoxy Composite Materials Under Dynamic Compression”. Journal of Composite Materials, 43, pp.1137-1154.

7. Khan AS, Colak OU, Centala P. 2002, "Compressive failure strengths and modes of woven S2-glass reinforced polyester due to quasi-static and dynamic loading". International Journal of Plasticity, 18, pp.1337-1357. 
8. Song B, Chen, W., Weerasooriya, T., 2003, "Quasi-Static and Dynamic Compressive Behaviors of a S-2 Glass/SC15 Composite". Journal of Composite Materials, 37(19), pp. $1723-1743$

9. John J. Lamb, Isabelle Albrecht, Benjamin M. Axilrod. 1949, "Mechanical Properties of Laminated Plastics at $-70^{\circ}, 77^{\circ}$, and $200^{\circ} F^{\prime \prime}$. Journal of Research of the National Bureau of Standards. 42, pp.257-288.

10. R. P. Reed and R. P. Walsh. 1994, "Tensile Properties of Resins at Low Temperatures. Advances in Cryogenic Engineering”, 40, Plenum Press, New York.

11. Morteza Janbaz, 2013, “Mechanical Properties and High-Temperature Performance of a Polyester Resin Modified Using Fgd Gypsum". Masters of Science in Engineering. The University of Wisconsin-Milwaukee.

12. Yunfu Ou, Deju Zhu, Huaian Zhang, Liang Huang, Yiming Yao, Gaosheng Li, Barzin Mobasher. 2016, "Mechanical Characterization of the Tensile Properties of Glass Fiber and Its Reinforced Polymer (GFRP) Composite under Varying Strain Rates and Temperatures" Polymers, 8,(5) pp. 196.

13. Ben Bogner. 2004, "The Influence of Polyester Resin Properties on the Stress Corrosion Resistance of Glass Fiber Reinforced Composites", Polymers and Polymer Composites, 12(6), pp. 457-467

14. Sugiman, M. Hulaifi Gozali, and Paryanto Dwi Setyawan. 2016, “Tensile properties and translaminar fracture toughness of glass fiber reinforced unsaturated polyester resin composites aged in distilled and salt water". AIP Conference Proceedings 1717, 1, pp.4-15 
15. C.Elanchezhian1, B. Vijaya Ramnath, J. Hemalatha. 2014, "Mechanical behavior of glass and carbon fiber reinforced composites at varying strain rates and temperatures". Procedia Materials Science 6, pp. $1405-1418$.

16. Shailesh Verma, Ashutosh Dwedi. 2016, "Analysis of Morphological Behavior of Maize-Husk Filled Polymer Composite", International Journal for Scientific Research \& Development, 4(10), pp. 2321-0613

17. P.J Herrera-Franco, A Valadez-González, 2004, “Mechanical properties of continuous natural fiber-reinforced polymer composites", Composites Part A: Applied Science and Manufacturing, 35(3), pp.339-345 


\section{CHAPTER 4: FATIGUE CRACK GROWTH RATE}

\subsection{Introduction}

One of the many challenges associated with aerospace engineering is material choice for the structures of the craft and other equipment. The combination of harsh environment, large forces at high cycles and the need for lowest possible installed cost mean that the choice of materials is limited [1-3]. The heart of a glass fibre reinforced polymers (GFRP), which are good candidate materials for these applications, is the polymer resin or matrix. The most common polymers used for composite matrices are the polyesters. The polymer is then cured, using a chemical or heat as a catalyst, causing irreversible cross inking of the material. Most of fatigue failure occurs within polymer matrix. Few studies are available related to fatigue crack propagation in these materials at extreme conditions. Broutman and Gagger [5] studied the behavior of a polyester resin (Paraplex P43) subjected to cyclic fatigue stresses. A tension-tension mode at zero stress loading in a fatigue machine was used. Temperature on the surface of specimen was recorded at the time of the test. The researchers concluded that the temperature rise during fatigue process is critical in determining the life of the material. Joneja[6] investigated the influence of polyester toughness on fatigue behavior of glass-fiber reinforced composites. The toughness of the polyester was varied by adding a flexible isophthalic polyester resin as a modifier to a standard polyester resin. The laminates fabricated form this resin was tested at four different tensile stress levels under a load-controlled mode. The results show that at a high fatigue stress, the rate of increase in fatigue life with respect to decrease in fatigue stress is nearly equal for the composites studied. 
Waigaonkar et al. [7] studied the impact of promotor, and glass fiber on gel time and peak exothermic temperature of curing of resin unsaturated polyester resin. It was found that gel time and peak exothermic temperature are affected significantly by glass fibers as reinforcements and methyl ethyl ketone peroxide as a catalyst. Strong interactions are found between the process variables. Kim et al. [8] studies fatigue crack growth rate of acrylonitrile butadiene styrene (ABS) over the temperature range $-50^{\circ} \mathrm{C}$ to $80^{\circ} \mathrm{C}$. They developed an Arrhenius type relationship between fatigue crack growth rate and absolute temperature. They found that the fracture surfaces was rather coarse in the temperature range $\left(-50^{\circ} \mathrm{C}\right.$ to $\left.19^{\circ} \mathrm{C}\right)$, whereas in the high temperature range $\left(30^{\circ} \mathrm{C}\right.$ to $\left.80^{\circ} \mathrm{C}\right)$ it was somewhat smooth due to different modes of crack at the two extremities. Sauer and Richardson [9] had reviewed and discussed the general nature of fracture in polymers, when subject to alternating loads as distinct from static or steadily increasing loads and micromechanics aspects of the fatigue fracture process and concluded that various methods can be utilized to provide significant degrees of enhancement in the fatigue resistance of polymers. The polymer matrix is often used with fiber reinforcement to make polymer composites. The effect of temperature on these composites could be an important aspect of the design and application of the composite. The polymer matrices are initially low viscosity fluids and can penetrate into the centre of the bundles and wet out all the glass fibres[10]. The polymer is then cured, using a chemical or heat as a catalyst, causing irreversible cross inking of the material. Most of fatigue failure occurs within polymer matrix. Few studies are available related to fatigue crack propagation in these materials at extreme conditions. Mandell and Samborsky [11] studied the propagation of a through-thethickness crack in notched specimens loaded in tension-tension fatigue $(\mathrm{R}=0.1, \mathrm{f}=4-7$ 
$\mathrm{Hz}$ ). Laminates were made of polyester resin and glass woven plies lined up with the load direction. The thickness was about $2.5 \mathrm{~mm}$ and the initial notch was cut with a $0.63 \mathrm{~mm}$ thickness diamond saw. The main characteristic underlined was that the crack growth was linked to fibre tow width. Moreover, difficulty was encountered in measuring the crack length because of the stepwise nature of the crack growth and the extensive damage region associated with the crack tip. Most polymer composites are subjected to mechanical loadings and environmental conditions such as temperature, moisture, chemicals, and radiation causes the formation and propagation of microcracks. Polymer composites subjected to synergistic effects of mechanical loading and environmental exposure usually are more susceptible to microcracks formation and propagation [11-16]. Tang et al. [17] studied the effect of temperature on fatigue life of glass fiber/vinyl ester composites from 4-65 ${ }^{\circ} \mathrm{C}$. They found that fatigue life is highest at $4{ }^{\circ} \mathrm{C}$. Based on experimental data, the material constants, constant and exponent of Paris law, were obtained as functions of temperature.

Barring fatigue failure which can be attributed to thermal runaway, crack propagation in polymers can generally be related to the Paris crack propagation law, originally developed to describe metal fatigue crack propagation, which describes the crack growth rate (da) as crack advancement per cycle $(\mathrm{dN})$ :

$$
\frac{d a}{d N}=C(\Delta K)^{m}
$$

Where $C$ and $m$ are material constants and $\Delta K$ is the stress intensity range $\left(K_{\max }-K_{\min }\right)$. 
Nevertheless, "other polymeric solids have shown fatigue crack growth plots which assume a sigmoidal shape; crack growth rates are sometimes found to decrease to vanishingly low values as $\Delta \mathrm{K}$ approaches some limiting threshold value $\Delta \mathrm{K}^{\text {th }}$ and increase to very high values as $\mathrm{K}_{\max }$ approaches $\mathrm{Kc}$ [9].”

$\mathrm{da} / \mathrm{dN}$ versus $\Delta \mathrm{K}$ curve is typically divided into three distinct regions (region I, II and III) as shown in Figure 4.1;

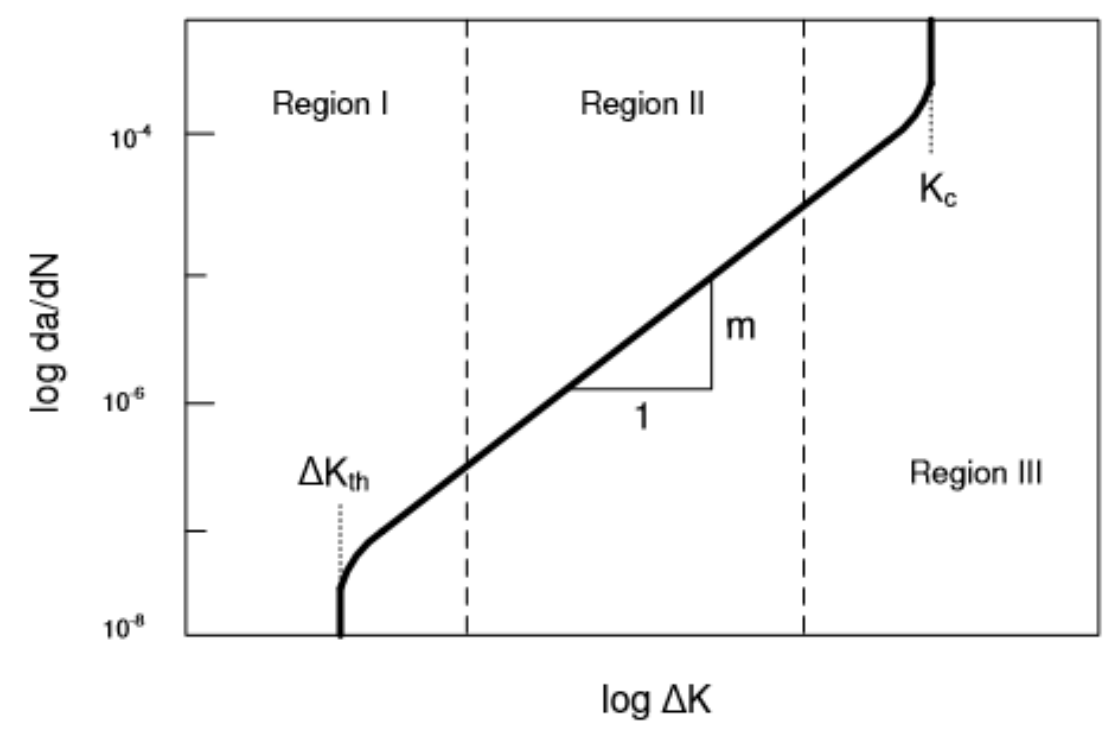

Figure 4.1. Typical da/dN versus $\Delta \mathrm{K}$ curve [10]

Region I represents the nucleation of the fatigue crack. This region is influenced by microscopic features such as grain size, type of bond, applied stress, temperature and environmental conditions. There exists a stress intensity factor range below which fatigue cracks should not propagate. This is known as fatigue crack growth threshold and is represented as $\Delta K_{\text {th. }}$. Region II represents crack propagation zone in which linear elastic fracture mechanics concepts are applicable. In this region crack tip is long compared to mean grain size but much smaller than the actual crack length. Stable crack growth can be seen in this region and the effects of microstructure, mean stress, and ductility are small. 
Region III represents the unstable crack growth just before the fracture. Stress intensity factor approaches fracture toughness Kc of the material. The plastic zone near the crack tip is considerably large and concepts of Linear Elastic Fracture Mechanics (LEFM) are not applicable in this region. Elasto Plastic Fracture Mechanics (EPFM) concepts should be applied for accurately predicting the unstable crack growth and fracture of the material [11]. Thus, determination of fatigue crack growth rate is a very critical component at designing of material for a specific application. In the present study, the fatigue and microstructure properties of a transparent polyester resin at a cryogenic condition $\left(-60{ }^{\circ} \mathrm{C}\right)$ and room temperature were studied at different crack lengths.

\subsection{Experimental work}

\subsubsection{Fabrication of composite material}

A commercially available unsaturated polyester-styrene resin (polymer content $=65 \mathrm{wt} \%$, styrene content $=35 \mathrm{wt} \%$, untreated, Aropol) was used as a curable polymer matrix. The vendor did not supply any information about the chemical composition of the resin as it is proprietary; earlier size exclusion chromatography experiments yielded an average molecular mass of around $1700 \mathrm{~g} / \mathrm{mol}$ of the nonpolymerized resin as delivered. After solidification, the solid polymer was tested for the thermal transition in possessed a $\mathrm{Tg}$ of $73^{\circ} \mathrm{C}$. At this temperature the polymer matrix softens and turns into a ductile polymer. This polymer matrix is a semi-crystalline polymer and under a tensile stress the amorphous chains will become aligned. This is usually evident for transparent and translucent

materials, which become opaque upon turning crystalline. The results of a differential scanning calorimeter (DSC) test show that the curing reaction starts at room temperature and gets completed around $50^{\circ} \mathrm{C}$. This clearly indicates that the unsaturated polyester resins 
have good induction period under this condition and therefore it can be expected that at room temperature the unsaturated polyester resins would have a very long induction period which is needed for better damage resistance. The sample is heated at $20 \mathrm{~K} / \mathrm{min}$ while the sample is cooled slowly $(0.1 \mathrm{~K} / \mathrm{min})$ goes through its $\mathrm{Tg}$ at $73{ }^{\circ} \mathrm{C}$. If it is then heated at 20 $\mathrm{K} / \mathrm{min}$, it does not transform until $73^{\circ} \mathrm{C}$. This means that the sample must absorb more energy to reach the enthalpy of the rubbery state.

All components were mixed together with a hand stirrer until the mixture was clear and transparent. The mixture was set in a vacuum degassing chamber to allow air bubbles inside it to escape by creating vacuum inside the chamber. After degassing, the mixture was poured into a $3.2 \mathrm{~mm}$ deep mold, which was made by placing aluminum frames on top of a polyvinyl chloride (PVC) plate with Mylar sheet. After filling the mold, another PVC plate with Mylar sheet was laid on top of the mold, the top and bottom plates were clamped with C-clamps. The clamped plates were erected sideways to let entrapped air escape from the mold. The setup was left at room temperature $\left(\sim 20 \mathrm{C}^{\circ}\right)$ for two days to ensure complete curing and crosslinking of the polyester matrix. The curing agent used was a cobalt 2ethylhexanoate accelerator (65\% in mineral spirit, Aldrich) initiator system of $0.03 / 2.0$ weight ratio, respectively, which was mixed into the resin first, before the MEKP initiator. The initiator was a solution of MEKP diluted in dibutyl phthalate of 50\% (w/w) MEKP content. This cure system was chosen to allow cure to occur in a reasonable time, in order to allow sheets of resin to be molded before gelation occurs.

\subsubsection{Fatigue test specimen}

The specimens used for this study are the unreinforced polymer matrix samples shaped according to ASTM Standard D647. The polyester sheets prepared in section 2.1 were used 
for this test after shaping. A Compact Tension (CT) specimen geometry (Figure 4.2) was used for this test, it is recommended for homogeneous structure and unidirectional fiber reinforced structures.
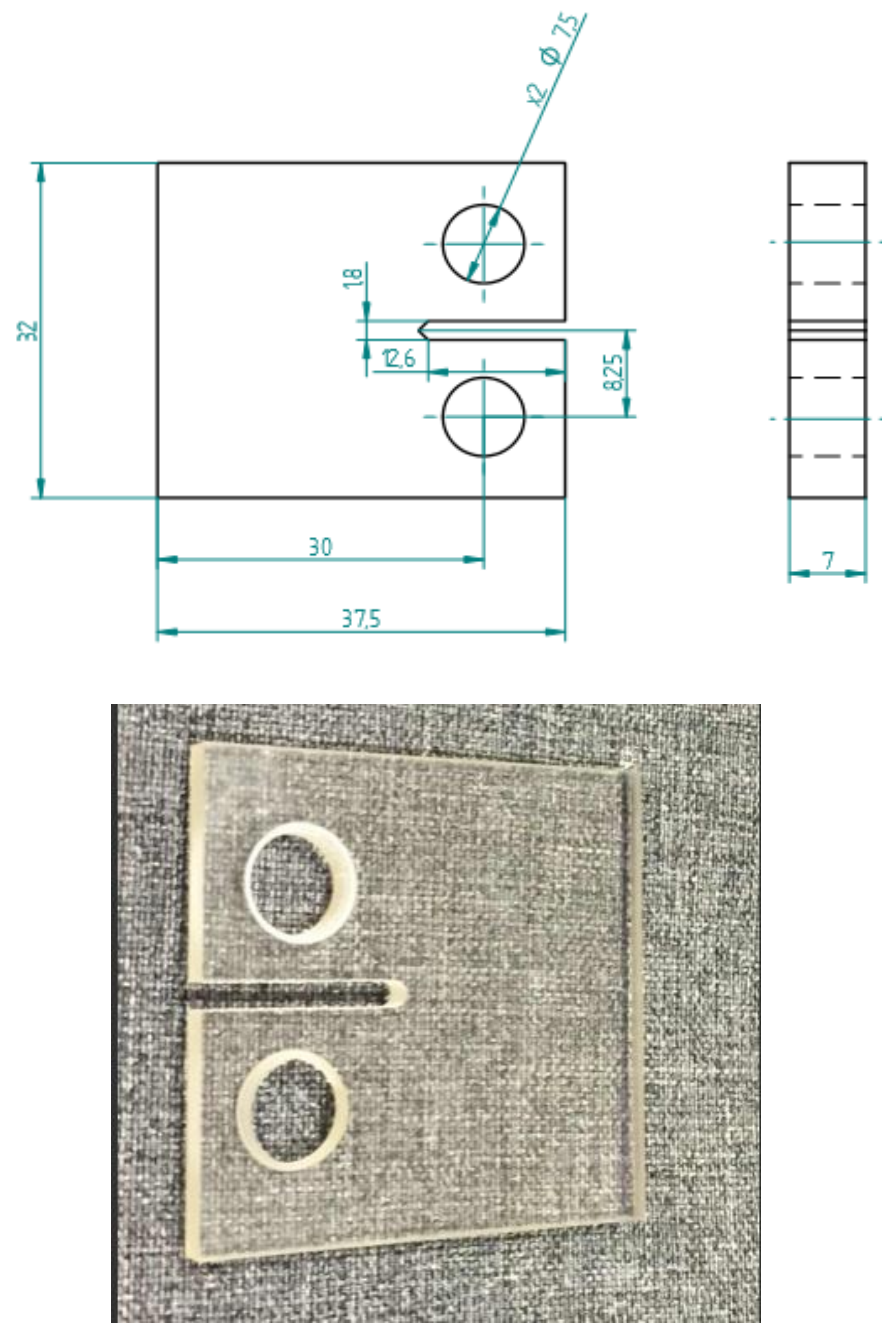

Figure 4.2. CT specimen dimensions and actual test specimen

To characterize the influence of temperature on the crack growth behavior of the unreinforced samples, the specimens were tested at $\mathrm{a} / \mathrm{w}=0.2$ and 0.35 . Additionally, $\mathrm{a}$ razor blade was used to make a notch of $0.5 \mathrm{~mm}$ length into the specimens prior to fatigue test. Figure 4.2 shows the notch in the specimen. 


\subsubsection{Fatigue Test method}

The testing was conducted according to ASTM E647 "Standard Test Methods for Measurement of Fatigue Crack Growth Rates.” A servo hydraulic MTS 810 Material Test System 380200-0 was used for this test (Figure 4.3).

Specimen was tested with an $\mathrm{R}$ ratio of 0.1 , a sinusoidal waveform and a frequency of $2 \mathrm{~Hz}$. Fatigue crack growth was monitored with an optical microscope. The number of cycles $(\mathrm{N})$ for each growth period was recorded. Specimens were cycled until failure occurred. The cyclic stress intensity $(\Delta \mathrm{K})$ and the average crack growth rate $(\mathrm{da} / \mathrm{dn})$ for each specimen were plotted. The cyclic stress intensity $(\Delta K)$ was calculated according to the following equation:

$$
\Delta K=\left(\frac{\Delta P}{B \sqrt{W}}\right) f(a / w)
$$

Where:

$\mathrm{f}(\mathrm{a} / \mathrm{w})$ : is the geometric correction factor for compact tension specimen as shown below.

$$
f\left(\frac{a}{w}\right)=\frac{\left(2+\frac{a}{w}\right)}{\left(1-\frac{a}{w}\right)^{3 / 2}}\left[0.886+4.64 \frac{a}{w}-13.32\left(\frac{a}{w}\right)^{2}+14.72\left(\frac{a}{w}\right)^{3}-5.6\left(\frac{a}{w}\right)^{4}\right]
$$

And $\Delta \mathrm{P}=$ load range [lbs], $\mathrm{B}=$ thickness [in], $\mathrm{W}=$ width [in.]. 

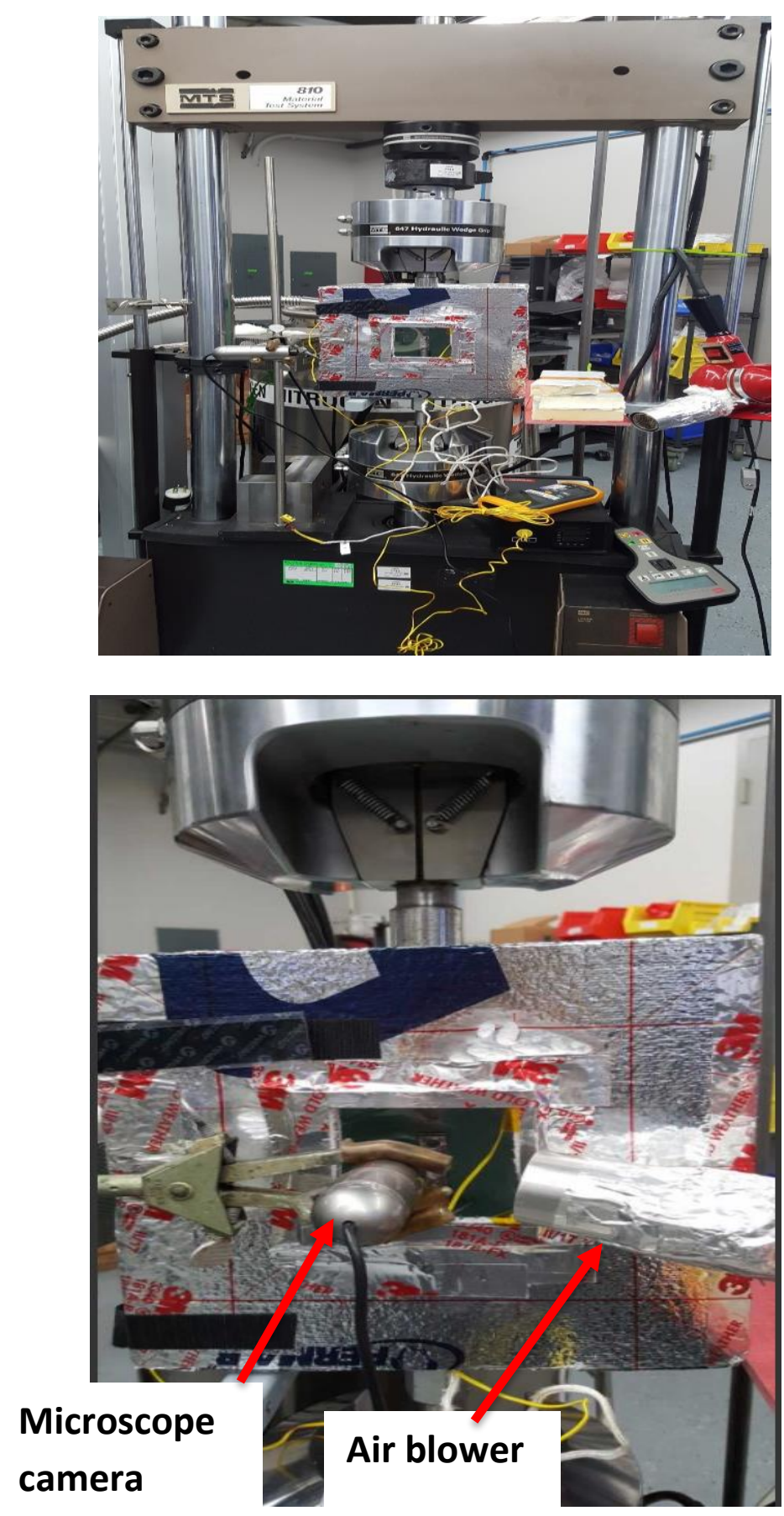

Figure 4.3. View of the MTS servo-hydraulic multipurpose testing system used for fatigue 
at low temperature. Right hand picture is a close-up view of the environment chamber. Linear regression analysis was performed on each resulting curve. The slope and intercept obtained from the linear regression analysis were used to determine the Paris law exponent, $\mathrm{m}$, and the coefficient, C. First, fatigue crack growth rate measurement was conducted at room temperature. The samples were pre-cracked at room temperature and low temperature with a starter razer blade crack followed by fatigue loading to initiate a sharp pre-crack. For operation at the lowest temperatures of $-80^{\circ} \mathrm{C}$ the specimen was very brittle, and no crack initiation and growth were noted up to 40,000 cycles, following which the specimen suddenly fractured into two pieces in a catastrophic manner. This behaviour was reproduced with replicate specimen testing. When the temperature was increased to $-60{ }^{\circ} \mathrm{C}$ a more stable crack growth was observed after 20,000 cycles of loading.

A nitrogen cooling chamber was used to cool the coupon during testing. A radiation thermometer measured $\pm 1{ }^{\circ} \mathrm{C}$ temperature change in surface temperature during the fatigue test. The temperature in the lab which houses the 380200-0 machine varied between $15^{\circ}$ and $19^{\circ} \mathrm{C}$. Five coupons were tested at each of separate a/w levels (Figure 4.4). Approximately twenty coupons of each material were tested over a maximum stress levels at $-60^{\circ} \mathrm{C}$ and room temperature that caused the coupons to fail between 20,000 cycles and 10,000 cycles. 


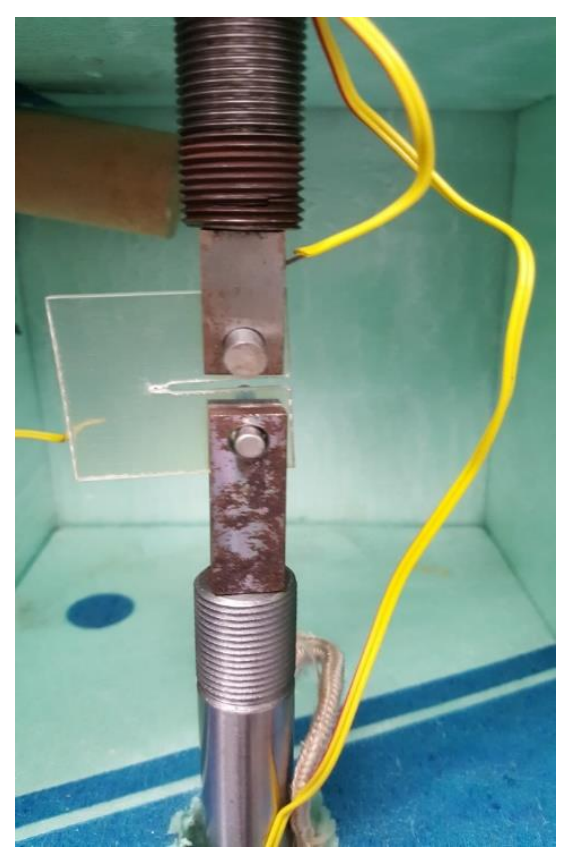

Figure 4.4. Ongoing fatigue crack growth test specimen

\subsection{Results and discussion}

For testing at room temperature, $\mathrm{R}=0.1$ and $\mathrm{a} / \mathrm{w}=0.2$ and 0.35 data were obtained considering only the positive range of $\Delta \sigma$. This polymer resin did not exhibit a sigmoidal variation consisting of the three regimes (near-threshold, intermediate growth rate and high growth rate), typical of ductile solids. Crack depth generated upon applying cyclic load at $\mathrm{R}=0.1$ and $\mathrm{a} / \mathrm{w}=0.2$ is shown in Figure 4.5 . No crack growth was observed up to about 70,000 cycles of loading. 


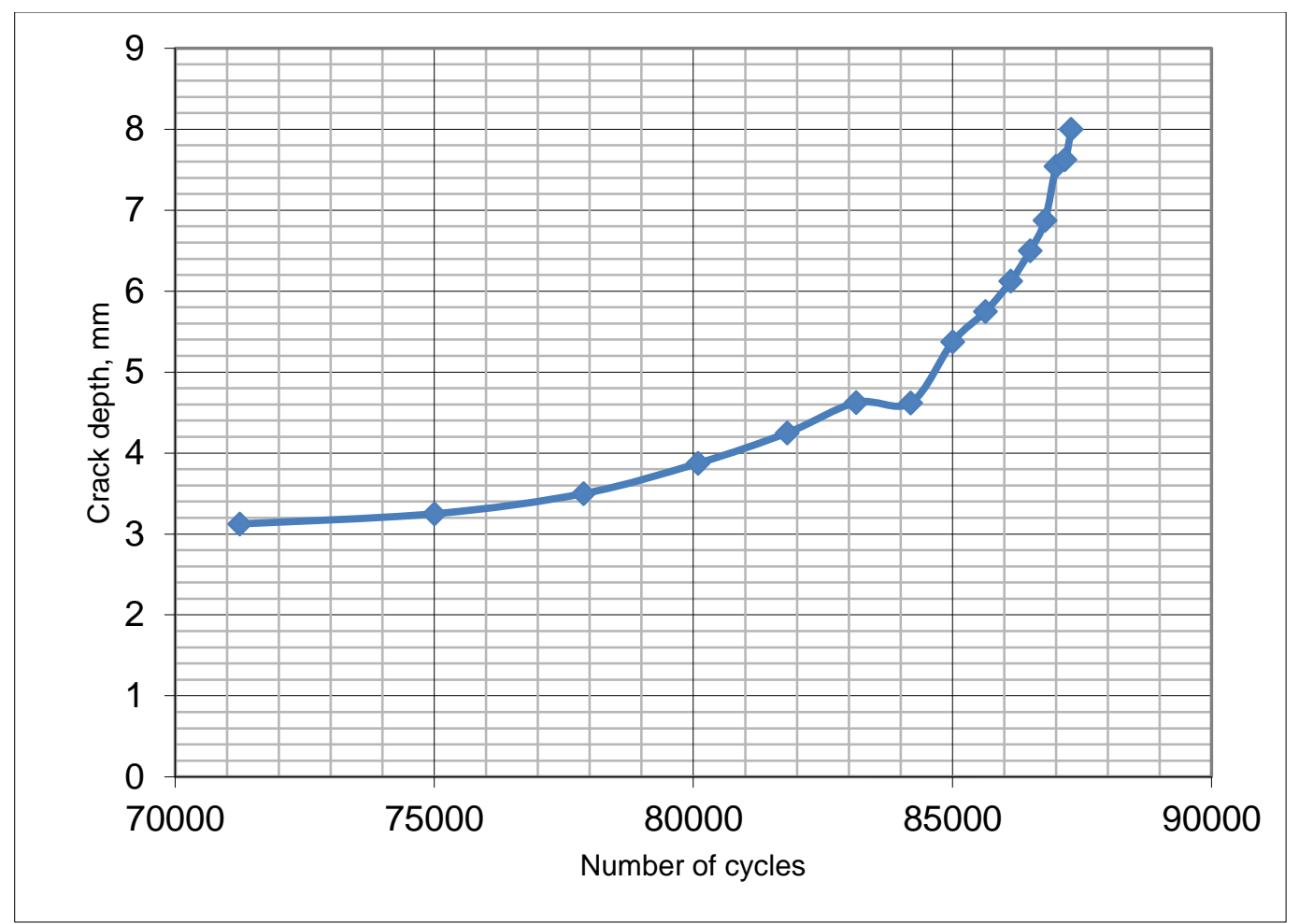

Figure 4.5. Fatigue crack growth test of unreinforced specimen at $\mathrm{a} / \mathrm{w}=0.2$ and room temperature

A gradual increase in crack depth was observed. A crack was first generated at $72 \mathrm{k}$ cycles then increases with applying higher load. However, the specimens failed shortly at $87.3 \mathrm{k}$. Fatigue crack growth rate was predicted by plotting da/dN versus $\Delta \mathrm{K}$ as shown in Figure 4.6. The Paris law was fitted to these data by regression, $\mathrm{m}$ and $\mathrm{C}$ being presented in Table 4.1. 


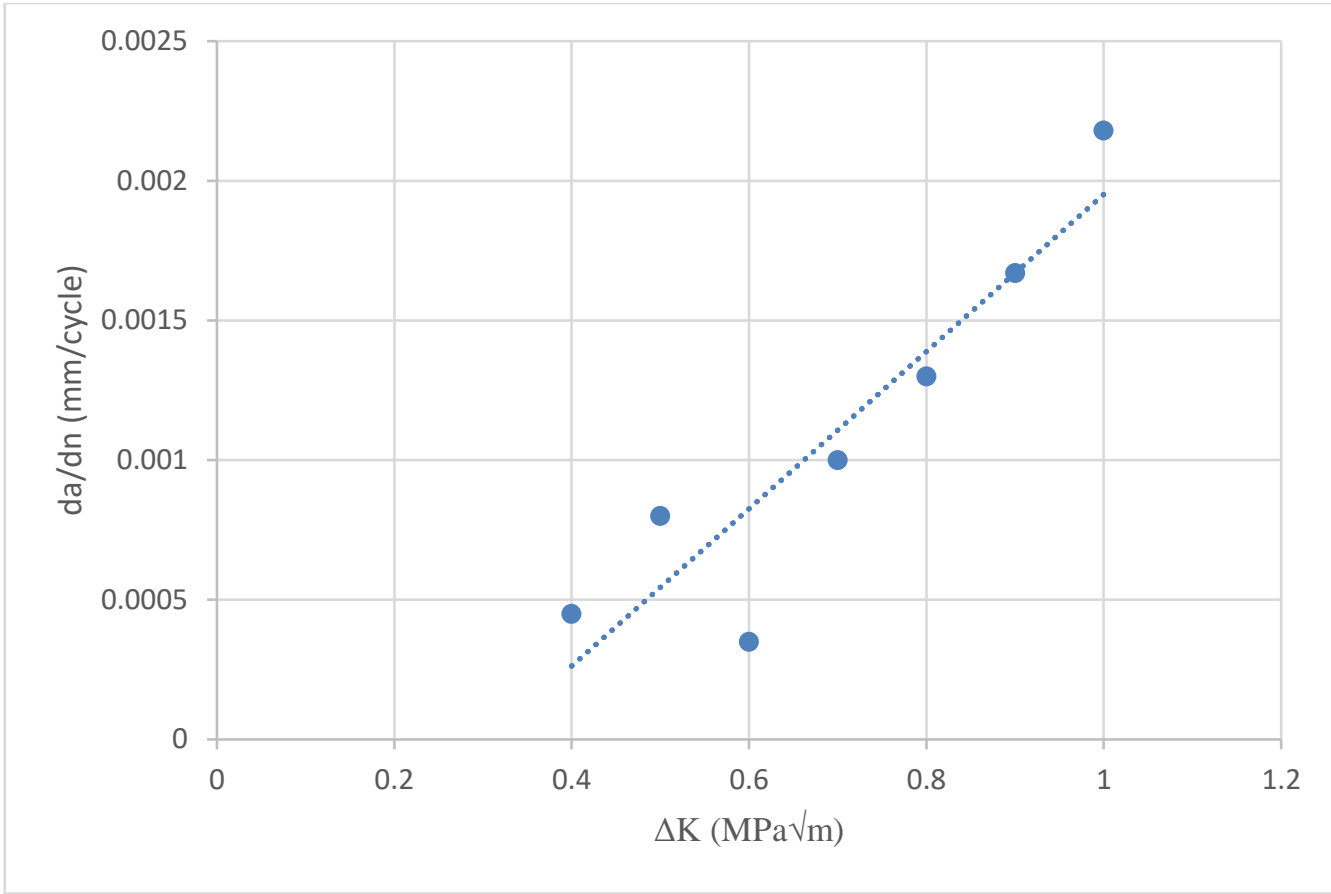

Figure 4.6. The relationship between $\log (\mathrm{da} / \mathrm{dN})$ and $\log (\Delta \mathrm{K})$ of unreinforced specimen at $\mathrm{a} / \mathrm{w}=0.2$ and room temperature

Table 4.1. Fatigue crack growth parameters per ASTM E647 at room temperature

\begin{tabular}{|c|c|c|c|}
\hline \multirow{2}{*}{ Specimen ID } & $\begin{array}{c}\Delta P \text { low level } / \triangle P \\
\text { high level }\end{array}$ & Exponent $(\mathrm{m})$ & Coefficient, C \\
\hline $\mathrm{a} / \mathrm{W}=0.2$ & $1 \mathrm{lbs} / 11 \mathrm{lbs}$ & 5.72 & $2.01 \mathrm{E}-02$ \\
\hline $\mathrm{a} / \mathrm{W}=0.35$ & $1 \mathrm{lbs} / 11 \mathrm{lbs}$ & 4.83 & $1.84 \mathrm{E}-02$ \\
& & & \\
\hline
\end{tabular}


The same trend was obtained for $\mathrm{a} / \mathrm{w}=0.35$ with higher rate of crack growth as shown in Figures 4.7 and 4.8 and Table 4.1 .

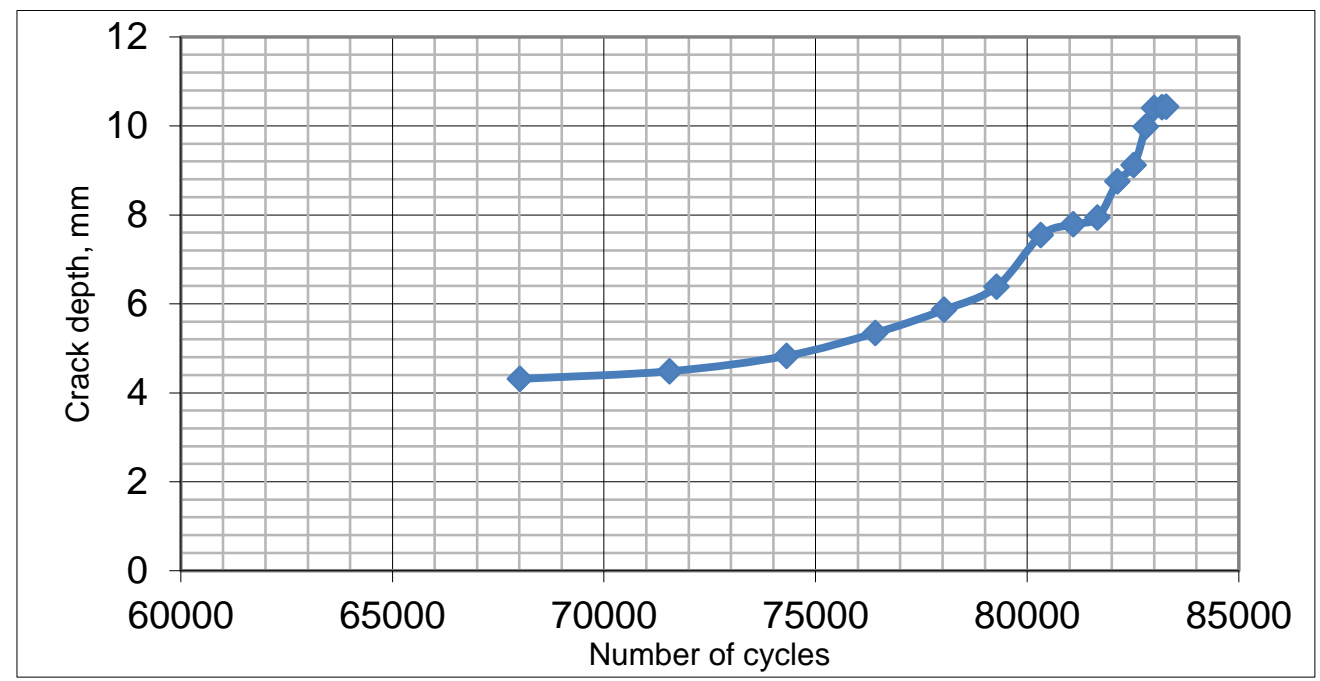

Figure 4.7. Fatigue crack growth test of unreinforced specimen at $\mathrm{a} / \mathrm{w}=0.35$ and room temperature

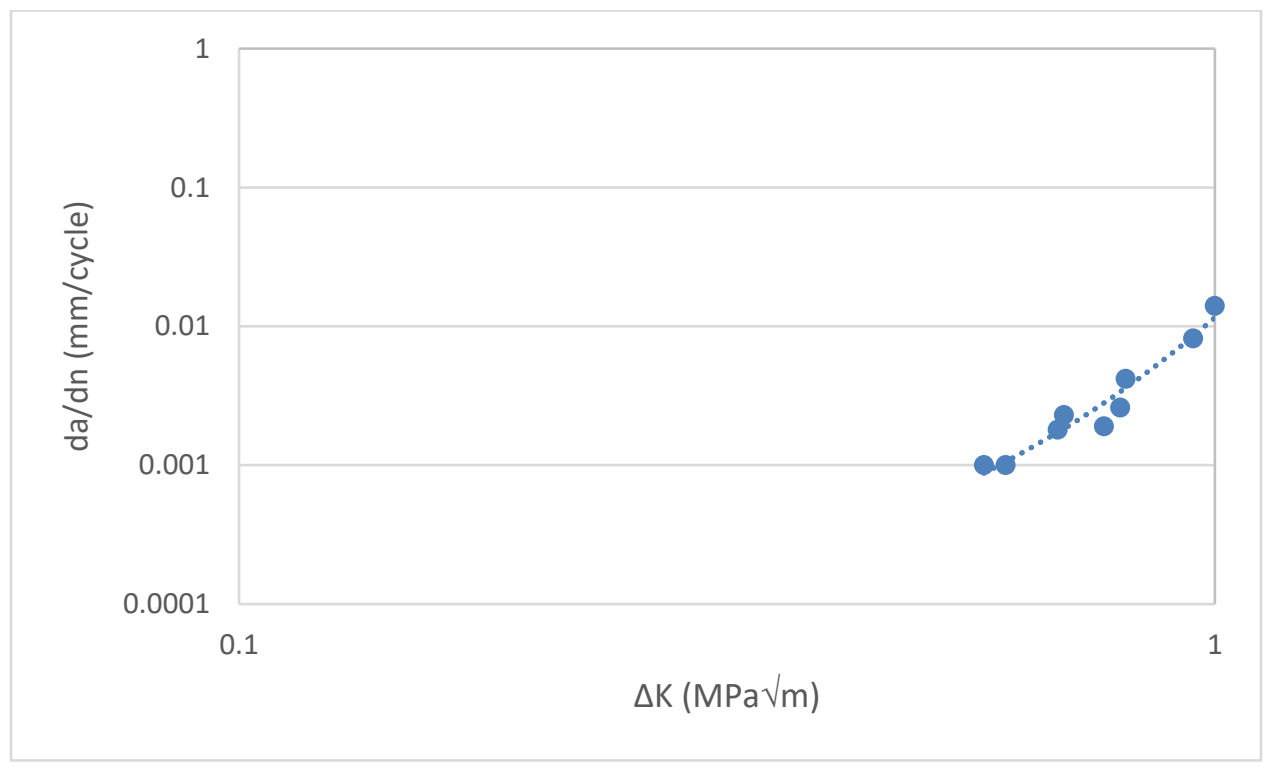

Figure 4.8. The relationship between $\log (\mathrm{da} / \mathrm{dN})$ and $\log (\Delta \mathrm{K})$ of unreinforced specimen at $\mathrm{a} / \mathrm{w}=0.35$ and room temperature 
Figure 4.9 shows the strain-life fatigue test results for the unreinforced unsaturated polyester resin at $\mathrm{a} / \mathrm{w}=0.2$ at $-60^{\circ} \mathrm{C}$. Based on the mean stress diagram procedure described above certainly the polymer resin specimens are experiencing a progressive fatigue damaged (crack length increases linearly between 60000-74620 cycles) before final failure as can be seen in Figure 4.9. The semi straight curve produced here is due to the fact that the specimen of unreinforced polyester resin became brittle at the low-test temperature of $-60^{\circ} \mathrm{C}$ and number of cracks generated are very low. Moreover, the propagation of these cracks is very slow because of the shrinkage of polymer matrix caused by extreme cooling. This was proved by the difficulty of measure the crack growth at the time of testing where some of the specimens fractured without crack growth at about $40 \mathrm{~K}$ cycles. According to Figure 4.9, the crack started growing at $20 \mathrm{k}$ cycle. As the number of cycles was increased, a steeper growing is observed. Scatter is clearly seen at $20 \mathrm{k}$ which is an issue with conducting the test at cryogenic conditions and for the main limiting factor on the crack growth rate data achieved in these results.

As per Equation 1, crack growth rates were calculated from the acquired crack progression data using the incremental polynomial method with a half window length of five points. Representative crack growth rate curves are shown in Figure 4.10. The curve of Figure 4.10 was fitted to obtain the corresponding power law. The identified fatigue strain-life power-law (Paris law) constants for the polymer material are given in Table 4.2, at $R=0.1$ and $-60^{\circ} \mathrm{C}$. 


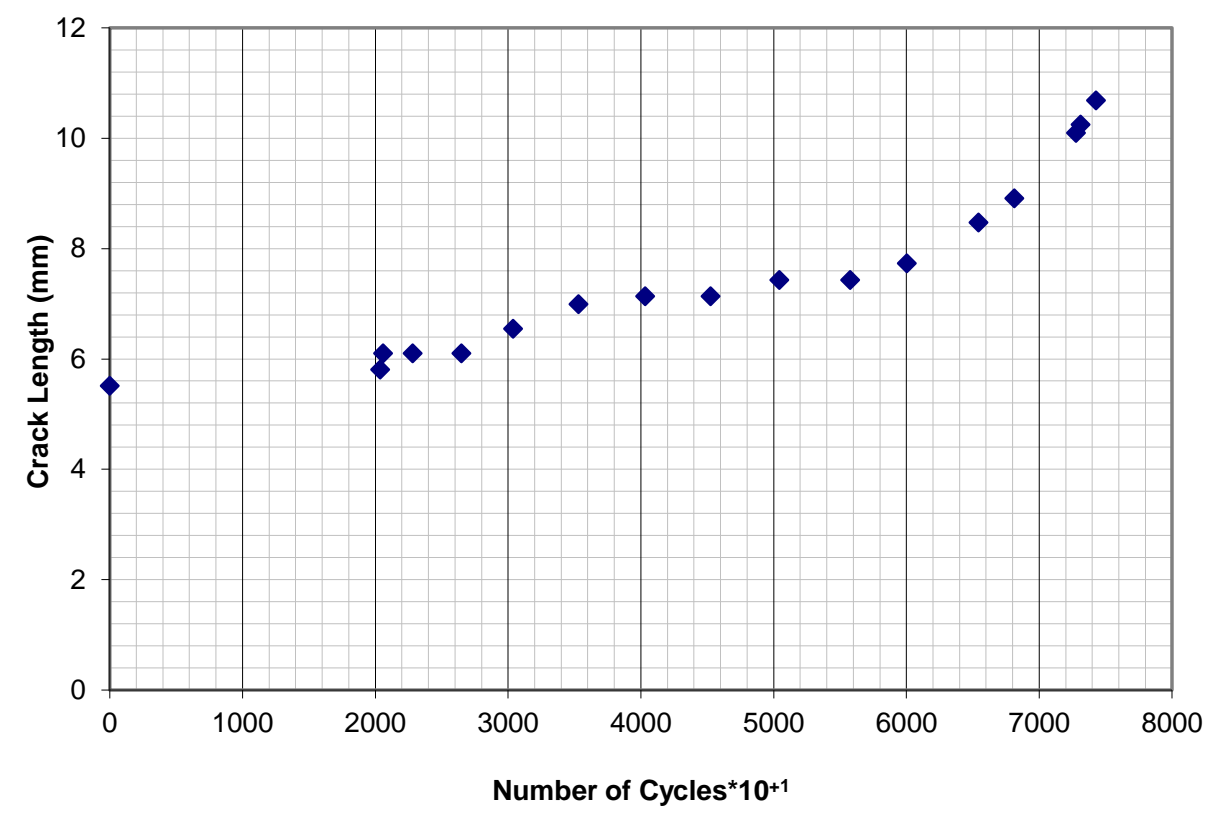

Figure 4.9. Fatigue crack growth test of un-reinforced specimen at $\mathrm{a} / \mathrm{w}=0.2$ and $-60^{\circ} \mathrm{C}$

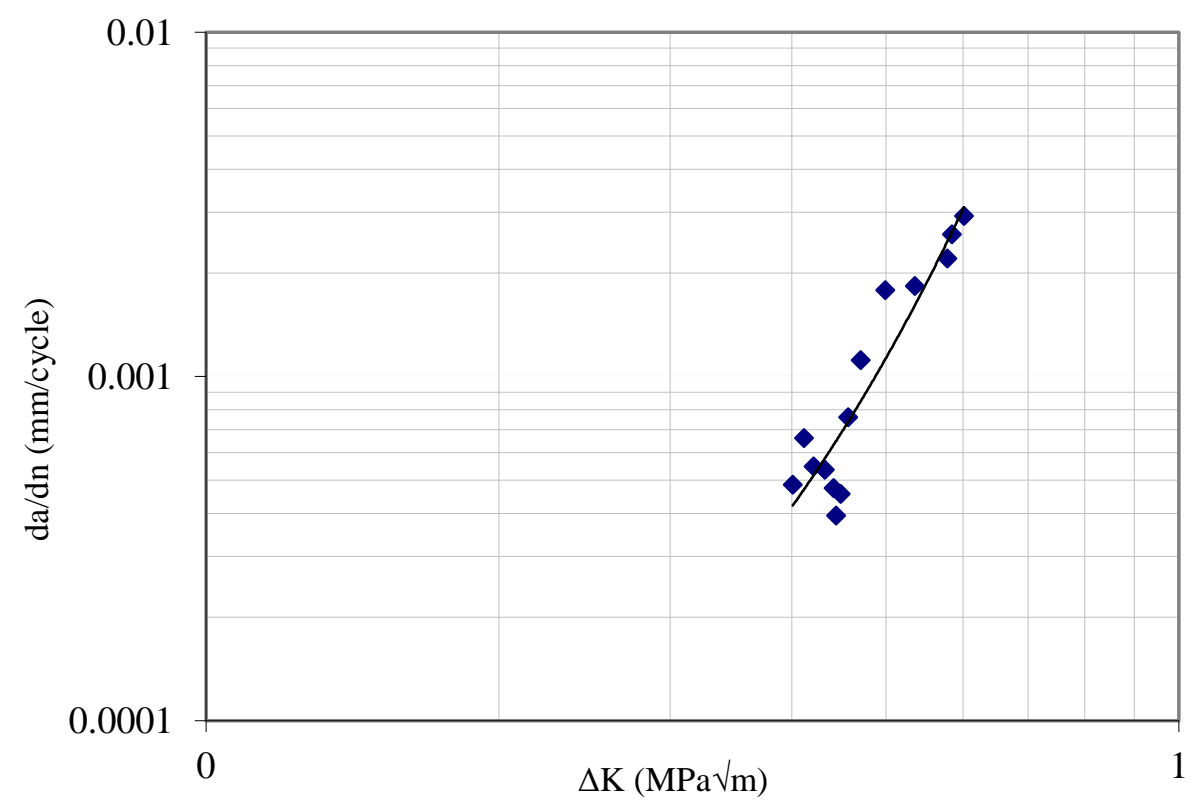

Figure 4.10 The relationship between $\log (\mathrm{da} / \mathrm{dN})$ and $\log (\Delta \mathrm{K})$ of unreinforced specimen at $\mathrm{a} / \mathrm{w}=0.2$ and $-60^{\circ} \mathrm{C}$ 
Table 4.2. Fatigue crack growth parameters per ASTM E647 at $-60^{\circ} \mathrm{C}$

\begin{tabular}{|c|c|c|c|}
\hline Specimen ID & $\begin{array}{c}\Delta P \text { low level } \\
/ \Delta P \text { high level }\end{array}$ & $\begin{array}{c}\text { Exponent } \\
(\mathrm{m})\end{array}$ & $\begin{array}{c}\text { Coefficient } \\
(\mathrm{C})\end{array}$ \\
\hline $\mathrm{a} / \mathrm{W}=0.2$ & $1 \mathrm{lbs} / 11 \mathrm{lbs}$ & 8.13 & $1.93 \mathrm{E}-02$ \\
\hline
\end{tabular}

The analysis of the data obtained at the environmental conditioned test shows that a unique relationship exists between $\log (\mathrm{da} / \mathrm{dN})$ and $\log (\Delta \mathrm{K})$ for the test at $-60^{\circ} \mathrm{C}$. Overall, the curve matches the typical representation of Paris law assumption (see Figure 4.1) which is almost has a steeper slope. Thus, a good fitting of this curve to a straight line was obtained with $\mathrm{R}^{2}=0.9269$. The results also show fairly good stable fatigue crack growth was achieved in the polyester specimen subjected to mode I fatigue loading. The fatigue crack growth rates $(\mathrm{da} / \mathrm{dN})$ from each specimen are shown in terms of stress intensity range $(\Delta \mathrm{K})$ in Figure 4.10, and for comparison, the results are in good agreement with the constants obtained by previous studies [18] who showed that operating at low temperatures influenced the values of Paris law constant. With this in mind, one can observe that values of $\mathrm{m}$ and $\mathrm{C}$ obtained at low temperatures (Table 4.2) are higher than those obtained at room temperature (Table 4.1). It is difficult to identify a definite trend of the temperature effect because of the very few literatures available for standardizing and comparison of results. However, it can be fairly determined that reducing the temperature appears to decrease the fatigue crack growth resistance, as described for most of the tough polymers including unreinforced polymer resins [19-20]. 
The crack length created versus number of cycles applied for the examined R-ratio $=0.1$ and $\mathrm{a} / \mathrm{w}=0.35$ and $-60^{\circ} \mathrm{C}$ is shown in Figure 4.11 . The results of growing of crack length as load increases prove that the relationship between number of cycles and crack length is highly dependent on the a/w ratio. Regardless of the operating temperature, steeper curve approaches low fatigue thresholds correspond to larger a/w ratio. For the impact of temperature, a smaller number of cycles need for the specimen of unsaturated polyester resin was need to fracture the specimen as temperature went down from room temperature to $-60^{\circ} \mathrm{C}$ at $\mathrm{a} / \mathrm{w}=0.35$. The same finding can be obtained from Figure 4.12 of Paris law curve. A steeper behavior is observed compared to Figure 4.10. Although cycles to failure were lower, reign I mode is more obvious in $\mathrm{a} / \mathrm{w}=0.35$ which indicates that the specimen has more time to grow the crack before failure. However, Figure 4.12 indicates that operating at cryogenic temperature $\left(-60^{\circ} \mathrm{C}\right)$ and at higher $\mathrm{a} / \mathrm{w}=0.35$ resulted in decreasing the resistance of the fabricated specimen as proved by Paris law exponent and constant shown in Table 4.3. 


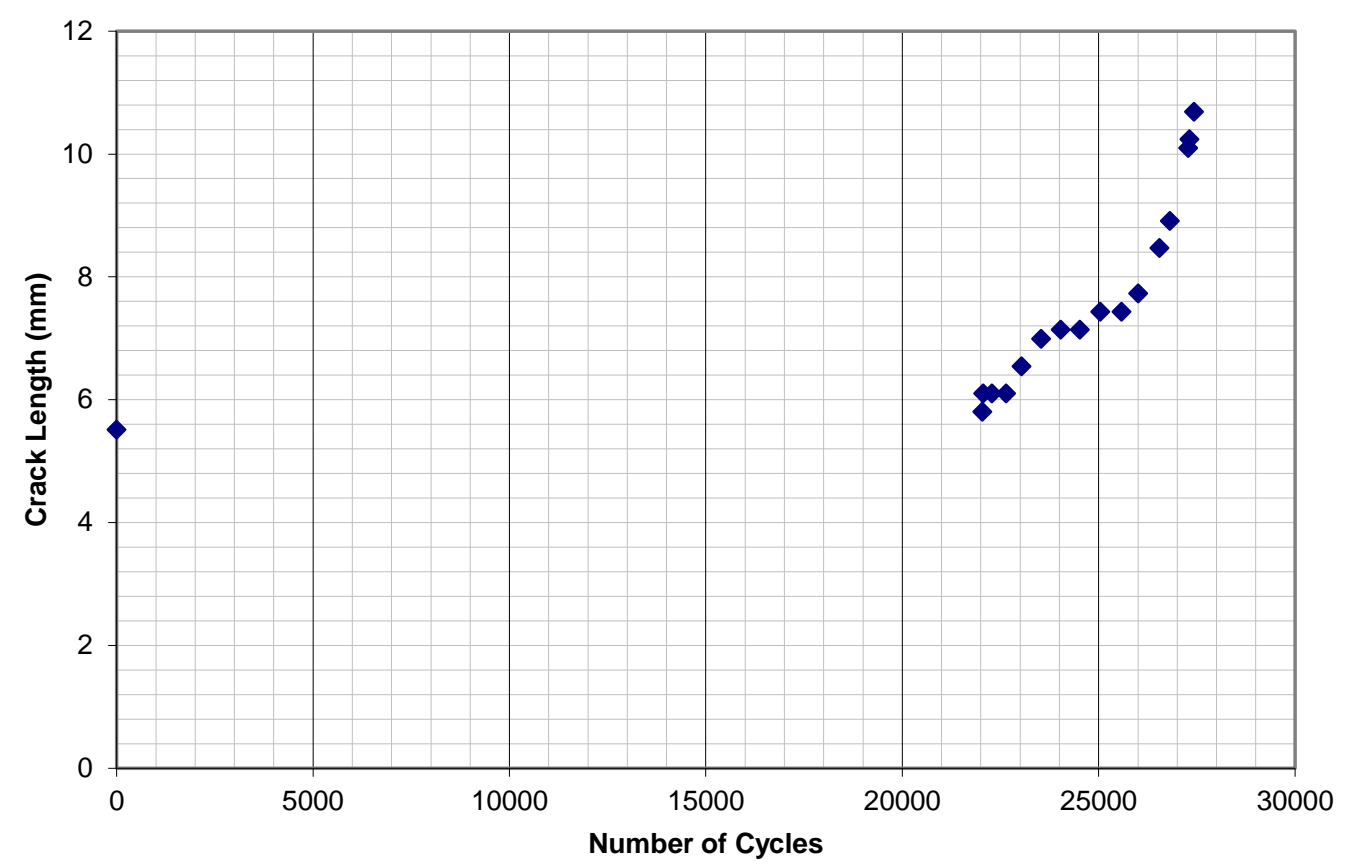

Figure 4.11. Fatigue crack growth test of unreinforced specimen at $\mathrm{a} / \mathrm{w}=0.35$ and $-60^{\circ} \mathrm{C}$.

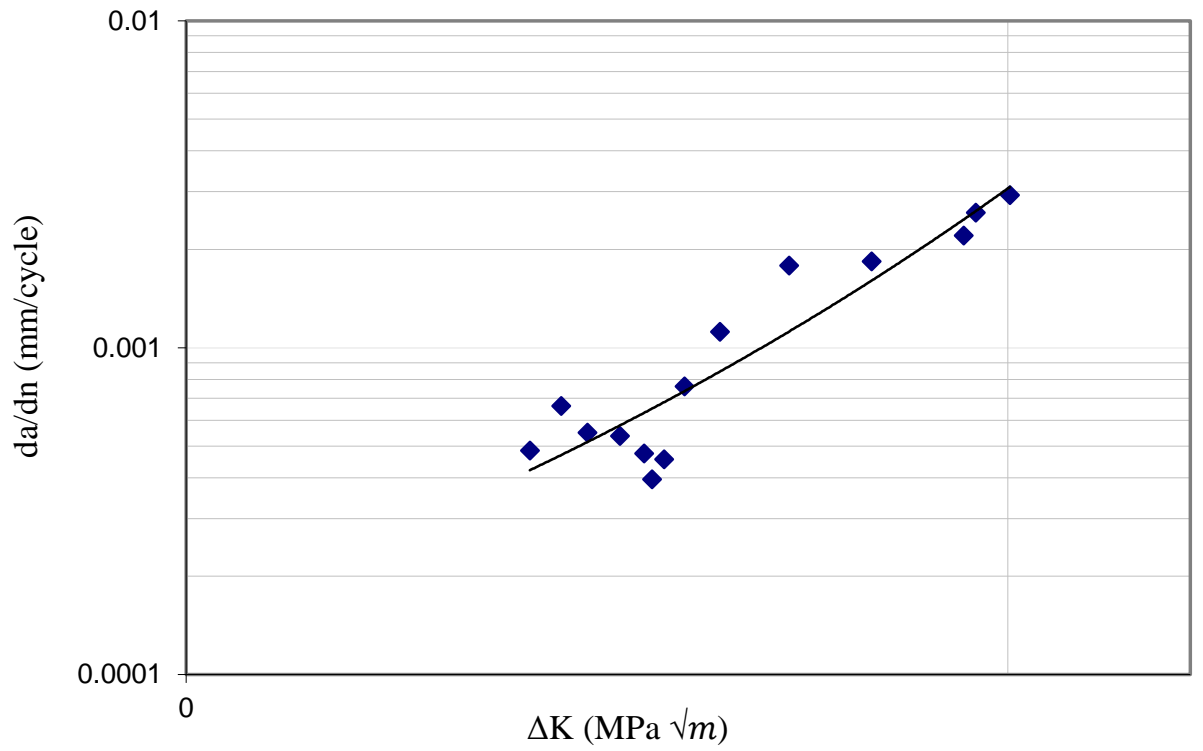

Figure 4.12. Fatigue Crack Growth Curves of un-reinforced $\mathrm{a} / \mathrm{W}=0.35$ and $-60^{\circ} \mathrm{C}$ 
Table 4.3. Fatigue Crack Growth Parameters per ASTM E647 at $-60^{\circ} \mathrm{C}$

\begin{tabular}{|c|c|c|c|}
\hline Specimen ID & $\begin{array}{c}\Delta \text { Plow level } \\
/ \Delta P \text { high level }\end{array}$ & $\begin{array}{c}\text { Exponent } \\
(m)\end{array}$ & Coefficient \\
\hline $\mathrm{a} / \mathrm{W}=0.35$ & $1 \mathrm{lbs} / 11 \mathrm{lbs}$ & 7.64 & $3.67 \mathrm{E}-02$ \\
\hline
\end{tabular}

\subsection{Conclusions}

The established formulations of Paris law for polyester resin manufactured in this study is based on the commonly used total fatigue life concept. The derivation of the new model is phenomenological, relying onto the existing experimental data under different $\mathrm{a} / \mathrm{w}$ ratios in order to estimate the necessary model parameters as functions of the $\mathrm{a} / \mathrm{w}$ ratio at low temperature. Thus, this work focused on determination of Paris law constants at low temperature and different a/w-ratio for a transparent polyester resin. As temperature decreases to $-60^{\circ} \mathrm{C}$, the fatigue crack growth resistance decreases due to extensive microcracks generated as the material becomes more brittle at cryogenic conditions. 


\section{References}

1. R.J. Sharmila, S. Premkumar, M. Alagar, Toughened polyester matrices for advanced composites, J. Appl. Polym. Sci. 103 (2007) 167-177.

2. D.H. Builes, H. Hernandez, A. Tercjak, Relationship between the morphology of nanostructured unsaturated polyesters modified with PEO-b-PPO-b-PEO triblock copolymer and their optical and mechanical properties, J. Phys. Chem. 117 (2013) $3563 \mathrm{e} 3571$.

3. Wei Han, Sheng Chen, Jonathan Campbell, Xiaojun Zhang, Youhong Tang. Fracture toughness and wear properties of nanosilica/epoxy composites under marine environment. Materials Chemistry and Physics 177 (2016) 147-155.

4. Siyao He, Nicholas D. Petkovich, Kunwei Liu, Yuqiang Qian, Christopher W. Macosko, Andreas Stein. Unsaturated polyester resin toughening with very low loadings of GO derivatives. Polymer 110 (2017) 149-157

5. Lawrence J. Broutman \& Satish K. Gaggar (1972) Fatigue Behavior of Epoxy and Polyester Resins, International Journal of Polymeric Materials and Polymeric Biomaterials, Vol 1, Issue 4, p295-316

6. Surendra K. Joneja (October 1987) Matrix Contribution to Fatigue Behavior of Glass Reinforced Polyester Composites, Journal of Reinforced Plastics and Composites, Volume: 6 issue: 4, p343-356

7. Sachin Waigaonkar, Bhaskara Jagadish, Chandra Babu, Amit Rajput, 2011, Curing Studies of Unsaturated Polyester Resin Used in Fiber Reinforced Plastic Products, Indian Journal of Engineering and Materials Science, 18, p31-39. 
8. H. S. Kim, X. M. Wang, N. A. H. Nik Abdullah (1994), Effect Of Temperature On Fatigue Crack Growth In The Polymer Abs, Fatigue \& Fracture Of Engineering Materials \& Structures Volume 17, Issue 3, National Institute Of Standards And Technology.

9. J. A. Sauer, G. C. Richardson (December 1980), Fatigue of Polymers, International Journal of Fracture, V16(6), p499-532.

10. Mandell, J.F., Samborsky, D.D., "DOE/MSU Composite Material Fatigue Database: Test Methods, Materials, and Analysis," Sandia National Laboratories Contractor Report, SAND 97-3002 (1997).

11. Ali, A., Rassiah, K., Othman, F., Lee, H. P., Tay, T. E., Hazin, M. S., and Megat Ahmad, M. M. H. (2016)."Fatigue and fracture properties of laminated bamboo strips from Gigantochloa scortechinii polyester composites," BioRes. 11(4), 91429153.

12. Wang, X.W., Takao, Y., Yuan, F.G., Potter, B.D., Pater, R.H., “The Interlaminar Mode I Fracture of IM7/LaRC-RP46 Composites at High Temperatures,’ Journal of Composite Materials, Vol.32, No. 16, 1998, pp. 1508-1525.

13. Sloan, E.F., Seymour, J.R., "The Effect of Seawater Exposure on Mode I Interlaminar Fracture and Crack Growth in Graphite / Epoxy," Journal of Composite Materials, Vol.26, No. 18, 1992, pp. 2655-2671. 
14. Sloan, E.F., Seymour, J.R., "The Effect of Seawater Exposure on Mode I Interlaminar Fracture and Crack Growth in Graphite / Epoxy," Journal of Composite Materials, Vol.26, No. 18, 1992, pp. 2655-2671.

15. Russell, A.J., Street, K.N., "Moisture and Temperature Effects on the Mixed-Mode Delamination Fracture of Unidirectional Graphite/Epoxy," Delamination and Debonding of Materials, ASTM STP 876, 1985, pp. 349-368.

16. Mei. Li. Temperature and moisture effects on composite materials for wind turbine blades. Thesis (M.S.) --Montana State University--Bozeman, 2000.

17. Hai C. Tang, Tinh Nguyen, Tze J. Chuang, Joannie W. Chin, Hanchang F. Wu, J Lesko (July 2000) Temperature Effects on Fatigue of Polymer Composites, Composites Engineering, Volume: 7, pp.861.

18. POLYMER, 1993, Volume 34, Number 20

19. Pearson, R. A. and Yee, A. F. in 'Tough Composite Materials', NASA Langley Research Center, Virginia, Noyes Publications, New Jersey, 1985, pp. 157-177

20. Hertzberg, R. A. and Manson, J. A. 'Fatigue of Engineering Plastics', Academic Press, New York, 198 


\section{CHAPTER 5: PUNCTURE RESISTANCE}

\subsection{Introduction}

In addition to their excellent quasi-static properties such as high specific stiffness and strength, fracture toughness and impact resistance of fiber reinforced thermoplastic composites are among the most important properties of polymers and their modified systems $[1,2]$. The impact capabilities and other properties of most composites has been studied and investigated extensively in recent years and many technical articles, books, and reviews about impact on composites, are available. Main goal in optimizing these materials for use in ballistic applications is to understand their characteristic properties and to evaluate their energy dissipating ballistic damage mechanisms [3]. One of them, quasistatic penetration resistance of a composite structure represents the energy dissipating capacity of the structure under transverse loading without dynamic and rate effects. Erkendirci and Gama $[4,5]$ studied quasi-static penetration resistance of glass and Carbon fiber reinforced composites. They reported dissipated energy capacity of these composite laminates. Gama et al. [6,7] investigated the punch shear behavior of thick-section composites under quasi-static, low velocity, and ballistic impact loading and identified the energy dissipating damage mechanisms during quasi-static punch shear of thick-section composites. Aslan et al. [8] studied experimentally the behavior of E-glass/epoxy laminate under low energy impact using different masses of indenter and the indentation in laminate was discussed. It was concluded that the delamination in the target plate increased with the span size of plate. The effect of diameter of indenter on delamination in the target plate was studied by Icten et al. [9] and it was concluded that the induced damage in the target was more in case of impact by bigger indenter. 
Wen [10] investigated the influence of projectile nose shape on penetration and perforation of fiber reinforced plastic composite laminates by varying impact velocities. Theoretical equations were derived for perforation tests in terms of penetration depth and ballistic limits. It was shown that theoretical and experimental predictions were in good agreements in terms of penetration depth and ballistic limits. Bandaru et al. [11] investigated the effect of hybridization on the ballistic performance of hybrid composite reinforced with various combinations and stacking sequences of Kevlar, glass and carbon fibers. It was found that stacking sequence of the fibers showed the major factor for ballistic performance. For example, it is revealed the good ballistic performance in the case of Kevlar fiber at rear side, glass fiber in the exterior side and carbon fiber at front side. Several studies have shown that these materials are sensitive to moisture and heat [12]. Findings obtained by investigators [13-19] describe the mechanical behavior of reinforced composite under quasi static or dynamic loading at room temperature while references [20-26] describe the mechanical behavior of a fiber reinforced composite under quasi static or dynamic loading as a function of temperature from high to low temperature. Ou et al [23] reported that there is an obvious dependence of the temperature on the mechanical properties of glass fiber reinforced polymer (GFRP). They reported that for GFRP, the tensile strength linearly decreases nearly $31.1 \%$ when temperature increases from room temperature to $75^{\circ} \mathrm{C}$. However tensile strength showed almost no change (within 3\%) when temperature increased from -25 to $50^{\circ} \mathrm{C}$. Elanchezhia et al [26] determined the mechanical properties of GFRP at different strain rates and temperatures. For a temperature range $35-70{ }^{\circ} \mathrm{C}$ they found a negligible change at a constant strain rate (8\%). Lamb et al [20] reported a increase of $30 \%$ in the tensile properties of a laminate made of unsaturated polyester reinforced with 
glass fabric at $-70^{\circ} \mathrm{F}$ over that at room temperature. The impact strength based on the Izod test increased by $45 \%$ at $-70^{\circ} \mathrm{F}$ over the room temperature most of the studies focused on damage modes and strain rate sensitive nature of these opaque polymer matrix composites at room and extreme temperatures. In 2010, Koerner and Koerner [27] have discussed the puncture resistance of polyester and polypropylene nonwoven geotextiles and found that there is a significant impact strength of temperature in reducing the puncture resistance. With all these research works in mind, investigation of puncture resistance at extreme conditions of unsaturated polyester composite is lacking. The present study focuses on examining the impact of exposure to extreme conditions (high and very low temperatures and moisture) on puncture behavior of transparent unsaturated polyester matrix and composite to obtain the optimum conditions under which these materials would be utilized for engineering applications.

\subsection{Experimental work}

\subsubsection{Background}

Drop weight impact testing is another type of low velocity testing, and it is the most common test for composite materials. Drop weight impact tests are done to test the impact behavior on composite plates, which most closely resemble impact damage in the field. When using a drop weight impact tester, two categories of damage can occur. The first is clearly visible impact damage (CVID), which can easily be seen by the naked eye. The second type of damage is barely visible impact damage (BVID), which can seldom be seen by the naked eye. 
In drop weight impact testing, a mass is raised to a known height and released, impacting the specimen. The choice can be made between either an instrumented or noninstrumented test machine. A figure displaying how an instrumented impact machine works is shown below.

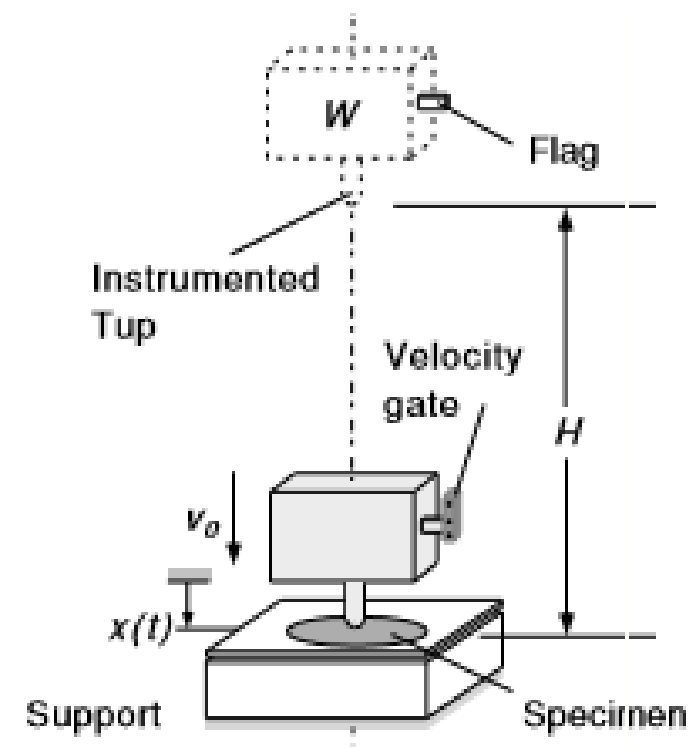

Figure 5.1 Example of the operation of a drop weight impact test machine

In Figure 5.1, $\mathrm{x}(\mathrm{t})$ is the coordinate system, $\mathrm{H}$ is the initial drop height, $\mathrm{W}$ is the impact weight, and $v_{\mathrm{o}}$ is the impact velocity. The tip is a hemispherical impactor that measures the strain during impact [28].

In order to characterize composites during impact, theory has been developed by Jang, Huang, Hsieh, Kowbel, and Jang [29]. This theory consists of treating the specimen like a beam in bending. In this treatment, the plate is clamped along two sides only. This theory is different from a more classic approach in which the plate is constrained on all sides. In order to begin, Newton's second law is used and the solution for acceleration, a(t), is given as 


$$
a(t)=g-\frac{P(t)}{M}
$$

where $g$ is the gravitational acceleration constant, $\mathrm{P}(\mathrm{t})$ is the load with respect to time, and $\mathrm{M}$ is the mass of the impactor. $\mathrm{t}=0$ at the time when impact has just begun, and, knowing the initial conditions,

$$
v(t)=V, \text { at } t=0 \quad x(t)=0, \text { at } t=0
$$

where $\mathrm{V}$ is the velocity just prior to impact. Equation 5.1 can be integrated to obtain an expression for $v(t)$, and this can be integrated to obtain a solution for $x(t)$.

$$
\begin{aligned}
& v(t) \\
& =V \\
& +\int_{0}^{t} g-\frac{P(\grave{t})}{M} d \grave{t} \\
& x(t) \\
& =0+\int_{0}^{t} v(\grave{t}) d \grave{t}
\end{aligned}
$$

It is important to remember that equations 5.3 work as long as the composite laminate is not punctured. Once the previous quantities are known, it is now possible to solve for the energy absorbed as a function of time.

$$
\Gamma(t)=\int_{0}^{t} P(\grave{t}) v(\grave{t}) d \grave{t}
$$

Integrating equation 5.4 from 0 until the time $t$ that the impactor is no longer touching the specimen will yield the total energy. This is a simplified method used to determine the energy absorbed by the specimen. 


\subsubsection{Experimental setup}

The puncture resistance of the reinforced and unreinforced unsaturated polyester was measured using the procedure ISO 6603-2 international standard test method for determination of puncture impact behavior of rigid plastics. A temperature range of $-80{ }^{\circ} \mathrm{C}$ to $60{ }^{\circ} \mathrm{C}$ was covered. At least three specimens per temperature were tested and the crosshead speed was set at $25 \mathrm{~mm} /$ minute. All specimens were machined, as a flat plate specimen (100 mm square plates, thickness $3 \mathrm{~mm}$ ) from the sheet prepared in Chapter 2 using a water-cooled diamond saw; the edges were sanded prior to conditioning. The impact striker has a $20 \mathrm{~mm}$ diameter hemispherical tip, and the test specimen support ring has a $40 \mathrm{~mm}$ diameter hole. Figure 5.2 shows the test assembly. The wet samples were stored in a plastic container of distilled water at $23^{\circ} \mathrm{C}$ in an oven. The schematic view of test setup is shown in Figure 5.3. This test was done in a compressive mode on a $15-\mathrm{kN}$ Instron Dynatup 9250HV impact tester Drop-Tower for impact testing. Environmental chamber option allows testing from $-40^{\circ} \mathrm{F}$ to $+350^{\circ} \mathrm{F}$. Under standard conditions of different temperatures and humidity 55\% RH. Table 5.1 presents the specifications of this machine. 


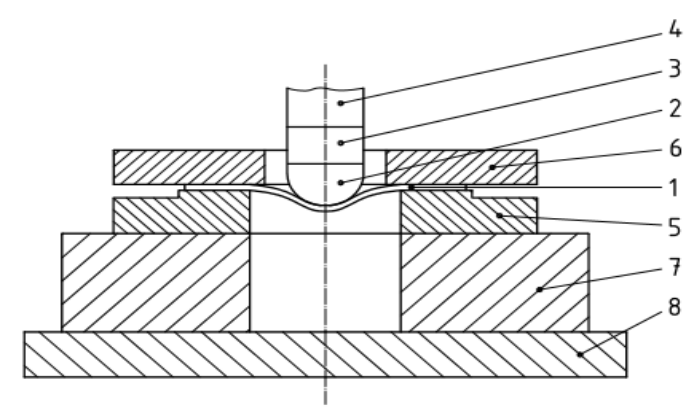

Key

1 Test specimen

5 Test specimen support

2 Hemispherical striker tip

6 Clamping ring (optional)

3 Load cell (preferred position)

7 Base

4 Shaft

8 Acoustical isolation (optional)

Figure 5.2 Puncture test assembly

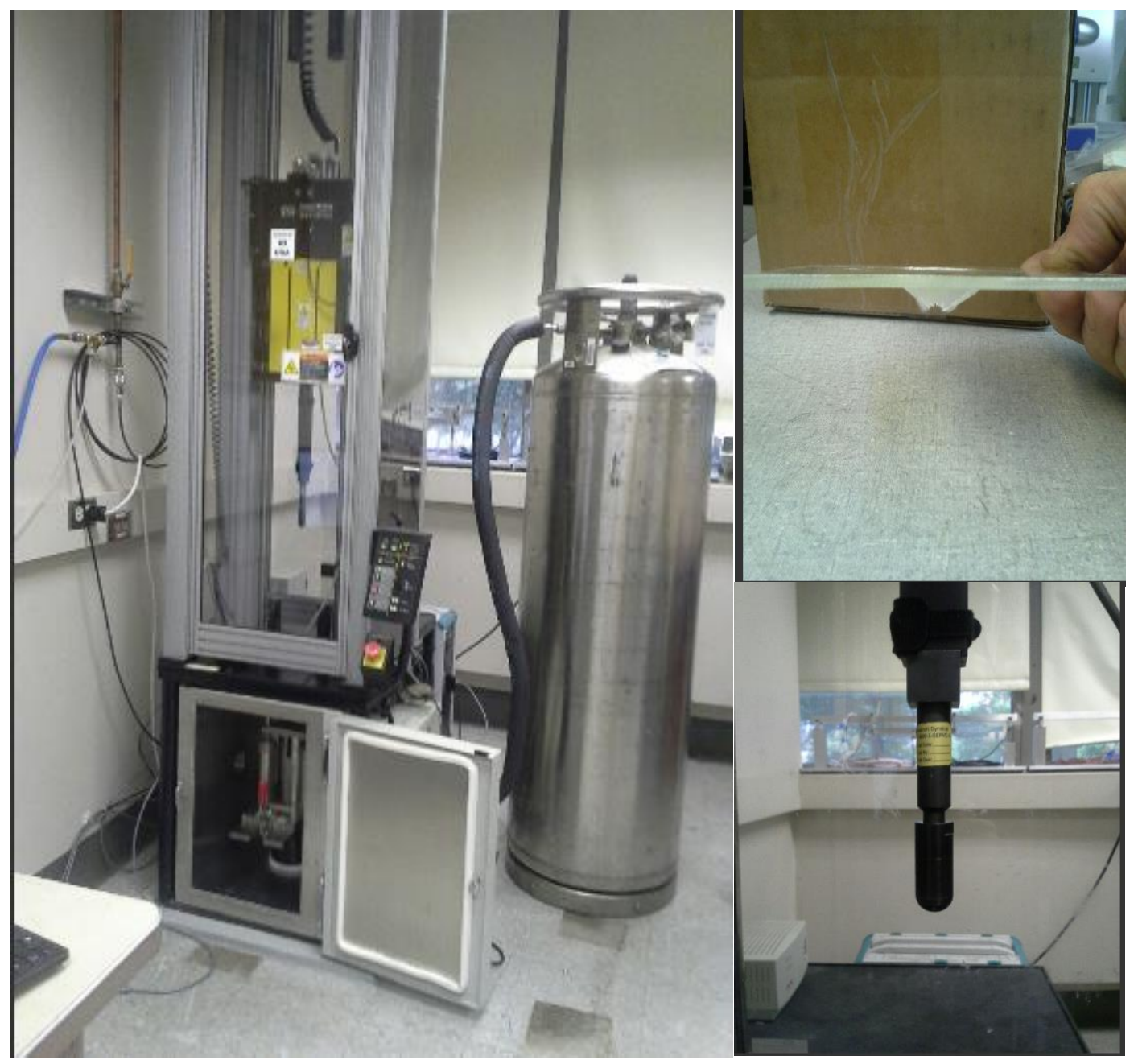

Figure 5.3 Experimental setup of puncture resistance test 
Table 5.1 Specifications of puncture test machine

\begin{tabular}{lll}
\hline Test Equipment & Frame & Frame 3 (CEAST Instron 9250 floor standing system) \\
& Last Calibration & $8 / 23 / 2017$ \\
Designed load & $0.59-757 \mathrm{~J}(0.44-558 \mathrm{ft}-\mathrm{lb})$ \\
Data acquisition & $4 \mathrm{MHz}$ simultaneous sampling. \\
Impact Speed & $0.77-24 \mathrm{~m} / \mathrm{s}(2.53-78.7 \mathrm{ft} / \mathrm{s})$ \\
& Drop Height & $0.03-29.4 \mathrm{~m}(1.18-1160 \mathrm{in})$ \\
& Drop Weight & $2.00-70.0 \mathrm{~kg}(4.41-154 \mathrm{lbs})$ \\
& \\
\end{tabular}

The load probe has a hemispherical tip with a radius of $5 \mathrm{~mm}$ at the tip and has a straight stem of diameter $10 \mathrm{~mm}$. A puncture probe test speed of $25 \mathrm{~mm}$ per minute was used for all samples. A five-pound load cell was used for this study. It was made sure that the load range to break was between 20 to $80 \%$ of the load cell capacity. The peak load and energy to break were noted. The reinforced and the unreinforced sample was secured in a clamping mechanism so that the rubber O-rings attached to the edge of the specimen holder prevented any slippage during the testing procedure. Each sample was placed in between the rubber padded grips of the CEAST Instron 9250 testing machine. The pressure on the grips was controlled pneumatically so as to prevent any slippage. Once the test specimen is clamped down, the mass is raised to the desired height, and the mass is locked into place. Once the machine is set to its correct configuration and all data acquisition software is running, the mass is released and allowed to impact the plate. A picture of an impacted test specimen is shown in Figure 5.4. 


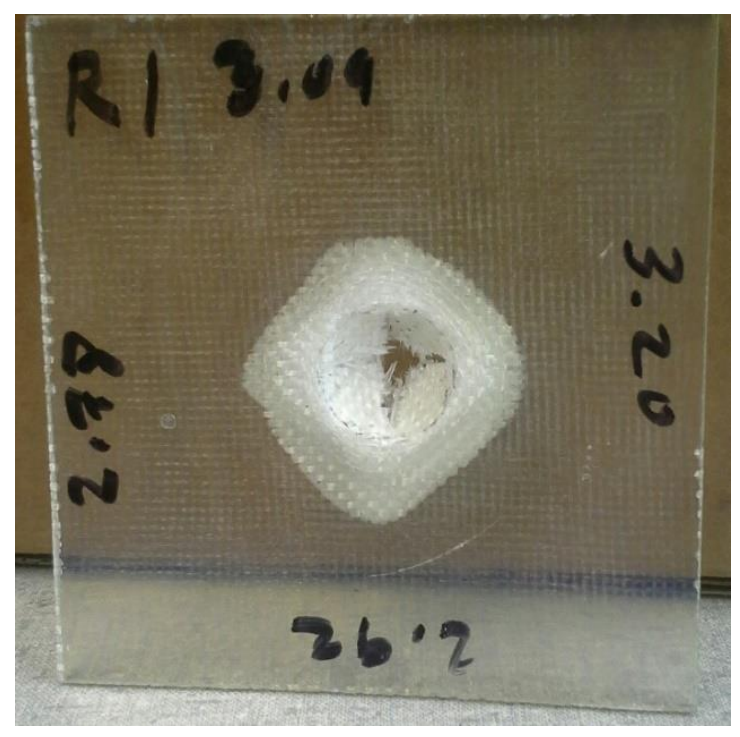

Figure 5.4 Post impact drop weight test specimen

The strains measured by the tup are loaded into a software program, and the data obtained from the test can be examined to see the impact resistance of the plate.

In this experiment, we measured and recorded the following operational parameters;

1. Drop mass $(\mathrm{kg})$

2. Drop height (meters)

3. Time elapsed from the moment of impact (a typical event lasts $\sim 10 \mathrm{msec}$ )

4. Velocity of the falling mass at impact (meters/sec)

5. Force exerted by the striker on the test specimen from the moment of impact until the end of the event (Newtons)

6. Energy (Joules) and Deflection (mm)

The data is plotted as force, energy, or displacement vs. time. The puncture data of the reinforced and the unreinforced specimens were analyzed to check if there was any significant effect based on the variables mentioned above and also for regression. The regression analysis was done on time-based puncture results to check if the values showed 
a corresponding change with change in temperature. Experiments at each temperature gave two typical graphs with load $(\mathrm{kN})$, and Energy $(\mathrm{J})$ plotted as a function of 1$)$ time (ms), and 2) deflection (mm).

\subsection{Results and discussion}

Three composite specimens were tested in each category. Seven different temperature were tested $\left(80^{\circ} \mathrm{C}, 60^{\circ} \mathrm{C}, 30^{\circ} \mathrm{C}, 0^{\circ} \mathrm{C},-30^{\circ} \mathrm{C},-60^{\circ} \mathrm{C}\right.$ and $\left.-80^{\circ} \mathrm{C}\right)$. All the specimens consist of six layers of E-fiber glass cloth embedded in a polyester matrix.

\subsubsection{Impact Loading Characteristic}

Load time curves from the puncture testing are shown in Figures 5.5 and 5.6. These shows that for temperatures below $60^{\circ} \mathrm{C}$ up to $-80^{\circ} \mathrm{C}$ the contact time of the impactor is higher for reinforced specimens compared to unreinforced polyester specimens. For unreinforced specimens at temperatures below $60^{\circ} \mathrm{C}$ the contact time is a function of temperature and reduces with reducing temperature. For temperatures of $60^{\circ} \mathrm{C}$ and $80^{\circ} \mathrm{C}$, that is in the vicinity of glass transition temperature, the contact time and peak load shows a dramatic increase. This is due to increased ductility of the matrix in the vicinity of the glass transition temperature resulting in higher deformation of the matrix region in contact with dropweight [30]. At low temperatures the stiffness of the material is higher [31] and hence the the frequency of vibration of specimen is higher along with slightly higher wave speed in the specimen that makes the impactor bounce back earlier (thus reducing contact time with decreasing temperature) than at higher temperatures. The unreinforced samples generally behave in a very brittle fashion and are completely perforated when the peak load is reached resulting in a steep drop in load, as shown in Figure 5.6. For reinforced specimens below 
$80^{\circ} \mathrm{C}$ temperature the contact time is independent of temperature variation as the composite is only partially damaged with no preformation.

When the unreinforced specimens is subjected to puncture load, the load increases linear by up to the damage initiation point. In the temperature range $-80^{\circ}$ to $30^{\circ} \mathrm{C}$ the peak load is nearly the same. The sudden drop in load after reacting the peak load is due to complete perforation of the specimen. The peak load values for reinforced specimens continuously increases from $80^{\circ} \mathrm{C}$ to $0^{\circ} \mathrm{C}$, for temperatures below $0^{\circ} \mathrm{C}$ to $-80^{\circ} \mathrm{C}$ the peak load is constant. The load-time curves for E-glass reinforced specimens reveal that the peak puncture load is higher than unreinforced at all temperatures. For temperatures above room temperature $\left(30^{\circ}, 60^{\circ}\right.$ and $\left.80^{\circ} \mathrm{C}\right)$ the load-time curve is linear initially followed by a constant load region before the load begins to drop due to a combination of increasing damage, flexure in the panel and bounce back of the drop weight. In the constant load region (or a plateau) duration of the constant load increases with increasing temperature signifying greater, contact duration of impactor. The polymer matrix is more compliant as temperature increase up to the glass transition temperature of $73^{\circ} \mathrm{C}$ and the flexural deformation on impact does not result in increased load. Below room temperature and up to $-80^{\circ} \mathrm{C}\left(0^{\circ}\right.$, $30^{\circ},-60^{\circ}$ and $-80^{\circ} \mathrm{C}$ ) the load - time curves are nearly identical and the peak load is higher than temperatures above room temperature $\left(\sim 20^{\circ} \mathrm{C}\right)$. It may be noted in Figure 4 that for temperatures $0^{\circ} \mathrm{C}$ to $-80^{\circ} \mathrm{C}$ the load-time curve is symmetric about the peak load. This signifies that the energy absorption in the pre-peak region is same as in the post-peak region. However, in the higher temperature conditions the post-peak region is larger than pre-peak region which indicates that these specimens can continue to sustain a load for longer duration after damage occurs at peak load [32]. Instrumented falling weight 
puncture testing involves varying time scales, as seen in Figures 5.5 and 5.6. The time taken for damage initiation and propagation through the entire specimen to the point of total collapse is smaller for unreinforced polyester specimens compared to reinforced specimens at each respective temperature. This indicates that the time taken to reach the peak impact load is strongly influenced by the stiffness of composite at different temperatures.

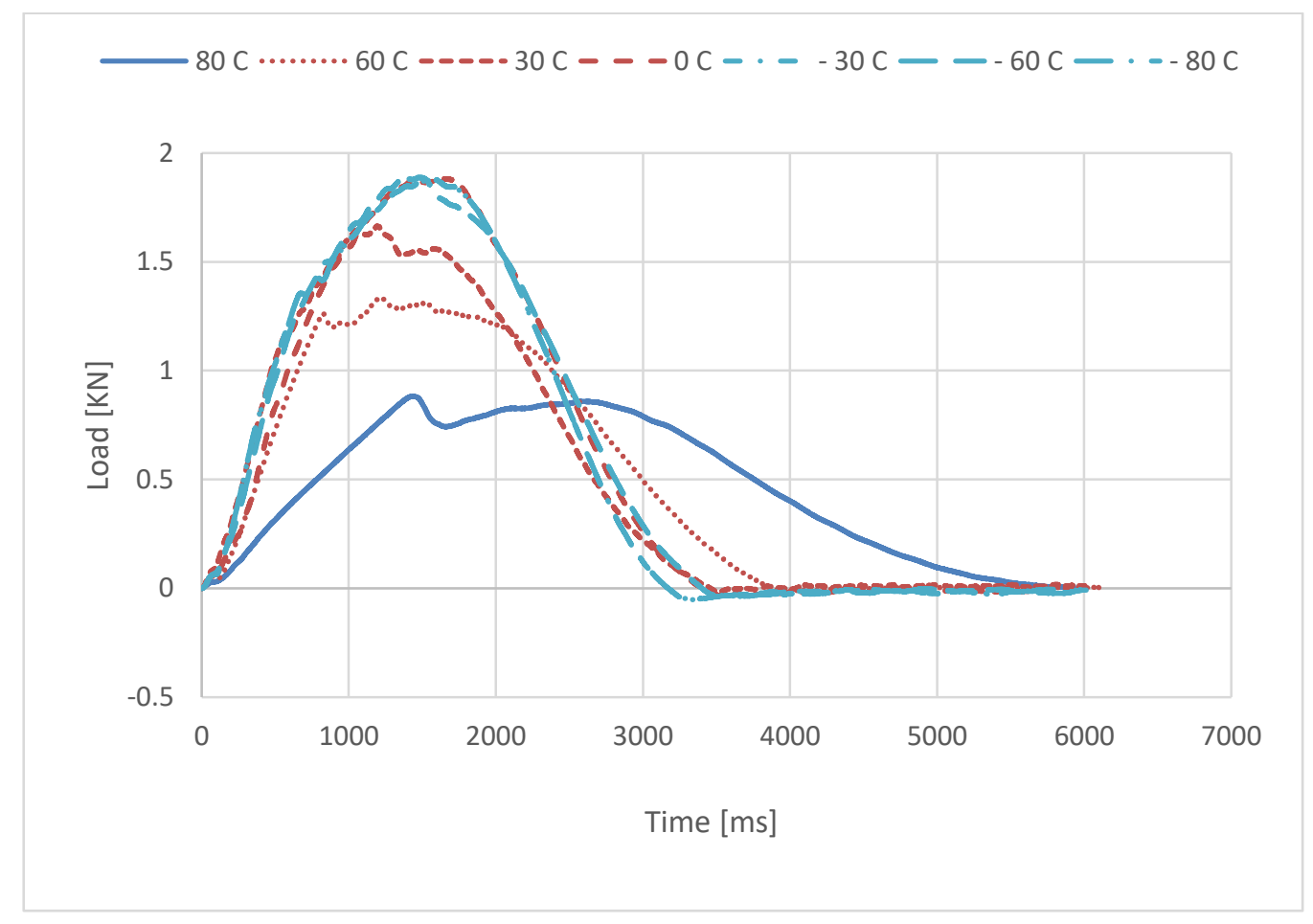

Figure 5.5. load - time traces of puncture event in the reinforced polyester composite material 


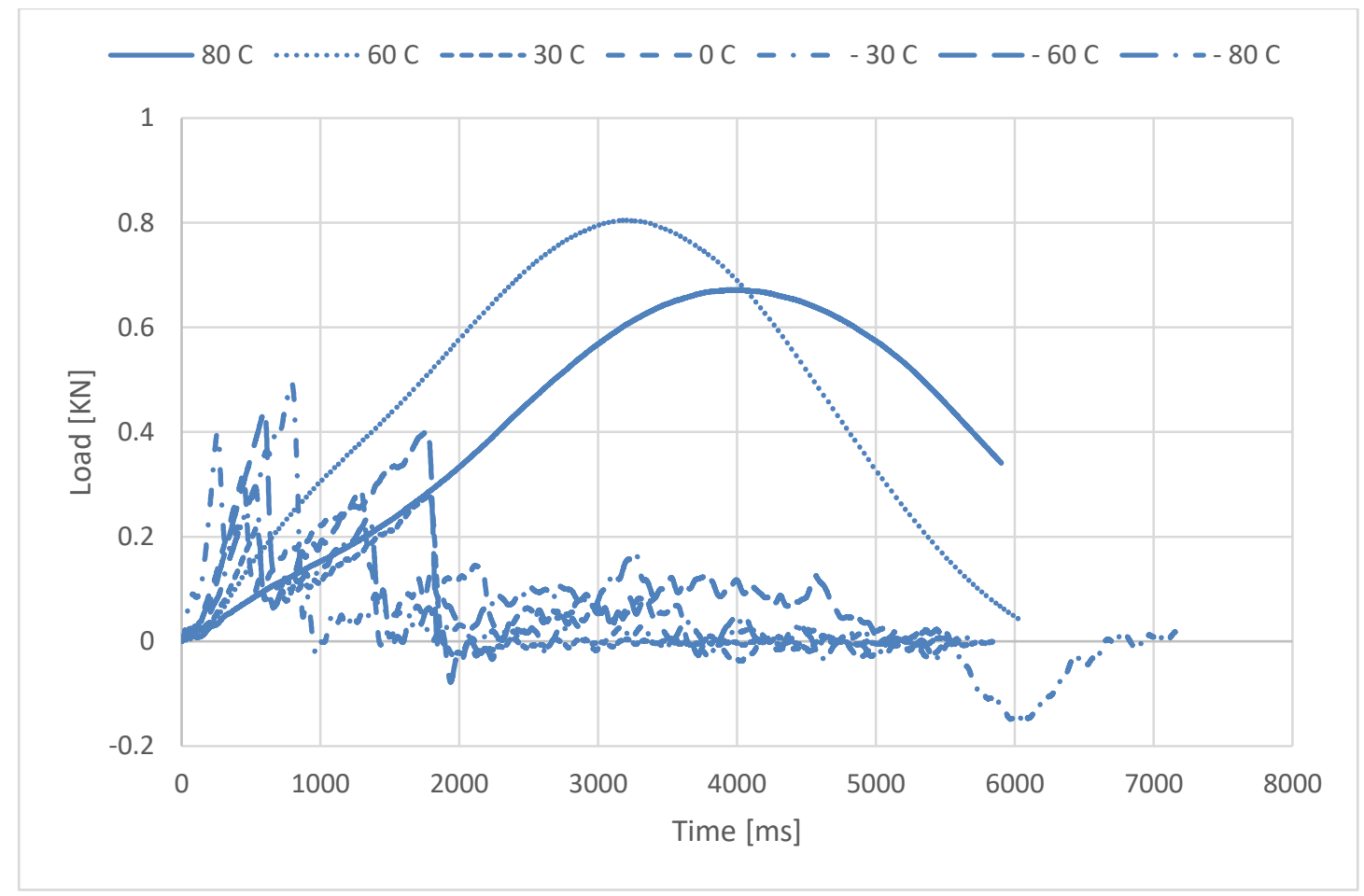

Figure 5.6 Load - time traces of puncture event in the unreinforced polyester composite material

In Figure 5.7, the influence of load level on the mechanical response is plotted schematically. The puncture occurs in 3 stages: The penetration force begins to continuously increase after the probe tip touches the upper surface of the reinforced (or unreinforced) composite until the tip causes damage or pierces the surface of the composite, resulting in the drop of load. From point $a$ to $b$ the load increases linearly due to elastic loading, from $b$ to $c$ the load - time curve becomes non - linear as localized damage initiates around the point of impact due to the high stresses caused by Hertzian contact of the drop - weight. After point $c$ the load begins to drop due to significant damage in the material resulting in loss of stiffness or decoupling of the drop - weight with the specimen due to bounce back. If the spherical portion of the drop-weight penetrates 
through the specimen, the area of specimen damage does not increase. The load (or stress) reaches the maximum at point $c$ and the load drops after that point.

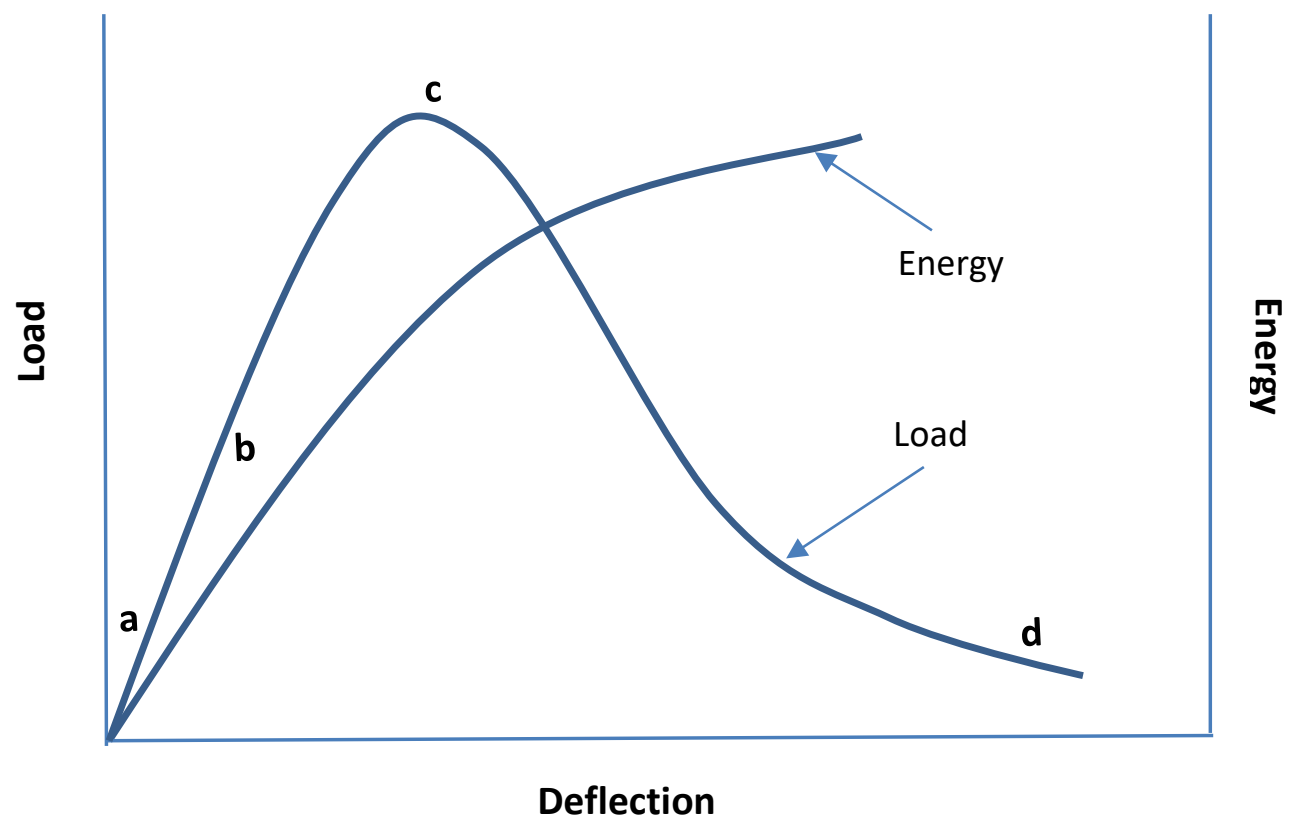

Figure 5.7 Damage stages in the punctured specimens.

For temperatures above room temperature $\left(30^{\circ}, 60^{\circ}, 80^{\circ}\right)$ the peak load achieved in reinforced specimens decreases with temperature while the deflection increases with temperature, as shown in Figure 5.8. In this temperature range a load plateau is observed indicating the start of damage in the specimen but the load carrying capacity is not degraded as the fibers are able to be carrying the load until. More widespread damage causes fibermatrix delamination, fiber breakage and matrix cracking. Below room temperature and up to $-80^{\circ} \mathrm{C}$ the peak load and deflection is nearly the same at all temperatures. For unreinforced polyester specimens at temperature below $60^{\circ} \mathrm{C}$ a brittle behavior is observed where in the deflection is linear up to the peak load at which point there is catastrophic failure and perforation in the polyester panel, resulting in sudden drop of load, as seen in Figure 5.9. However, at temperatures of $60^{\circ} \mathrm{C}$ and $80^{\circ} \mathrm{C}$, which are closer to the glass 
transition temperature, the specimens behave in a more ductile manner due increased stretching of the polymer matrix without fracture. The value of the peak load achieved is highest at these temperatures and occurs at higher deflections.

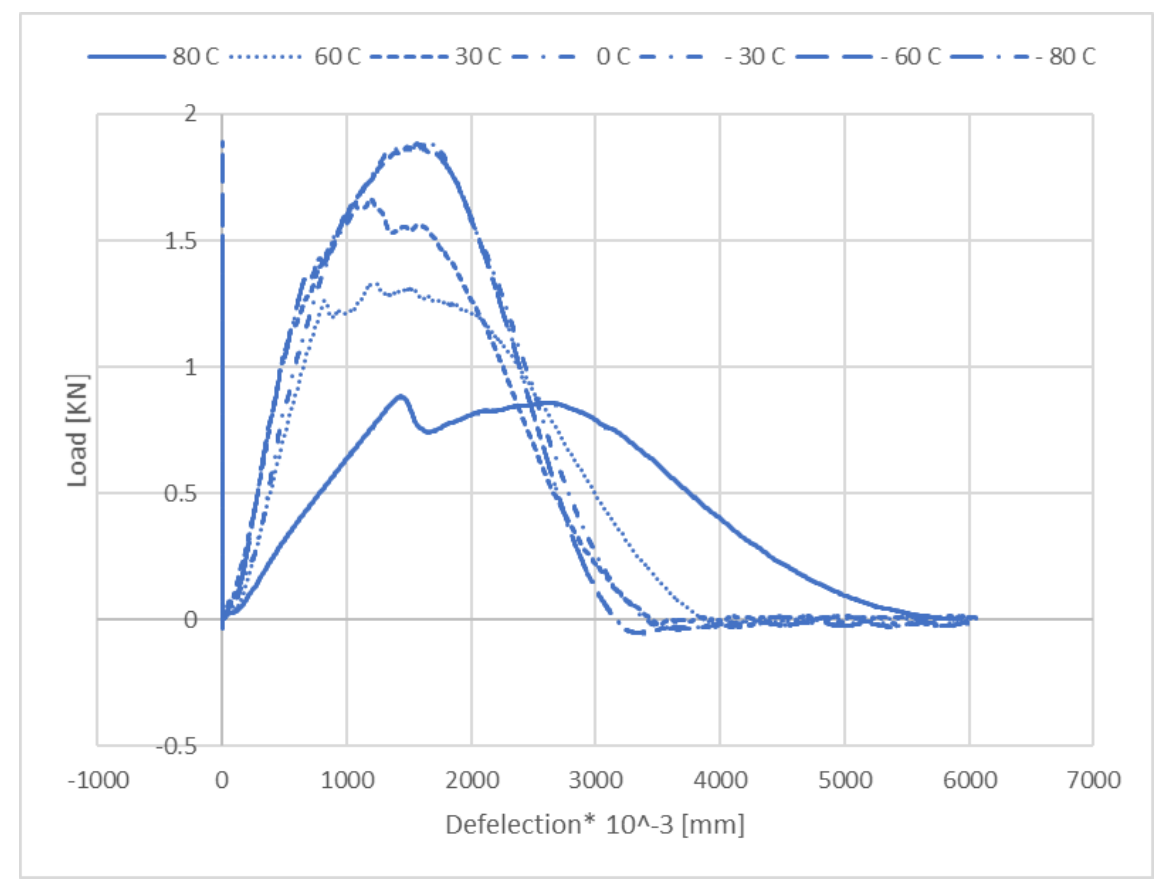

Figure 5.8. load - deflection traces of puncture event in the reinforced polyester composite material 


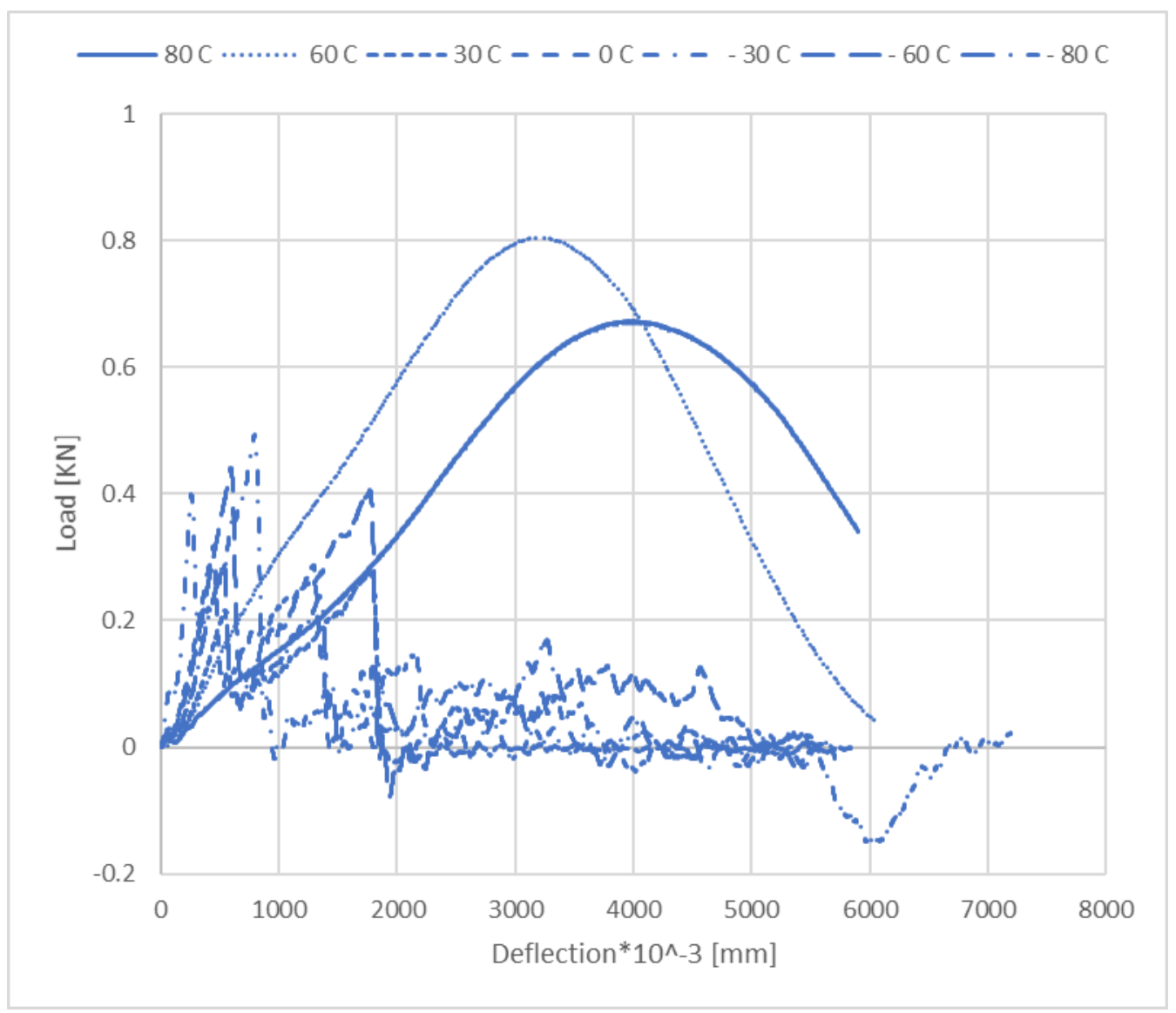

Figure 5.9. Load - deflection traces of puncture event in the unreinforced polyester composite material

\subsubsection{Energy absorption}

Puncture damage in composite materials involves different fracture modes. Figures 5.10 and 5.11 show the variations in energy absorption for reinforced and unreinforced specimens respectively. Figure 8 shows that energy observed after contact in the composite specimen with the drop - weight continuous to increase with time up to about $2000 \mathrm{~ms}$ after which a small drop is displayed as the drop - weight becomes back and reverses it velocity direction. Energy absorption is calculated using the formula shown below.

$\mathrm{E}_{\mathrm{ab}}(\mathrm{t})=\frac{1}{2} \mathrm{~m}\left[\left(\mathrm{~V}_{\mathrm{anp}}\right)^{2}-(\mathrm{V}(\mathrm{t}))^{2}\right]$ 
Where:

$\mathrm{E}_{\mathrm{ab}}(\mathrm{t})$ : energy absorbed.

$\mathrm{t}$ : is the time after impact at $\mathrm{t}=0$.

The maximum energy absorption is reached when the velocity of the drop - weight is zero, which occurs at $2000 \mathrm{~ms}$ for the reinforced specimens at all temperatures from $+80^{\circ}$ to $80^{\circ} \mathrm{C}$. Moreover, the peak energy absorption is nearly the same for all temperatures and is about $75 \%$ of the available energy in the drop - weight before impact. No difference is noted as there was no puncture in all cases, though the damage zone showed a variation with temperature (and is discussed in the next section).

Figure 5.10 displays the energy absorption during the puncture event in the reinforced polyester specimens as the temperature changes from $+80^{\circ} \mathrm{C}$ to $-80^{\circ} \mathrm{C}$. At the temperature of $+80^{\circ} \mathrm{C}$, which is slightly higher than glass transition temperature $73^{\circ} \mathrm{C}$ of the polyester matrix, no puncture is observed as the matrix material can stretch significantly on impact and eventually the drop - weight comes to the rest after about $6000 \mathrm{~ms}$. The energy absorption in unreinforced polyester specimens is low for all temperatures below $80^{\circ} \mathrm{C}$ as the material fractures around $1000 \mathrm{~ms}$, as shown in Figure 5.10, after impact and the drop - weight pushes through the punctured region.

In the case of reinforced polyester specimens at $80^{\circ} \mathrm{C}$ a similar behavior is observed though the impactor reverses its movement at about $4000 \mathrm{~ms}$ after impact, however, the rebound velocity is low at about $0.1 \mathrm{~m} / \mathrm{s}$ compared to the impact velocity of $0.9 \mathrm{~m} / \mathrm{s}$. The rebound velocity at all negative temperatures in reinforced sample is higher at about $0.4 \mathrm{~m} / \mathrm{s}$, as shown in Figure 5.11. 


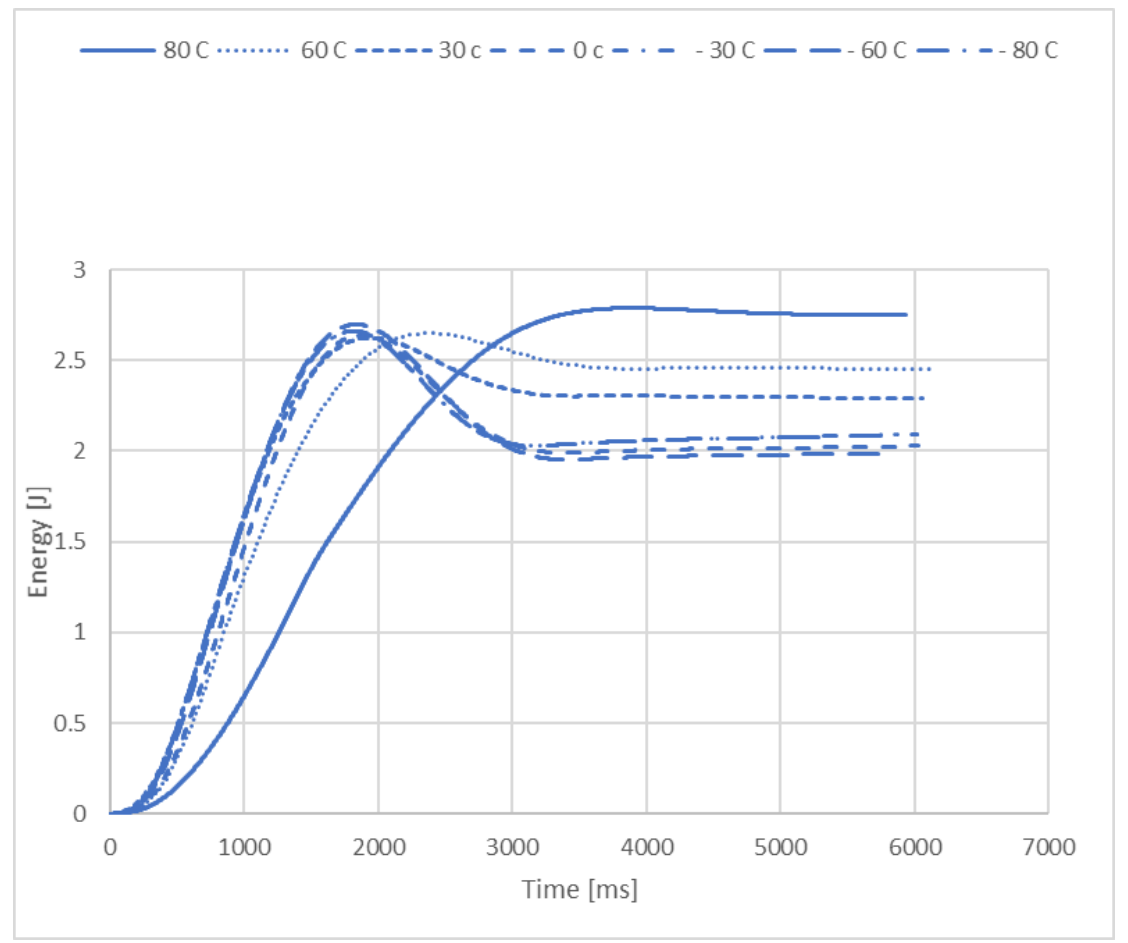

Figure 5.10. Absorbed energy as a function of time during a drop - weight puncture test of the reinforced polyester composite.

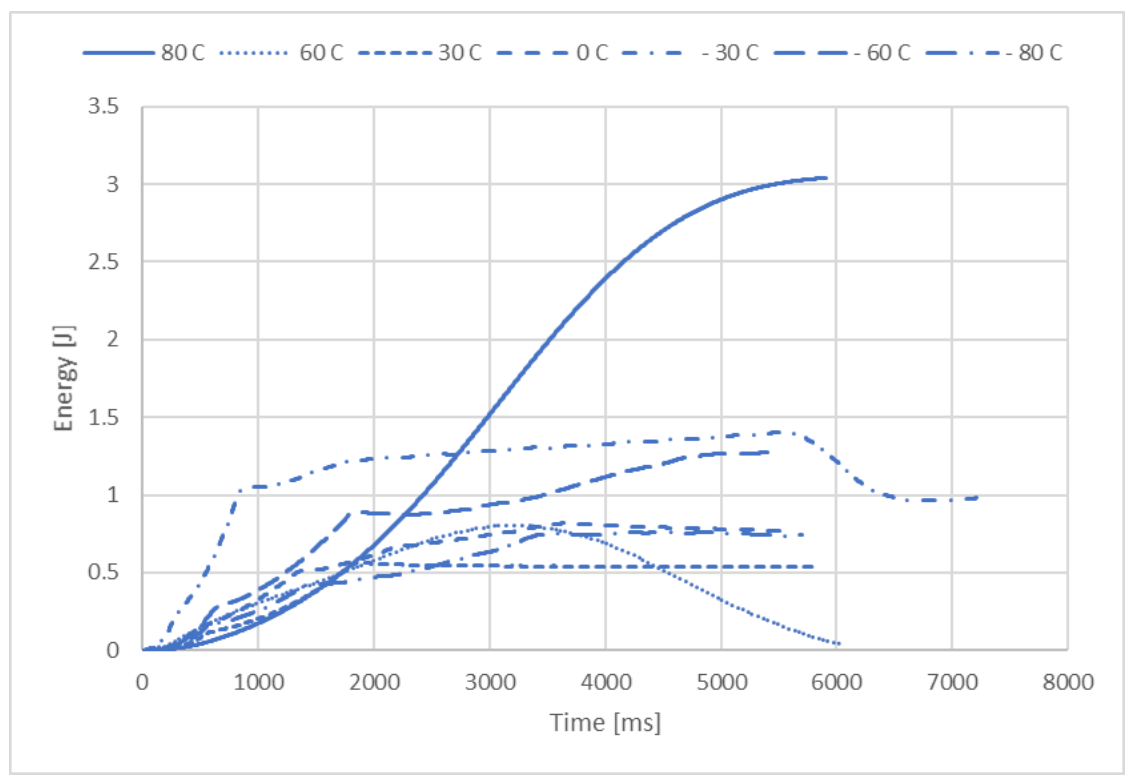

Figure 5.11. Absorbed energy as a function of time during a drop - weight puncture test of the unreinforced polyester composite. 
Figure 5.12 and 5.13 compares the velocity-time curves for different test specimens. Although puncture velocity alone does not the puncture properties of material but it can affect the energy dissipated during puncture. The change of the puncture momentum as it passes through the specimen relates to the energy consumed by the fracture process. The velocity of the puncture become zero when the composite specimen reaches the maximum deflection. The velocity of puncture in unreinforced is higher than in reinforced. In reinforced reduced the velocity with reduce the temperature the same thing in unreinforced except at $60^{\circ} \mathrm{C}$ was higher velocity than the other

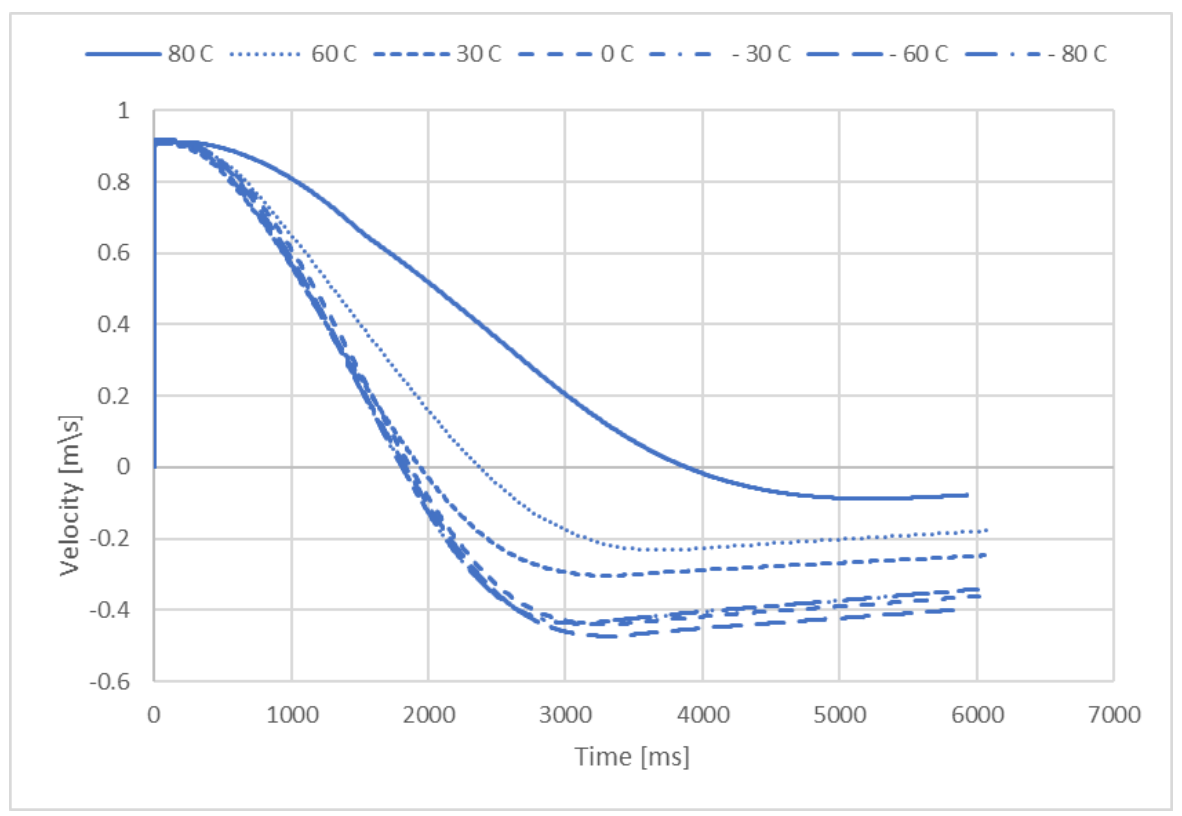

Figure 5.12. Velocity as a function of time during a drop - weight puncture test of the reinforced polyester composite. 


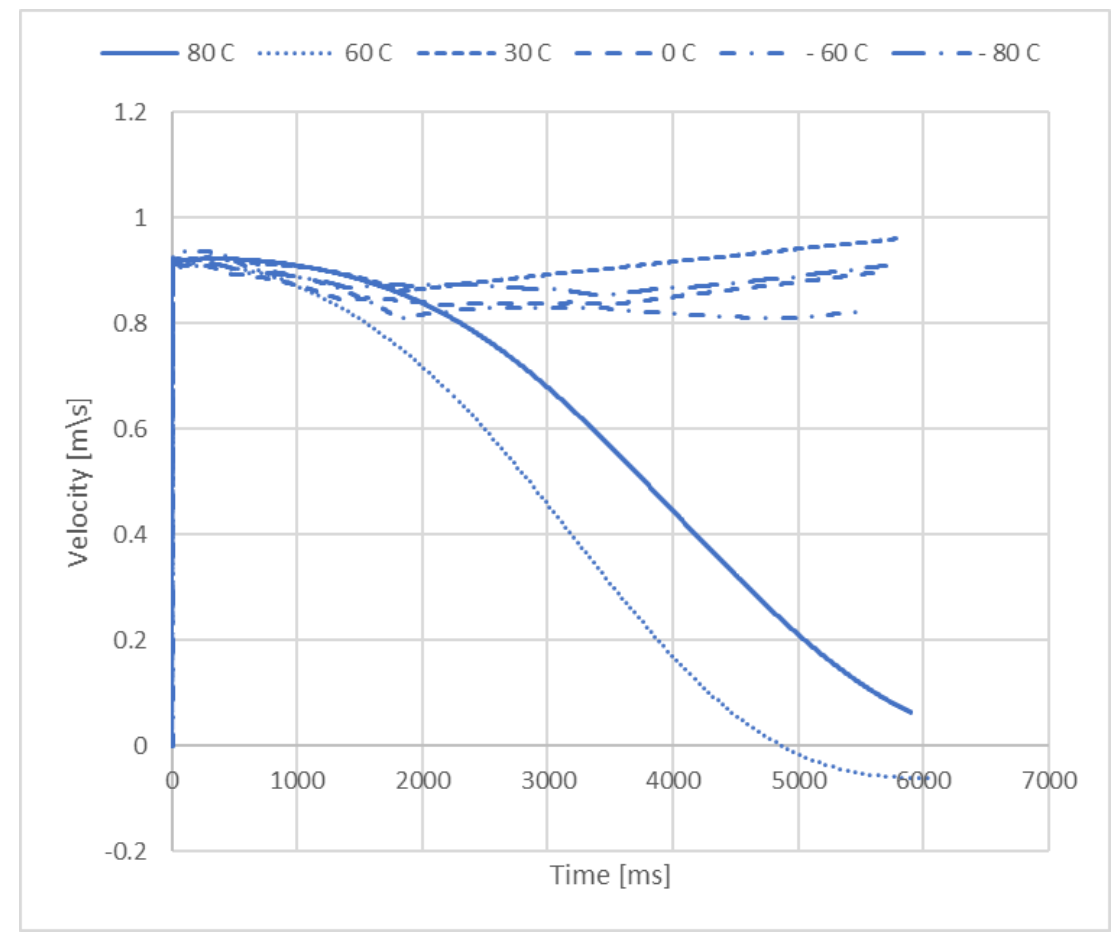

Figure 5.13. Velocity as a function of time during a drop - weight puncture test of the unreinforced polyester composite.

\subsubsection{Fragmentation characteristics under dynamic loading}

Glass fiber reinforced polyester composite specimens and unreinforced polyester specimens were subjected to dynamic (impact) loading by a drop - weight. Test were conducted at different temperatures ranging from $+80^{\circ} \mathrm{C}$ to $-80^{\circ} \mathrm{C}$. The damage created in the vicinity of the impact region in the two types of material is shown in Figures 5.14 and 5.15 for the unreinforced and reinforced polyester specimens, respectively.

The unreinforced polyester undergoes permanent local deformation without puncture for temperatures $60^{\circ} \mathrm{C}$ and $80^{\circ} \mathrm{C}$, which are close to the polyester glass transition temperature of $73^{\circ} \mathrm{C}$. At room temperature and negative temperatures, the material punctures under the 
dynamic load. At very low temperatures of $-60^{\circ} \mathrm{C}$ and $-80^{\circ} \mathrm{C}$ the polyester specimens begin to shatter into fragments on impact as shown in Figure 5.14.

As fiber reinforced composite specimens behave differently from unreinforced specimens in terms of damage evolution under impact damage in the composite specimens at $60^{\circ} \mathrm{C}$ and $80^{\circ} \mathrm{C}$ is different form that seen at room temperature and below up to $-80^{\circ} \mathrm{C}$. At the two higher temperatures in the proximity to the glass transition temperature of $73^{\circ} \mathrm{C}$ the damage zone is of random shape, as seen in Figure 5.14 with slightly more damage on the back side of the specimen. As the temperature continuous decrease the damage is more symmetric and organized. At the point of impact there is a Hertzian - like crushing of the material. This is then followed by flexural deformation of the specimen. The maximum principal stress occurs in the back side on the line directly behind the impact point. Thus, local damage zone and radial cracking initials at these locations at the front impact point and the backside of the specimen. As the temperature decreases the residual stress in the polymer matrix increases due to greater shrinkage of the matrix relative to glass fiber further promoting radial cracking. Figure 5.15 shows an enlarged view of the damage in the composite specimens on the near side with respect to the impacted side. The damages are clearly visible as a transparent composite panel was used for testing. At $0^{\circ} \mathrm{C}$ fiber de bonding is apparent along the radial cracks, minor fiber breakage below the impact point on the rear face and extensive de bonding and matrix cracking over a circular region around the impact point. At a lower temperature of $-60^{\circ} \mathrm{C}$ the damage zone is smaller in size, however, the fiber breakage and longer cracks in the matrix are visible on the rear side, as seen in Figure 5.15. 

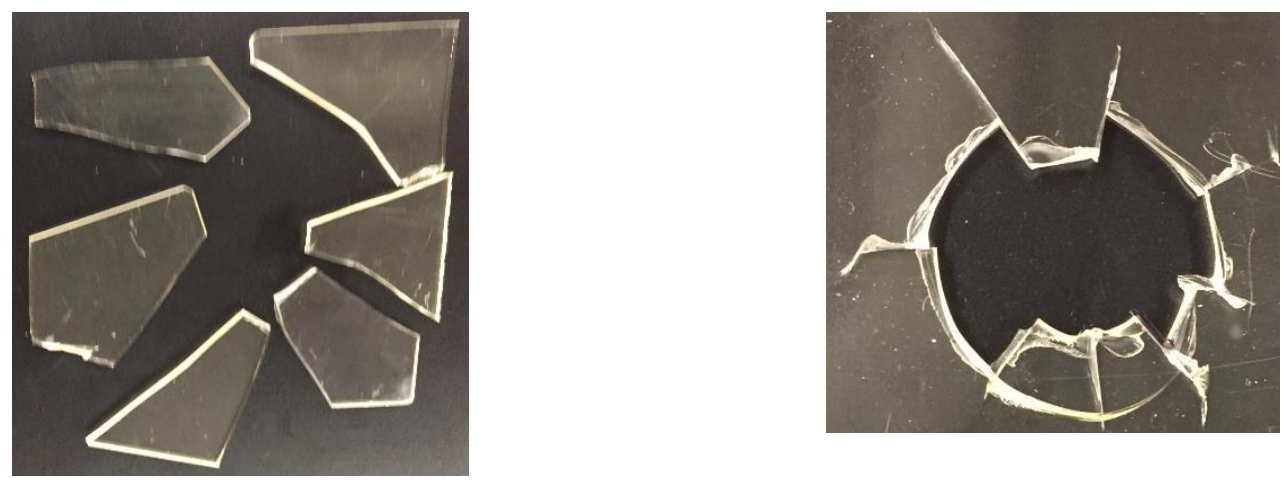

$\left(0^{\circ} \mathrm{C}\right)$
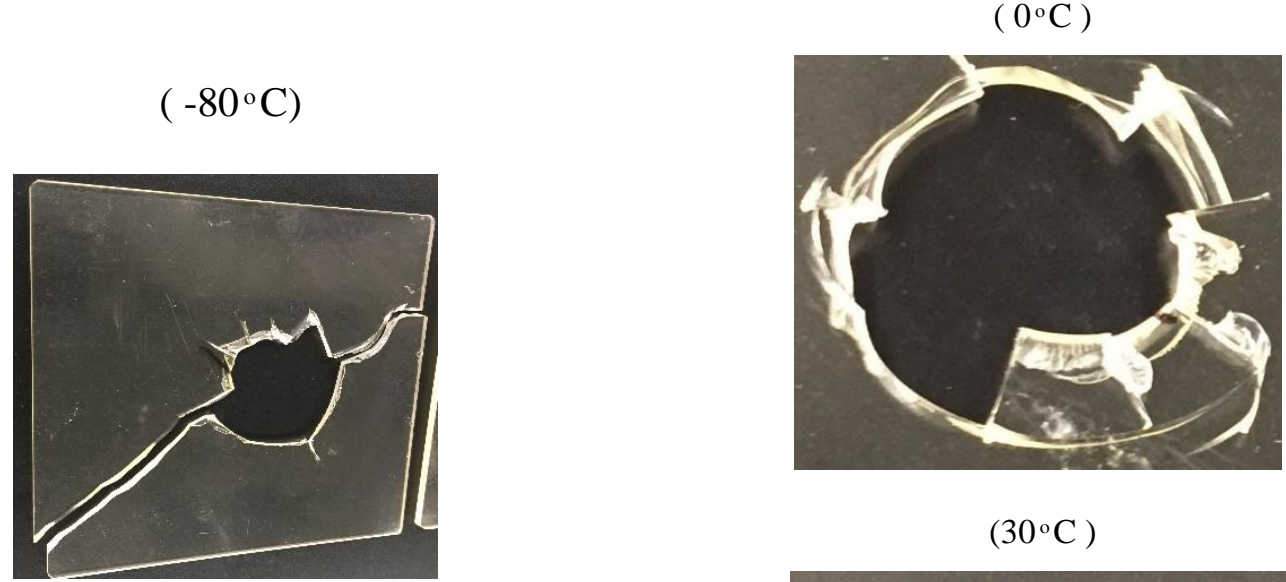

$\left(30^{\circ} \mathrm{C}\right)$

$\left(-60^{\circ} \mathrm{C}\right)$
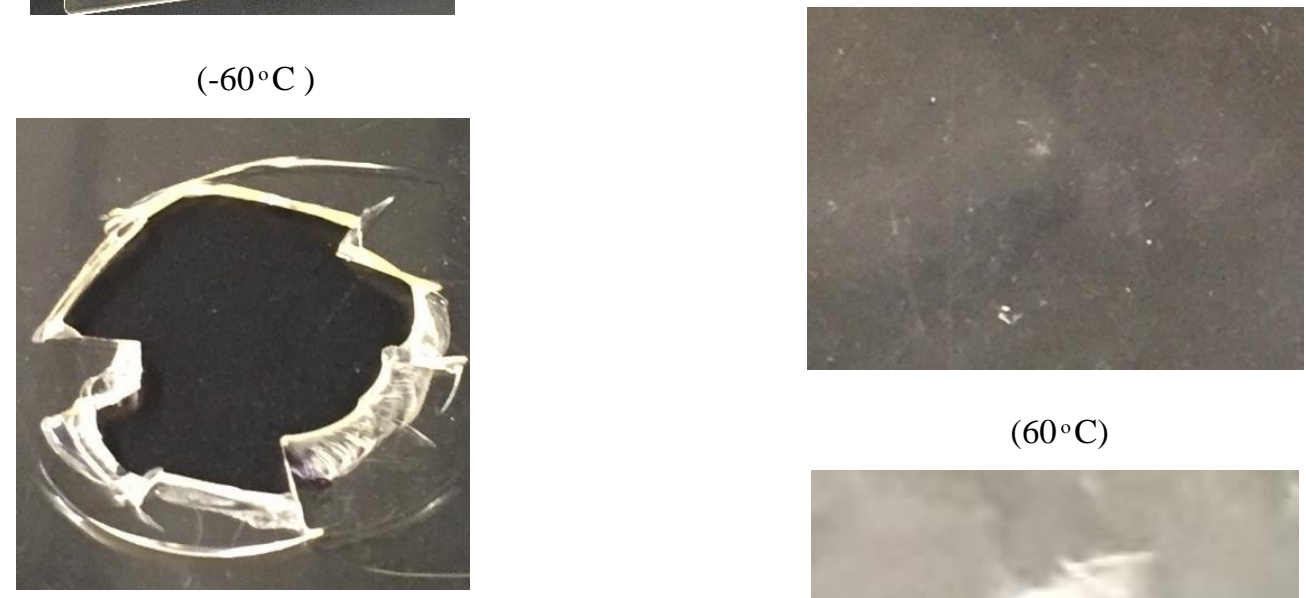

$\left(60^{\circ} \mathrm{C}\right)$

$\left(-30^{\circ} \mathrm{C}\right)$

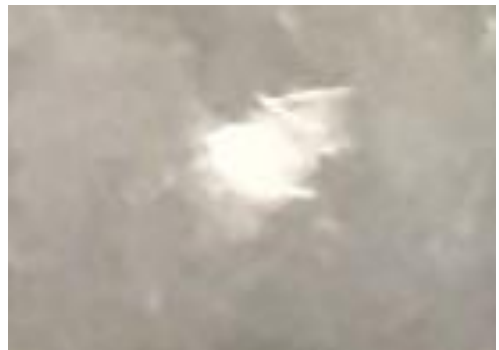

$\left(80^{\circ} \mathrm{C}\right)$

Figure 5.14. Fragmentation characteristics under dynamic loading for unreinforced specimens. 

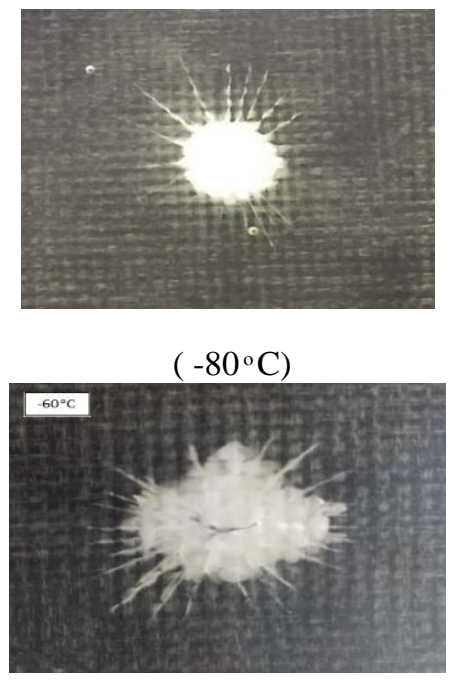

$\left(-60^{\circ} \mathrm{C}\right)$
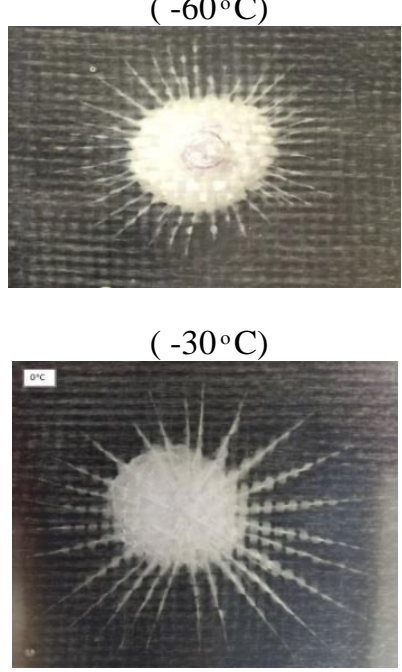

$\left(0^{\circ} \mathrm{C}\right)$

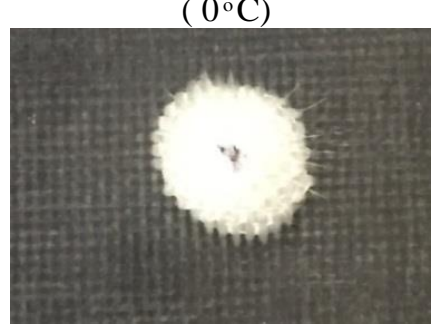

$\left(30^{\circ} \mathrm{C}\right)$

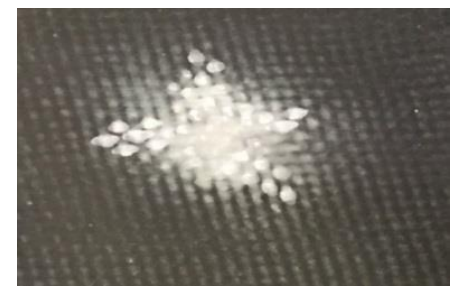

$\left(80^{\circ} \mathrm{C}\right)$

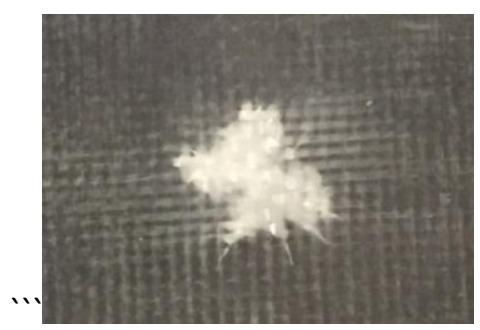

$\left(60^{\circ} \mathrm{C}\right)$

Figure 5.15. Fragmentation

characteristics under dynamic loading

for reinforced specimens. 


\subsection{Conclusions}

In this work, the dynamic behavior of reinforced and the unreinforced preconditioned in a humid environment was studied. The findings can be concluded as follows;

- A better behavior, in terms of maximum puncture load, was observed for the reinforced specimens for the low temperatures. A low puncture resistance was obtained at high temperatures.

- An investigation has been conducted to study the effect E-glass fiber reinforcement on the low velocity puncture response of an unsaturated polyester.

- The change between reinforce specimen and unreinforced results in an increased damage propagation phase thus increasing the puncture resistance properties. At reinforce specimen the failure mode of the composites is more ductile with correspondingly higher energy absorption characteristics. 


\section{References}

1. Bucknall CB., 1977, “Toughened plastics”. London: Applied Science Publication.

2. Paul DR, Bucknall CB. 2001, "Polymer blends, performance", 2. New York: WileyInterscience.

3. Omer Faruk Erkendirci, 2016, "Investigation of the quasi static penetration resistance behavior of carbon fiber reinforced laminate HDPE composites”, Composites Part B $93,344-351$

4. Erkendirci O F, Haque B Z (Gama), 2013, "Investigation of penetration mechanics of PW Kevlar fiber reinforced HDPE composites”. Int J Damage Mech, 22, pp. 304-322.

5. Erkendirci O F, Haque B Z (Gama), 2012, “Quasi-static penetration resistance behavior of glass fiber reinforced thermoplastic composites”. Compos Part B, pp. 3391-3405.

6. Xiao JR, Gama BA, Gillespie Jr JW., 2007, "Progressive damage and delamination in Plain weave S-2 glass/SC-15 composites under quasi-static punch shear loading”. Compos Struct, 78, pp. 182-96.

7. Yen C-F, Cheeseman BA, Hoppel CPR, Gama BA, Gillespie Jr JW., 2004, "Modeling the compressive failure of Plain weave composites". In: ASC/ASTM-D30 joint $19^{\text {th }}$ annual technical conference; October 17-20, 2004 [Atlanta, GA].

8. Z. Aslan, R. Karakuzu, B. Okutan, 2003, "The response of laminated composite plates under low velocity impact loading”, Compos. Struct. 59, pp. 119-127.

9. B.M. Icten, B.G. Kıral, M.E. Deniz, 2013, “Impactor diameter effect on low velocity impact response of woven glass epoxy composite plates”, Compos.: Part B 50, pp. 325332. 
10. Wen HM. 2000, "Predicting the penetration and perforation of FRP laminates struck normally by projectiles with different nose shapes". Compos Struct, 49, pp. 321-329.

11. Bandaru AK, Vetiyatil L, Ahmad S. 2015, "The effect of hybridization on the ballistic impact behavior of hybrid composite armors". Compos Part B, 76, pp. 300-319.

12. Mukhopadhyay S, Fangueiro R., 2009, "Physical modification of natural fibers and thermoplastic films for composites - a review". J Thermoplast Compos mater, 22, pp. $135-62$.

13. Naik NK, Venkateswara Rao K, Veerraju C, Ravikumar G. 2010, "Stress-strain behavior of composites under high strain rate compression along thickness direction: Effect of loading condition”, Materials \& Design, 31, pp.396-401.

14. Ochola RO, Marcus K, Nurick GN, Franz T. 2004, "Mechanical behaviour of glass and carbon fibre reinforced composites at varying strain rates". Composite Structures, 63, pp.455-467.

15. Oguni K, Ravichandran G., 2001, "Dynamic compressive behavior of unidirectional E-glass/vinylester composites”. Journal of Materials Science; 36, pp. 831-838.

16. Shokrieh MM, Omidi MJ. 2009, "Compressive response of glass-fiber reinforced polymeric composites to increasing compressive strain rates", Composite Structures, 89, pp.517-523. 
17. Tarfaoui M, Neme, A., Choukri, S. 2009, "Damage Kinetics of Glass/Epoxy Composite Materials Under Dynamic Compression". Journal of Composite Materials, 43, pp.1137-54.

18. Khan AS, Colak OU, Centala P. 2002, "Compressive failure strengths and modes of woven S2-glass reinforced polyester due to quasi-static and dynamic loading". International Journal of Plasticity, 18, pp.1337-57.

19. Song B, Chen, W., Weerasooriya, T., 2003, "Quasi-Static and Dynamic Compressive Behaviors of a S-2 Glass/SC15 Composite". Journal of Composite Materials, 37, pp. $1723-1724$

20. John J. Lamb, Isabelle Albrecht, Benjamin M. Axilrod. 1949, “Mechanical Properties of Laminated Plastics at $-70^{\circ}, 77^{\circ}$, and $200^{\circ} F^{\prime \prime}$. Journal of Research of the National Bureau of Standards., 42, pp.257-288.

21. Minh-Tai Le, Shyh-Chour Huang. 2015, “Thermal and Mechanical Behavior of Hybrid Polymer Nanocomposite Reinforced with Graphene Nanoplatelets”. Materials 8, pp. $5526-5536$.

22. A. Bersani, L. Canonica, M. Cariello, R. Cereseto, S. Di Domizio, M. Pallavicini. 2013, "Long term elongation of Kevlar-49 single fiber at low temperature". Cryogenics 54, pp. 50-53.

23. Yunfu Ou, Deju Zhu, Huaian Zhang, Liang Huang, Yiming Yao, Gaosheng Li and Barzin Mobasher, 2016, "Mechanical Characterization of the Tensile Properties of 
Glass Fiber and Its Reinforced Polymer (GFRP) Composite under Varying Strain Rates and Temperatures" Polymers, 8, 196.

24. Disder S., J.M. Rey, P. Pailler, A.R. Bunsell, 1998, "Helium permeation in composite materials for cryogenic application”, Cryogenics, 38, pp. 135-142

25. Dutta P.K. and H.W. Lord, 1988, "On the design of polymeric composite structures for cold regions applications", Journal of reinforced plastics and composites, 7, pp. 436456

26. C.Elanchezhian1, B.Vijaya Ramnath, J.Hemalatha, 2014, "Mechanical behavior of glass and carbon fiber reinforced composites at varying strain rates and temperatures". Procedia Materials Science, 6, pp. 1405 - 1418.

27. G. R. Koerner and R. M. Koerner, Geotext. Geomembr., 2010, "Puncture resistance of polyester (PET) and polypropylene (PP) needle-punched nonwoven geotextiles", 29, 360-362.

28. Jang, B., Huang, C., Hsieh, C., Kowbel, W., and Jang, B., 1991, "Repeated impact failure of continuous fiber reinforced thermoplastic and thermoset composites," Journal of composite materials, 25(9), pp. 1171-1203.

29. Jang, B., Huang, C., Hsieh, C., Kowbel, W., and Jang, B., 1991, "Repeated impact failure of continuous fiber reinforced thermoplastic and thermoset composites," Journal of composite materials, 25(9), pp. 1171-1203

30. Budhooa Yougashwar, Liawa Benjamin, Delalea Feridun, Iyerb Ramki , Raju Basavaraju, 2010, ”Temperature Effect On Drop-Weight Impact Of Hybrid Woven Composites," ASME-IMECE Conference Vancouver, British Columbia, Canada, November 12-18, 
31. Dutta, P. K., and Lord, H. W., 1988, "On the design of polymeric composite structures for cold regions applications," Journal of reinforced plastics and composites 7(5), pp. $436-456$.

32. Elanchezhian, C., Vijaya Ramnath, and B., Hemalatha, J., 2014, "Mechanical behavior of glass and carbon fiber reinforced composites at varying strain rates and temperatures," Procedia Materials Science 6, pp. 1405-1418. 


\section{CHAPTER 6: CONCLUSIONS AND FUTURE WORK}

\subsection{Conclusions}

The objective of this dissertation was to develop an environment resistance polyester composite to withstand high and temperatures at the time of engineering applications and examining the material performance under different mechanical loadings. Because of this work, several important conclusions were derived and are listed below.

- An optically transparent glass fiber reinforced polyester composite was manufactured with high light transmittance. However, transmittance decreases as fiber is added as a reinforcement agent. A low temperature environment does not significantly change the optical properties. However, operating at high temperatures above room temperature modified the optical properties significantly.

- Significant improvements were obtained under tensile loading in glass fiber reinforced polyester due to their superior tensile properties at low temperatures compared to unreinforced polyester. Tensile properties of the unreinforced material were found to degrade above room temperature. For temperatures below room temperature up to $80^{\circ} \mathrm{C}$ both materials show a brittle behavior, though reinforced composites display higher tensile strength and small ductility potentially due to microcracking.

- The Puncture test, also displayed high damage resistance to impact loading in reinforced composite at low temperatures whereas a low puncture resistance was obtained at high temperatures. A decrease in damage propagation phase has been observed along with a higher energy absorption characteristic in reinforced polyester composite compared to the unreinforced material. 
- Formulation of Paris law model of polymer matrix at different $\mathrm{a} / \mathrm{w}$ ratios and low temperature reveals that fatigue crack growth rate increases as temperature decreases potentially due to extensive microcracks generated as the material becomes more brittle at cryogenic conditions. 


\subsection{Future Work}

Based on the experimental results obtained and behaviors observed, following suggestions are made for future investigation.

- Incorporating polymer additive to raise glass transition temperature may also provide additional advantage of good performance of the polymer matrix and the composite at high temperature with respect to mechanical and thermal stability.

- Study the effect of fiber-matrix interface bonding characteristics to maximize the mechanical properties of the composite at both high and low temperatures.

- Simulation of the composite material prepared under different static and dynamic loading could be conducted by finite element analysis in ANSYS or LS-DYNA to set up the loading distribution on the specimen and determine any defect with composite and determination of change in mechanical behavior due to heating or cooling.

- Fracture life time is a very indicative design parameter and could be measured at different temperatures to predicted life time of engineering parts manufactured from the materials fabricated in this study. Some of preliminary results are shown below. 


\subsubsection{Introduction to fracture toughness of polyester composite}

The polymer matrix is often cured, using a chemical or heat as a catalyst, causing irreversible cross inking of the material. Few studies are available related to fatigue crack propagation in woven laminates. Much effort has been put into researching and developing tougheners that can improve the fracture toughness of thermosets, in particular epoxy resins. But for unsaturated polyester resin (UPM), which is a low-cost thermosetting resin with advantageous chemical resistance that requires only mild curing conditions [1,2 ], the toughening results are still far from satisfactory. Han et al. [3] reported the use of a commercial epoxy-based nanocomposite with 2 wt $\%$ nanosilica to enhance the fracture toughness and wear performance of neat epoxy under marine environment. The neat epoxy and the nanocomposite were deleteriously affected by salt water immersion, with decreased fracture toughness values. However, the increment of fracture toughness due to the addition of nanosilica was able to complement the loss due to salt water immersion. He et al. [4] studied the impact of adding graphene oxides (GO) and its appropriately functionalized derivatives as materials for toughening of unsaturated polyesters. Chemical modifications studied in that work improved the toughening effect by enhancing particle-matrix bonding and surface compatibility. Silva et al. [5] showed that, in general, the fracture toughness was not affected by the applied strain-rate in coconut fiber composites and is inferior to the sisal fiber ones and even to the neat polyurethane matrix, whereas the best performance was displayed by the sisal fabric composite. Ali et al. [6] studied the fatigue and fracture properties of bamboo fiber composites made of woven layers. In these experiments, unsaturated polyester (UP) and bamboo fiber (BF) strips were prepared through a hand layup technique using 3-mm thick aluminum mold. These findings suggest that the bamboo 
strips, based on unsaturated polyester, provided relatively good fatigue and fracture properties and a good method of reinforcing fibers to combat fatigue and fracture failures. For the influence of temperature and moisture on performance of composite materials, several studies had been implemented [7-9]. Many tests have been set up to quantify the toughness of composites since interlaminar fracture may occur during practical applications under extreme conditions [10]. Experimental evidence of these studies is strictly related to their studies' conditions and components of composites. Moreover, most of the published experimental data are limited to the opaque polyester composites that are used for automotive structures excluded thin and transparent types of polyester composites. Since it is very time and fund-consuming to estimate the fatigue threshold, and difficult to monitor the fast region of fracture, the majority of studies focus on following cracks in notched specimens loaded in tension-tension fatigue to calculate $\mathrm{K}_{\mathrm{IC}}$ parameter and examine fracture morphology. In continuation of a strategic project to develop a comprehensive evaluation of glass-like unsaturated polyester composite at extreme condition, the present study aim to characterize fracture toughness difference in a humid environment and over a wide range of temperature. These findings suggest that the bamboo strips, based on unsaturated polyester, provided relatively good fatigue and fracture properties and a good method of reinforcing fibers to combat fatigue and fracture failures. For the influence of temperature and moisture on performance of composite materials, several studies had been implemented [7-9]. Many tests have been set up to quantify the toughness of composites since interlaminar fracture may occur during practical applications under extreme conditions [10]. Experimental evidence of these studies is strictly related to their studies' conditions and components of composites. Moreover, most 
of the published experimental data are limited to the opaque polyester composites that are used for automotive structures excluded thin and transparent types of polyester composites. Since it is very time and fund-consuming to estimate the fatigue threshold, and difficult to monitor the fast region of fracture, the majority of studies focus on following cracks in notched specimens loaded in tension-tension fatigue to calculate $\mathrm{K}_{\mathrm{IC}}$ parameter and examine fracture morphology. In continuation of a strategic project to develop a comprehensive evaluation of glass-like unsaturated polyester composite at extreme condition, the present study aim to characterize fracture toughness difference in a humid environment and over a wide range of temperatures.

\subsubsection{Experimental method}

\subsubsection{Coupon fabrication of polymer composite}

The specimens used for this study are the polymer composite samples shaped according to ASTM Standard D647. The specimens prepared in Chapter 2 were used for this test after shaping. A Compact Tension (CT) specimen geometry (Figure 4.10) was used for this test, it is recommended for homogeneous structure and unidirectional fiber reinforced structures. 

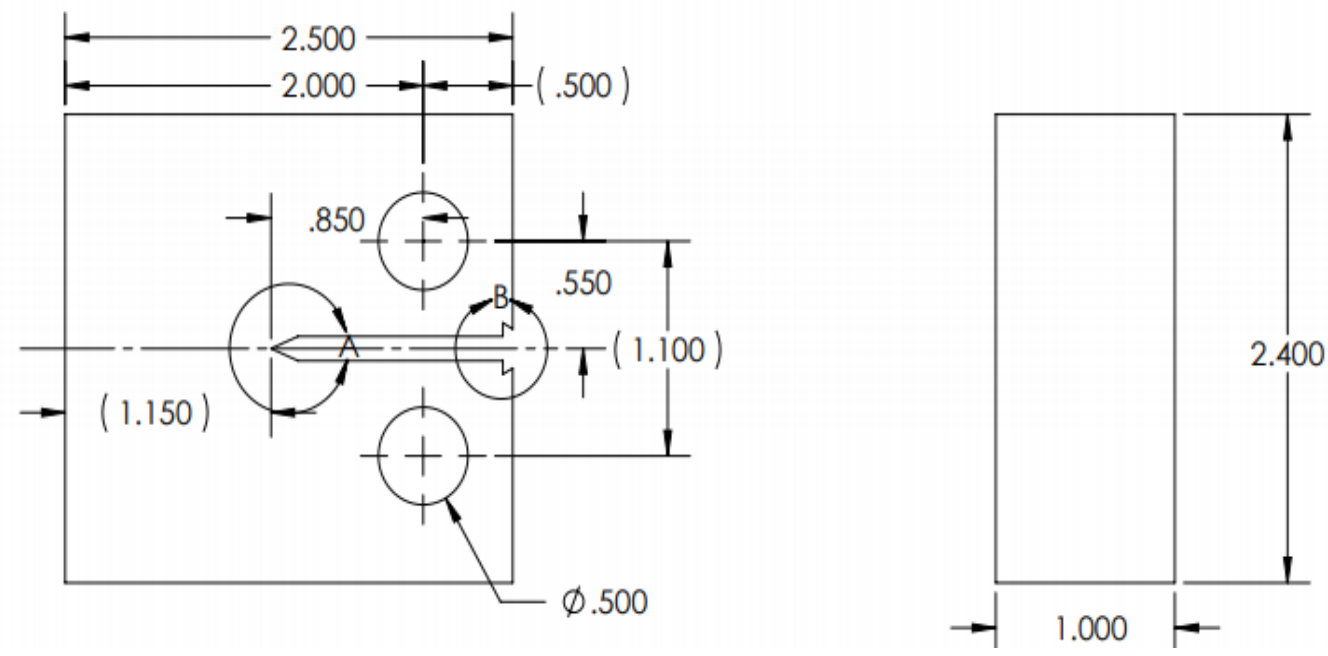

Figure 6.1 Fracture toughness specimen

To characterize the influence of temperature on fracture toughness, KIC test with a statically induced crack was conducted to give an estimate of toughness but not crack growth rate. In the beginning of this study it was planned to estimate fatigue crack growth rate; however, at the time of the test there were several cracks in the polymer but the compliance of the sample is not changing due to the fibers. Therefore, the tests were switched to fracture toughness. The only change made to the dimensions of CT specimens is only making a crack that is half way though the width of the sample. A razor blade was used to start the crack and perform just a particular load to failure to estimate $\mathrm{K}$ at the different temperatures.

\subsubsection{Test method}

Samples were measured using ASTM E399 as a guide. To minimize the effects of residual stress and residual plastic deformation around the pre-crack tip, a sharp pre-crack was introduced to the sample by razor blade tapping. The notch was sharpened using a razor 
blade prior to testing. Samples were held at temperature for 1 hour prior to testing. Samples were loaded using a constant displacement rate to failure using a 1,000 lb load cell. $\mathrm{K}$ was calculated using the original notch size and the K calibration coefficients listed in ASTM E399. A servo hydraulic MTS 810 frame and a chamber of MTS 651 last calibrated in June 14, 2018 were used in this work. Figure 6.2 shows the frame under the environmental chamber during testing at 60 , room temperature, $0,-30,-60$ and $-80{ }^{\circ} \mathrm{C}$.
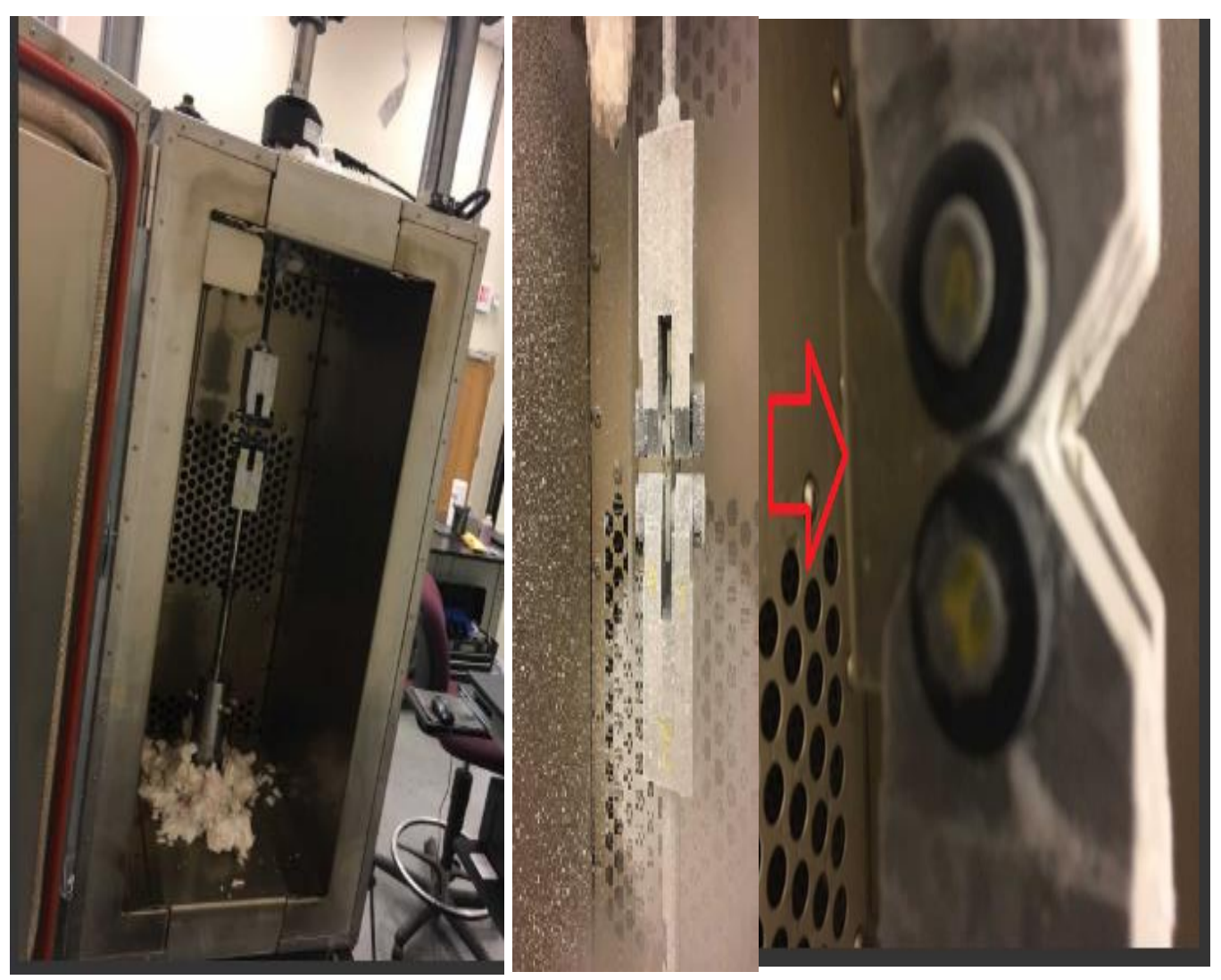

Figure 6.2 Fracture toughness specimen clamped on MTS servo-hydraulic multipurpose testing machine

A nitrogen cooling chamber was also used to cool the coupon during testing. A radiation thermometer measured less than $1^{\circ} \mathrm{C}$ temperature rise/drop in surface temperature during the highest stress cycling test. The temperature in the test room with the testing machine is 
maintained at $21^{\circ} \mathrm{C}$ and the temperature in the lab which houses the machine varies between $15^{\circ}$ and $19^{\circ} \mathrm{C}$. Five coupons were tested at each of three separate a/w levels. Specimen was tested with an R- ratio of 0.1 ; a sinusoidal waveform and a frequency of 2 Hz. depending on the load we run the test at we can correct for the COD gage by adjusting the R-ratio to cancel out the effect of the COD gage forces.

All fracture tests were conducted a loading rate of $1 \mathrm{~mm} / \mathrm{min}$. Only those specimens which fulfilled the condition of a/W $=0.2$ (a: the pre-crack length; $\mathrm{W}$ : the distance from the centre of the loading pin to the edge of the CT specimen) were used to calculate the critical stress intensity factor $\left(\mathrm{K}_{\mathrm{IC}}\right)$. At least $3 \mathrm{CT}$ specimens were tested for each temperature. Figure 6.3 shows the procedure of determination. Figure 6.4 shows the CT specimen after failure.

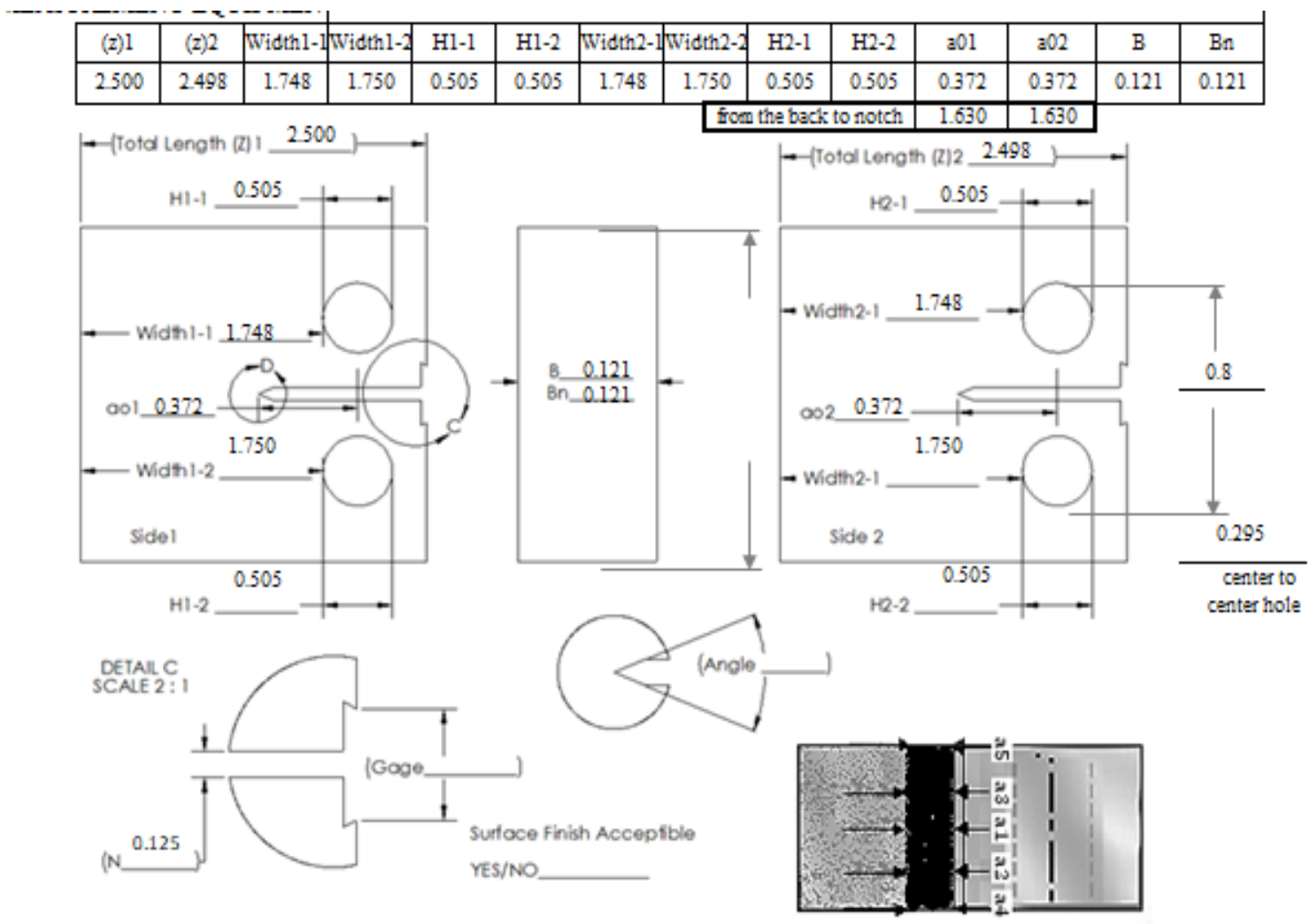




\begin{tabular}{|c|c|c|c|c|c|}
\hline $\mathrm{W}$ (in) & $B$ (in) & $\mathrm{Bn}$ (in) & $\mathrm{a} 0$ (in) & $\mathrm{H}$ ave. (in) & $Z$ ave. (in) \\
\hline 2.002 & 0.121 & 0.121 & 0.372 & 0.505 & 2.499 \\
\hline \multicolumn{5}{|c|}{ Distance from back of the specimen to pre-crack or just pre-crack length* } & \\
\hline $\mathrm{a} 5^{*}$ & $\mathrm{a} 3 *$ & $\mathrm{al}^{*}$ & $\mathrm{a} 2 *$ & $\mathrm{a} 4^{*}$ & \\
\hline- & - & - & - & - & \\
\hline \multicolumn{5}{|c|}{ Final Crack Lengths } & \\
\hline a.5 & a3 & al & $\mathrm{a} 2$ & a4 & \\
\hline - & - & - & - & - & \\
\hline
\end{tabular}

Figure 6.3. Process of following fracture propagation

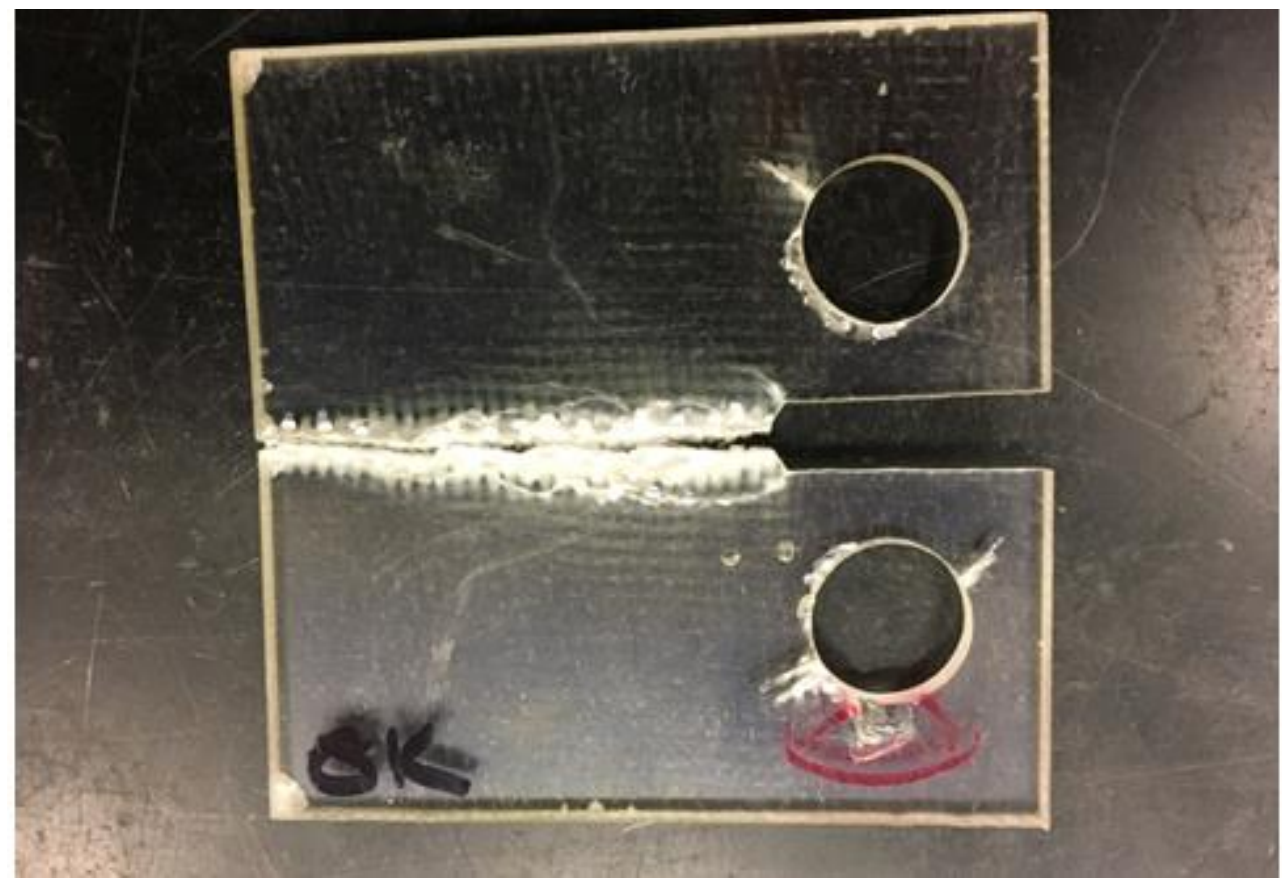

Figure 6.4 CT specimen after failure

\subsubsection{Results and discussion}

Dynamic mechanical behavior of the fiber glass polyester composite has been performed in regards to fracture toughness properties at different temperatures. The impact of exposure to different temperatures is shown in Figure 6.5. From Figure 6.5, it can be seen that working at different temperature resulted in a significant change in fracture toughness.

It is suggested that the toughness increases as time of testing is going on characterization.

The $\mathrm{K}_{\mathrm{IC}}$ at room temperature approaches a maximum of $5.3 \mathrm{kpsi}^{*}$ in $^{0.5}$ after 10.4 secs. 
Fracture toughness increases as temperature decreases over the cryogenic range of 0 through $-80{ }^{\circ} \mathrm{C}$. Fracture toughness index jumped to $7.5 \mathrm{kpsi} *$ in $^{0.5}$ after 11.6 secs as temperature decreases to $-60{ }^{\circ} \mathrm{C}$ and to a maximum value of $10 \mathrm{kpsi} * \mathrm{in}^{0.5}$ after 18 secs as temperature has been reduced to $-80^{\circ} \mathrm{C}$. The sharp increase of fracture toughness index as temperature decreases may attributes to the increase in multiple microcracking and fiber bridging for post-curing of polymer matrix during reinforcement. As temperature increases to $60{ }^{\circ} \mathrm{C}$, an obvious decrease in fracture toughness is observed. Figure 6.5 shows that fracture tough at $60{ }^{\circ} \mathrm{C}$ is $3.5 \mathrm{kpsi}^{*}$ in ${ }^{0.5}$ at $22 \mathrm{sec}$ compared to $8.6 \mathrm{kpsi} *$ in ${ }^{0.5}$ at $-80{ }^{\circ} \mathrm{C}$ recorded at the same time of testing. This indicates over $150 \%$ increase in the fracture toughness. Marom [11] showed that interlaminar fracture energy decreased $25-30 \%$ as the temperature increased from room to $50^{\circ} \mathrm{C}$. The temperature effect on the mechanical properties of composites derives partly from the internal stresses introduced by the differential thermal coefficients of composite components. Such internal stresses change magnitude with temperature change, in some cases producing matrix cracking at very low temperatures. The cyclic stress intensity $(\Delta \mathrm{K})$ was calculated according to equation 1 : 


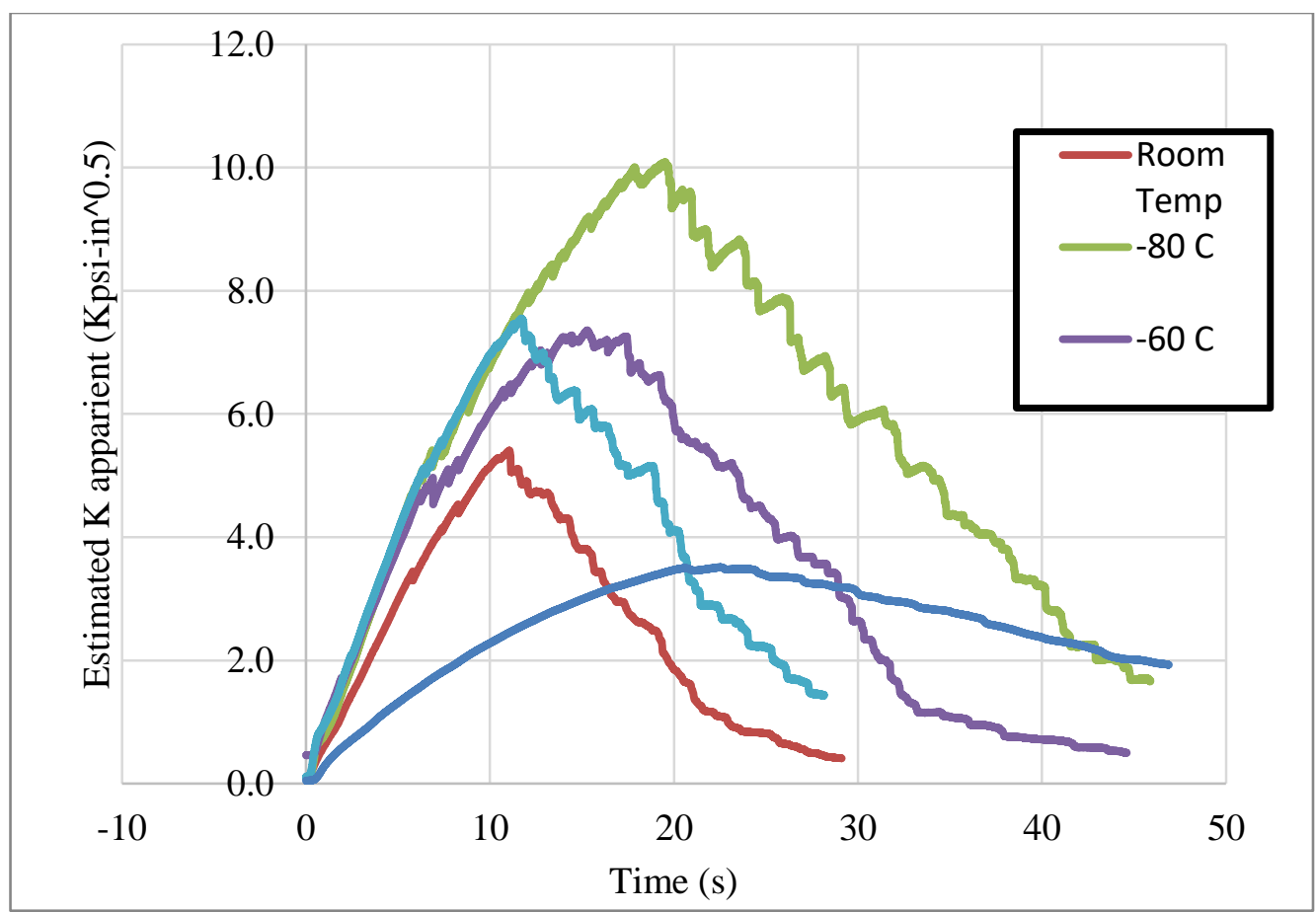

Figure 6.5 Fracture toughness vs. time of polyester composite materials comparing atmospheric to different temperatures.

$$
\Delta K=\left(\frac{\Delta P}{B \sqrt{W}}\right) f(a / w)
$$

Where:

$$
f\left(\frac{a}{w}\right)=\frac{\left(2+\frac{a}{w}\right)}{\left(1-\frac{a}{w}\right)^{3 / 2}}\left[0.886+4.64 \frac{a}{w}-13.32\left(\frac{a}{w}\right)^{2}+14.72\left(\frac{a}{w}\right)^{3}-5.6\left(\frac{a}{w}\right)^{4}\right]
$$

$\Delta \mathrm{P}=$ load range, [lbs], $\mathrm{B}=$ thickness, [in], $\mathrm{W}=$ width [in.], $\mathrm{f}(\mathrm{a} / \mathrm{w})=$ geometric correction factor for compact tension specimen. 


\subsubsection{Visual analysis of fracture-tested composites}

The purpose of this evaluation was to study the fracture surfaces of composites after fracture testing at various temperatures. Samples were tested at $-100^{\circ} \mathrm{C},-80^{\circ} \mathrm{C},-60^{\circ} \mathrm{C}, 0^{\circ} \mathrm{C}$, ambient temperature, and $+60^{\circ} \mathrm{C}$. Some of these samples are shown in Figure 6.6.

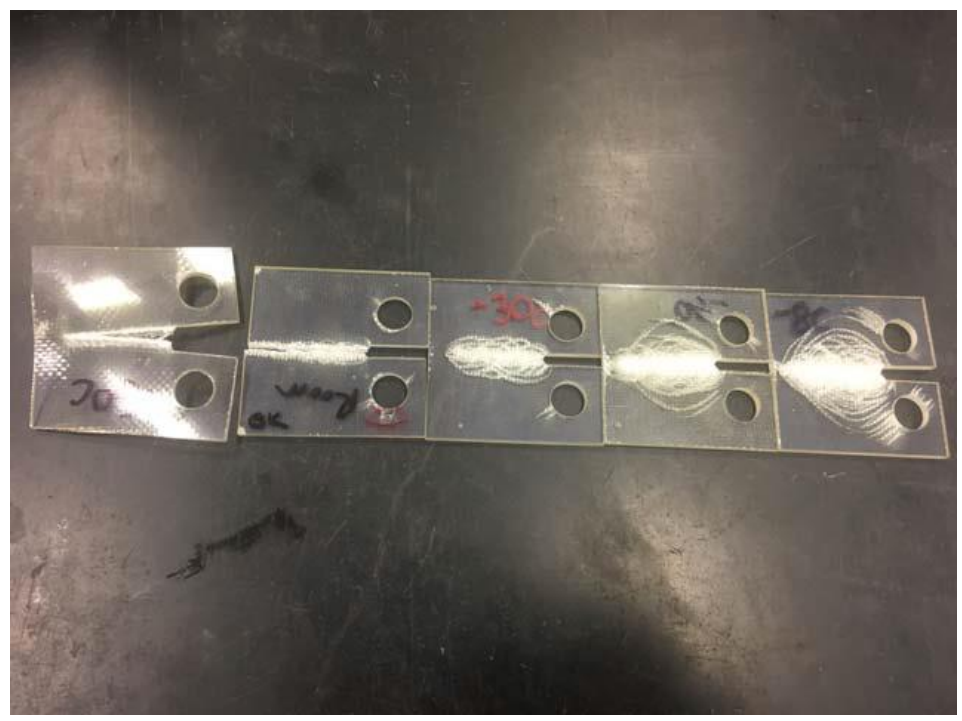

Figure 6.6: Samples after fatigue-testing; from left to right: $+60^{\circ} \mathrm{C}$, ambient temperature, $-30^{\circ} \mathrm{C}$, $-60^{\circ} \mathrm{C}$, and $-80^{\circ} \mathrm{C}$

Figures 6.7 and 6.8 show the surfaces of each sample at different temperatures and magnifications. These figures show the fracture surfaces of each sample with the fatigue origin notch to the right of each image.

Figure 6.7a shows fracture surface areas near fibers from sample tested at $-100^{\circ} \mathrm{C}$; crack arrest (arrow) is shown. Fracture surface of general area (top) and area away from fibers (bottom) from sample is shown and smoothness is observed in bottom image. Fracture surface of general area from sample tested at $-80^{\circ} \mathrm{C}$ is shown in Figure $6.7 \mathrm{~b}$. Fracture surface areas away from fibers from sample is shown in this figure. Smoothness in top image and crack arrests in bottom image (arrows) are observed. The direction of crack growth is indicated by arrows. Fracture surface of general area from sample tested at $-60^{\circ} \mathrm{C}$ 
is shown in Figure 6.7c. Fracture surface areas away from fibers from sample tested is shown and directions of crack growth are pointed by arrows. Fracture surface of general area (top) and area away from fibers (bottom) from sample tested at $-30^{\circ} \mathrm{C}$ is shown in Figure $6.7 \mathrm{~d}$. The direction of crack growth is pointed by crack arrest (arrows). Fracture surface area (top) and fracture origin (bottom) near fibers from sample tested at $-30^{\circ} \mathrm{C}$.

Fracture surface of general area (top) and area away from fibers (bottom) from sample tested at $0^{\circ} \mathrm{C}$; the directions of crack growth (arrows) are pointed in Figure 6.8-a. Fracture surface area near fibers from sample tested and directions of crack growth (arrows) are shown. Figure 6.8-b shows fracture surface of general area (top) and area away from fibers (bottom) from sample tested at ambient temperature; directions of crack growth (arrows) are shown. Fracture origin (arrow) is observed in this figure. Fracture surface of general area (top) and area away from fibers (bottom) from sample tested at $+60^{\circ} \mathrm{C}$; note directions of crack growth (arrows). The bottom image shows fracture surface areas near fibers from sample tested and directions of crack growth and crack arrests (arrows). 

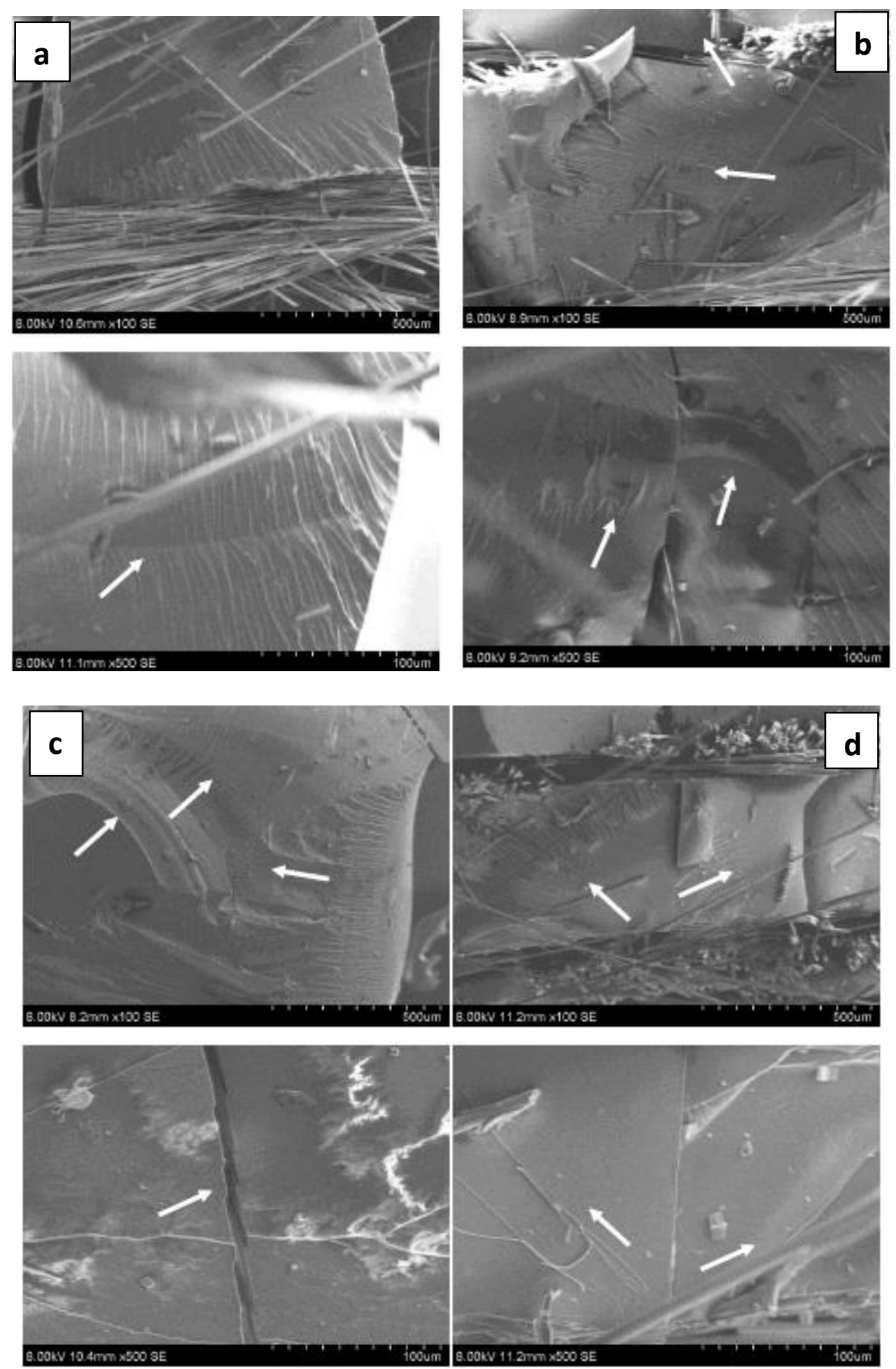

Figure 6.7: a) Fracture at $-100^{\circ} \mathrm{C} \mathrm{b}$ ) Fracture at $-80^{\circ} \mathrm{C}$ c) Fracture at $-60^{\circ} \mathrm{C}$ d) Fracture at $-30^{\circ} \mathrm{C}$ 

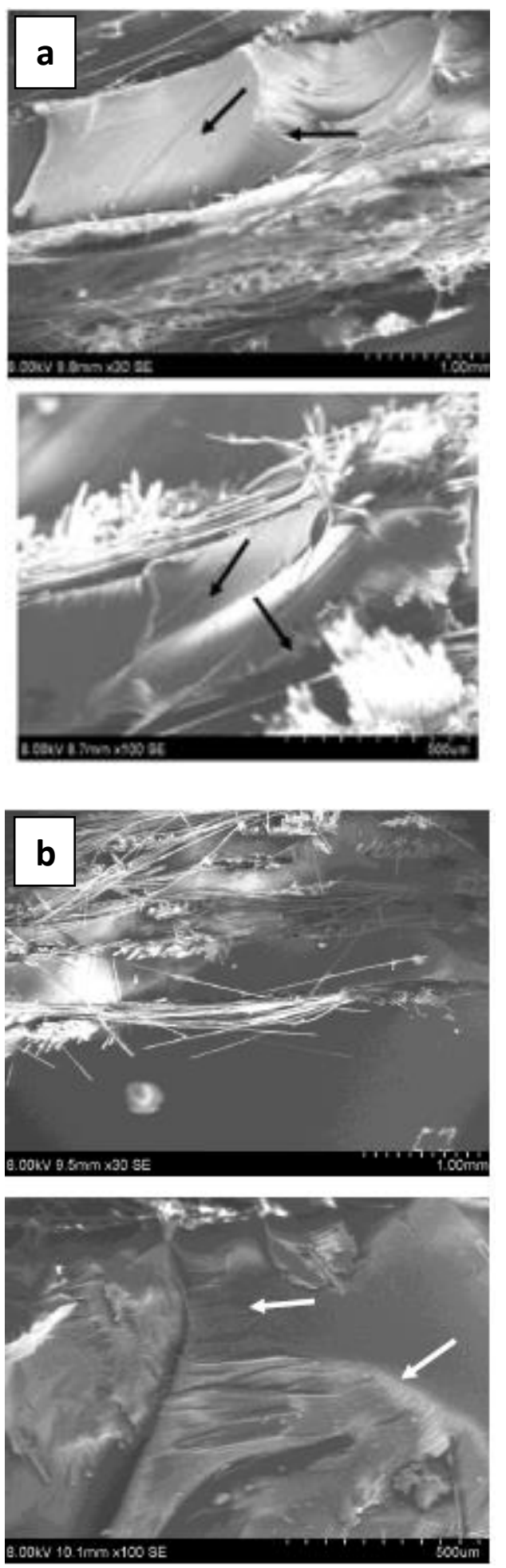
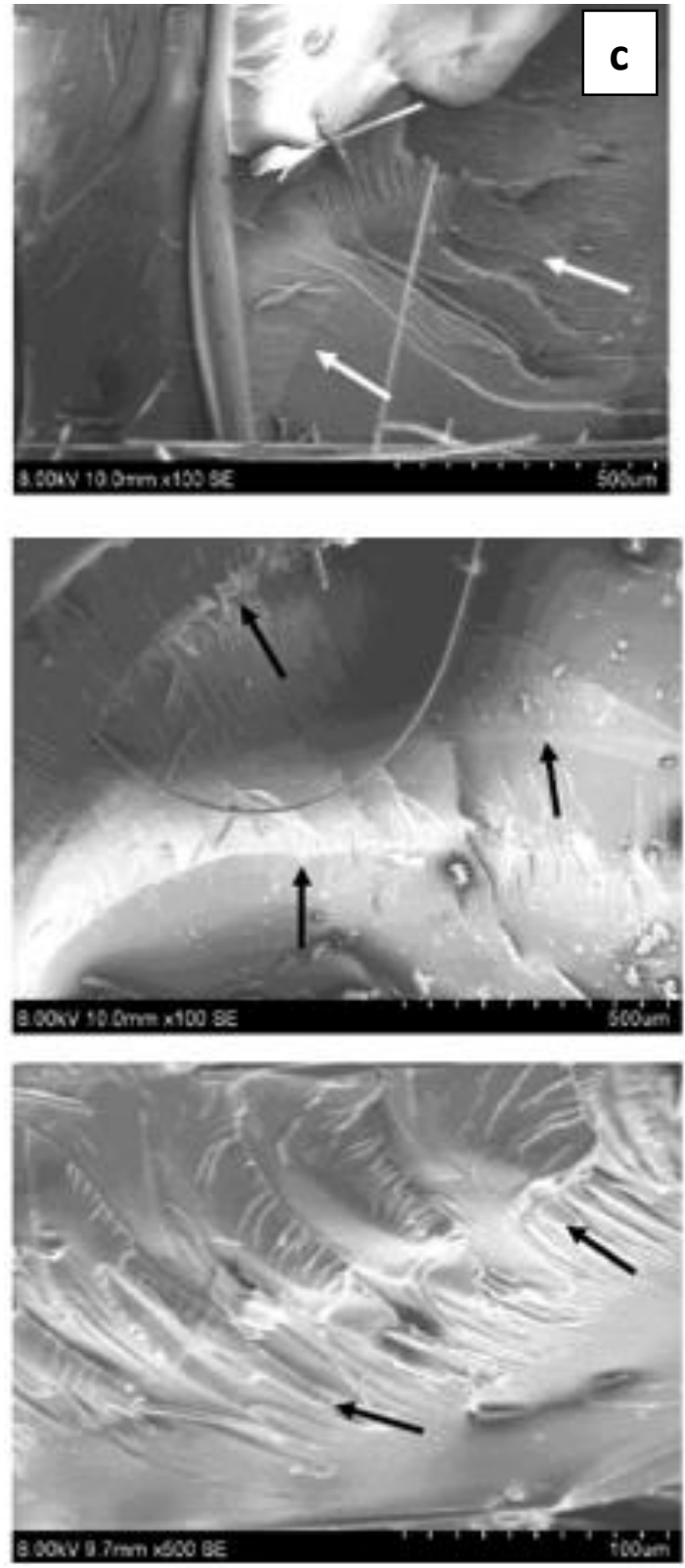

Figure 6.8: Fracture surface areas near fibers from sample tested at a) $0^{\circ} \mathrm{C}$; b) ambient temperature and c) $+60^{\circ} \mathrm{C}$ 


\section{References}

1. R.J. Sharmila, S. Premkumar, M. Alagar, 2007, "Toughened polyester matrices for advanced composites”, J. Appl. Polym. Sci. 103, pp. 167-177.

2. D.H. Builes, H. Hernandez, A. Tercjak, 2013, "Relationship between the morphology of nanostructured unsaturated polyesters modified with PEO-b-PPO-b-PEO triblock copolymer and their optical and mechanical properties", J. Phys. Chem. 117, 35633571.

3. Wei Han, Sheng Chen, Jonathan Campbell, Xiaojun Zhang, Youhong Tang, 2016, "Fracture toughness and wear properties of nanosilica/epoxy composites under marine environment” Materials Chemistry and Physics, 177, 147-155.

4. Siyao He, Nicholas D. Petkovich, Kunwei Liu, Yuqiang Qian, Christopher W. Macosko, Andreas Stein, 2017, “Unsaturated polyester resin toughening with very low loadings of GO derivatives”. Polymer 110, pp. 149-157

5. R.V. Silva, D. Spinelli, W.W. Bose Filho, S. Claro Neto, G.O. Chierice, J.R. Tarpani, 2006, "Fracture toughness of natural fibers/castor oil polyurethane composites", Composites Science and Technology 66, pp.1328-1335.

6. Ali, A., Rassiah, K., Othman, F., Lee, H. P., Tay, T. E., Hazin, M. S., and Megat Ahmad, M. M. H., 2016."Fatigue and fracture properties of laminated bamboo strips from Gigantochloa scortechinii polyester composites," BioRes. 11(4), 9142-9153.

7. Wang, X.W., Takao, Y., Yuan, F.G., Potter, B.D., Pater, R.H., 1998, “The Interlaminar Mode I Fracture of IM7/LaRC-RP46 Composites at High Temperatures,” Journal of Composite Materials, 32(16), pp. 1508-1525. 
8. Sloan, E.F., Seymour, J.R., "The Effect of Seawater Exposure on Mode I Interlaminar Fracture and Crack Growth in Graphite / Epoxy,” Journal of Composite Materials, Vol.26, No. 18, 1992, pp. 2655-2671.

9. Russell, A.J., Street, K.N., 1985, "Moisture and Temperature Effects on the MixedMode Delamination Fracture of Unidirectional Graphite/Epoxy," Delamination and Debonding of Materials, ASTM STP 876, pp. 349-368.

10. Mei. Li. 2000, “Temperature and moisture effects on composite materials for wind turbine blades". Thesis (M.S.). Montana State University--Bozeman.

11. Marom, G., 1989, "Environmental effects on fracture mechanical properties of polymer composites" K. Friedrich (Ed.), Application of fracture mechanics to composite materials, Elsevier, New York (1989), p. 397. 


\section{Vita}

Saad Ahmed was born in Tikrit, Iraq in 1982. He received his B.S. in

Production and Meturaullugy Engineering from University of

Technology, Baghdad, Iraq in 2004. He received the M.S. degree in

Mechanical Engineering in the University of Tikrit in 2012. In 2015, he obtained a scholarship supported by the Iraqi Ministry of Higher Education and Scientific Research (MOHSER) to earn PhD degree in Mechanical Engineering. He received a non-stop thesis M.S. in Mechanical Engineering from University of Missouri Columbia in May 2016 and passed the qualifying exam successfully in the area of Materials in July 2016. During the PhD study, he studied on the Mechanical Behavior of Unsaturated Polyester Resin under Extreme Conditions. He participated as a first author in four international conferences during 2016, and 2017. He also has two manuscripts ready for submit. Moreover, he participated in two faculty workshops on how to apply a safe environment of work in material laboratories. 
